JOÃO MENDES FILHO

\title{
ALGORITMOS EFICIENTES PARA EQUALIZAÇÃO AUTODIDATA DE SINAIS QAM
}

Tese apresentada à Escola Politécnica da Universidade de São Paulo para obtenção do Título de Doutor em Ciências. 

JOÃO MENDES FILHO

\section{ALGORITMOS EFICIENTES PARA EQUALIZAÇÃO AUTODIDATA DE SINAIS QAM}

Tese apresentada à Escola Politécnica da Universidade de São Paulo para obtenção do Título de Doutor em Ciências.

Área de Concentração:

Sistemas Eletrônicos

Orientador:

Prof. Dr. Magno Teófilo Madeira da Silva

Coorientadora:

Profa. Dra. Maria D. Miranda 
Este exemplar foi revisado e alterado em relação à versão original, sob responsabilidade única do autor e com a anuência de seu orientador.

São Paulo, 30 de novembro de 2011.

Assinatura do autor

Assinatura do orientador

FICHA CATALOGRÁFICA

Mendes Filho, João

Algoritmos eficientes para equalização autodidata de sinais QAM / J. Mendes Filho. -- ed. rev. -- São Paulo, 2011.

149 p.

Tese (Doutorado) - Escola Politécnica da Universidade de São Paulo. Departamento de Engenharia de Sistemas Eletrônicos.

1. Filtros elétricos adaptativos 2. Algoritmos 3. Análise de algoritmos 4. Equalização. I. Universidade de São Paulo. Escola Politécnica. Departamento de Engenharia de Sistemas Eletrônicos II.t 
"Que riqueza não é, até entre os pobres, ser filho de um bom pai."

Juan Luis Vives Deus me agraciou duplamente com pai e mãe excelentes. 
Aos meus queridos pais

João (in memoriam) e Maria. 


\section{Agradecimentos}

Agradeço primeiramente ao amigo e orientador Prof. Dr. Magno Teófilo Madeira da Silva pelos ensinamentos, orientação, incentivo, dedicação e sobretudo por sua ética e alto grau de profissionalismo durante toda a minha jornada aqui na Escola Politécnica.

À Profa. Dra. Maria D. Miranda que muito contribuiu com incentivo, dedicação, orientação e opiniões relevantes para que este trabalho pudesse ser concluído.

Ao Prof. Dr. Miguel Arjona Ramírez pelos ensinamentos e atenção dispensada.

Ao Prof. Dr. Vítor Heloiz Nascimento pelos ensinamentos e opiniões importantes.

Aos Profs. Drs. Phillip Mark Seymour Burt e Romis Ribeiro de Faissol Attux pelas sugestões importantes no meu exame de qualificação.

Ao Prof. Dr. Márcio Einseincraft e ao Prof. Dr. Mário Minami pela amizade.

Aos demais professores do programa com os quais tive o prazer de aprender e conviver.

Ao Prof. Dr. Alberto Yoshihiro Nakano, com quem tive conversas produtivas e agradáveis.

Ao amigo Dr. Ricardo Bressan Pinheiro pela amizade e constante incentivo.

Ao amigo e Prof. Carlos Eduardo da Silva Dantas (in memoriam) pelos ensinamentos e pelo incentivo no início de minha carreira.

Aos funcionários da secretaria de pós-graduação e demais colaboradores da EPUSP.

À CAPES - Coordenação de Aperfeiçoamento de Pessoal de Nível Superior - pelo suporte financeiro.

A todos os amigos da Elétrica, em especial os do Laboratório de Processamento de Sinais e Acústica, pelo apreço.

Aos meus irmãos, tios, primos (em particular ao Alexandre e ao Carlos Alberto), à minha sobrinha Aline e especialmente aos meus adoráveis pais por todo carinho.

Por último, porém de forma mais intensa, agradeço a Deus por me dar saúde e me aproximar de pessoas de boa índole. 


\section{Resumo}

Neste trabalho, são propostos e analisados algoritmos autodidatas eficientes para a equalização de canais de comunicação, considerando a transmissão de sinais QAM (quadrature amplitude modulation). Suas funções de erro são construídas de forma a fazer com que o erro de estimação seja igual a zero nas coordenadas dos símbolos da constelação. Essa característica os possibilita ter um desempenho similar ao de um algoritmo de equalização supervisionada como o NLMS (normalized least mean-square), independentemente da ordem da constelação QAM. Verifica-se analiticamente que, sob certas condições favoráveis para a equalização, os vetores de coeficientes dos algoritmos propostos e a correspondente solução de Wiener são colineares. Além disso, usando a informação da estimativa do símbolo transmitido e de seus símbolos "vizinhos", esquemas de baixo custo computacional são propostos para aumentar a velocidade de convergência dos algoritmos. No caso do algoritmo baseado no critério do módulo constante, evita-se sua divergência através de um mecanismo que descarta estimativas inconsistentes dos símbolos transmitidos. Adicionalmente, apresentase uma análise de rastreio (tracking), que permite obter expressões analíticas para o erro quadrático médio em excesso dos algoritmos propostos em ambientes estacionários e nãoestacionários. Através dessas expressões, verifica-se que com sobreamostragem, ausência de ruído e ambiente estacionário, os algoritmos propostos podem alcançar a equalização perfeita, independentemente da ordem da constelação QAM. Os algoritmos são estendidos para a adaptação conjunta dos filtros direto e de realimentação do equalizador de decisão realimentada, levando-se em conta um mecanismo que evita soluções degeneradas. Resultados de simulação sugerem que a utilização dos esquemas aqui propostos pode ser vantajosa na recuperação de sinais QAM, fazendo com que seja desnecessário o chaveamento para o algoritmo de decisão direta.

Palavras-chave: filtragem adaptativa; equalização de canais de comunicação; equalização autodidata; algoritmo do módulo constante; decisão direta; QAM; análise de algoritmos. 


\section{Abstract}

In this work, we propose efficient blind algorithms for equalization of communication channels, considering the transmission of QAM (quadrature amplitude modulation) signals. Their error functions are constructed in order to make the estimation error equal to zero at the coordinates of the constellation symbols. This characteristic enables the proposed algorithms to have a similar performance to that of a supervised equalization algorithm as the NLMS (normalized least mean-square), independently of the QAM order. Under some favorable conditions, we verify analytically that the coefficient vector of the proposed algorithms are collinear with the Wiener solution. Furthermore, using the information of the symbol estimate in conjunction with its neighborhood, we propose schemes of low computational cost in order to improve their convergence rate. The divergence of the constant-modulus based algorithm is avoided by using a mechanism, which disregards nonconsistent estimates of the transmitted symbols. Additionally, we present a tracking analysis in which we obtain analytical expressions for the excess mean-square error in stationary and nonstationary environments. From these expressions, we verify that using a fractionally-spaced equalizer in a noiseless stationary environment, the proposed algorithms can achieve perfect equalization, independently of the QAM order. The algorithms are extended to jointly adapt the feedforward and feedback filters of the decision feedback equalizer, taking into account a mechanism to avoid degenerative solutions. Simulation results suggest that the proposed schemes may be advantageously used to recover QAM signals and make the switching to the decision direct mode unnecessary.

Keywords: adaptive filtering; equalization of communication channels; blind equalization; constant modulus algorithm; decision-directed algorithm; QAM; algorithm analysis. 


\section{Sumário}

Lista de figuras . . . . . . . . . . . . . . . . . . . . vii

Lista de tabelas . . . . . . . . . . . . . . . . . . xiii

Lista de abreviaturas ....................... xiv

Lista de símbolos . . . . . . . . . . . . . . . . . . . xvii

1 Introdução e formulação do problema $\quad 1$

1.1 Sinais com modulação QAM . . . . . . . . . . . . . . . . . . 1

1.2 O efeito do canal de comunicação . . . . . . . . . . . . . . . . . . . . . 7

1.3 Aplicações de sinais QAM . . . . . . . . . . . . . . 8

1.4 A equalização autodidata . . . . . . . . . . . . . . . . . . . 10

1.5 A equalização autodidata de sinais QAM . . . . . . . . . . . . . 13

1.6 Formulação do problema . . . . . . . . . . . . . . . . . . . . 18

1.7 Objetivos e justificativa . . . . . . . . . . . . . . . . . . . 22

1.8 Contribuições . . . . . . . . . . . . . . . . . . . . . . . . . . 24

1.9 Organização da tese . . . . . . . . . . . . . . . . . . . . . . 31

2 Funções de erro de estimação 32

2.1 A função de erro do algoritmo multimódulo (MMA) . . . . . . . . . . . . . 33

2.2 A função de erro do algoritmo de decisão direta suave (SDD) . . . . . . . . . 34

2.3 A função de erro do algoritmo concorrente com decisão suave (CSD) . . . . . 38

2.4 A função de erro do algoritmo de decisão direta suave modificado (MSD) . 40

2.5 A função de erro do algoritmo multimódulo regional (RMA) . . . . . . . . . 41

2.6 A função de erro do algoritmo de decisão baseada nos símbolos (SBD) . . . . 44 
2.7 Custo computacional . . . . . . . . . . . . . . . . . . . . . . . 47

2.8 Conclusões . . . . . . . . . . . . . . . . . . . . . . . . . . . . . . . . . . 48

3 O receptor de Wiener e soluções autodidatas $\quad 50$

3.1 O receptor de Wiener . . . . . . . . . . . . . . . . . . . . . 50

3.2 A solução RMA e o receptor de Wiener . . . . . . . . . . . . . . . . . 52

3.3 A solução SBD e o receptor de Wiener . . . . . . . . . . . . . . . . . . . 55

3.4 Conclusões . . . . . . . . . . . . . . . . . . . . . . . . . . 56

4 Esquemas que aumentam a velocidade de convergência e evitam a di$\begin{array}{ll}\text { vergência } & 57\end{array}$

4.1 Simulações introdutórias . . . . . . . . . . . . . . . . . 5 58

4.1.1 A velocidade de convergência e a ordem da constelação QAM . . . . 58

4.1.2 A divergência do RMA . . . . . . . . . . . . . . . . . . . 61

4.2 Aumentando a velocidade de convergência . . . . . . . . . . . . . 63

4.2.1 A vizinhança no erro de estimação do RMA . . . . . . . . . . . . 63

4.2.2 A vizinhança no erro de estimação do SBD . . . . . . . . . . . . . . 69

4.2 .3 Descartando a vizinhança . . . . . . . . . . . . . . . . . 72

4.2.4 O efeito dos esquemas Axial-1 e Axial-2 na convergência . . . . . . . 74

4.3 Sobre a convergência do SBD e do RMA . . . . . . . . . . . . . . . 77

4.3.1 Revisitando a convergência do NLMS . . . . . . . . . . . . 78

4.3.2 Assegurando a convergência do SBD . . . . . . . . . . . . . . . 79

4.3.3 Evitando a divergência do RMA . . . . . . . . . . . . . . 80

4.4 Conclusões . . . . . . . . . . . . . . . . . . . . . . . . . . 85

5 Análise de rastreio $\quad 86$

5.1 Preliminares da análise . . . . . . . . . . . . . . . . . . . . . . 87

5.1 .1 Modelo para variação da solução ótima . . . . . . . . . . . . . . 87

5.1 .2 Medida de desempenho . . . . . . . . . . . . . . . . 88

5.1 .3 Modelo para a saída do equalizador . . . . . . . . . . . . 88

5.1 .4 Método da realimentação . . . . . . . . . . . . . . . . . . . 90 
5.2 Análise do algoritmo multimódulo . . . . . . . . . . . . . . . . . . . . . . . . 92

5.3 Análise do RMA . . . . . . . . . . . . . . . . . . . . . . . . . . 94

5.4 Análise do algoritmo SBD . . . . . . . . . . . . . . . . . . . . . . 96

5.5 Conclusões . . . . . . . . . . . . . . . . . . . . . . . . . . . . . . . 97

6 O equalizador de decisão realimentada $\quad 98$

6.1 O modelo do DFE . . . . . . . . . . . . . . . . . . . . . . 99

6.2 O DFE autodidata: problemas e soluções . . . . . . . . . . . . . . . . . 101

6.3 Algoritmos eficientes para o DFE autodidata . . . . . . . . . . . . . 104

6.4 Conclusões . . . . . . . . . . . . . . . . . . . . . . . . . . 109

$\begin{array}{lll}7 & \text { Resultados de simulação } & 110\end{array}$

7.1 Canais de comunicação . . . . . . . . . . . . . . . . . . 110

7.2 Simulações com o equalizador linear transversal . . . . . . . . . . . . . . . . 111

7.2 .1 Equalização perfeita . . . . . . . . . . . . . . . . . 112

7.2.2 Solução de Wiener e vizinhança . . . . . . . . . . . . . . . . . . . . . 114

7.2 .3 Desempenho com ruído . . . . . . . . . . . . . . . . . 117

7.2.4 Precisão da análise em regime . . . . . . . . . . . . . . . . . . . . . . 118

7.3 Evitando a divergência do MMA e RMA . . . . . . . . . . . . . . . . 122

7.4 Simulações com realimentação de decisões . . . . . . . . . . . . . . . . . . . 123

7.5 Conclusões . . . . . . . . . . . . . . . . . . . . . . . . . . . . . 128

8 Conclusões e trabalhos futuros $\quad 130$

8.1 Conclusões . . . . . . . . . . . . . . . . . . . . . . 131

8.2 Trabalhos futuros . . . . . . . . . . . . . . . . . . . 133

$\begin{array}{ll}\text { Referências } & 135\end{array}$

$\begin{array}{lr}\text { Apêndice } & 146\end{array}$

$\begin{array}{lr}\text { A Medidas de desempenho } & 146\end{array}$ 


\section{Lista de Figuras}

1.1 Formas de onda do sinal: (a) Transmissão em banda base; (b) PAM; $T_{b}$ é o intervalo de bit. . . . . . . . . . . . . . . . . . 2

1.2 Constelações QAM com número de símbolos diferentes. . . . . . . . . . . . 3

1.3 Identificação dos símbolos de uma constelação 4-QAM. . . . . . . . . . . . . 5

1.4 Codificação de Gray para a constelação 16-QAM. . . . . . . . . . . . . . . 5

1.5 Diagrama simplificado de um sistema de comunicação com modulação de amplitude em quadratura $[$ LATHI, 1998]. . . . . . . . . . . . . . 6

1.6 $\log _{10}(\mathrm{SER})$ em função da SNR (dB) para as constelações quadradas 16, 64, 256,1024 e 4096 -QAM. . . . . . . . . . . . . . . . . 8

1.7 Constelação 64-QAM e raiz quadrada da constante de dispersão $r$. . . . . . . 12

1.8 Raios usados no algoritmo RDE para (a) 64-QAM; (b) 256-QAM. . . . . . . 17

1.9 Sistema de comunicação simplificado com um equalizador autodidata. . . . . 18

1.10 (a) sinal transmitido em banda base, (b) sequência de tempo discreto equiva-

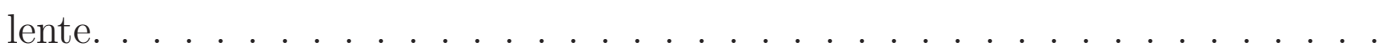

1.11 Sistema de comunicação simplificado com um equalizador autodidata, incluindo a possibilidade de chaveamento para o modo de decisão direta. . . .

1.12 Relações entre os algoritmos propostos e os existentes na literatura. . . . . .

2.1 Parte real do erro do MMA em função de $y_{\mathrm{R}}(n)$ para: (a) 4-QAM e 16QAM; (b) 64-QAM. Os erros nas posições correspondentes às coordenadas dos símbolos das constelações são indicados por * (4-QAM) e o (16-QAM e

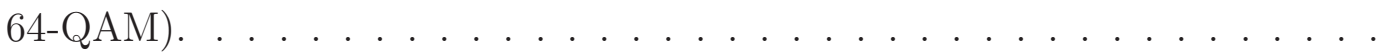


2.2 Regiões da parte real de uma constelação 64-QAM; o centro da região $A_{k}$ é representado por $c_{k}$ e $k= \pm 2, \pm 1 \ldots \ldots \ldots \ldots$

2.3 Parte real do erro do algoritmo SDD em função de $y_{\mathrm{R}}(n)$ para 64-QAM; $\rho=$ $0,6, K=1,0025$. Os erros nas coordenadas dos símbolos da constelação são

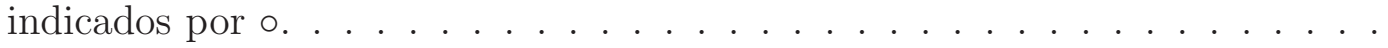

2.4 Parte real do erro do algoritmo CSD em função de $y_{\mathrm{R}}(n)$ para 64-QAM com $\rho=0,6$; (a) $\beta=10^{-2}, K=3,1625$; (b) $\beta=2 \times 10^{-3}, K=1$, 4345. Os erros nas coordenadas dos símbolos da constelação são indicados por o. . . . . . .

2.5 Parte real do erro MSD como função de $y_{\mathrm{R}}(n)$ para 64-QAM, $\rho=0,6 \mathrm{e}$ $K=6,0153$. Os erros nas coordenadas dos símbolos da constelação são indi-

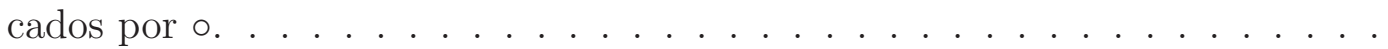

2.6 Parte real do erro do RMA em função de $y_{\mathrm{R}}(n)$ para 64-QAM, usando os fatores de escala ótimos $\left(\alpha_{\ell}=\alpha_{\ell, \mathrm{o}}, K=244,9926\right)$ e os valores absolutos dos centros das regiões $\left(\alpha_{\ell}=\left|c_{\ell}\right|, K=36\right)$. Os erros nas coordenadas dos símbolos são indicados por o. . . . . . . . . . . . . . . . . . . .

2.7 Parte real do erro do algoritmo DD em função de $y_{\mathrm{R}}(n)$ para 64-QAM; $K=1$. Os erros nas coordenadas dos símbolos da constelação são indicados por o. .

2.8 Parte real do erro para (a) MRD (64-QAM, curva contínua) e MMA (4-QAM com quatro diferentes fatores de escala, curvas tracejadas), $K=128$;(b) SBD (64-QAM), $K=7$. Os erros nas coordenadas dos símbolos da constelação são

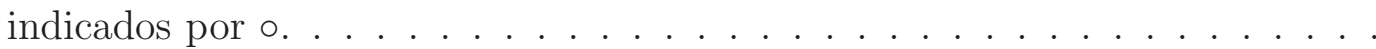

4.1 Erro quadrático médio em excesso do algoritmo NLMS, média de 100 realizações, $\mu_{64-\mathrm{QAM}}=2 \times 10^{-2}, \mu_{256-\mathrm{QAM}}=5 \times 10^{-3}$ e $\mu_{1024-\mathrm{QAM}}=1 \times 10^{-3} \ldots \ldots$.

4.2 Erro quadrático em excesso, única realização; (a) algoritmo RMA, $\mu_{64-\mathrm{QAM}}=4 \times 10^{-3}$, $\mu_{256-\mathrm{QAM}}=6 \times 10^{-4}$ e $\mu_{1024-\mathrm{QAM}}=2 \times 10^{-4}$; (b) algoritmo $\mathrm{SBD}, \mu_{64-\mathrm{QAM}}=$ $4 \times 10^{-3}, \mu_{256-\mathrm{QAM}}=7 \times 10^{-4}$ e $\mu_{1024-\mathrm{QAM}}=2,5 \times 10^{-4} \ldots \ldots \ldots$

4.3 Erro quadrático em excesso do algoritmo RMA, única realização, sem mecanismo para evitar divergência, $\mu_{64-\mathrm{QAM}}=2,75 \times 10^{-2}, \mu_{256-\mathrm{QAM}}=1,5 \times 10^{-2} \mathrm{e}$ $\mu_{1024-\mathrm{QAM}}=2,4 \times 10^{-3} \ldots \ldots \ldots \ldots \ldots \ldots$ 
4.4 Regiões da parte real de uma constelação 64-QAM; o centro da região $A_{k}$ é representado por $c_{k}$ e $k= \pm 2, \pm 1 \ldots \ldots \ldots \ldots$

4.5 Parte real do erro do RMA em função de $y_{\mathrm{R}}(n)$ para (a) 64-QAM $(K=90)$ e (b) 256-QAM $(K=239,43)$ segundo o esquema de vizinhança Axial-1. A parte real do erro do MMA $(K=1660,80)$ para 256-QAM é mostrada apenas para referência. Os erros nas coordenadas dos símbolos da constelação são

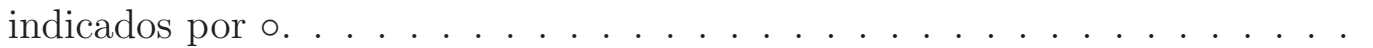

4.6 Esquema de vizinhança Axial-2 com quatro vizinhos para o RMA em uma constelação 64-QAM. . . . . . . . . . . . . . . . . . . . . . . .

4.7 Parte real do erro do RMA em função de $y_{\mathrm{R}}(n)$ para (a) 64-QAM $(K=91,5)$ e (b) 256-QAM $(K=324,01)$ segundo o esquema de vizinhança Axial-2. A parte real do erro do MMA $(K=1660,80)$ para 256-QAM é mostrada apenas para referência. Os erros nas coordenadas dos símbolos da constelação são

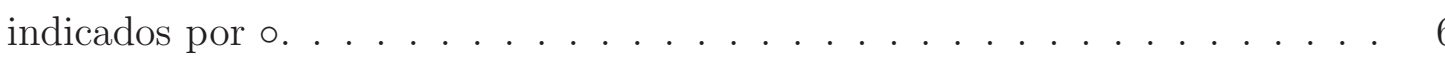

4.8 Regiões da parte real de 64-QAM para o algoritmo SBD. . . . . . . . . . . . 69

4.9 Esquema de vizinhança Axial-2 com quatro vizinhos para o SBD em uma constelação 64-QAM. . . . . . . . . . . . . . . . . . . . . . .

4.10 Parte real do erro do SBD em função de $y_{\mathrm{R}}(n)$ considerando o esquema Axial-1: (a) 64-QAM $(K=10,75)$ e (b) 256-QAM $(K=24,75)$; e o esquema Axial-2: (c) 64-QAM $(K=14,25)$ e (d) 256-QAM $(K=19,31)$. A parte real do erro do MMA $(K=1660,80)$ para 256-QAM é mostrada apenas para referência. Os erros nas coordenadas dos símbolos da constelação são indicados por o. . . .

4.11 (a) o expoente $p(n)$ em função de $\bar{\xi}(n)$; (b) "medida" da influência dos vizinhos em função de $\bar{\xi}(n)$; (c) "medida" da abertura do olho em função de $\bar{\xi}(n)$. . . 73

4.12 EMSE para o RMA, média de conjunto de 20 realizações. (a) Sem vizinhos (repetição da Figura (4.2)-(a)); (b) vizinhança Axial-1, (c) vizinhança Axial-2, $\mu_{64-\mathrm{QAM}}=1,8 \times 10^{-3}, \mu_{256-\mathrm{QAM}}=6 \times 10^{-4}$ e $\mu_{1024-\mathrm{QAM}}=9 \times 10^{-5} \ldots \ldots \ldots$ 
4.13 EMSE para o SBD, média de conjunto de 20 realizações. (a) sem vizinhos (repetição da Figura (4.2)-(b)); (b) vizinhança Axial-1, (c) vizinhança Axial-2; $\mu_{64-\mathrm{QAM}}=4 \times 10^{-3}, \mu_{256-\mathrm{QAM}}=5 \times 10^{-3}$ e $\mu_{1024-\mathrm{QAM}}=2,5 \times 10^{-4} \ldots \ldots \ldots$ 76

4.14 Erro quadrático em excesso do algoritmo RMA, única realização, sem mecanismo para evitar divergência (a) sem vizinhos, $\mu_{64-\mathrm{QAM}}=2,75 \times 10^{-2}$, $\mu_{256-\mathrm{QAM}}=1,5 \times 10^{-2}$ e $\mu_{1024-\mathrm{QAM}}=2,4 \times 10^{-3}$; (b) com vizinhos, $\mu_{64-\mathrm{QAM}}=$ $9 \times 10^{-3}, \mu_{256-\mathrm{QAM}}=5 \times 10^{-3}$ e $\mu_{1024-\mathrm{QAM}}=1,5 \times 10^{-3} \ldots \ldots \ldots . . \ldots$

4.15 EMSE para o algoritmo RMA, com mecanismo para evitar divergência, média de 100 realizações: (a) sem vizinhos, (b) com vizinhos, $\mu_{64-\mathrm{QAM}}=2,75 \times 10^{-2}$, $\mu_{256-\mathrm{QAM}}=1,5 \times 10^{-2}$ e $\mu_{1024-\mathrm{QAM}}=2,4 \times 10^{-3}$; (c) com vizinhos, $\mu_{64-\mathrm{QAM}}=$ $9 \times 10^{-3}, \mu_{256-\mathrm{QAM}}=5 \times 10^{-3}$ e $\mu_{1024-\mathrm{QAM}}=1,5 \times 10^{-3} \ldots \ldots \ldots \ldots$

6.1 Sistema de comunicação simplificado com DFE e sobreamostragem $(T / 2)$. . 99

6.2 Relações entre algoritmos autodidatas para a equalização de sinais QAM com o DFE. .

7.1 Sistema de comunicação simplificado com um equalizador autodidata.

7.2 MSE para (a) MMA $\left(\mu=2 \times 10^{-6}\right), \operatorname{CSD}\left(\mu=10^{-1}, \beta=10^{-4}, \rho=0,6\right)$, $\operatorname{MSD}\left(\mu=8 \times 10^{-3}, \rho=0,6\right)$; (b) $\operatorname{MRD}\left(\mu=10^{-4}\right)$, RMA $\left(\mu=4 \times 10^{-3}\right)$, SBD $\left(\mu=10^{-2}\right)$, NLMS $\left(\mu=5 \times 10^{-1}, \Delta_{1}=2\right)$, WIE $\left(\Delta_{1}=2\right) ;$ canal $\mathbf{h}_{1}, M=20$, 1024-QAM, equalizador sobreamostrado com $T / 2$, ausência de ruído, sem vizinhos, média de conjunto de 50 simulações independentes.

7.3 (a) MSE para MMA $\left(\mu=2 \times 10^{-5}\right)$, RMA $\left(\mu=10^{-3}\right)$, $\operatorname{SBD}\left(\mu=10^{-2}\right)$, NLMS $\left(\mu=5 \times 10^{-1}, \Delta_{2}=\Delta_{3}=11\right), \operatorname{WIE}\left(\Delta_{2}=\Delta_{3}=11\right) ;($ b) média de $p(n) ;$ vizinhança Axial-1 (2 vizinhos), canais $\mathbf{h}_{2}$ e $\mathbf{h}_{3}, M=21$, 256-QAM; sem ruído, 50 realizações.

7.4 (a) MSE para MMA $\left(\mu=10^{-7}\right), \operatorname{RMA}\left(\mu=5 \times 10^{-4}\right)$, SBD $\left(\mu=1.5 \times 10^{-3}\right)$, RMA com vizinhos $\left(\mu=10^{-4}\right)$, SBD com vizinhos $\left(\mu=5 \times 10^{-3}\right)$, NLMS $\left(\mu=5 \times 10^{-1}\right)$; (b) média de $p(n) ; \Delta_{2}=13$; vizinhança Axial-1 (4 vizinhos); canal $\mathbf{h}_{2} ; M=21 ; 4096$-QAM; sem ruído; 50 realizações. 
7.5 Log da SER em função da SNR: (a) 1024-QAM, MMA $\left(\mu=2 \times 10^{-6}\right)$, MSD $\left(\mu=5 \times 10^{-3}\right)$, RMA $\left(\mu=4 \times 10^{-3}\right)$, SBD $\left(\mu=5 \times 10^{-3}\right)$; (b) 4096-QAM, MMA $\left(\mu=10^{-7}\right), \operatorname{MSD}\left(\mu=2 \times 10^{-3}\right), \operatorname{RMA}$ e SBB $\left(\mu=3 \times 10^{-3}\right) ; \operatorname{NLMS}(\mu=0,5$, $\left.\Delta_{4}=44\right) ; \rho=0,6$; vizinhança Axial-1 (quatro vizinhos); canal $\mathbf{h}_{4} ; M=52$.

7.6 EMSE em função do passo de adaptação $\mu$ (a) ambiente estacionário (b) ambiente não-estacionário $\mathbf{Q}=10^{-7} \mathbf{I} ; 256$-QAM, canal $\mathbf{h}_{5}$, ausência de ruído, equalizador à taxa de símbolos, sem vizinhos, $M=21$, média de conjunto de 50 realizações independentes. .

7.7 EMSE em função do passo de adaptação $\mu$ (a) ambiente estacionário (b) ambiente não-estacionário $\mathbf{Q}=10^{-7} \mathbf{I} ; 64$-QAM, canal $\mathbf{h}_{5}$, ausência de ruído, equalizador à taxa de símbolos, sem vizinhos, $M=21$, média de conjunto de 50 realizações independentes.

7.8 (a) Erro de decisão ao quadrado ao longo das iterações; (b) Expoente $p(n)$ ao longo das iterações; 256-QAM, canal $\mathbf{h}_{6}$, única realização, MMA $\left(\mu=4 \times 10^{-5}\right)$, RMA $\left(\mu=7 \times 10^{-4}\right)$ com vizinhos, ausência de ruído, equalizador à taxa de símbolos.

7.9 Sistema de comunicação simplificado com DFE e sobreamostragem $(T / 2) \ldots$. 123

7.10 (a) MSE; (b) média de $p(n) ; 64$-QAM; SNR $=35 \mathrm{~dB} ; \Delta=61$; CSD $\left(\mu_{\mathrm{MMA}}=\right.$ $\left.10^{-5} ; \mu_{\mathrm{SDD}}=10^{-2} ; \rho=0,6\right) ; \mu_{\mathrm{MMA}}=2 \times 10^{-3} ; \mu_{\mathrm{SMMA}}=10^{-4} ; \mu_{\mathrm{NLMS}}=\mu_{\mathrm{RMA}}=$ $\mu_{\mathrm{SBD}}=5 \times 10^{-3}$.

7.11 (a) MSE; (b) $\mathrm{E}\{p(n)\} ; 1024-\mathrm{QAM} ; \mathrm{SNR}=40 \mathrm{~dB} ; \Delta=61 ; \mathrm{CSD}\left(\mu_{\mathrm{MMA}}=\right.$ $\left.5 \times 10^{-7} ; \mu_{\mathrm{SDD}}=10^{-2} ; \rho=0,6\right) ; \mu_{\mathrm{NLMS}}=10^{-3} ; \mu_{\mathrm{MMA}}=5 \times 10^{-4} ; \mu_{\mathrm{SMMA}}=4 \times 10^{-6}$; $\mu_{\mathrm{RMA}}=\mu_{\mathrm{SBD}}=5 \times 10^{-3} \ldots \ldots \ldots \ldots \ldots \ldots$

7.12 (a) MSE; (b) E $\{p(n)\} ; 4096-\mathrm{QAM} ; \mathrm{SNR}=50 \mathrm{~dB} ; \Delta=61 ; \operatorname{CSD}\left(\mu_{\mathrm{MMA}}=3 \times\right.$ $\left.10^{-7} ; \mu_{\mathrm{SDD}}=10^{-2} ; \rho=0,6\right) ; \mu_{\mathrm{NLMS}}=5 \times 10^{-2} ; \mu_{\mathrm{MMA}}=5 \times 10^{-4} ; \mu_{\mathrm{SMMA}}=9 \times 10^{-7}$; $\mu_{\mathrm{RMA}}=\mu_{\mathrm{SBD}}=2 \times 10^{-3}$. 
7.13 Log da SER em função da SNR para 64-QAM, SER para CSD $\left(\mu_{\mathrm{CMA}}=1 \times 10^{-5}\right.$; $\left.\mu_{\mathrm{SDD}}=1 \times 10^{-2} ; \rho=0,6\right), \operatorname{MMA}\left(\mu=2 \times 10^{-3}\right)$, RMA $\left(\mu=5 \times 10^{-3}\right), \mathrm{SBD}$ $\left(\mu=5 \times 10^{-3}\right)$, SMMA $\left(\mu=1 \times 10^{-4}\right)$, NLMS $\left(\mu=5 \times 10^{-3}\right)$, WIE (Atraso $\Delta=61$ ); vizinhança Axial 1 (2 vizinhos), canal $\mathbf{h}_{4} ; M_{\mathrm{f}}=118, M_{\mathrm{b}}=20 \ldots . .127$

7.14 Log da SER em função da SNR para 1024-QAM, SER para CSD $\left(\mu_{\mathrm{CMA}}=\right.$ $\left.5 \times 10^{-7} ; \mu_{\mathrm{SDD}}=1 \times 10^{-2} ; \rho=0,6\right), \operatorname{MMA}\left(\mu=5 \times 10^{-4}\right), \operatorname{RMA}\left(\mu=5 \times 10^{-3}\right)$, $\operatorname{SBD}\left(\mu=5 \times 10^{-3}\right)$, SMMA $\left(\mu=4 \times 10^{-6}\right)$, NLMS $\left(\mu=1 \times 10^{-3}\right)$, WIE (Atraso $\Delta=61$ ); vizinhança Axial 1 (2 vizinhos), canal $\mathbf{h}_{4} ; M_{\mathrm{f}}=118, M_{\mathrm{b}}=20 \ldots .127$

7.15 Log da SER em função da SNR para 4096-QAM, SER para CSD $\left(\mu_{\mathrm{CMA}}=\right.$ $\left.3 \times 10^{-7} ; \mu_{\mathrm{SDD}}=1 \times 10^{-2} ; \rho=0,6\right), \operatorname{MMA}\left(\mu=5 \times 10^{-4}\right), \operatorname{RMA}\left(\mu=2 \times 10^{-3}\right)$, $\operatorname{SBD}\left(\mu=2 \times 10^{-3}\right)$, SMMA $\left(\mu=9 \times 10^{-7}\right)$, NLMS $\left(\mu=5 \times 10^{-2}\right)$, WIE (Atraso $\Delta=61$ ); vizinhança Axial 1 (4 vizinhos), canal $\mathbf{h}_{4} ; M_{\mathrm{f}}=118, M_{\mathrm{b}}=20 \ldots \ldots 128$ 


\section{Lista de Tabelas}

1.1 Codificação do sinal 4-QAM. . . . . . . . . . . . . . . . . . 4

1.2 Estatísticas do sinal QAM em função da ordem da constelação. . . . . . . . . 15

2.1 Sumário do algoritmo RMA. . . . . . . . . . . . . . . . . . . . . 43

2.2 Sumário do algoritmo SBD. . . . . . . . . . . . . . . . . . . . 47

2.3 Erros de estimação dos algoritmos considerados. . . . . . . . . . . . . . . . . 48

2.4 Custo computacional em termos de operações reais por iteração - LTE. . . 48

4.1 Número de iterações para convergência. . . . . . . . . . . . . . . . . . . . . . 74

6.1 Sumário do DFE-MMA-FB. . . . . . . . . . . . . . . . 106

6.2 Sumário do RMA que evita soluções degeneradas. . . . . . . . . . . . . . . . 107

6.3 Sumário do SBD que evita soluções degeneradas. . . . . . . . . . . . . . . . 108

6.4 Custo computacional em termos de operações reais por iteração - DFE. . . . 109

7.1 Coeficientes dos canais considerados nas simulações. . . . . . . . . . . . . . . 111 


\section{Lista de Abreviaturas}

A seguir são listadas as principais abreviaturas usadas na tese.

ADSL asymmetric digital subscriber line

(linha de assinante digital e assimétrica)

AWGN additive white Gaussian noise (ruído aditivo branco gaussiano)

CMA constant modulus algorithm (algoritmo do módulo constante)

CME constellation matched error (função de erro casada à constelação)

CSD concurrent soft-decision (algoritmo concorrente com decisão suave)

DAB digital audio bradcasting (rádiodifusão de áudio digital)

DD decision-directed (decisão direta)

DFE decision feedback equalizer (equalizador de decisão realimentada)

DFE-CMA-FB CMA for adaptation of DFE with constraint in the feedback filter

(CMA para ajuste do DFE com restrição no filtro de realimentação)

DFT discrete Fourier transform (transformada discreta de Fourier)

DM-CMA dual mode constant modulus algorithm

(algoritmo do módulo constante de modo duplo)

DVB digital video bradcasting (rádiodifusão de vídeo digital)

DVB-C2 digital video bradcasting cable - second generation

(rádiodifusão de vídeo digital de segunda geração)

DVB-T digital video bradcasting terrestrial

(rádiodifusão de vídeo digital - terrestre)

EMSE

excess mean-square error (erro quadrático médio em excesso) 
f.d.p.

função densidade de probabilidade

FFT

fast Fourier transform (transformada rápida de Fourier)

FIR

finite impulse response (resposta ao pulso unitário finita)

HOS

higher order statistics (estatísticas de ordem superior)

IDFT

inverse discrete Fourier transform

(transformada discreta de Fourier inversa)

IFFT

inverse fast Fourier transform

(transformada rápida de Fourier inversa)

i.i.d.

independente e identicamente distribuída

IIR

infinite impulse response (resposta ao pulso unitário infinita)

ISDB-T

integrated services digital broadcasting - terrestrial

(serviço integrado de transmissão digital - terrestre)

ISI

intersymbol interference (interferência intersimbólica)

LMS

least-mean squares (algoritmo dos mínimos quadrados)

LTE

MMA

linear transversal equalizer (equalizador linear transversal)

MRD

multimodulus algorithm (algoritmo multimódulo)

multimodulus radius-directed

(algoritmo multimódulo guiado pelos raios)

MSD

modified soft decision-directed

(algoritmo de decisão direta suave modificado com partes real

e imaginária do erro calculadas separadamente)

MSDD

modified soft decision-directed

(algoritmo de decisão direta suave modificado)

MSE

mean-square error (erro quadrático médio)

NDEG-SDD-CMA

non-degenerative soft decision-directed constant modulus algorithm

(algoritmo concorrente SDD+CMA que evita soluções degeneradas)

NLMS

normalized least-mean squares

(algoritmo dos mínimos quadrados normalizado) 
OFDM

PAM

QAM

RDE

RMA

ROI

RLS

SBD

SCA

SDD

SER

SNR

SWA

WIE orthogonal frequency division multiplexing

(multiplexação por divisão de frequências ortogonais)

pulse amplitude modulation (modulação por amplitude de pulso)

quadrature amplitude modulation

(modulação de amplitude em quadratura)

radius-directed equalization

(algoritmo guiado pelos raios)

regional multimodulus algorithm (algoritmo multimódulo regional)

region of interest (região de interesse)

recursive least-squares

(algoritmo dos mínimos quadrados recursivos)

symbol-based decision (algoritmo de decisão baseada nos símbolos)

square contour algorithm (algoritmo de contorno quadrado)

soft decision-directed (decisão direta suave)

symbol error rate (taxa de erro de símbolos)

signal-to-noise ratio (razão sinal-ruído)

Shalvi-Weinstein algorithm (algoritmo de Shalvi-Weinstein)

Wiener solution (solução de Wiener) 


\section{Lista de Símbolos}

Nesta tese, matrizes são indicadas por letras maiúsculas em negrito, por exemplo R. Vetores coluna são indicados usando-se letras minúsculas em negrito, por exemplo $\mathbf{w}(n)$. Escalares são representados por letras minúsculas ou maiúsculas em itálico, por exemplo $M, \mu$ e $y(n)$. A seguir, são listados os principais símbolos gerais, e também os demais símbolos na medida em que aparecem em cada um dos capítulos.

\section{Símbolos gerais}

$(\cdot)^{T} \quad$ transposição de vetores ou matrizes

$(\cdot)^{*} \quad$ complexo conjugado

$j(\cdot) \quad$ parte imaginária de um número complexo

$(\cdot)^{H} \quad$ hermitiano (transposição do complexo conjugado) de vetores ou matrizes

valor estimado

$\mathrm{E}\{\cdot\} \quad$ operador esperança matemática

$v(\cdot) \quad$ função degrau unitário

$\operatorname{dec}(\cdot$ função de decisão baseada nos símbolos da constelação

$z^{-1} \quad$ operador de atraso, $z^{-1} y(n)=y(n-1)$

$\|\mathbf{x}\| \quad$ norma euclidiana ou $\ell_{2}$ do vetor $\mathbf{x}$

$\operatorname{Tr}(\mathbf{A}) \quad$ traço (soma dos elementos da diagonal) da matriz A

$\sigma_{x}^{2} \quad$ variância do sinal $x$

I matriz identidade

0 vetor nulo

$\operatorname{Re}(\cdot)$ ou $(\cdot)_{\mathrm{R}}$ parte real 


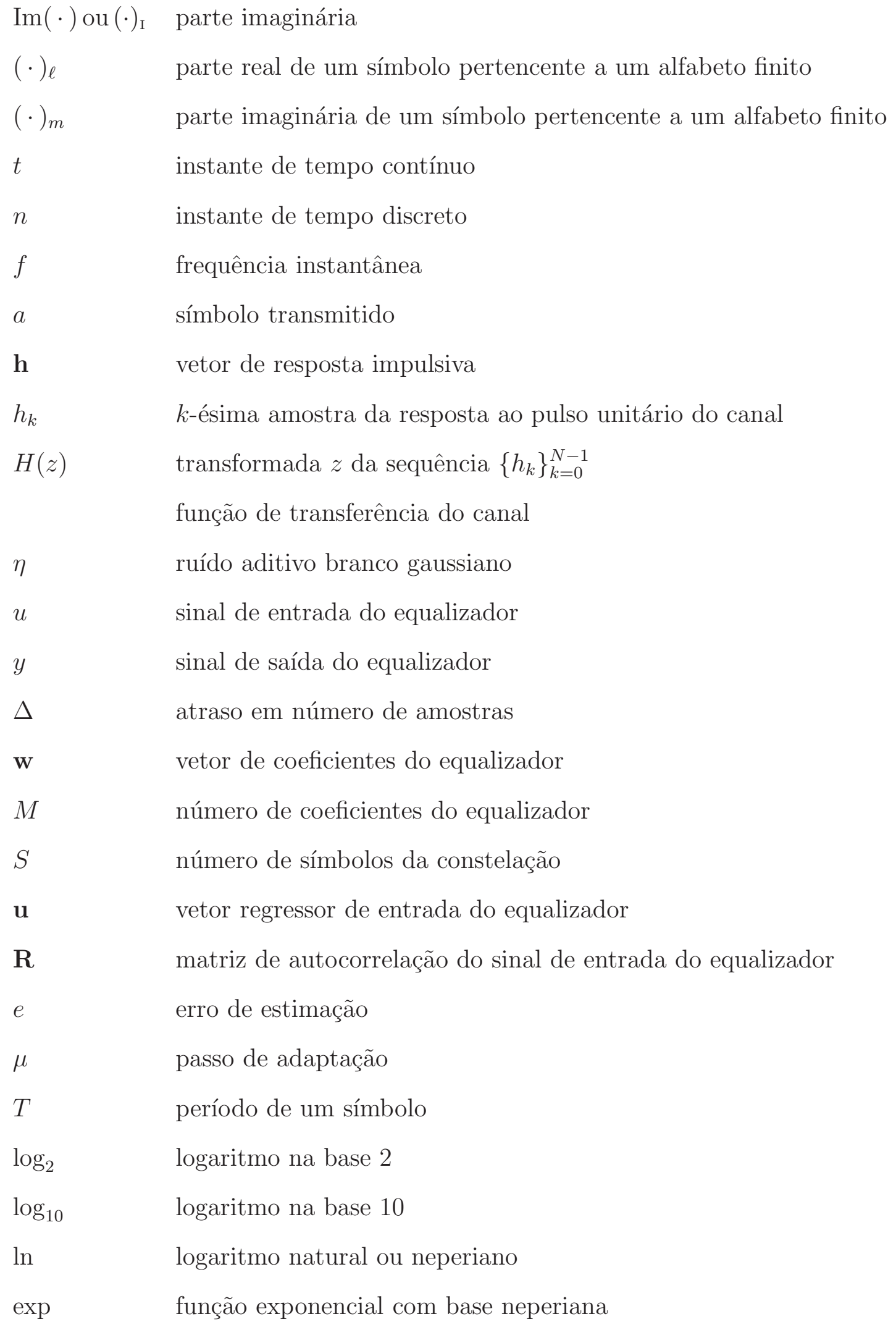




\section{Símbolos do capítulo 1}

$\begin{array}{ll}J_{\mathrm{CMA}} & \text { função custo do CMA } \\ r & \text { constante de dispersão do CMA } \\ r_{n} & \text { constante de dispersão do RDE } \\ \phi_{\mathrm{PAM}, \ell}(t) & \text { sinal PAM no tempo contínuo } \\ g(t) & \text { função para formatação do espectro do sinal PAM/QAM } \\ f_{c} & \text { frequência da portadora } \\ \phi_{\mathrm{QAM}, \ell, \mathrm{m}}(t) & \text { sinal QAM no tempo contínuo } \\ \cos & \text { função cosseno } \\ \text { sen } & \text { função seno } \\ \delta & \text { fator de regularização (constante positiva pequena) }\end{array}$

\section{Símbolos do capítulo 2}

$\begin{array}{ll}J_{\mathrm{MMA}} & \text { função custo do MMA } \\ r_{2} & \text { constante de dispersão do MMA } \\ e_{\mathrm{MMA}} & \text { erro de estimação do MMA } \\ J_{\mathrm{SDD}} & \text { função custo do SDD } \\ \hat{f} & \text { aproximação local da função densidade de probabilidade } \\ \rho & \text { variância da parte real do ruído, } \varrho_{\mathrm{R}}, \text { ou da parte imaginária, } \varrho_{\mathrm{I}} \\ \varepsilon_{\mathrm{SDD}} & \text { erro de estimação do SDD } \\ J_{\mathrm{CSD}} & \text { função custo do CSD } \\ \beta & \text { razão entre os passos de adaptação do MMA e do algoritmo SDD } \\ e_{\mathrm{CSD}} & \text { erro de estimação do CSD } \\ A_{k} & \text { região } k \text { de uma dada constelação } \\ e_{\mathrm{MSD}} & \text { erro de estimação do MSD } \\ e_{\mathrm{RMA}} & \text { erro de estimação do RMA } \\ \breve{y} & \text { saída do equalizador transladada para a origem do plano complexo }\end{array}$




$\begin{array}{ll}J_{\mathrm{RMA}} & \text { função custo do RMA } \\ \alpha & \text { fator de escala } \\ c & \text { centro da região identificada } \\ e_{\mathrm{MRD}} & \text { erro de estimação do MRD } \\ e_{\mathrm{SBD}} & \text { erro de estimação do SBD } \\ J_{\mathrm{SBD}} & \text { função custo do SBD }\end{array}$

\section{Símbolos do capítulo 3}

$\begin{array}{ll}J_{\mathrm{MSE}} & \text { função custo do MSE } \\ \xi & \text { erro entre o sinal desejado e a saída do equalizador } \\ \mathbf{p}_{\Delta} & \text { vetor de correlação cruzada entre } \mathbf{u} \text { e o sinal desejado } \\ \breve{a} & \text { sinal desejado transladado para a origem do plano complexo }\end{array}$

\section{Símbolos do capítulo 4}

\% $\quad$ escalar que relaciona a solução do RMA à solução de Wiener

- fator de ponderação

b constante usada nos esquemas de vizinhança

$p \quad$ expoente obtido a partir de função não-linear

$\bar{\xi} \quad$ estimativa do valor médio do erro de decisão quadrático

$\lambda \quad$ fator de esquecimento

$\tilde{\mathbf{u}} \quad$ vetor regressor de entrada normalizado

$\bar{\gamma} \quad$ variável que depende das estatísticas da constelação

$\tilde{\mu} \quad$ passo de adaptação do MMA/RMA com mecanismo para evitar divergência

e $\quad$ erro de estimação do MMA/RMA com mecanismo para evitar divergência

$J_{\min }(\Delta) \quad$ mínimo da função custo do erro quadrático médio 


\section{Símbolos do capítulo 5}

$\begin{array}{ll}\mathbf{q} & \text { vetor de perturbação aleatória } \\ \mathbf{Q} & \text { matriz de covariância } \\ \zeta & \text { erro quadrático médio em excesso (EMSE) } \\ e_{a} & \text { erro a priori } \\ \tilde{\mathbf{w}} & \text { vetor de erro de coeficientes } \\ v & \text { perturbação i.i.d. de média nula } \\ \mathbf{w} & \text { vetor de coeficientes ótimo } \\ \beta, \gamma & \text { variáveis aleatórias que dependem das estatísticas da constelação } \\ \overline{\bar{\gamma}} & \text { variável que depende das estatísticas da constelação } \\ \zeta_{\mathrm{MMA}} & \text { erro quadrático médio em excesso do MMA } \\ \zeta_{\mathrm{RMA}} & \text { erro quadrático médio em excesso do RMA } \\ \zeta_{\mathrm{outROI}} & \text { erro quadrático médio em excesso fora da região de interesse } \\ \zeta_{\mathrm{SBD}} & \text { erro quadrático médio em excesso do SBD }\end{array}$

\section{Símbolos do capítulo 6}

$\begin{array}{ll}\mathbf{h}_{\mathrm{e}}, \mathbf{h}_{\mathrm{o}} & \text { vetores de respostas impulsivas dos subcanais } \\ \mathbf{w}_{\mathrm{fe}}, \mathbf{w}_{\mathrm{fo}} & \text { vetores dos filtros diretos dos subequalizadores } \\ \mathbf{w}_{\mathrm{f}} & \text { vetor do filtro direto sem sobreamostragem } \\ \mathbf{w}_{\mathrm{b}} & \text { vetor do filtro de realimentação } \\ \mathbf{x}_{\mathrm{b}} & \text { vetor regressor de entrada do filtro direto } \\ \hat{\mathbf{a}}_{\Delta} & \text { vetor regressor de entrada do filtro de realimentação } \\ \mathbf{u} & \text { vetor regressor resultado da concatenação dos vetores } \mathbf{x}_{\mathrm{b}} \text { e } \hat{\mathbf{a}}_{\Delta} \\ E_{y \mathrm{f}} & \text { estimativa da potência do sinal de saída do filtro direto } \\ C & \text { variável: representa a restrição do algoritmo que evita soluções degeneradas } \\ \lambda_{\mathrm{L}} & \text { multiplicador de Lagrange } \\ \mathbf{g} & \text { vetor de correlação cruzada entre } \mathbf{x} \text { e a saída do filtro direto }\end{array}$




\section{Capítulo 1}

\section{Introdução e formulação do problema}

Neste capítulo, são discutidos inicialmente o conceito de sinais QAM e o efeito que um canal de comunicação ruidoso e dispersivo causa sobre esses sinais. Um breve panorama de aplicações atuais que utilizam sinais QAM também é apresentado. Em seguida, os princípios da equalização autodidata baseada em estatísticas de ordem superior são revisitados. Revisitam-se também soluções existentes na literatura relacionadas à equalização de sinais QAM. Finalmente, os objetivos, as contribuições e a estrutura do trabalho são apresentados.

\subsection{Sinais com modulação QAM}

Sistemas de comunicação atuais necessitam transmitir grandes quantidades de informação em intervalos de tempo cada vez menores, com taxas de erro de símbolo reduzidas e considerando diferentes tipos de canais de comunicação [PROAKIS, 2001; HAYKIN, 2000]. Para tais requisitos, vários esquemas de modulação digital foram propostos na literatura. Dentre eles, destaca-se a modulação de amplitude de pulso (PAM - pulse amplitude modulation), em que a portadora é modulada por sinais transmitidos em banda base com amplitudes discretas $a_{\ell}$, codificadas com $k$ bits. Os valores (níveis) dessas amplitudes são dados por $(2 \ell-1-S)$, sendo $1 \leq \ell \leq S$ e $S=2^{k}$ o número de símbolos do alfabeto. A forma de onda de um sinal 
com modulação do tipo PAM é dada por

$$
\phi_{\mathrm{PAM}, \ell}(t)=\operatorname{Re}\left\{a_{\ell} g(t) \mathrm{e}^{j 2 \pi f_{c} t}\right\}=a_{\ell} g(t) \cos \left(2 \pi f_{c} t\right), \quad 0 \leq t \leq T
$$

em que $\operatorname{Re}\{\cdot\}$ representa a parte real de um número complexo, $T$ é o intervalo de símbolo, $f_{c}$ é a frequência da portadora e $g(t)$ é uma função real, também chamada de pulso, cuja forma influencia o espectro do sinal transmitido [PROAKIS, 2001; HAYKIN, 2000; PRANDONI; VETTERLI, 2008; LATHI, 1998]. Para exemplificar, na Figura 1.1-(a) é mostrado um sinal transmitido em banda base com uma possível codificação, considerando $k=2$ e $g(t)=1,0 \leq t \leq T$. O sinal 4-PAM correspondente é mostrado na Figura 1.1-(b). Neste exemplo, os valores das amplitudes $a_{\ell}$ são $\{1,-3,-1,3,-3,1,-1,-1,3,1\}$.
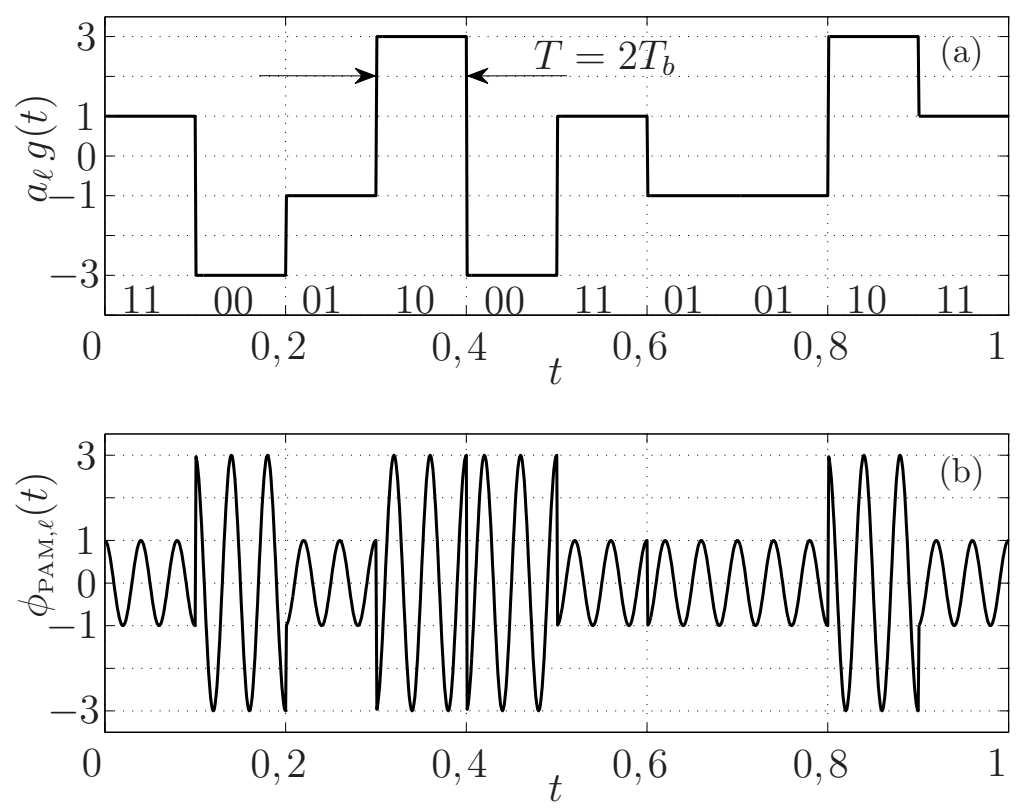

Figura 1.1: Formas de onda do sinal: (a) Transmissão em banda base; (b) PAM; $T_{b}$ é o intervalo de bit.

Um outro esquema que usa a largura de banda disponível de forma mais eficiente é o da modulação de amplitude em quadratura (QAM - quadrature amplitude modulation), na qual símbolos com $k$ bits de informação são alocados separadamente em duas portadoras em quadratura, i.e., $\cos \left(2 \pi f_{c} t\right)$ e $\operatorname{sen}\left(2 \pi f_{c} t\right)$. A técnica de modulação resultante é chamada de 
PAM em quadratura ou simplesmente QAM, cujo sinal é expresso por

$$
\begin{aligned}
\phi_{\mathrm{QAM}, \ell, m}(t) & =\operatorname{Re}\left\{\left(a_{\ell}+j a_{m}\right) g(t) \mathrm{e}^{j 2 \pi f_{c} t}\right\} \\
& =a_{\ell} g(t) \cos \left(2 \pi f_{c} t\right)-a_{m} g(t) \operatorname{sen}\left(2 \pi f_{c} t\right),
\end{aligned}
$$

sendo $a_{\ell}$ e $a_{m}$ as amplitudes discretas dos sinais que modulam as portadoras em fase e em quadratura, respectivamente [PROAKIS, 2001; HAYKIN, 2000; LATHI, 1998; HOWALD, 2002; ZHOU; ZOU, 2011]. Em outras palavras, um sinal QAM é uma combinação linear de dois sinais PAM: uma portadora cossenoidal modulada pela parte rea $\ell a_{\ell}$ e uma portadora senoidal modulada pela parte imaginária $a_{m}$ do símbolo $\left(a_{\ell}+j a_{m}\right)$ [PRANDONI; VETTERLI, 2008]. Um diagrama amplamente utilizado para representar um sinal com modulação do tipo QAM é mostrado na Figura 1.2.
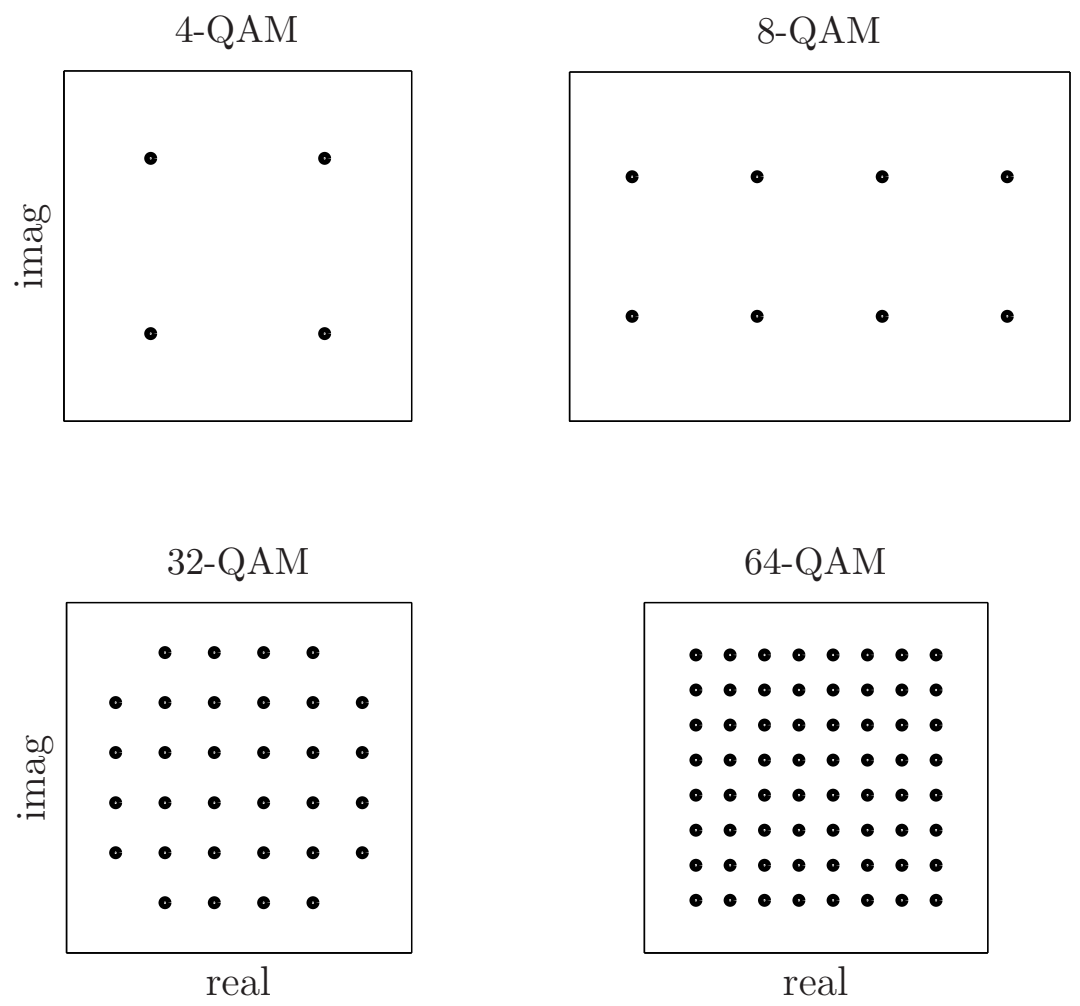

Figura 1.2: Constelações QAM com número de símbolos diferentes.

Nessa representação gráfica no plano complexo, comumente chamada de constelação, os símbolos transmitidos podem ser identificados e ainda é possível observar a relação existente entre as portadoras em fase e quadratura. Nessa figura, são mostradas três tipos de cons- 
telação QAM: quadrada (4-QAM e 64-QAM), retangular (8-QAM) e cruzada (32-QAM). No caso das constelações quadradas, os possíveis níveis das amplitudes $a_{\ell}$ e $a_{m}$ são dados respectivamente por $(2 \ell-1-\sqrt{S})$ e $(2 m-1-\sqrt{S})$ sendo $1 \leq \ell, m \leq \sqrt{S}$ e $S$ o número de símbolos do alfabeto. Tomando como exemplo a modulação 4-QAM ( $S=4$ símbolos codificados com $k=2$ bits cada), uma possível codificação binária dos símbolos, os sinais transmitidos e as correspondentes representações no plano complexo são mostrados na Tabela 1.1.

Tabela 1.1: Codificação do sinal 4-QAM.

\begin{tabular}{|c|c|c|}
\hline Bits & $\phi_{\mathrm{QAM}, \ell, m}(t)$ & $a_{\ell}+j a_{m}$ \\
\hline 00 & $g(t) \cos \left(2 \pi f_{c} t\right)-g(t) \operatorname{sen}\left(2 \pi f_{c} t\right)$ & $1-j$ \\
\hline 01 & $-g(t) \cos \left(2 \pi f_{c} t\right)-g(t) \operatorname{sen}\left(2 \pi f_{c} t\right)$ & $-1-j$ \\
\hline 11 & $-g(t) \cos \left(2 \pi f_{c} t\right)+g(t) \operatorname{sen}\left(2 \pi f_{c} t\right)$ & $-1+j$ \\
\hline 10 & $g(t) \cos \left(2 \pi f_{c} t\right)+g(t) \operatorname{sen}\left(2 \pi f_{c} t\right)$ & $1+j$ \\
\hline
\end{tabular}

A constelação 4-QAM com a codificação da Tabela 1.1 é mostrada na Fig 1.3, onde são identificados os eixos do plano complexo, as coordenadas e os pares de bits (duo-bits) associados a cada símbolo. A sequência dos duo-bits considerada corresponde à codificação de Gray, em que ocorre a mudança de apenas um bit para símbolos adjacentes. Erros devido à ação do ruído ocasionam a escolha incorreta de uma amplitude adjacente à originalmente transmitida. Neste caso, a probabilidade de erro do sistema pode ser reduzida se a codificação de símbolos adjacentes diferir de um número mínimo de bits, o que é alcançado com a codificação de Gray [PROAKIS, 2001]. Um outro exemplo é mostrado na Figura 1.4 em que $k=4$, resultando na constelação quadrada 16-QAM. É possível observar na figura que para encontrar os vizinhos do símbolo 0101, por exemplo, basta alterar o estado lógico, um a um, de seus quatro dígitos binários, resultando nos símbolos com codificação binária 0100,0111,0001 e 1101. Cabe observar que uma constelação QAM cruzada não permite a utilização da codificação de Gray perfeita como no caso das constelações quadradas. Além disso, a constelação cruzada não pode ser gerada a partir de duas constelações PAM iguais, como ocorre no caso das quadradas, o que dificulta a obtenção de uma expressão analítica para probabilidade de erro de símbolos [HAYKIn, 2000]. Por esses motivos, a maioria das 
aplicações práticas considera a utilização de constelações quadradas, que são geradas com um número de bits par e maior ou igual a $4(k \geq 4)$.

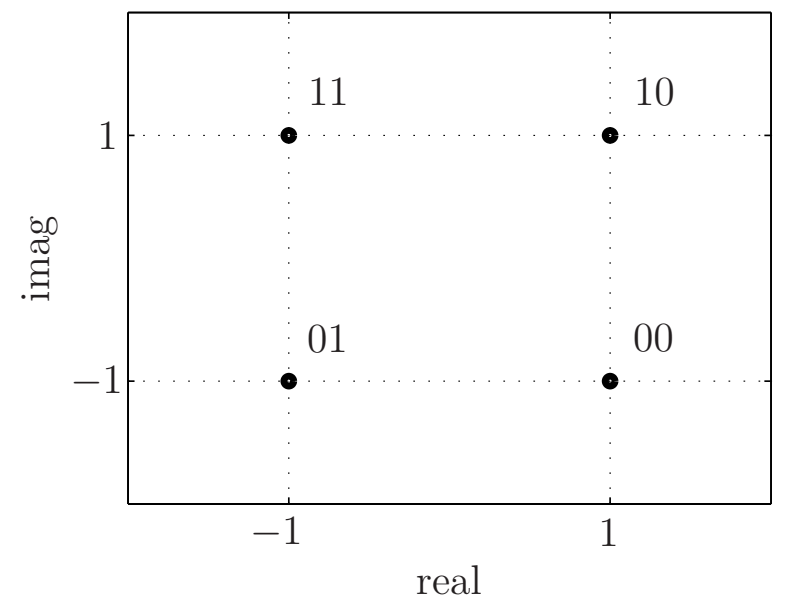

Figura 1.3: Identificação dos símbolos de uma constelação 4-QAM.

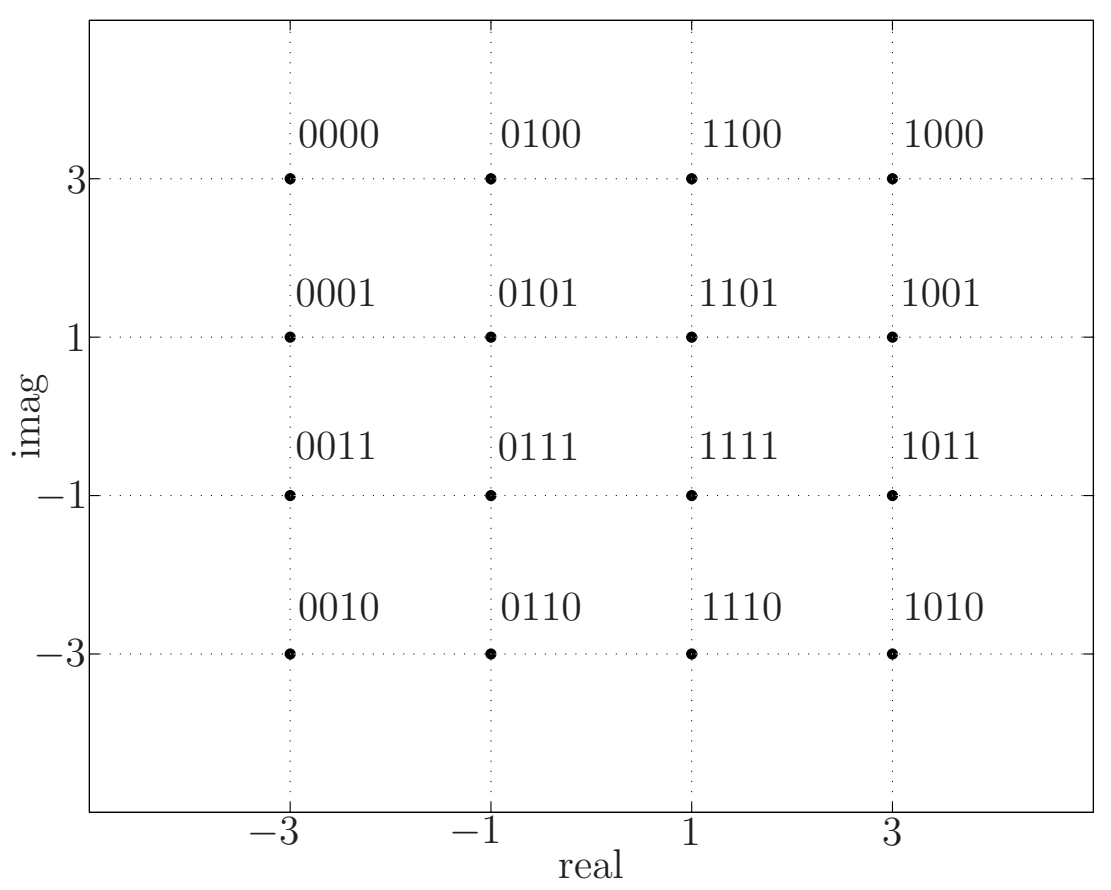

Figura 1.4: Codificação de Gray para a constelação 16-QAM.

A geração de um sinal QAM é obtida de forma relativamente simples, como ilustrado na Figura 1.5. As mensagens $a_{\ell} g(t)$ e $a_{m} g(t)$ são moduladas através de portadoras de mesma 
frequência, porém com defasagem de $\pi / 2$ radianos. Os blocos multiplicadores realizam a modulação das mensagens com suas respectivas portadoras, resultando nos correspondentes sinais modulados em amplitude com portadora suprimida. Esses sinais são somados e transmitidos. No receptor, através da detecção coerente, ou seja, mediante produtos com portadoras sincronizadas em fase e frequência com as correspondentes portadoras de transmissão, se realiza a translação no espectro de frequências. Assim, nas saídas dos blocos multiplicadores, as mensagens transmitidas podem ser localizadas em duas regiões do espectro: em torno de $f=0$ e em torno de $f=2 f_{c}$. Portanto, para recuperação das mensagens originais, basta utilizar filtros passa-baixas. Para preservar a amplitude das mensagens transmitidas, as amplitudes das portadoras de recepção são iguais ao dobro das de transmissão [LATHI, 1998].

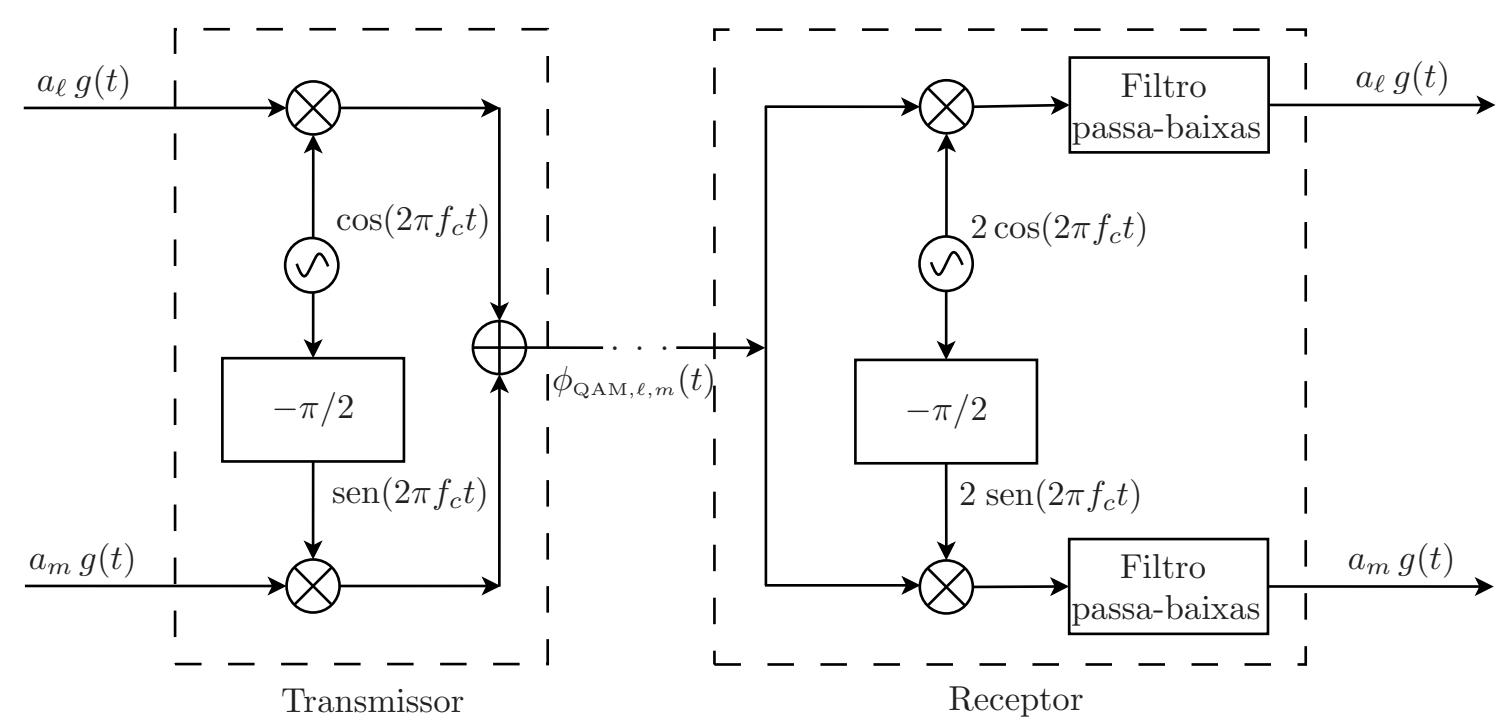

Figura 1.5: Diagrama simplificado de um sistema de comunicação com modulação de amplitude em quadratura [LATHI, 1998].

Nesta seção, foram vistos aspectos básicos importantes para a obtenção de sinais QAM para o entendimento deste trabalho. Nas demais seções, não são consideradas as portadoras ou quaisquer outros blocos relacionados diretamente a elas. Além disso, são consideradas apenas constelações QAM quadradas, embora os esquemas aqui propostos possam ser estendidos para constelações QAM retangulares e cruzadas. 


\subsection{O efeito do canal de comunicação}

No diagrama da Figura 1.5, o canal de comunicação foi considerado ideal. Na prática, o canal é ruidoso e dispersivo e para recuperar corretamente o sinal QAM, é necessário incluir blocos adicionais no receptor. Se o canal contiver apenas a influência de uma fonte de ruído, haverá erros na recuperação dos sinais transmitidos. Quanto menor o número de símbolos da constelação, menor será a taxa de erro para uma dada razão sinal-ruído (SNR - signal to noise ratio). Para exemplificar, na Figura 1.6 são mostradas curvas de taxa de erro de símbolos (SER - symbol error rate) em função da SNR, para diferentes constelações QAM e admitindo um canal com ruído aditivo branco e gaussiano (AWGN - additive white Gaussian noise). É possível observar na figura que à medida que a ordem da constelação aumenta, deve-se ter uma razão sinal-ruído maior para se obter uma mesma taxa de erro. Como exemplo, obtém-se uma taxa de erro de símbolos de $10^{-5}$ com uma SNR de 20 dB para 16-QAM. Entretanto, essa mesma taxa de erro só é obtida para 4096-QAM se a SNR estiver em torno de 45 dB. Porém, o QAM é considerado atrativo devido à sua eficiência espectral, ou seja, quanto maior a ordem da constelação, mais informação por segundo pode ser transmitida.

A característica dispersiva do canal de comunicação dificulta ainda mais a recuperação dos sinais transmitidos devido à interferência intersimbólica (ISI - intersymbol interference). A ISI ocorre devido aos multipercursos do canal, que fazem com o sinal que chega ao receptor seja constituído por um somatório de réplicas atenuadas e defasadas do sinal transmitido, acrescidas de ruído. Para combater a ISI, é necessário utilizar um equalizador no receptor. Além disso, o canal pode variar devido à movimentação do transmissor e/ou receptor (por exemplo, quando se usa telefone celular em um carro em movimento) e também em função da temperatura e fenômenos meteorológicos tais como chuva, neve, vento, ionização atmosférica etc. Para acompanhar essas possíveis variações, é importante que o equalizador seja adaptativo. Neste contexto, para continuar utilizando a banda de forma eficiente, além da modulação do tipo QAM, os equalizadores adaptativos devem ser autodidatas, já que eles não utilizam uma sequência de treinamento previamente conhecida no receptor e por isso economizam a banda disponível [GODARD, 1980]. 


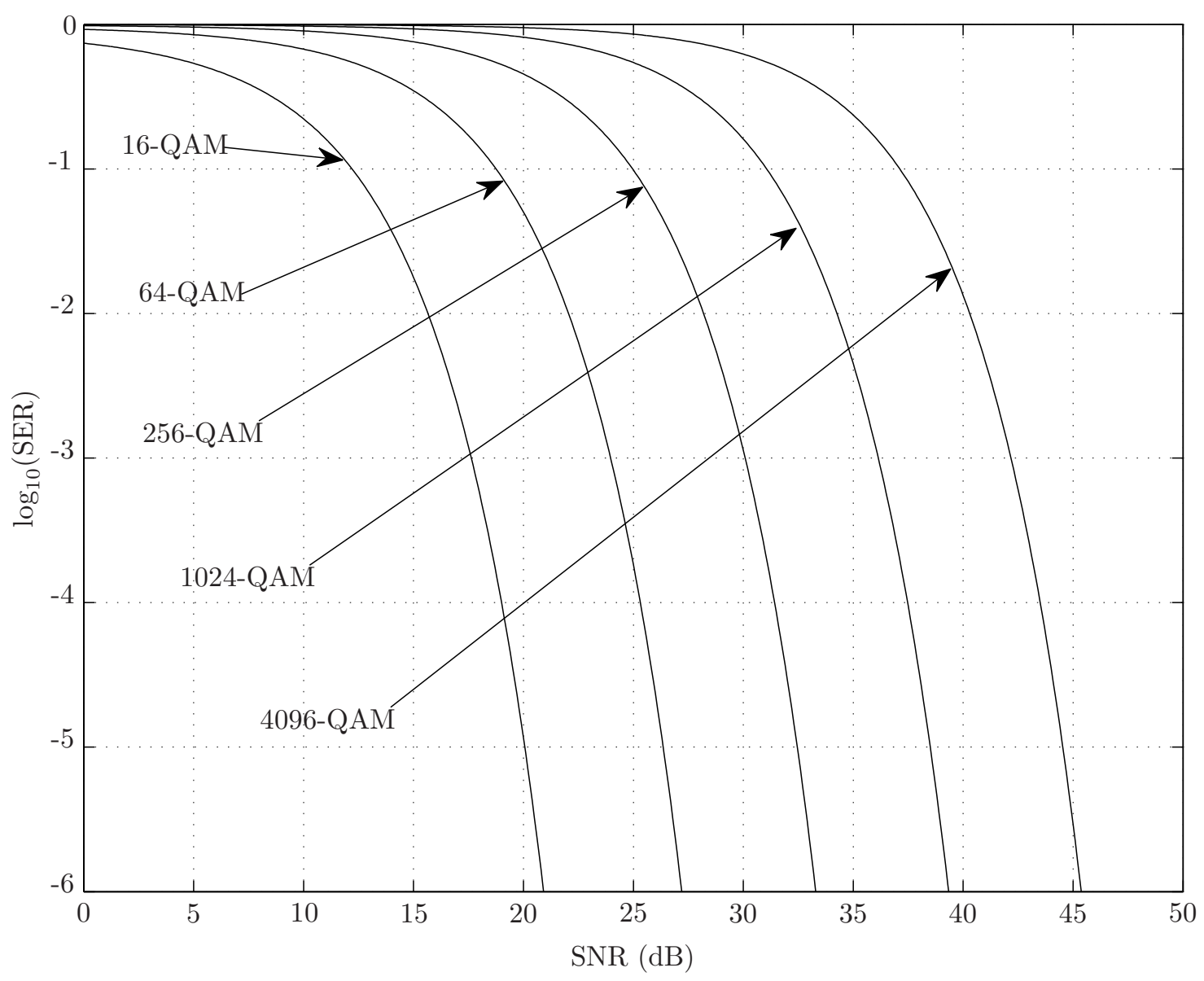

Figura 1.6: $\log _{10}(\mathrm{SER})$ em função da SNR (dB) para as constelações quadradas 16, 64, 256, 1024 e 4096-QAM.

\subsection{Aplicações de sinais QAM}

Pelo fato de sinais QAM permitirem a utilização mais eficiente da largura de banda disponível, eles têm sido utilizados há muito tempo em sistemas de comunicação digital tanto com portadora única quanto com multiportadoras. As aplicações são diversas, destacandose principalmente: a comunicação via satélite, radiodifusão de sinais de áudio e vídeo, comunicação ponto a ponto através de enlaces de rádios digitais ou via cabo, dentre outras [HOWALD, 2002; ZHOU; ZOU, 2011; DVB GUIDELINES, 2010]. Na maioria dessas aplicações, sinais QAM de diferentes ordens (de 16 a 4096-QAM) são utilizados em sistemas com múltiplas portadoras. Em contrapartida, há poucos trabalhos publicados na literatura que consideram a equalização autodidata temporal de sinais QAM de ordem elevada (maior que 256-QAM) 
em sistemas com portadora única, sendo alguns exemplos encontrados em [KURAKAKE, 2004; TAN et al., 1998; ZAOUCHE; DAYOUB; ROUVAEN, 2005]. Tal fato pode ser explicado principalmente por dois motivos:

i) algumas vantagens da utilização de modulações com multiportadoras em várias aplicações, como por exemplo: nos sistemas europeus de radiodifusão de áudio digital (DAB - digital audio bradcasting) e vídeo digital (DVB-T - digital video bradcasting terrestre), no padrão para radiodifusão do sinal de televisão digital japonês e brasileiro (ISDB-T - Integrated services digital broadcasting - terrestrial), nos sistemas de transmissão de dados em banda larga para linhas telefônicas (ADSL - asymmetric digital subscriber line), nos sistemas de banda larga sem fio padrão IEEE802.11a, dentre outros [ACÁCIO, 2004]. O crescimento vertiginoso de aplicações com múltiplas portadoras tem como uma de suas principais sustentações o avanço dos processadores digitais de sinais e a consequente utilização de técnicas robustas como o par de transformadas discretas de Fourier (DFT - discrete Fourier transform e IDFT - inverse discrete Fourier transform) implementadas com algoritmos eficientes como FFT (fast Fourier transform) e IFFT (inverse fast Fourier transform). Esse avanço começou na década de 60 e continua até os dias atuais como mostrado em [GOMES, 2002; ACÁCIO, 2004; DE PAULA, 2010]. Em [DE PAULA, 2010], é mostrado um resumo histórico acerca da modulação com múltiplas portadoras ortogonais (OFDM - orthogonal frequency division multiplexing) e uma comparação entre esse esquema de modulação e o que utiliza portadora única, ambos utilizando equalizadores no domínio da frequência. Por fim, cabe salientar que na segunda geração do sistema europeu de transmissão via cabo (DVB-C2), está prevista a utilização de sinais QAM de ordem elevada (1024-QAM e 4096-QAM) em sistemas com mutiportadoras [DVB GUIDELINES, 2010];

ii) desempenho insatisfatório de algoritmos de equalização autodidata temporal com portadora única. Embora tenha havido grandes avanços desde o surgimento do algoritmo de equalização autodidata do módulo constante [GODARD, 1980], os algoritmos existentes na literatura apresentam um desempenho insatisfatório para sinais QAM de ordem elevada. Alguns resultados razoáveis foram obtidos para constelações QAM com até 
256 símbolos às custas de um difícil ajuste nos parâmetros de adaptação, como o passo de algoritmos do gradiente estocástico, por exemplo. Esses são os casos dos algoritmos propostos em [DE CASTRO; DE CASTRO; ARANTES, 2001; CHEN, 2003; ABRAR; AXFORD JR., 2005; GOUPIL; PALICOT, 2007]. Neste contexto, ainda há muitos problemas em aberto para tornar a utilização de sistemas de portadora única com equalização autodidata competitiva com sistemas baseados em múltiplas portadoras.

\subsection{A equalização autodidata}

Levando-se em conta a forma de adaptação, os equalizadores adaptativos podem ser classificados como supervisionados ou autodidatas. No caso da equalização supervisionada, há a necessidade do envio de uma sequência de treinamento, previamente conhecida no receptor, para que o equalizador possa ajustar seus coeficientes. Após a fase de treinamento, o equalizador entra no modo de decisão direta, retornando ao treinamento sempre que houver inclusão de um novo elemento na rede, quando ocorrer falta de energia, ou quando variações do canal de comunicação impuserem um novo ajuste aos coeficientes do filtro utilizado. Apesar de ser relativamente simples, esse mecanismo implica paradas previstas e não previstas e, principalmente, perda de banda disponível, já que parte da banda deve ser alocada para a transmissão da sequência de treinamento [QURESHI, 1985; GODARD, 1980].

No caso da equalização autodidata, o sinal de treinamento é substituído por uma filosofia de aprendizado permanente com base nas estatísticas de ordem superior a dois (HOS higher-order statistics) do sinal transmitido. Em outras palavras, o equalizador autodidata "conhece" as estatísticas do sinal que se pretende transmitir e então ajusta permanentemente os coeficientes com base num algoritmo que avalia o quão distante estão as estatísticas do sinal de saída do equalizador das do sinal transmitido [BENVENISTE; GOURSAT; RUGET, 1980]. Os métodos que utilizam HOS são baseados principalmente em momentos e cumulantes de ordem superior a dois. Neste contexto, destacam-se dois critérios: o de Shalvi-Weinstein, proposto originalmente em [DONOHO, 1981] e depois simplificado em [SHALVI; WEINSTEIN, 1990, 1993] e o de Godard, também conhecido como critério do módulo constante, proposto 
independentemente em [GODARD, 1980] e [TREICHLER; AGEE, 1983]. O critério de ShalviWeinstein considera a curtose do sinal transmitido, ou seja, para recuperar a sequência transmitida, é suficiente que as curtoses das sequências transmitida e de saída do equalizador sejam iguais [SHALVI; WEINSTEIN, 1990]. O critério do módulo constante minimiza a distância do módulo ao quadrado do sinal de saída do equalizador de uma constante de dispersão [GODARD, 1980]. Sob certas circunstâncias, esses critérios são equivalentes, como mostrado analiticamente em [SHALVI; WEINSTEIN, 1993; REGALIA, 1999]. Na literatura, ainda existem critérios baseados na teoria da informação, que ajustam o equalizador para que a função densidade de probabilidade do sinal de saída seja igual a do sinal transmitido [ERDOGMUS; PRINCIPE; HILD, 2002].

O critério do módulo constante consiste na minimização da seguinte função custo [GODARD, 1980]

$$
J_{\mathrm{CMA}}=\mathrm{E}\left\{\left(r-|y(n)|^{2}\right)^{2}\right\}
$$

em que $\mathrm{E}\{\cdot\}$ representa o operador esperança matemática, $y(n)$ é a saída do equalizador e $r$ é a constante de dispersão que depende de estatísticas do sinal transmitido $a(n)$, ou seja,

$$
r=\frac{\mathrm{E}\left\{|a(n)|^{4}\right\}}{\mathrm{E}\left\{|a(n)|^{2}\right\}}
$$

Para exemplificar, na Figura 1.7 são mostradas a constelação 64-QAM e a circunferência correspondente à raiz quadrada de sua constante de dispersão, ou seja, $\sqrt{r}=\sqrt{58}=7,6158$. Neste caso, o critério do módulo constante deve minimizar o valor quadrático médio da distância entre $|y(n)|^{2}$ e $r=58$. Cabe observar que só quando os sinais têm módulo constante, a raiz quadrada da constante de dispersão coincide com o módulo dos símbolos da constelação, que é o caso de 4-QAM, por exemplo, em que $a(n) \in\{-1-j,-1+j,+1-j,+1+j\}$ $\mathrm{e}|a(n)|=\sqrt{2}=\sqrt{r}$.

A minimização de uma versão instantânea de $J_{\mathrm{CMA}}$ deu origem ao algoritmo estocástico do módulo constante (CMA - constant modulus algorithm), que é o mais popular para a adaptação autodidata de equalizadores com resposta impulsiva finita (FIR - finite impulse response) devido ao seu baixo custo computacional. No entanto, o CMA apresenta algumas desvantagens como a impossibilidade de resolver as ambiguidades de fase introduzidas pelo 


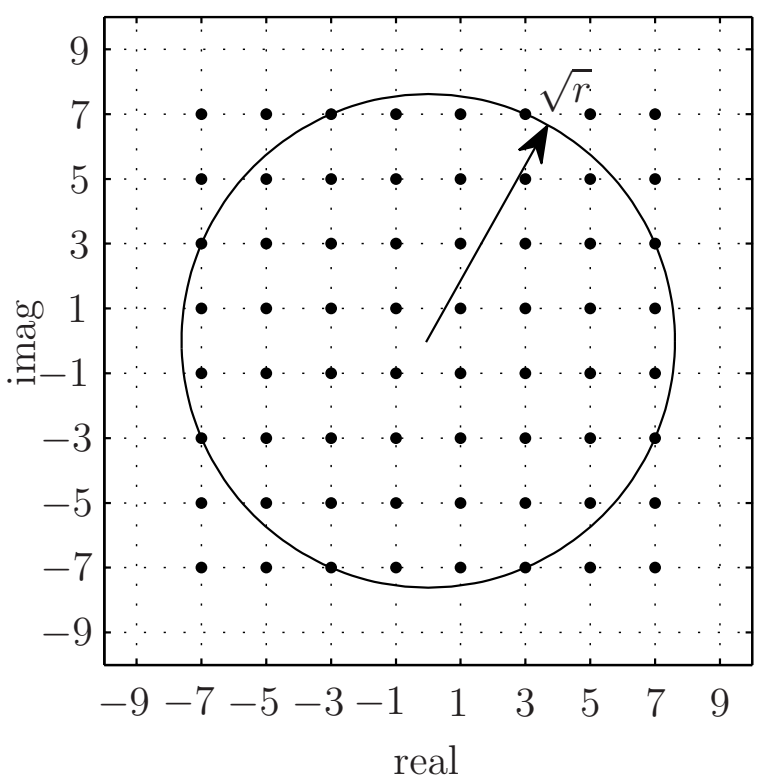

Figura 1.7: Constelação 64-QAM e raiz quadrada da constante de dispersão $r$.

canal de comunicação, a possível convergência para mínimos locais indesejáveis e problemas de instabilidade [JOHNSON R. et al., 1998; SILVA, 2005; MIRANDA; SILVA; NASCIMENTO, 2008a]. Além disso, o melhor desempenho do CMA ocorre para sinais de módulo constante, já que o fato de $\sqrt{r}$ não coincidir com o módulo dos símbolos da constelação gera um erro quadrático médio em regime não nulo, que é tanto maior quanto maior for a ordem da constelação QAM.

Para mitigar o problema da ambiguidade de fase do CMA, o algoritmo multimódulo (MMA - multimodulus algorithm) foi proposto em [OH; CHIN, 1995] e depois analisado em [YANG; WERNER; DUMONT, 2002]. O MMA minimiza a dispersão das componentes real e imaginária da saída do equalizador separadamente. Embora o MMA apresente uma melhor convergência que o CMA para sinais QAM de alta ordem, ele ainda pode ocasionar rotações de fase múltiplas de $90^{\circ}$ como demonstrado em [GARTH; YANG; WERNER, 2001].

A questão da instabilidade do CMA foi abordada em [MIRANDA; SILVA; NASCIMENTO, 2008a], onde foi proposto um mecanismo para evitar divergência em uma versão normalizada do algoritmo. O algoritmo proposto em [MIRANDA; SILVA; NASCIMENTO, 2008a], denominado dual-mode-CMA (DM-CMA), trabalha com dois modos de operação. No primeiro modo, ele funciona como o CMA normalizado e no segundo, rejeita estimativas não consis- 
tentes do sinal transmitido. Em [MIRANDA; SILVA; NASCIMENTO, 2008b], esse mecanismo foi estendido para o algoritmo de Shalvi-Weinstein (SWA) e foi mostrado que a versão do SWA proposta, quando adequadamente implementada, não diverge mesmo considerando aritmética de precisão finita.

Cabe observar que os algoritmos baseados no módulo constante só podem alcançar um erro quadrático médio em regime nulo para sinais de módulo constante em um ambiente estacionário, livre de ruído e se for adotada a sobreamostragem [MAI; SAYED, 2000; SILVA; MIRANDA, 2004; SILVA; NASCIMENTO, 2008b]. Por isso, esses algoritmos apresentam um desajuste relativamente grande, quando usados para recuperar sinais de módulo não-constante, como é o caso de sinais QAM de alta ordem. Dada a importância dessa questão para este trabalho, ela é abordada separadamente na seção seguinte ${ }^{1}$.

\subsection{A equalização autodidata de sinais QAM}

A natureza não-linear, a multimodalidade e a dependência da qualidade das estimativas dos algoritmos baseados no módulo constante tornam uma análise de convergência e estabilidade consistente consideravelmente difícil [SILVA, 2005]. Por isso, muitos artigos foram publicados nas últimas duas décadas contendo análises e/ou propostas de modificações nos algoritmos existentes para melhorar o desempenho [JOHNSON R. et al., 1998].

Através de uma análise de estabilidade segundo Lyapunov, uma expressão analítica em regime para o erro quadrático médio em excesso (EMSE - excess mean-square error) do CMA foi obtida em [FIJALKOW; MANLOVE; JOHNSOn, 1998]. Em seguida, usando o método da realimentação (conservação de energia) de [SAYED, 2008], o comportamento em regime

\footnotetext{
${ }^{1}$ Neste texto, os termos "desajuste", "erro quadrático médio" (MSE - mean-square error) e "erro quadrático médio em excesso" (EMSE - excess mean-square error) são muitas vezes usados como sinônimos. Entretanto, o EMSE mede a distância entre o MSE e o erro quadrático médio mínimo $\left(J_{\min }\right)$ que pode ser alcançado pelo algoritmo. O desajuste, por sua vez, é uma medida relativa de desempenho, definida como a razão entre o EMSE e o $J_{\min }$. Grosso modo, dizer que um algoritmo apresenta um desajuste elevado é equivalente a dizer que ele apresenta um EMSE elevado, que por sua vez, equivale a um MSE grande. Essas medidas estão definidas com detalhes no Apêndice A.
} 
do CMA foi analisado em [MAI; SAYED, 2000; YOUSEF; SAYED, 1999], levando-se em conta ambientes estacionários e não-estacionários. Considerando ainda o método da realimentação, em [SILVA; MIRANDA, 2004] foi analisado o rastreio (tracking) de algoritmos baseados no módulo constante de maneira unificada. Em [SILVA; NASCIMENTO, 2008a], foi proposto um modelo para o erro de estimação do CMA em regime em função do erro a priori e de um termo que mede a variabilidade do módulo do sinal transmitido. Esse modelo, proposto inicialmente para sinais reais em [SILVA; NASCIMENTO, 2008a] e estendido para sinais complexos em [SILVA; NASCIMENTO, 2008b], é baseado na hipótese de que o filtro ótimo leva à equalização perfeita, o que só é possível no caso da sobreamostragem [SILVA, 2005]. Ele permite analisar o desempenho de rastreio de algoritmos supervisionados e autodidatas de maneira unificada, já que a variabilidade no módulo do sinal transmitido tem um papel similar ao do ruído de medida no caso supervisionado. A expressão do EMSE em regime do CMA obtida em [SILVA; NASCIMENTO, 2008b] para um ambiente estacionário e passo de adaptação suficientemente pequeno é dada por

$$
\mathrm{EMSE} \approx \frac{\mu M G_{h} \sigma_{a}^{2} \sigma_{\beta}^{2}}{2 \bar{\gamma}}
$$

em que $\mu$ é o passo de adaptação, $M$ é o número de coeficientes do equalizador, $\sigma_{a}^{2}$ é a variância do sinal transmitido, $G_{h}=\sigma_{u}^{2} / \sigma_{a}^{2}$ é o ganho do canal de comunicação, $\sigma_{u}^{2}$ é a variância do sinal que chega ao receptor, $\bar{\gamma}$ é uma constante que depende de estatísticas do sinal transmitido e $\sigma_{\beta}^{2}$ uma constante que mede a variabilidade do módulo da constelação ${ }^{2}$. Para exemplificar, na Tabela 1.2 são mostrados os valores de $\sigma_{\beta}^{2}, \sigma_{a}^{2}, \bar{\gamma}$ e $\left(\sigma_{a}^{2} \sigma_{\beta}^{2}\right) /(2 \bar{\gamma})$ para diferentes constelações QAM. É possível observar na tabela que $\sigma_{\beta}^{2}=0$ para 4-QAM (módulo constante) e aumenta com o ordem da constelação QAM. Para um mesmo canal de comunicação, passo de adaptação e número de coeficientes do equalizador, o EMSE em regime do CMA é proporcional a $\left(\sigma_{a}^{2} \sigma_{\beta}^{2}\right) /(2 \bar{\gamma})$. Dessa forma, o EMSE aumenta a medida que a constelação se afasta da de módulo constante.

O fato do CMA apresentar um EMSE que cresce com a ordem do sinal QAM motivou vários trabalhos em que foram propostos esquemas alternativos para melhorar o desempenho da equalização desses sinais. Um desses esquemas leva em conta a combinação concorrente

\footnotetext{
${ }^{2}$ Essas variáveis estão definidas no Capítulo 5 onde são apresentadas análises de rastreio.
} 
Tabela 1.2: Estatísticas do sinal QAM em função da ordem da constelação.

\begin{tabular}{||r||r|r|r|r||}
\hline \hline Constelação & $\sigma_{\beta}^{2}$ & $\sigma_{a}^{2}$ & $\bar{\gamma}$ & $\left(\sigma_{a}^{2} \sigma_{\beta}^{2}\right) /(2 \bar{\gamma})$ \\
\hline \hline 4-QAM & 0 & 2 & 2 & 0 \\
\hline 16-QAM & 218 & 10 & 7 & 160 \\
\hline 64-QAM & 23616 & 42 & 26 & 19074 \\
\hline 256-QAM & 1696627 & 170 & 103 & 1402853 \\
\hline 1024-QAM & 111673408 & 682 & 410 & 92879591 \\
\hline 4096-QAM & 7197035789 & 2730 & 1639 & 5994602057 \\
\hline \hline
\end{tabular}

do CMA com o algoritmo de decisão direta (DD - decision-directed) e foi proposto originalmente em [De CASTRO; De CASTRO; ARANTES, 2001; De CASTRO, 2001]. Para minimizar o MSE residual do CMA, é usual considerar um chaveamento para o algoritmo DD após a convergência. Entretanto, o nível de MSE em que esse chaveamento deve ocorrer varia em função do número de símbolos da constelação QAM e do canal de comunicação, e pode ser que não ocorra de maneira adequada. Para contornar esse problema, a solução proposta em [DE CASTRO; DE CASTRO; ARANTES, 2001] considera a operação concorrente desses dois algoritmos. Dessa forma, a atualização do algoritmo DD é feita depois da atualização do CMA e seus coeficientes são ajustados apenas se a adaptação do CMA tiver sido considerada correta com uma alta probabilidade. Isto é feito para evitar propagação de erros devido às decisões incorretas. Com um aumento moderado na complexidade computacional, o CMA+DD apresenta uma considerável melhora de desempenho em relação ao CMA, como pode ser observado nas simulações apresentadas em [DE CASTRO; DE CASTRO; ARANTES, 2001; DE CASTRO, 2001]. Uma outra característica interessante desse algoritmo concorrente é que ele corrige rotações de fase não-múltiplas de $90^{\circ}$, comportamento que também é observado no MMA [GARTH; YANG; WERNER, 2001].

Inspirando-se no algoritmo concorrente de [DE CASTRO; DE CASTRO; ARANTES, 2001], Chen (2003) propôs uma modificação nesse esquema substituindo o algoritmo de DD pelo último estágio do algoritmo de decisão direta suave (SDD - soft decision-directed) e adaptando os coeficientes do CMA e SDD simultaneamente. O CMA+SDD também evita 
rotações de fase não-múltiplas de $90^{\circ}$, mas possui um custo computacional menor e uma taxa de convergência maior do que o $\mathrm{CMA}+\mathrm{DD}$, como pode ser observado nas simulações de [CHEN, 2003; CHEN; COOK; ANDERSON, 2004]. Embora esses algoritmos concorrentes apresentem uma melhora no desempenho quando comparados ao CMA, o ajuste de seus passos de adaptação não é simples. O desempenho do CMA+SDD, por exemplo, depende do bom comportamento de cada algoritmo. Se o CMA tiver um MSE elevado devido a uma escolha inadequada do passo de adaptação, o algoritmo concorrente apresentará um desempenho ruim. Além disso, somente o último estágio do SDD (sem ser concorrente) não tem um desempenho adequado para sinais QAM de alta ordem. Neste caso, o esquema multi-estágio de [CHEN et al., 1995] deve ser utilizado para assegurar uma boa equalização. Dessa forma, uma questão ainda em aberto na literatura é como escolher adequadamente os passos do CMA e do SDD para garantir um bom desempenho do algoritmo concorrente. Além disso, é importante entender porque algumas escolhas são melhores do que outras.

Como o melhor desempenho do CMA ocorre para sinais de módulo constante, então, tratar uma constelação de módulo não-constante como várias de módulo constante poderia, em princípio, proporcionar uma melhora no desempenho para equalização de sinais QAM de alta ordem. Essa ideia foi explorada em [READY; GOOCH, 1990], onde o algoritmo radiusdirected equalization (RDE) foi proposto. Em vez de usar uma única constante de dispersão como em $J_{\mathrm{CMA}}$, a função custo do RDE considera múltiplas constantes de dispersão (múltiplos raios), ou seja,

$$
J_{\mathrm{RDE}}=\mathrm{E}\left\{\left(r_{n}-|y(n)|^{2}\right)^{2}\right\}
$$

em que $r_{n}=|\operatorname{dec}[y(n)]|^{2}$ e $\operatorname{dec}[\cdot]$ a função de decisão baseada nos símbolos. Com essa função custo, a raiz quadrada da constante de dispersão $\sqrt{r_{n}}$ sempre coincide com os diferentes módulos dos símbolos da constelação, como pode ser observado na Figura 1.8 para as constelações 64-QAM e 256-QAM. Para decidir por uma constante de dispersão, o algoritmo RDE divide o plano complexo em regiões de decisão anelares escolhidas de maneira adhoc, sendo que cada uma delas deve conter a circunferência de raio $\sqrt{r_{n}}$. Dessa forma, quanto maior for a ordem da constelação QAM, menor é a distância entre raios e pior é o desempenho do algoritmo [READY; GOOCH, 1990; OH; PARK, 1997]. A redução da distância 
dos raios também pode ser observada na Figura 1.8. É possível perceber que à medida que a constelação aumenta, o número de raios aumenta e algumas distâncias se tornam muito pequenas. Portanto, apesar do MSE em regime do RDE ser menor do que o do CMA para equalização de sinais QAM de alta ordem, ele pode exibir uma convergência lenta e altas taxas de erro, dificultando ou até mesmo impossibilitando sua utilização para razões sinalruído baixas e/ou níveis elevados de interferência intersimbólica. Nessas condições, o padrão de olho do sinal recebido não fica suficientemente aberto e o RDE pode exibir um desajuste elevado, já que o erro de estimação se baseia em múltiplos raios, como observado em [OH; PARK, 1997].
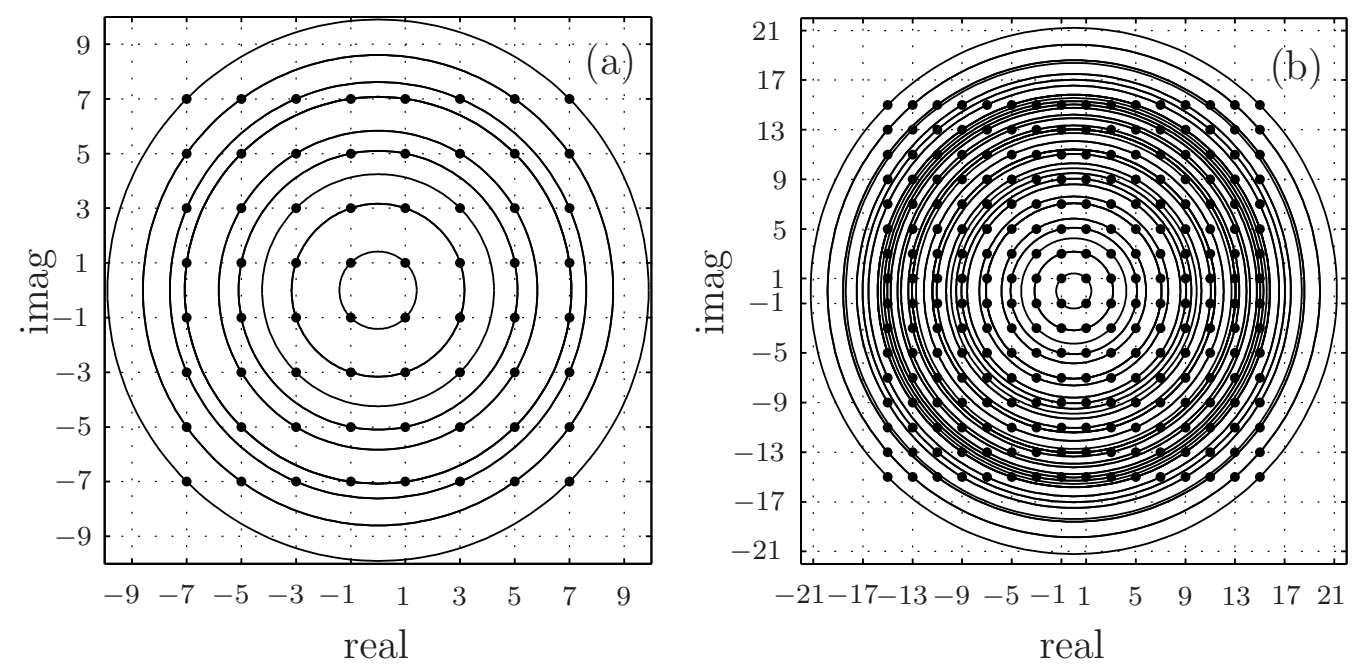

Figura 1.8: Raios usados no algoritmo RDE para (a) 64-QAM; (b) 256-QAM.

Usando ideias similares à do RDE, outros algoritmos foram propostos na literatura com o objetivo de reduzir o desajuste exibido tanto pelo CMA como pelo MMA na equalização de sinais QAM. Em [HE et al., 2004], por exemplo, um termo que leva em conta a localização dos símbolos da constelação foi adicionado à função custo do módulo constante. Esse termo ficou conhecido na literatura como função de erro casada à constelação (CME - constellation matched error) e penaliza o desvio entre o sinal de saída do equalizador e os símbolos da constelação. Diferentes funções CME foram consideradas em [HE et al., 2004] e [LABED et al., 2009], levando a diferentes algoritmos, que em geral apresentam um MSE menor que o do CMA convencional na recuperação de sinais QAM. Usando uma abordagem do tipo MMA e uma constante de dispersão ponderada pela estimativa do sinal transmitido, o Sliced-MMA 
foi proposto em [ABRAR; AXFORD JR., 2005]. Posteriormente em [ABRAR; NANDI, 2010], esse algoritmo foi generalizado e modificado, levando a duas famílias de algoritmos para equalização de sinais QAM. Na literatura, ainda há algumas soluções baseadas no algoritmo de contorno quadrado (SCA - square contour algorithm) que em vez de circunferências, usa quadrados como dispersão [THAIUPATHUMP; KASSAM, 2003; ABRAR, 2004; ABRAR; AMIN; SIDDIQ, 2005; SHEIKH; FAN, 2006a, 2006b]. Em geral, esses algoritmos podem alcançar um desajuste em regime estacionário menor do que o do CMA (ou MMA) para sinais QAM, mas que ainda é relativamente grande quando comparado ao desajuste obtido na equalização de sinais de módulo constante com o próprio CMA (ou MMA), sob as mesmas condições.

\subsection{Formulação do problema}

O modelo simplificado de um sistema de comunicação com transmissão em banda base é mostrado na Figura 1.9 [PROAKIS, 2001]. O bloco "canal" representa não só o canal físico de transmissão mas também o sistema de transmissão/modulação e o sistema de recepção/demodulação efetivamente presentes em qualquer sistema de comunicação prático. Assim, denomina-se aqui como canal um modelo de tempo discreto para o sistema de transmissão, o canal físico e o sistema de recepção. Considerando esse modelo e a transmissão do sinal PAM da Figura 1.10-(a), tudo se passa como se a sequência de tempo discreto da Figura 1.10-(b) tivesse sido transmitida. Cabe observar que essa sequência é obtida a partir da amostragem do correspondente sinal transmitido em banda base com um período de amostragem igual ao intervalo de símbolos $T$.

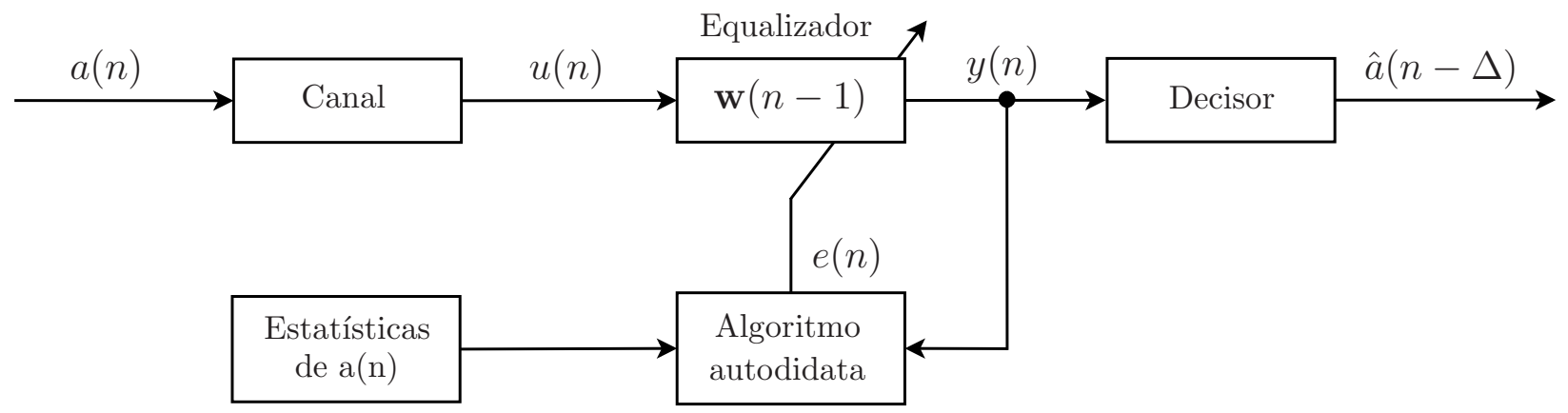

Figura 1.9: Sistema de comunicação simplificado com um equalizador autodidata. 

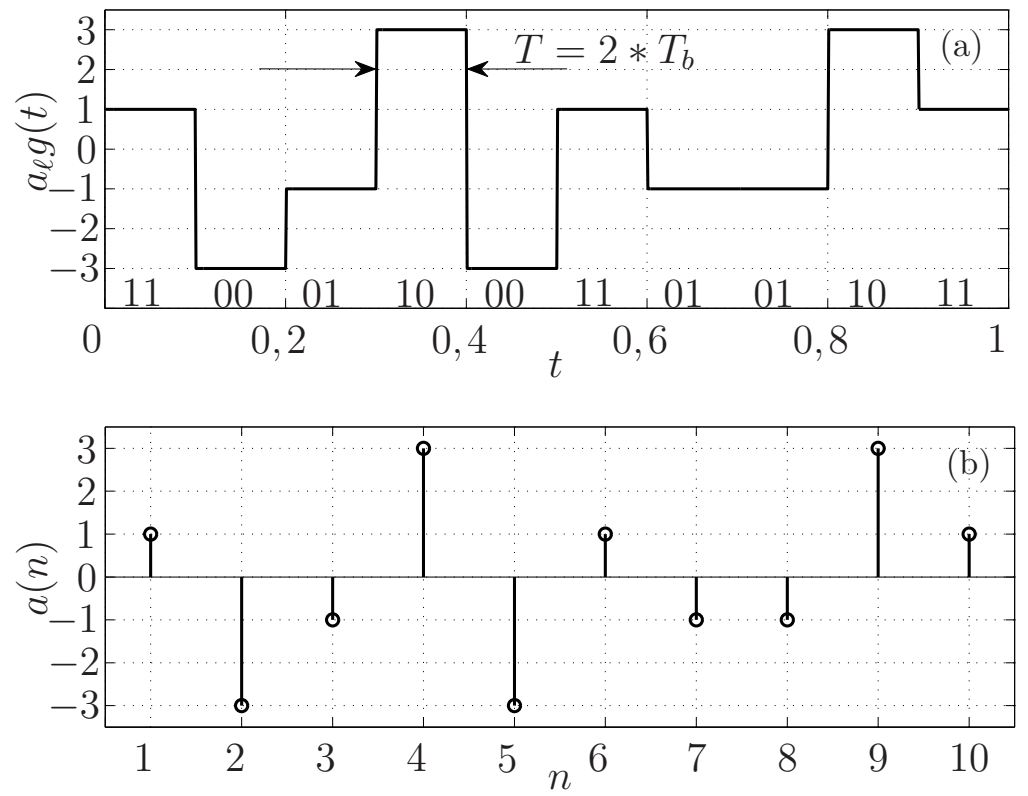

Figura 1.10: (a) sinal transmitido em banda base, (b) sequência de tempo discreto equivalente.

Em geral, a sequência transmitida $a(n)=a_{\ell}(n)+j a_{m}(n)$ é independente e identicamente distribuída (i.i.d.) e não-gaussiana. Ela é transmitida por um canal desconhecido, cujo modelo de tempo discreto é constituído por um filtro FIR, com vetor de resposta impulsiva dado por

$$
\mathbf{h}=\left[h_{0} h_{1} \cdots h_{K-1}\right]^{T}
$$

e ruído aditivo branco gaussiano (AWGN - additive white Gaussian noise), em que $[\cdot]^{T}$ indica transposição. Para o equalizador, admite-se o modelo correspondente ao de um filtro FIR com $M$ coeficientes, ou seja,

$$
\mathbf{w}(n-1)=\left[\begin{array}{llll}
w_{0}(n-1) & w_{1}(n-1) & \cdots & w_{M-1}(n-1)
\end{array}\right]^{T}
$$

com vetor regressor de entrada

$$
\mathbf{u}(n)=\left[\begin{array}{llll}
u(n) & u(n-1) & \cdots & u(n-M+1)
\end{array}\right]^{T}
$$

e saída

$$
y(n)=\mathbf{u}^{T}(n) \mathbf{w}(n-1)=y_{\mathrm{R}}(n)+j y_{\mathrm{I}}(n),
$$


sendo $y_{\mathrm{R}}(n)$ e $y_{\mathrm{I}}(n)$ as componentes real e imaginária de $y(n)$, respectivamente. $\mathrm{O}$ erro de estimação expresso por

$$
e(n)=e_{\mathrm{R}}(n)+j e_{\mathrm{I}}(n)
$$

é utilizado para atualizar o vetor de coeficientes do equalizador. A partir do sinal recebido $u(n)$ e das propriedades estatísticas do sinal transmitido, o equalizador autodidata deve mitigar a interferência intersimbólica introduzida pelo canal e recuperar uma versão atrasada da sequência $a(n)=a_{\mathrm{R}}(n)+j a_{\mathrm{I}}(n)$, obtendo a estimativa $\hat{a}(n-\Delta)$ na saída do decisor, sendo $\Delta$ um número inteiro ${ }^{3}$.

Existem diferentes formas de adaptar o vetor de coeficientes do equalizador [HAYKIN, 2002; SAYED, 2008]. No entanto, nesta tese, considera-se a classe de algoritmos normalizados, cuja equação de atualização é dada por

$$
\mathbf{w}(n)=\mathbf{w}(n-1)+\frac{\mu}{\delta+\|\mathbf{u}(n)\|^{2}} e(n) \mathbf{u}^{*}(n)
$$

em que $\mu$ é o passo de adaptação, $\delta$ é o fator de regularização (constante pequena positiva), $\|\cdot\|$ representa a norma euclidiana e $(\cdot)^{*}$ representa o complexo conjugado. As componentes real $e_{\mathrm{R}}(n)$ e imaginária $e_{\mathrm{I}}(n)$ do erro de estimação são calculadas separadamente como no caso do MMA. Essa classe de algoritmos apresenta três vantagens principais:

i. a normalização melhora a taxa de convergência e facilita a escolha adequada do passo de adaptação [HAYKIN, 2002; SAYED, 2008];

ii. a definição do erro de estimação com base em suas componentes real e imaginária pode evitar ambiguidades de fase [YANG; WERNER; DUMONT, 2002; YUAN; TSAI, 2005; GARTH; YANG; WERNER, 2001], e;

iii. um custo computacional compatível com uma implementação prática em tempo real.

\footnotetext{
${ }^{3}$ Note que $a_{\mathrm{R}}(n)=a_{\ell}(n)$ e $a_{\mathrm{I}}(n)=a_{m}(n)$. Os índices $\ell$ e $m$ são utilizados para salientar que as amostras da sequência transmitida pertencem a um alfabeto finito, enquanto os índices $R$ e $I$ são usados para denotar a parte real e imaginária dessa sequência complexa. Neste trabalho, ambas as notações serão utilizadas e a escolha por uma ou outra ocorrerá em função do que se deseja enfatizar.
} 
A Figura 1.11 mostra um sistema de comunicação simplificado similar ao da Figura 1.9, porém explicitando a possibilidade de se efetuar o chaveamento para o modo de decisão direta. Esse modo é normalmente usado quando o algoritmo autodidata inicial, baseado nas estatísticas do sinal transmitido, alcança um nível de MSE tal que a identificação dos símbolos da constelação seja possível (condição de "olho aberto") a partir do algoritmo de decisão direta. Nesse caso, esse último algoritmo autodidata deixa de considerar as estatísticas do sinal transmitido e se baseia nas decisões tomadas pelo decisor. O chaveamento é um mecanismo que possibilita a redução do MSE, já que o erro de estimação é calculado com base na saída do decisor. A despeito dessa vantagem, o nível de MSE em que se realiza o chaveamento é um problema cuja implementação prática se mostra bastante complexa [DE CASTRO; DE CASTRO; ARAnTES, 2001]. Como exemplo, admite-se na Figura 1.11 a transmissão de um sinal modulado em 4-QAM, identificando-se os sinais: transmitido, $a(n)$; recebido, $u(n)$; na saída do equalizador, $y(n)$; e o sinal recuperado, $\hat{a}(n-\Delta)$.
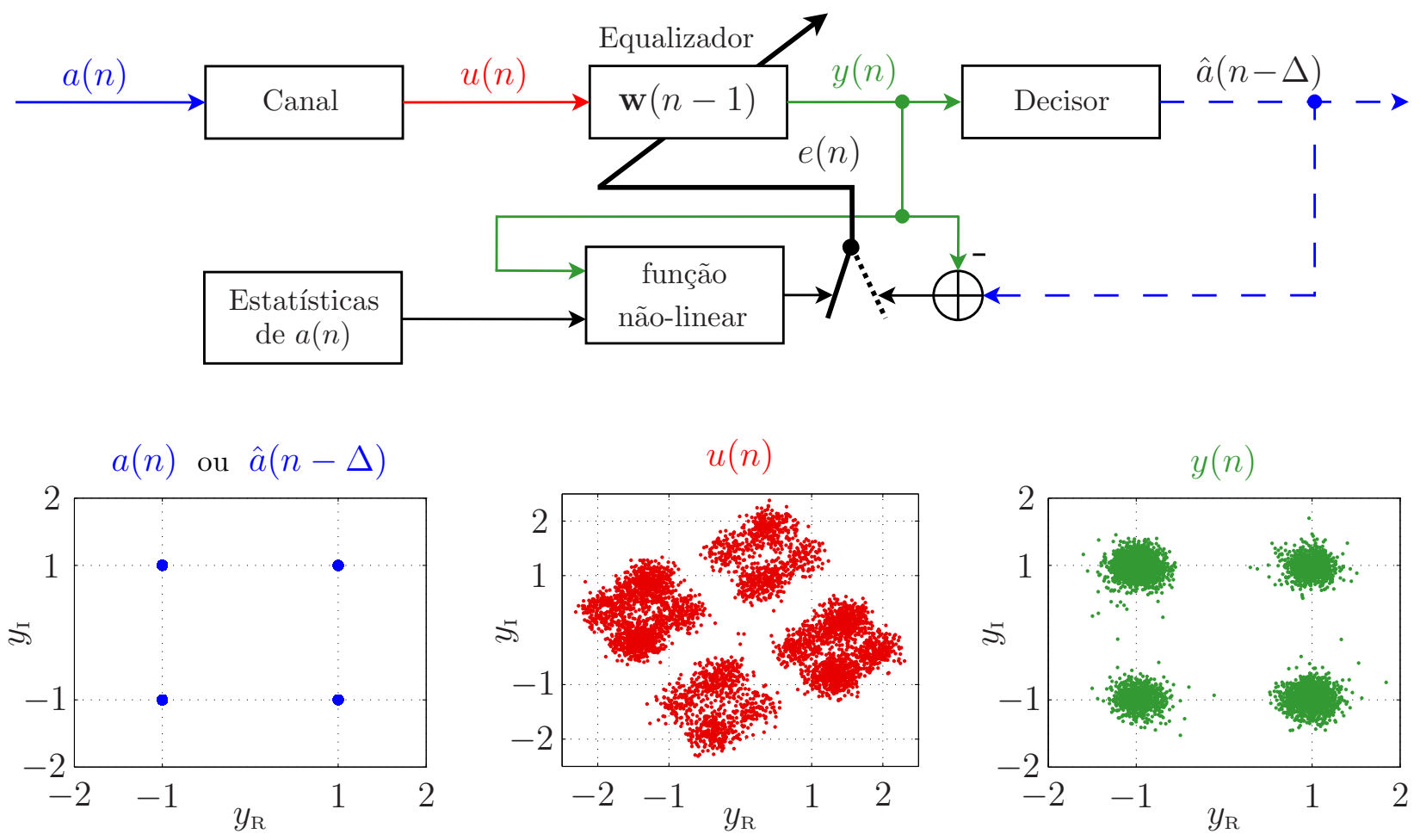

Figura 1.11: Sistema de comunicação simplificado com um equalizador autodidata, incluindo a possibilidade de chaveamento para o modo de decisão direta. 
Até agora, admitiu-se que o sinal é amostrado no receptor com período igual ao intervalo de símbolo $T$. No entanto, em diversas situações consideradas neste trabalho, utiliza-se a sobreamostragem com um fator igual a dois, ou seja, considera-se que o sinal é amostrado no receptor com período igual à metade do intervalo de símbolo, i.e., T/2. Equalizadores sobreamostrados, também chamados de equalizadores com espaçamento fracionário, são largamente empregados em situações práticas já que asseguram a condição de equalização perfeita num ambiente livre de ruído e sob certas condições bem conhecidas [TREICHLER; FIJALKOW; JR., 1996; SILVA, 2005].

Cabe observar que a condição de equalização perfeita, também chamada na literatura de forçamento a zero (zero-forcing), ocorre quando a resposta combinada canal + equalizador impõe apenas um atraso $\Delta$ ao sinal transmitido. Nessa condição, o equalizador consegue forçar um valor nulo à resposta combinada exceto para o atraso mencionado. Assim, o sinal recebido pode ser escrito simplesmente como $\hat{a}(n-\Delta)$.

\subsection{Objetivos e justificativa}

O objetivo desta tese é obter algoritmos eficientes para equalização autodidata de sinais QAM em sistemas com portadora única. Sabe-se que o melhor desempenho de um algoritmo estocástico autodidata ocorre quando ele se comporta como o algoritmo supervisionado equivalente. Considerando a classe de algoritmos normalizados (1.12), espera-se que o desempenho dos algoritmos autodidatas aqui propostos esteja o mais próximo possível do desempenho do algoritmo supervisionado NLMS (normalized least-mean squares), independentemente da ordem da constelação QAM.

Na literatura, o algoritmo de Sato [SATO, 1975] é considerado um dos precursores dos algoritmos de equalização autodidata. No entanto, a ideia da recuperação não-supervisionada baseada em estatísticas de ordem superior a dois só veio à tona no início da década de 1980 graças aos trabalhos [BENVEniste; GOURSAT; RUGET, 1980] e [DONOHO, 1981]. Nessa mesma época, o CMA [GODARD, 1980; TREICHLER; AGEE, 1983] foi proposto e a partir de então se tornou o algoritmo mais conhecido e utilizado na prática, dado seu baixo custo 
computacional. Devido à natureza não-linear e à multimodalidade de sua função custo, o CMA pode convergir para mínimos locais indesejáveis, além de sofrer uma forte influência das condições iniciais. Essa influência somada a uma escolha inadequada do passo de adaptação ainda podem levá-lo à divergência. Pelo fato do critério do módulo constante minimizar uma dispersão do módulo do sinal de saída do equalizador, o CMA não resolve ambiguidades de fase introduzidas pelo canal de comunicação. Apesar de seu nome, o CMA consegue recuperar sinais de módulo não-constante, mas neste caso, seu desempenho é tanto pior quanto mais longe a constelação estiver da de módulo constante. Esses problemas deram origem a um vasto estudo sobre o CMA. Alguns trabalhos procuraram resolver o problema da ambiguidade de fase, outros o problema da divergência e outros buscaram através de análises, muitas vezes complexas, entender seu comportamento para então proporcionar um ajuste adequado de seu passo de adaptação. Em muitos desses trabalhos, foram propostos diferentes algoritmos que resolveram parcialmente os problemas do CMA.

Nos sistemas de comunicação atuais, para usar a largura de banda de forma eficiente, é usual transmitir sinais QAM de alta ordem. É neste caso em que os algoritmos baseados no módulo constante apresentam seu pior desempenho em termos de erro quadrático médio. Talvez seja esse um dos motivos que levaram à preferência atual por sistemas com múltiplas portadoras. No caso de portadora única, muitos trabalhos buscaram melhorar o desempenho do CMA. Algoritmos concorrentes, algoritmos que consideram modificações na constante de dispersão, algoritmos que buscam "casar" a saída do equalizador com os símbolos da constelação são apenas alguns exemplos. Embora os desempenhos desses algoritmos sejam superiores ao do CMA, ainda estão longe do desempenho do algoritmo supervisionado equivalente. Em outras palavras, o desempenho dessas soluções autodidatas fica muito aquém do desempenho dos algoritmos LMS ou NLMS em termos de MSE e/ou velocidade de convergência.

Diante do exposto, algoritmos autodidatas que apresentem um desempenho próximo ao do algoritmo NLMS para equalização de sinais QAM em sistemas de portadora única são de interesse e justificam este trabalho. 


\subsection{Contribuições}

Neste trabalho, são propostos algoritmos autodidatas para recuperação de sinais QAM em sistemas de portadora única que:

1. permitem a recuperação simultânea do módulo e da fase do sinal transmitido;

2. possuem erro igual a zero quando a saída do equalizador coincide com as coordenadas dos símbolos da constelação, condição necessária para tratar sinais de módulo nãoconstante como sinais de módulo constante, o que permite a convergência em média quadrática para a solução de Wiener;

3. convergem relativamente rápido; e

4. não divergem, se o passo de adaptação for escolhido adequadamente.

Algoritmos autodidatas que apresentam essas propriedades podem ser classificados como algoritmos autodidatas eficientes e assim justificam o título deste trabalho.

Com tais propriedades e considerando a equação de atualização (1.12), os algoritmos autodidatas propostos tendem a se comportar como o algoritmo supervisionado NLMS, independentemente da ordem da constelação QAM.

Quando um algoritmo supervisionado é utilizado em equalização, é necessário um tempo para aquisição do sincronismo da sequência pseudo-aleatória usada pelo transmissor. Neste trabalho, esse tempo não foi levado em conta nas comparações com os algoritmos autodidatas propostos. Isso corrobora os resultados obtidos, já que se esse tempo fosse considerado, o algoritmo NLMS demoraria mais para alcançar o regime.

As principais contribuições desta tese são enumeradas a seguir.

\section{Versão MMA do algoritmo concorrente CMA+SDD}

A versão MMA do algoritmo concorrente CMA+SDD de [CHEN, 2003] foi obtida diretamente da minimização de uma função custo. Para isso, a função custo em questão foi definida como a soma da função custo do MMA multiplicada por uma "constante" com a do SDD, sendo a constante de ponderação definida como a razão entre os passos 
de adaptação desses dois algoritmos. Essa versão foi chamada neste trabalho de algoritmo concorrente com decisão suave (CSD - concurrent soft decision). Verificou-se que quando o passo de adaptação do MMA é muito maior do que o do SDD, o algoritmo CSD apresenta um comportamento parecido com o do MMA. Em contrapartida, se o passo do SDD é muito maior que o do MMA, o CSD fica próximo do último estágio do SDD e neste caso, os sinais transmitidos são recuperados somente em condições favoráveis. Diante isso, a razão dos passos de adaptação desses algoritmos deve estar em um certo intervalo para que o algoritmo CSD apresente um comportamento adequado. No entanto, esse intervalo varia com o número de símbolos da constelação e sua escolha pode se tornar muito complicada. Associando-se o desempenho do CSD com a função de erro, que também é função da razão dos passos de adaptação, percebeu-se que o melhor comportamento do CSD ocorre quando a função de erro se aproxima de zero nas coordenadas dos símbolos da constelação. Esse comportamento motivou a proposição de dois novos algoritmos: o algoritmo de decisão suave modificado (MSD - Modified Soft Decision) e o algoritmo multimódulo regional (RMA - region-based multimodulus algorithm).

\section{O algoritmo de decisão suave modificado - MSD}

Neste algoritmo, o papel do MMA no concorrente foi substituído por fatores de escala que dependem dos segmentos de reta em que a parte real e imaginária da saída do equalizador se encontram em cada instante de tempo. Cabe observar que o algoritmo MSD aqui proposto é uma versão MMA do algoritmo SDD modificado (MSDD - Modified SDD) de [MENDES FILHO, 2007]. Embora o desempenho do MSD seja melhor que o do MMA e do CSD, seu erro de estimação não é igual a zero quando a saída do equalizador coincide com as coordenadas de um dos símbolos da constelação, o que contribui para um desajuste indesejável e inevitável. Por isso, foi proposto o algoritmo multimódulo regional.

\section{O algoritmo multimódulo regional - RMA}

Esse algoritmo foi obtido, considerando-se quatro premissas principais: 
a) a reta real foi dividida em segmentos contendo duas coordenadas dos símbolos da constelação;

b) os dois segmentos de reta que contêm a parte real e imaginária da saída do equalizador são transladados para origem em cada instante de tempo;

c) o erro de estimação é calculado como no MMA, mas como se o sinal fosse de módulo constante (4-QAM);

d) a parte real e imaginária do erro de estimação são multiplicadas por fatores de escala que dependem dos segmentos de reta originais antes da translação.

Com essas premissas, obteve-se um algoritmo cuja função de erro é igual a zero quando a saída do equalizador coincide com os símbolos da constelação. Isso possibilitou que ele se aproximasse da solução de Wiener em regime, independentemente da ordem da constelação QAM. Na ausência de ruído e considerando sobreamostragem, o RMA ainda é capaz de equalizar perfeitamente o canal.

\section{O algoritmo de decisão baseada nos símbolos - SBD}

O bom desempenho do RMA em termos de erro quadrático médio em regime inspirou a proposição do algoritmo de decisão baseada nos símbolos (SBD -symbol-based decision). A função de erro usada no RMA é contínua por partes e é zero quando a saída do equalizador coincide com os símbolos da constelação. Existem inúmeras funções de erro contínuas por partes que podem apresentar essa propriedade. A versão MMA do algoritmo RDE, aqui denominada de algoritmo multimódulo guiado pelos raios (MRD - multimodulus radius-directed) [FERNANDES; FAVIER; MOTA, 2007], considerara uma função não-linear em cada trecho que apresenta uma envoltória com crescimento exponencial. Em vez de considerar essa função, o algoritmo SBD utiliza segmentos de reta ponderados por fatores de escala que dependem da posição de cada coordenada dos símbolos, o que faz com que sua envoltória tenha um crescimento linear. Com isso, obtém-se um algoritmo com menor custo computacional e que apresenta um erro quadrático em regime menor que o MRD. Dada a similaridade com a função de erro do algoritmo de decisão direta, o SBD pode ser interpretado como uma extensão do 
algoritmo DD para equalização de sinais QAM. Como o RMA, esse algoritmo também converge em regime para a solução de Wiener, independente da ordem da constelação QAM e sob condições favoráveis para equalização. Além disso, ele também pode equalizar perfeitamente o canal na ausência de ruído e usando-se sobreamostragem.

\section{Relação com a solução de Wiener-Hopf}

Os resultados de [SUYAMA et al., 2003; BELLANGER, 2004] foram estendidos aqui para mostrar analiticamente que, sob certas condições favoráveis de equalização, os algoritmos RMA e SBD convergem para a solução de Wiener em regime.

\section{Mecanismo para melhorar a convergência dos algoritmos propostos}

Os algoritmos RMA e SBD podem levar muitas iterações para atingirem a solução de Wiener. A velocidade de convergência desses algoritmos depende de vários fatores como dificuldade de equalização do canal, razão sinal-ruído, inicialização, etc. Nas iterações iniciais, esses fatores fazem com que o vetor de coeficientes esteja distante da solução ótima e consequentemente a saída do equalizador pode ficar distante do símbolo da constelação que deveria ser recuperado. Para melhorar a convergência, foi proposto um mecanismo baseado na vizinhança da saída do equalizador. Assim, o erro de estimação é calculado não apenas na região em que a saída se encontra em um determinado instante de tempo, mas também em regiões vizinhas. Tudo se passa como se a saída do equalizador pertencesse a cada uma dessas regiões e o erro global é calculado a partir de uma ponderação dos erros de cada região. Essa ideia possibilitou uma melhora significativa na velocidade de convergência dos algoritmos sem aumentar demasiadamente o custo computacional.

\section{Questões de estabilidade}

Uma análise da convergência do algoritmo SBD foi apresentada. Através dessa análise, obteve-se o intervalo do passo de adaptação para que ele não divirja, considerando-se o uso ou não do mecanismo de vizinhança para acelerar a convergência. Para evitar a divergência do RMA, estendeu-se a filosofia de dois modos de adaptação proposta em [MIRANDA; SILVA; NASCIMENTO, 2008a, 2008b] para incluir o mecanismo de vizinhança. 
Neste caso, o RMA passou a trabalhar com dois modos de operação: no primeiro, ele funciona como o RMA com ou sem vizinhos e no segundo modo, ele rejeita estimativas não-consistentes do sinal transmitido.

\section{Análise de rastreio}

Usando o método da realimentação de [SAYED, 2008][Sec. 20.2], foi apresentada uma análise de rastreio para os algoritmos MMA, RMA e SBD. Nas análises de rastreio do MMA existentes na literatura, sempre se considera o uso da sobreamostragem. $\mathrm{Na}$ análise aqui apresentada, adicionou-se ao caso de sobreamostragem, o caso em que o sinal é amostrado com o intervalo de símbolos $T$. Com relação aos algoritmos RMA e SBD, a análise de rastreio possibilitou obter expressões analíticas para o EMSE no caso sem vizinhos. Através dessas expressões, verificou-se que o EMSE desses algoritmos é sempre inferior ao do MMA no caso de sinais de módulo não-constante. Usando-se a sobreamostragem em um ambiente estacionário sem ruído, é possível verificar através das expressões que o EMSE do RMA e do SBD é nulo para constelações QAM de qualquer ordem.

\section{Equalizador de decisão realimentada}

Usando o mecanismo proposto em [SZCZECINSKI; GEI, 2002], os algoritmos RMA e SBD foram estendidos para a adaptação autodidata dos filtros direto e de realimentação do equalizador de decisão realimentada (DFE - decision feedback equalizer). A adaptação do DFE com os algoritmos propostos e considerando tal mecanismo possibilitou a obtenção de bons resultados na equalização de sinais QAM, mesmo para canais de difícil equalização.

Na Figura 1.12, é mostrado um diagrama de blocos com as relações entre os algoritmos propostos e os existentes na literatura. As linhas tracejadas indicam que um algoritmo serviu como fonte de inspiração para a obtenção do seguinte. As soluções propostas estão destacadas na figura. 


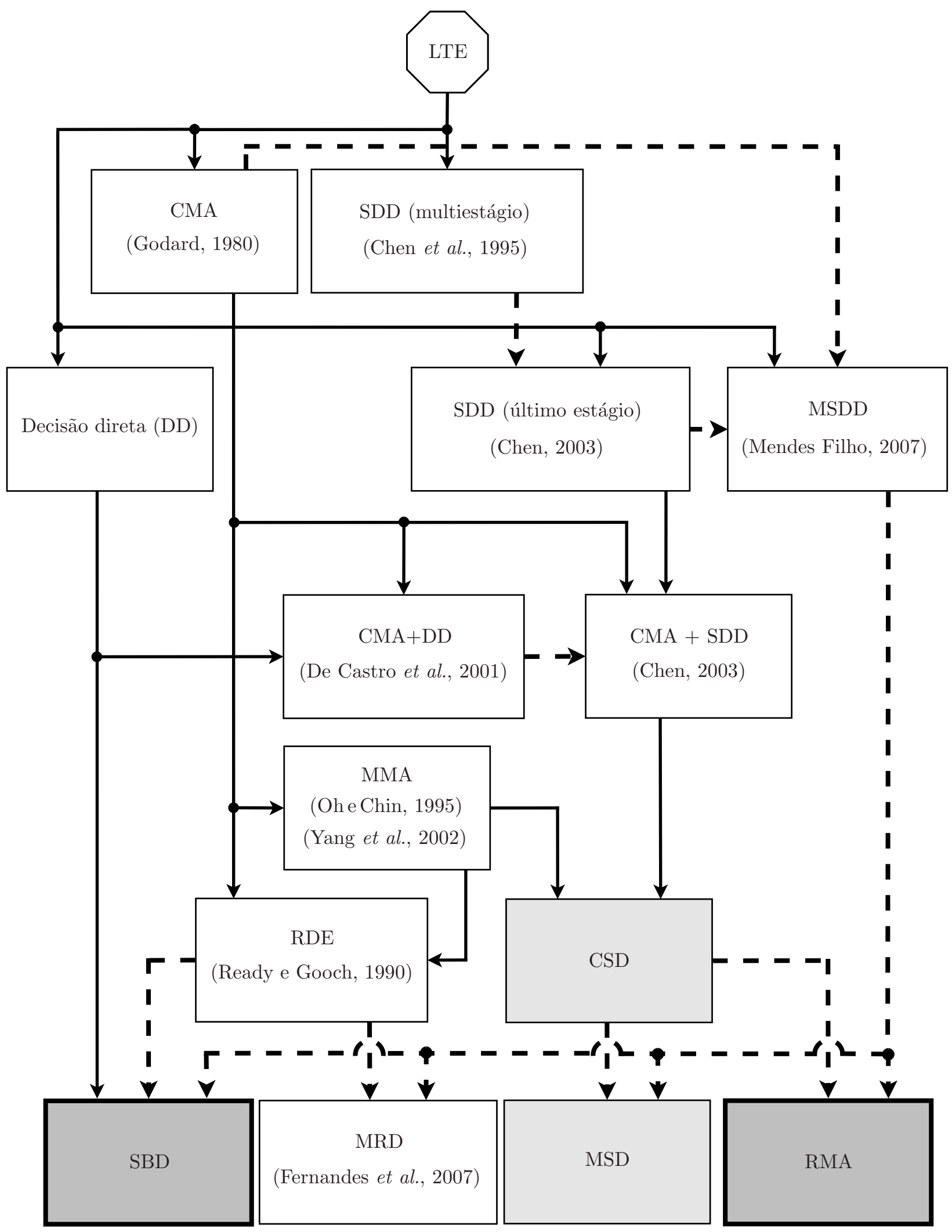

Figura 1.12: Relações entre os algoritmos propostos e os existentes na literatura. 
Como resultado das contribuições desta tese, foram publicados e submetidos os seguintes trabalhos:

$\diamond$ Trabalhos apresentados em congressos internacionais:

- J. Mendes Filho, M. T. M. Silva e M. D. Miranda, "A family of algorithms for blind equalization of QAM signals coefficients." In: Proc. of the IEEE International Conference on Acoustics, Speech, and Signal Processing (ICASSP), Praga, República Tcheca, 2011, pp. 3388-3391.

- J. Mendes Filho, M. D. Miranda e M. T. M. Silva, "Improving the decision feedback blind equalization of QAM Signals." In: Proc. of the International Workshop on Telecommunications, (IWT), Rio de Janeiro, RJ, 2011, pp. 275-281.

- J. Mendes Filho, M. T. M. Silva, M. D. Miranda e V. H. Nascimento, "A regionbased algorithm for blind equalization of QAM signals." In: Proc. of the IEEE Workshop on Statistical Signal Processing (SSP), Cardiff, País de Gales, 2009, pp. 685-688.

$\diamond$ Trabalhos aceitos para publicação em periódicos:

- J. Mendes Filho, M. D. Miranda e M. T. M. Silva, "On the decision-directed feedback equalisation for QAM signals", Electronic Letters, 2011.

- J. Mendes Filho, M. D. Miranda e M. T. M. Silva, "An efficient algorithm for decision feedback blind equalization of QAM signals", Revista Telecomunicações, 2011.

$\diamond$ Trabalho submetido a periódico:

- J. Mendes Filho, M. D. Miranda e M. T. M. Silva, "A regional multimodulus algorithm for blind equalization of QAM signals: introduction and steady-state analysis" submetido à revista Signal Processing da Elsevier em novembro de 2011. 


\subsection{Organização da tese}

Esta tese foi organizada em oito capítulos.

No Capítulo 2, o erro de estimação do algoritmo concorrente baseado no MMA e SDD é apresentado. Em seguida, verifica-se como a forma da função que descreve esse erro varia em função da razão dos passos de adaptação dos algoritmos. Através desse estudo, perceberam-se quais são as características necessárias para que a função de erro possibilite um bom desempenho na equalização de sinais QAM. Dessa forma, obtiveram-se os erros de estimação dos algoritmos multimódulo com decisão suave (MSD), multimódulo regional (RMA) e decisão baseada nos símbolos (SBD), que formam a base deste trabalho.

No Capítulo 3, estendendo-se os resultados de [SUYAMA et al., 2003], verifica-se analiticamente que os algoritmos RMA e SBD atingem a solução de Wiener, sob certas condições favoráveis de equalização e independentemente da ordem da constelação QAM.

No Capítulo 4, é proposto um esquema baseado na vizinhança da estimativa do símbolo transmitido para acelerar a convergência dos algoritmos RMA e SBD. Uma análise de convergência do algoritmo SBD também é apresentada. Por fim, o mecanismo para evitar divergência do CMA proposto em [MIRANDA; SILVA; NASCIMENTO, 2008a] é estendido para o RMA, considerando ou não o uso dos vizinhos.

No Capítulo 5, são apresentadas análises de rastreio para os algoritmos MMA, RMA e SBD. Através dessas análises, é possível comprovar que o RMA e o SBD, sob certas condições, podem atingir a equalização perfeita para constelações QAM de qualquer ordem.

No Capítulo 6, o RMA e SBD são estendidos para adaptar os filtros direto e de realimentação do equalizador de decisão realimentada. A extensão se baseia no mecanismo proposto em [SZCZECINSKI; GEI, 2002] para evitar soluções degeneradas.

No Capítulo 7, são apresentadas simulações numéricas para comprovar o bom comportamento dos algoritmos propostos e também dos mecanismos usados para acelerar a convergência e evitar a divergência. Além disso, os resultados teóricos dos capítulos 3 e 5 são validados através de resultados de simulação.

Para finalizar, no Capítulo 8, são apresentadas as conclusões do trabalho e algumas sugestões para trabalhos futuros. 


\section{Capítulo 2}

\section{Funções de erro de estimação}

No contexto da equalização de sinais QAM de alta ordem, o CMA e o MMA apresentam um EMSE em regime elevado. Além de análises teóricas que comprovam esse comportamento, um simples gráfico do erro de estimação desses algoritmos em função da saída do equalizador pode dar uma ideia do porquê isso ocorre. De fato, o gráfico do erro do MMA em função do sinal de saída do equalizador mostra que ele é igual a zero nas coordenadas dos símbolos da constelação apenas quando o sinal transmitido é de módulo constante. Isso faz com que esses algoritmos se distanciem do comportamento de um algoritmo supervisionado, principalmente quando a ordem do sinal QAM é alta.

Através de um estudo baseado em funções de erro de estimação, procura-se neste capítulo obter funções que satisfaçam algumas propriedades de interesse para que o algoritmo autodidata se aproxime do supervisionado equivalente, independentemente da ordem da constelação QAM. Para isso, considera-se a classe de algoritmos normalizados descrita pela Equação (1.12), que é repetida aqui por conveniência, ou seja,

$$
\mathbf{w}(n)=\mathbf{w}(n-1)+\frac{\mu}{\delta+\|\mathbf{u}(n)\|^{2}} e(n) \mathbf{u}^{*}(n) .
$$

Dessa forma, todos os erros de estimação descritos neste capítulo podem ser usados em (2.1) para adaptar o vetor de coeficientes do equalizador. Além disso, cabe salientar que a maioria das figuras que exibem as funções de erro neste capítulo consideram a constelação 64-QAM apenas para simplificar a visualização dos nuances de interesse. A rigor, qualquer outra constelação poderia ter sido utilizada. 
Inicialmente, revisita-se a função de erro do MMA e deriva-se uma versão do algoritmo SDD em que as componentes real e imaginária do erro são calculadas separadamente. Em seguida, obtém-se uma versão multimódulo do algoritmo concorrente CMA+SDD a partir da função custo do SDD somada à função custo do MMA ponderada. A constante de ponderação, definida como a razão entre os passos do MMA e do SDD, aparece no erro de estimação usado pelo algoritmo. Com isso, é possível verificar que os passos influenciam na forma da função de erro e consequentemente no desempenho. Verifica-se que a melhor forma da função de erro para obter um MSE pequeno em regime é aquela que se aproxima de zero nas coordenadas dos símbolos da constelação e apresenta uma envoltória, imposta neste caso pelo MMA, que por simulação parece ser essencial para a recuperação dos símbolos.

Tendo em mente essas características da função de erro, são propostos dois novos algoritmos: o algoritmo de decisão suave modificado (MSD - Modified Soft Decision) e o algoritmo multimódulo regional (RMA - region-based multimodulus algorithm). As funções de erro desses algoritmos são contínuas por partes, mas só a do RMA é igual a zero quando a saída do equalizador coincide com as coordenadas dos símbolos da constelação.

Revisita-se a função de erro do algoritmo multimódulo baseado guiado pelos raios (MRD - multimodulus radius-directed) de [FERNANDES; FAVIER; MOTA, 2007] que também é igual zero nas coordenadas dos símbolos, mas tem uma envoltória com crescimento exponencial. Por fim, considerando uma função linear por partes e uma envoltória também linear, se propõe o algoritmo de decisão baseada nos símbolos (SBD -symbol-based decision). Dada a similaridade com a função de erro do algoritmo de decisão direta, o SBD pode ser interpretado como uma extensão do algoritmo DD para equalização de sinais QAM.

\subsection{A função de erro do algoritmo multimódulo (MMA)}

O algoritmo multimódulo minimiza a função custo instantânea [OH; PARK, 1997; YANG; WERNER; DUMONT, 2002]

$$
J_{\mathrm{MMA}}(n)=\left[r_{2}-y_{\mathrm{R}}^{2}(n)\right]^{2}+\left[r_{2}-y_{\mathrm{I}}^{2}(n)\right]^{2},
$$


em que

$$
r_{2}=\frac{\mathrm{E}\left\{a_{\mathrm{R}}^{4}(n)\right\}}{\mathrm{E}\left\{a_{\mathrm{R}}^{2}(n)\right\}}=\frac{\mathrm{E}\left\{a_{\mathrm{I}}^{4}(n)\right\}}{\mathrm{E}\left\{a_{\mathrm{I}}^{2}(n)\right\}}
$$

para constelações quadradas e $\mathrm{E}\{\cdot\}$ representa o operador esperança matemática. Seu erro de estimação é dado por

$$
e_{\mathrm{MMA}}(n)=\left[r_{2}-y_{\mathrm{R}}^{2}(n)\right] y_{\mathrm{R}}(n)+j\left[r_{2}-y_{\mathrm{I}}^{2}(n)\right] y_{\mathrm{I}}(n)
$$

A parte real desse erro, denotada por $e_{\mathrm{MMA}, \mathrm{R}}(n)$, é mostrada na Figura 2.1 em função de $y_{\mathrm{R}}(n)$, admitindo um sinal de módulo constante (4-QAM) e dois de módulo não-constante (16-QAM e 64-QAM). As figuras para as correspondentes partes imaginárias desses erros em função de $y_{\mathrm{I}}(n)$ são idênticas. Para todos esses sinais, a parte real do erro do MMA é igual a zero quando $y_{\mathrm{R}}^{2}(n)$ é nulo ou quando $y_{\mathrm{R}}^{2}(n)$ é igual à constante de dispersão $r_{2}$. Para 4-QAM (Figura 2.1-(a)), $r_{2}=1$ e $e_{\mathrm{MMA}, \mathrm{R}}(n)=0$ quando a saída do equalizador é igual à coordenada de um dos símbolos da constelação, ou seja, quando $y_{R}(n)= \pm 1$. Esse comportamento não ocorre para sinais de módulo não-constante. Para 16-QAM (Figura 2.1-(a)), $r_{2}=8.2 \mathrm{com}\left|e_{\mathrm{MMA}, \mathrm{R}}(n)\right|=7.2$ e $\left|e_{\mathrm{MMA}, \mathrm{R}}(n)\right|=2.4$ para $y_{\mathrm{R}}(n)= \pm 1$ e $y_{\mathrm{R}}(n)= \pm 3$, respectivamente. Para 64-QAM (Figura 2.1-(b)), $r_{2}=37$ e $\left|e_{\mathrm{MMA}, \mathrm{R}}(n)\right|$ assume um valor do conjunto $\{36,60,84\}$, quando $y_{\mathrm{R}}(n)$ é igual à coordenada de um dos símbolos da constelação, isto é, $\{ \pm 1, \pm 3, \pm 5, \pm 7\}$. Portanto, similarmente ao CMA, o MMA exibe um erro quadrático médio em regime relativamente elevado para sinais de módulo não-constante.

\subsection{A função de erro do algoritmo de decisão direta suave (SDD)}

O algoritmo de decisão direta suave foi proposto originalmente em [KARAOGUZ; ADARLAN, 1992] para 4-QAM e estendido em [CHEN et al., 1995] para constelações S-QAM quadradas de qualquer ordem. Para isso, considerou-se um esquema de adaptação multiestágio que divide a tarefa de equalização de um sinal $S$-QAM em $\log _{2}(S) / 2$ sub-tarefas mais simples. Em cada etapa do processo de adaptação, tudo se passa como se uma constelação 4-QAM tivesse sido transmitida. Como observado em [CHEN, 2003], seu principal problema é que 

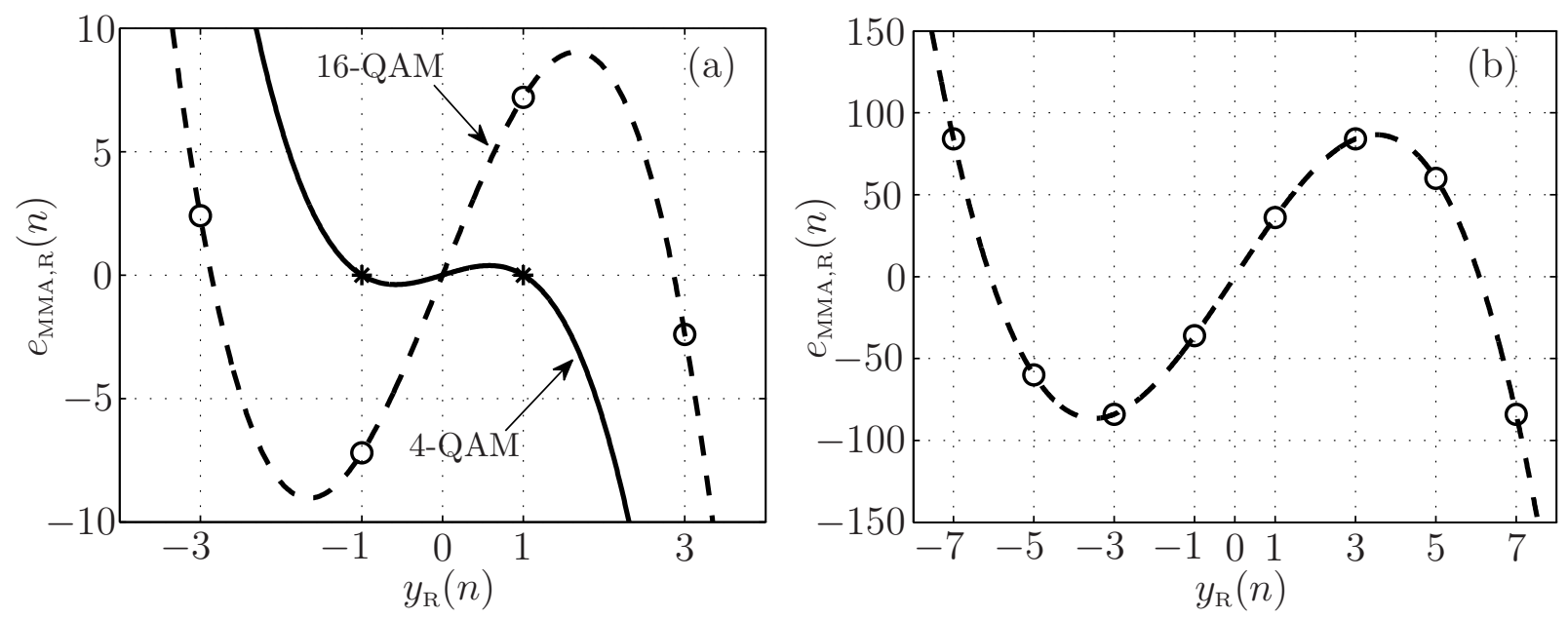

Figura 2.1: Parte real do erro do MMA em função de $y_{\mathrm{R}}(n)$ para: (a) 4-QAM e 16-QAM; (b) 64-QAM. Os erros nas posições correspondentes às coordenadas dos símbolos das constelações são indicados por * (4-QAM) e o (16-QAM e 64-QAM).

cada etapa requer um conjunto de parâmetros diferentes, que muitas vezes são difíceis de ajustar. Para evitar esse processo de adaptação complexo, apenas o último estágio do SDD de [CHEN et al., 1995] foi considerado no algoritmo concorrente de [CHEN, 2003], sendo que os demais estágios foram substituídos por simples comparações. A seguir, obtém-se uma versão desse algoritmo, em que as partes real e imaginária do erro de estimação são calculadas separadamente como no MMA.

Para calcular as componentes real e imaginária do erro separadamente, o algoritmo SDD deve minimizar a seguinte função custo instantânea [CHEN et al., 1995; CHEN, 2003]

$$
J_{\mathrm{SDD}}(n)=-\rho\left\{\ln \left[\hat{f}\left(y_{\mathrm{R}}(n)\right)\right]+\ln \left[\hat{f}\left(y_{\mathrm{I}}(n)\right)\right]\right\}
$$

em que $\hat{f}(\cdot)$ é uma aproximação local da função densidade de probabilidade (f.d.p.) a posteriori de $y_{\mathrm{R}}(n)$ e $y_{\mathrm{I}}(n)$, e $\rho$ é uma constante definida a seguir. Após uma convergência "satisfatória", o sinal $y_{\mathrm{R}}(n)$ pode ser aproximado por $y_{\mathrm{R}}(n) \approx \hat{a}_{\mathrm{R}}(n-\Delta)+\varrho_{\mathrm{R}}(n)$, em que $\varrho_{\mathrm{R}}(n)$ é aproximadamente um ruído branco gaussiano (igualmente para a componente imaginária). Usando esse modelo e supondo-se uma constelação $S$-QAM quadrada, $y_{\mathrm{R}}(n)$ e $y_{\mathrm{I}}(n)$ podem ser aproximados por $\sqrt{S}$ agrupamentos gaussianos, com médias iguais às coordenadas dos símbolos e variância $\rho \triangleq \mathrm{E}\left\{\varrho_{\mathrm{R}}^{2}(n)\right\}=\mathrm{E}\left\{\varrho_{\mathrm{I}}^{2}(n)\right\}$. 
A fim de obter a aproximação local $\hat{f}(\cdot)$, a reta real é dividida em $\sqrt{S} / 2$ segmentos de reta $A_{k}$ com centros $c_{k}$, sendo $k=-\sqrt{S} / 4, \cdots,-1,1, \cdots, \sqrt{S} / 4$, como mostrado na Figura 2.2 para a parte real de 64-QAM. Cada segmento de reta $A_{k}$, denominado de região

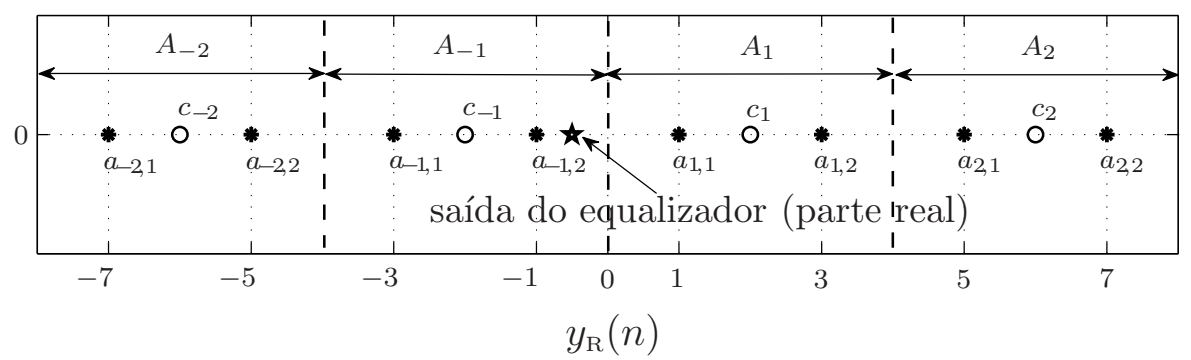

Figura 2.2: Regiões da parte real de uma constelação 64-QAM; o centro da região $A_{k}$ é representado por $c_{k}$ e $k= \pm 2, \pm 1$.

$A_{k}$, contém duas coordenadas de símbolos denotadas por $a_{k, 1}$ e $a_{k, 2}$, e indicados por asteriscos nessa figura. Dada a saída do equalizador $y(n)$, com $\left(\log _{2}(S)-2\right)$ comparações, é possível identificar a região $A_{\ell}$ à qual $y_{\mathrm{R}}(n)$ pertence e a região $A_{m}$ à qual $y_{\mathrm{I}}(n)$ pertence. $\mathrm{O}$ índice $\ell$ (respectivamente, $m$ ) é um inteiro usado para identificar a região, em que a parte rea $\ell$ (respectivamente, imaginária) da saída do equalizador "cai". Usando essa informação, uma aproximação local para a f.d.p. de $y_{\mathrm{R}}(n)$ é dada por

$$
\hat{f}\left(y_{\mathrm{R}}(n)\right) \approx \frac{1}{\sqrt{2 \pi \rho}} \sum_{p=1}^{2} \exp \left[x_{\ell, p}(n)\right],
$$

em que

$$
x_{\ell, p}(n)=-\frac{\left[a_{\ell, p}-y_{\mathrm{R}}(n)\right]^{2}}{2 \rho} .
$$

Usando a mesma aproximação para a f.d.p. de $y_{\mathrm{I}}(n)$, chega-se a

$$
\hat{f}\left(y_{\mathrm{I}}(n)\right) \approx \frac{1}{\sqrt{2 \pi \rho}} \sum_{p=1}^{2} \exp \left[x_{m, p}(n)\right],
$$

em que

$$
x_{m, p}(n)=-\frac{\left[a_{m, p}-y_{\mathrm{I}}(n)\right]^{2}}{2 \rho} .
$$

Substituindo (2.6) e (2.8) em (2.5), se obtém o vetor gradiente de $J_{\mathrm{SDD}}(n)$, dado por $\varepsilon_{\mathrm{SDD}}(n) \mathbf{u}^{*}(n)$, em que

$$
\varepsilon_{\mathrm{SDD}}(n)=\varepsilon_{\ell}(n)+j \varepsilon_{m}(n)
$$


é o erro de estimação do algoritmo SDD, sendo

$$
\varepsilon_{\ell}(n)=\frac{\sum_{p=1}^{2}\left[a_{\ell, p}-y_{\mathrm{R}}(n)\right] \exp \left[x_{\ell, p}(n)\right]}{\sum_{p=1}^{2} \exp \left[x_{\ell, p}(n)\right]}
$$

e

$$
\varepsilon_{m}(n)=\frac{\sum_{p=1}^{2}\left[a_{m, p}-y_{\mathrm{I}}(n)\right] \exp \left[x_{m, p}(n)\right]}{\sum_{p=1}^{2} \exp \left[x_{m, p}(n)\right]} .
$$

Para assegurar uma separação adequada dos agrupamentos, $\rho$ deve ser menor do que a metade da distância entre as coordenadas de dois símbolos adjacentes [CHEN, 2003]. Portanto, um valor típico usado para $\rho$ é 0,6 , independentemente da ordem da constelação QAM.

O erro $\varepsilon_{\ell}(n)$ é mostrado na Figura 2.3 em função de $y_{\mathrm{R}}(n)$ para 64-QAM. É possível observar que cada região $A_{\ell}$ contém duas coordenadas de símbolos da constelação e que a função de erro é contínua por partes. Isso decorre do fato do algoritmo SDD usar a informação da posição de $y(n)$ através da identificação das regiões $A_{\ell}$ e $A_{m}$. Comparando a função de erro em cada região com o erro do MMA da Figura 2.1, é possível notar que existe uma certa semelhança no formato dessas funções, apesar de $J_{\mathrm{SDD}}$ e $J_{\mathrm{MMA}}$ serem diferentes. Além disso, a função de erro do SDD tem uma característica interessante: ela se aproxima de zero nas coordenadas dos símbolos da constelação. No entanto, essa característica não é suficiente para que o SDD seja capaz de recuperar os símbolos transmitidos em situações de MSE relativamente elevado. Geralmente, antes de ter uma condição de equalização satisfatória, o vetor de coeficientes está longe da solução ótima, o que faz com que $y_{\mathrm{R}}(n)$ caia em regiões erradas. Neste caso, pode ser que o algoritmo não perceba que está na direção errada. Por exemplo, se a parte real do sinal transmitido for +5 e $y_{\mathrm{R}}(n)=+3$ ou $y_{\mathrm{R}}(n)=+7$, o valor absoluto do erro de estimação $\varepsilon_{\ell}(n)$ será aproximadamente zero, mas deveria ser grande para fazer com que o algoritmo percebesse que uma boa condição de equalização não foi alcançada. Esse "aviso" que o algoritmo necessita pode ser dado por um outro algoritmo como no caso do algoritmo concorrente ou por uma envoltória na função de erro, conforme simulações realizadas. Esses casos serão analisados a seguir.

Para facilitar a comparação entre a função de erro do SDD com as demais funções de erro apresentadas neste capítulo, ela foi normalizada por $K=1,0025$. Assim, seu valor máximo 


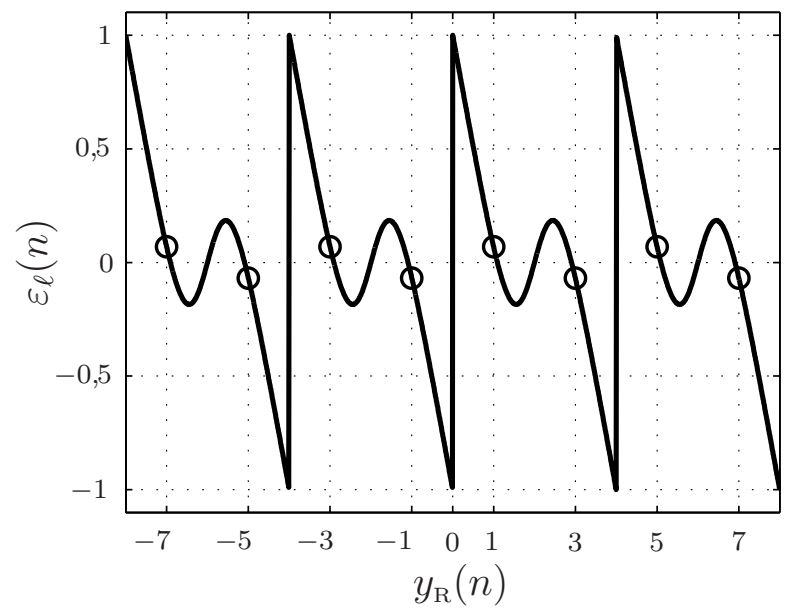

Figura 2.3: Parte real do erro do algoritmo SDD em função de $y_{\mathrm{R}}(n)$ para 64 -QAM; $\rho=0,6$, $K=1,0025$. Os erros nas coordenadas dos símbolos da constelação são indicados por o.

absoluto ficou igual a um. Esse procedimento é repetido daqui por diante e os fatores de normalização $K$ são indicados nas legendas das figuras. Cabe observar que esses fatores podem ser incorporados ao passo de adaptação $\mu$ dos algoritmos da forma (2.1), sem alterar o desempenho.

\subsection{A função de erro do algoritmo concorrente com decisão suave (CSD)}

A versão MMA do algoritmo concorrente CMA+SDD de [CHEN, 2003], proposta neste trabalho, é denominada de algoritmo concorrente com decisão suave (CSD - concurrent softdecision) e sua função custo instantânea é dada por

$$
J_{\mathrm{CSD}}(n)=\beta J_{\mathrm{MMA}}(n)+J_{\mathrm{SDD}}(n),
$$

em que $\beta$ representa a razão entre os passos de adaptação do MMA e do algoritmo SDD, sendo, em geral, $0<\beta \ll 1$. A constante $\beta$ afeta o desempenho do algoritmo CSD e seu valor depende do número de símbolos da constelação QAM. Se $\beta$ for grande $(\beta \geq 0.1$ para 64-QAM, por exemplo), o algoritmo CSD se comportará como o MMA. Em contrapartida, se $\beta$ for pequeno $\left(\beta \leq 10^{-4}\right.$ para 64 -QAM, por exemplo), o algoritmo CSD se comportará 
como o último estágio do algoritmo SDD e, neste caso, os símbolos transmitidos só serão recuperados em condições favoráveis para a equalização. Portanto, um valor intermediário de $\beta$ deve ser escolhido. Usando (2.10) e (2.4), o erro de estimação do algoritmo CSD pode ser expresso como

$$
e_{\mathrm{CSD}}(n)=\beta\left[r_{2}-y_{\mathrm{R}}^{2}(n)\right] y_{\mathrm{R}}(n)+\varepsilon_{\ell}(n)+j\left\{\beta\left[r_{2}-y_{\mathrm{I}}^{2}(n)\right] y_{\mathrm{I}}(n)+\varepsilon_{m}(n)\right\} .
$$

O bom desempenho do algoritmo CSD depende dos valores de $\rho$ e $\beta$. Como no algoritmo SDD, um valor típico usado para $\rho$ é 0,6, independentemente da ordem da constelação QAM. Em contrapartida, a escolha de $\beta$ não é simples. Para verificar como $\beta$ afeta a forma da função de erro do algoritmo CSD, a Figura 2.4 mostra a parte real do erro $e_{\mathrm{CSD}, \mathrm{R}}(n)$ em função da parte real da saída do equalizador $y_{\mathrm{R}}(n)$ para 64-QAM, considerando dois valores de $\beta$ (as curvas para a parte imaginária são idênticas). Pelo fato do CSD usar o algoritmo SDD, que, por sua vez, considera a informação da posição de $y(n)$ através da identificação das regiões $A_{\ell}$ e $A_{m}$, as partes real e imaginária de seu erro de estimação são funções contínuas por partes como pode ser visto na Figura 2.4. Comparando a Figura 2.4-(a) com a Figura 2.4-(b), podese observar que o erro está mais próximo de zero nas coordenadas dos símbolos da constelação na Figura 2.4-(b). Portanto, quando o algoritmo usa a função erro da Figura 2.4-(b), ele poderá atingir um erro quadrático médio em regime menor do que o alcançado com a função erro da Figura 2.4-(a). A menos de um fator de escala, é possível identificar na Figura 2.4-(b) um padrão de erro, que se repete nas regiões contendo a parte real das coordenadas de seus símbolos adjacentes na constelação. Além disso, pode-se observar na Figura 2.4-(b) que o MMA tem um papel fundamental no algoritmo concorrente: ele é responsável por tornar o erro CSD diferente em cada região, o que é essencial para a recuperação dos símbolos transmitidos como verificado por simulação.

Diante do observado na Figura 2.4 e da semelhança no formato das funções de erro do MMA e do SDD, são propostos dois algoritmos: um baseado somente no último estágio do SDD e aqui denominado algoritmo de decisão suave modificado (MSD -modified softdecision) e um outro baseado somente no MMA, aqui chamado de algoritmo multimódulo regional (RMA - region-based multimodulus algorithm). Esses algoritmos são apresentados na sequência. 

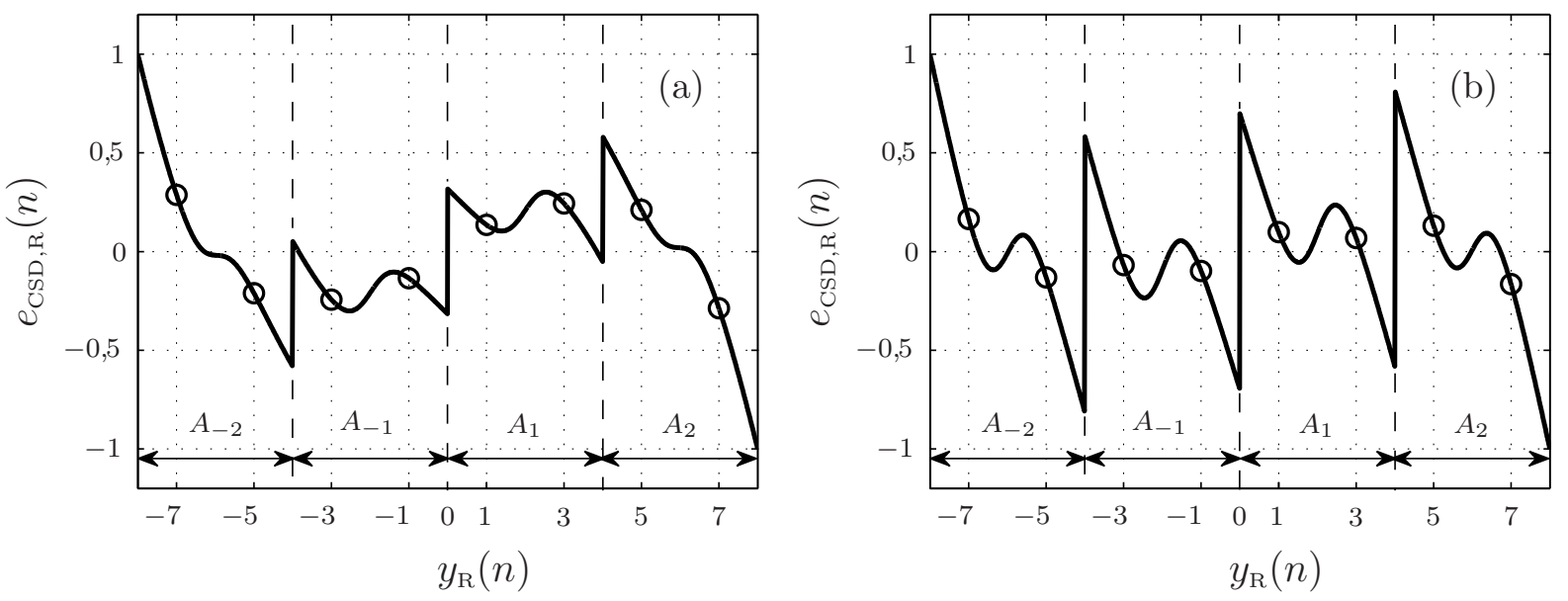

Figura 2.4: Parte real do erro do algoritmo CSD em função de $y_{\mathrm{R}}(n)$ para 64-QAM com $\rho=0,6$; (a) $\beta=10^{-2}, K=3,1625$; (b) $\beta=2 \times 10^{-3}, K=1,4345$. Os erros nas coordenadas dos símbolos da constelação são indicados por o.

\subsection{A função de erro do algoritmo de decisão direta suave modificado (MSD)}

Para obter uma função de erro mais simples que a do CSD, mas que seja similar àquela da Figura 2.4-(b), pode-se considerar a função de erro SDD ponderada por um fator de escala para cada região $A_{k}$. Usando como fatores de escala os valores absolutos dos centros das regiões $A_{\ell}$ e $A_{m}$, denotados respectivamente por $\left|c_{\ell}\right|$ e $\left|c_{m}\right|$, se propõe o algoritmo MSD, cujo erro de estimação é dado por

$$
e_{\mathrm{MSD}}(n)=\left|c_{\ell}\right| \varepsilon_{\ell}(n)+j\left|c_{m}\right| \varepsilon_{m}(n) .
$$

Na Figura 2.5, é mostrada a parte real desse erro em função de $y_{\mathrm{R}}(n)$ para 64-QAM. Podese observar que o papel do MMA no algoritmo concorrente é substituído pelos fatores de escala no algoritmo MSD. Apesar do MSD poder superar o MMA e o CSD em termos de erro quadrático médio em regime, seu erro de estimação não se anula nas coordenadas dos símbolos da constelação, o que contribui para um desajuste indesejável e inevitável.

Cabe observar que esse algoritmo é uma extensão do algoritmo SDD modificado (MSDD - modified SDD), proposto originalmente em [MENDES FILHO, 2007], para o caso em que as componentes real e imaginária do erro são calculadas separadamente, como no MMA. 


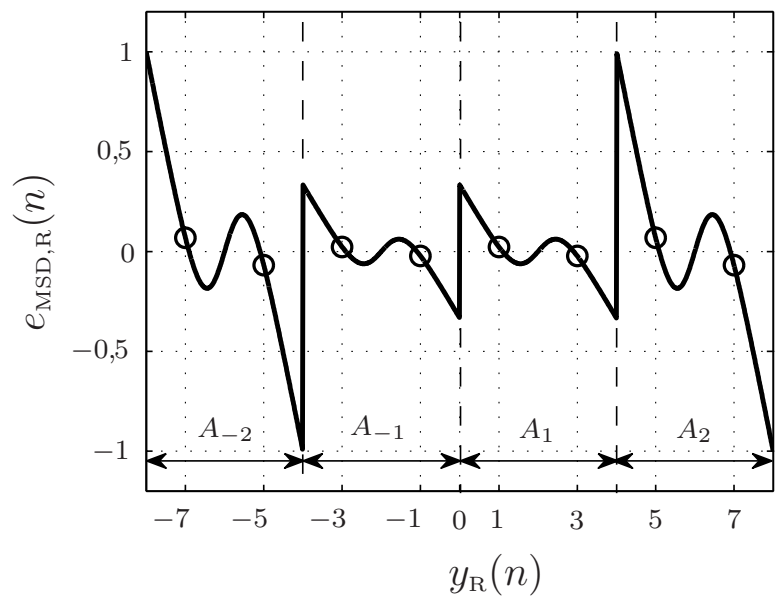

Figura 2.5: Parte real do erro MSD como função de $y_{\mathrm{R}}(n)$ para 64-QAM, $\rho=0,6$ e $K=6,0153$. Os erros nas coordenadas dos símbolos da constelação são indicados por o.

\subsection{A função de erro do algoritmo multimódulo regio- nal (RMA)}

Para minimizar o desajuste do algoritmo MSD, se propõe o algoritmo multimódulo regional, cuja função de erro se anula quando a saída do equalizador é igual à coordenada de um dos símbolos da constelação. A função de erro do RMA é obtida através da repetição da função de erro do MMA com $r_{2}=1$ para cada região $A_{k}$, ponderada por um fator de escala, ou seja,

$$
e_{\mathrm{RMA}}(n)=\alpha_{\ell}\left[1-\breve{y}_{\ell}^{2}(n)\right] \breve{y}_{\ell}(n)+j \alpha_{m}\left[1-\breve{y}_{m}^{2}(n)\right] \breve{y}_{m}(n)
$$

em que

$$
\breve{y}_{\ell}(n)=y_{\mathrm{R}}(n)-c_{\ell}
$$

e

$$
\breve{y}_{m}(n)=y_{\mathrm{I}}(n)-c_{m}
$$

correspondem às versões transladadas das partes real e imaginária da saída do equalizador. Os escalares $c_{\ell}$ e $c_{m}$ são os centros das regiões identificadas e $\alpha_{\ell}$ e $\alpha_{m}$ são fatores de escala, que dependem dessas regiões. Devido à translação de $y(n)$ para origem do plano complexo, tudo se passa como se somente os símbolos $\{ \pm 1 \pm j\}$ de uma constelação 4-QAM tivessem sido transmitidos. 
Os valores ótimos dos fatores de escala $\alpha_{\ell}$ e $\alpha_{m}$ são derivados a seguir. Dadas as regiões $A_{\ell}$ e $A_{m}$, o RMA procura minimizar a função custo

$$
J_{\mathrm{RMA}}=\mathrm{E}\left\{\alpha_{\ell}\left[1-\breve{y}_{\ell}^{2}(n)\right]^{2}\right\}+\mathrm{E}\left\{\alpha_{m}\left[1-\breve{y}_{m}^{2}(n)\right]^{2}\right\}
$$

Com base em [GOUPIL; PALICOT, 2007], admitindo que $\sqrt{\alpha_{\ell}} \breve{y}_{\ell}^{2}(n)=\kappa_{\ell} a_{\ell, p}^{2}, p=1,2$, sendo $\kappa_{\ell}$ uma constante e calculando

$$
\left.\frac{\partial J_{\mathrm{RMA}}}{\partial \kappa_{\ell}}\right|_{\kappa_{\ell}=1}=0,
$$

se obtém o valor ótimo para $\alpha_{\ell}$, ou seja,

$$
\alpha_{\ell, \mathrm{o}}=\left[\frac{\mathrm{E}\left\{a_{\ell, p}^{4}\right\}}{\mathrm{E}\left\{a_{\ell, p}^{2}\right\}}\right]^{2}=\left[\frac{a_{\ell, 1}^{4}+a_{\ell, 2}^{4}}{a_{\ell, 1}^{2}+a_{\ell, 2}^{2}}\right]^{2} .
$$

Analogamente para a parte imaginária,

$$
\alpha_{m, \mathrm{o}}=\left[\frac{\mathrm{E}\left\{a_{m, p}^{4}\right\}}{\mathrm{E}\left\{a_{m, p}^{2}\right\}}\right]^{2}=\left[\frac{a_{m, 1}^{4}+a_{m, 2}^{4}}{a_{m, 1}^{2}+a_{m, 2}^{2}}\right]^{2} .
$$

Para 64-QAM, por exemplo, se obtém $\alpha_{-1, \mathrm{o}}=\alpha_{1, \mathrm{o}}=2,86^{2}$ e $\alpha_{-2, \mathrm{o}}=\alpha_{2, \mathrm{o}}=6,39^{2}$. É possível observar que quanto mais distante estiver a região $A_{k}$ da origem, mais próximo o valor de $\alpha_{k, \mathrm{o}}$ estará do quadrado da distância que une o centro da região e a origem da reta real. Dessa forma, em vez de usar os valores ótimos para os fatores de escala, pode-se usar o valor absoluto dos centros das regiões. Isso facilita a implementação e a análise do algoritmo já que a distância entre centros de regiões adjacentes é sempre igual a quatro.

Na Figura 2.6, é mostrada a parte real do erro do RMA em função de $y_{\mathrm{R}}(n)$ para 64-QAM, usando os fatores de escala ótimos e os valores absolutos dos centros das regiões. Devido à normalização, pode-se notar que a função de erro que considera os valores absolutos dos centros praticamente coincide com a dos valores ótimos. Por isso, o uso de um ou outro fator não altera o desempenho do algoritmo. Assim, daqui por diante, serão usados apenas os valores absolutos dos centros das regiões como fatores de escala. É possível notar ainda que a função de erro do RMA é contínua por partes, similar àquelas das figuras 2.4-(b) e 2.5, mas com a vantagem de se anular quando a saída do equalizador coincide com a coordenada de um dos símbolos da constelação.

As operações do RMA são mostradas na Tabela 2.1. 


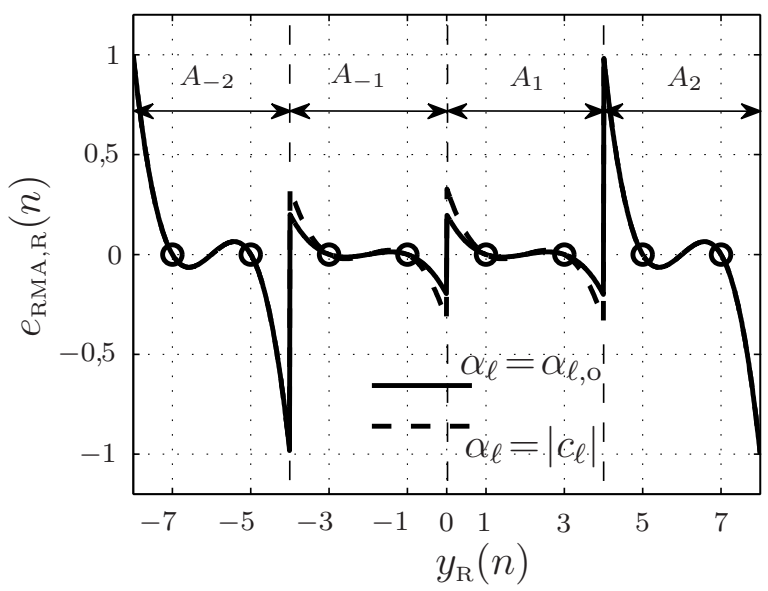

Figura 2.6: Parte real do erro do RMA em função de $y_{\mathrm{R}}(n)$ para 64-QAM, usando os fatores de escala ótimos $\left(\alpha_{\ell}=\alpha_{\ell, \mathrm{o}}, K=244,9926\right)$ e os valores absolutos dos centros das regiões $\left(\alpha_{\ell}=\left|c_{\ell}\right|, K=36\right)$. Os erros nas coordenadas dos símbolos são indicados por $\circ$.

Tabela 2.1: Sumário do algoritmo RMA.

Inicialize o algoritmo ajustando:

$$
\mathbf{w}(0)=\left[\begin{array}{lllllll}
0 & \cdots & 0 & 1 & 0 & \cdots & 0
\end{array}\right], \quad 0<\mu<2 \quad \text { e } \quad 0<\delta \ll 1
$$

Para $n=1,2,3 \ldots$, calcule:

$$
y(n)=\mathbf{u}^{T}(n) \mathbf{w}(n-1)=y_{\mathrm{R}}(n)+j y_{\mathrm{I}}(n)
$$

A partir de $y_{\mathrm{R}}(n)$ e $y_{\mathrm{I}}(n)$, obtêm-se $c_{\ell}$ e $c_{m}$, respectivamente

$$
\begin{aligned}
& \breve{y}_{\ell}(n)=y_{\mathrm{R}}(n)-c_{\ell} ; \quad \breve{y}_{m}(n)=y_{\mathrm{I}}(n)-c_{m} \\
& e_{\mathrm{R}}(n)=\left|c_{\ell}\right|\left[1-\breve{y}_{\ell}^{2}(n)\right] \breve{y}_{\ell}(n) ; \quad e_{\mathrm{I}}(n)=\left|c_{m}\right|\left[1-\breve{y}_{m}^{2}(n)\right] \breve{y}_{m}(n) \\
& e(n)=e_{\mathrm{R}}(n)+j e_{\mathrm{I}}(n) \\
& \mathbf{w}(n)=\mathbf{w}(n-1)+\frac{\mu}{\delta+\|\mathbf{u}(n)\|^{2}} e(n) \mathbf{u}^{*}(n)
\end{aligned}
$$

Fim 


\subsection{A função de erro do algoritmo de decisão baseada nos símbolos (SBD)}

Além das funções de erro consideradas até agora, é possível encontrar outras funções contínuas por partes que se anulam nas coordenadas dos símbolos da constelação e que podem ser adequadas para equalização de sinais QAM. A fim de obter uma função de erro mais simples do que a do RMA, se buscou inspiração no erro do algoritmo de decisão direta (DD), que é o método mais rudimentar de equalização autodidata [MAZO, 1980; MACCHI; EWEDA, 1984; PAPADIAS; SLOCK, 1994]. Na Figura 2.7, é mostrada a parte real do erro do algoritmo DD em função de $y_{\mathrm{R}}(n)$ para 64-QAM. Como no caso do algoritmo SDD, o DD só opera corretamente se o MSE for baixo, já que sua função de erro é idêntica em torno de cada símbolo da constelação. Em outras palavras, o algoritmo DD só consegue fazer um "ajuste fino" numa situação de MSE baixo depois da ação de um outro algoritmo. Apesar de sua ação limitada, a função de erro do DD se anula nas coordenadas dos símbolos da constelação. Uma questão que surge a partir dessa observação é a seguinte: "É possível alterar a função de erro do algoritmo DD para que ele funcione adequadamente para equalização de sinais QAM?". Como será visto a seguir, a resposta é "sim". Porém, antes de responder essa questão é importante revisitar alguns resultados da literatura nos quais a resposta foi inspirada.

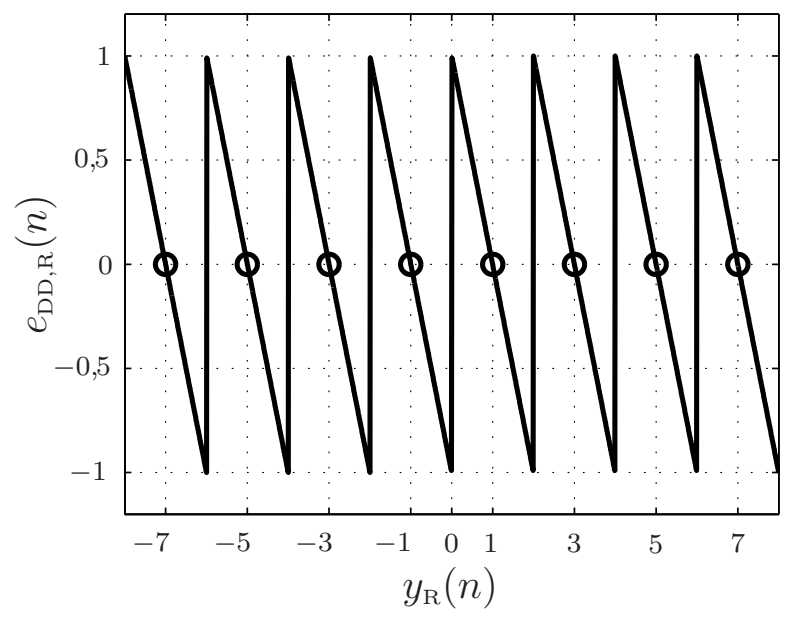

Figura 2.7: Parte real do erro do algoritmo DD em função de $y_{\mathrm{R}}(n)$ para 64 -QAM; $K=1$. Os erros nas coordenadas dos símbolos da constelação são indicados por o. 
Calculando separadamente as partes real e imaginária do erro de estimação do algoritmo RDE (ver página 17), obtém-se o algoritmo aqui denominado de multimódulo guiado pelos raios (MRD - multimodulus radius-directed algorithm), cujo erro de estimação é definido como

$$
e_{\mathrm{MRD}}(n)=\left[\hat{a}_{\mathrm{R}}^{2}(n)-y_{\mathrm{R}}^{2}(n)\right] y_{\mathrm{R}}(n)+j\left[\hat{a}_{\mathrm{I}}^{2}(n)-y_{\mathrm{I}}^{2}(n)\right] y_{\mathrm{I}}(n),
$$

em que $\hat{a}_{\mathrm{R}}(n)=\operatorname{dec}\left[y_{\mathrm{R}}(n)\right]$ (respectivamente, $\left.\hat{a}_{\mathrm{I}}(n)=\operatorname{dec}\left[y_{\mathrm{I}}(n)\right]\right)$ representa a parte real (respectivamente, imaginária) da coordenada do símbolo da constelação mais próxima de $y_{\mathrm{R}}(n)$ (respectivamente, $y_{\mathrm{I}}(n)$ ). Esse erro foi usado em [FERNANDES; FAVIER; MOTA, 2007] para atualizar um algoritmo com dois modos de operação, proposto para equalização de sinais $S$-QAM, com $S \leq 64$. A Figura 2.8-(a) mostra a parte real do erro do MRD em função de $y_{\mathrm{R}}(n)$ para 64-QAM (curva contínua). As quatro curvas tracejadas representam o erro $e_{\mathrm{MMA}, \mathrm{R}}(n)$ em função de $y_{\mathrm{R}}(n)$ para uma constelação 4-QAM com diferentes fatores de escala. Esses fatores estão associados a quatro diferentes constelações 4-QAM, ou seja, $k\{ \pm 1 \pm j\}, k=1,3,5,7$. No caso de 64-QAM, o erro do MRD coincide com o erro do MMA em intervalos para constelações 4-QAM escaladas. Por exemplo, no intervalo $4<y_{\mathrm{R}}(n)<6$, os erros $e_{\mathrm{MRD}, \mathrm{R}}(n)$ e $e_{\mathrm{MMA}, \mathrm{R}}(n) \operatorname{com} k=5$ são idênticos. O mesmo ocorre para os outros valores de fatores de escala $k$. É importante perceber que o erro do MRD se anula quando a saída do equalizador se iguala à coordenada de um dos símbolos da constelação, preservando a mesma característica do erro do RDE. Além disso, como o MRD usa múltiplos raios, a envoltória da curva contínua da Figura 2.8-(a) cresce exponencialmente com a amplitude de $y_{\mathrm{R}}(n)$. Esse crescimento está relacionado com a posição do símbolo estimado e consequentemente com o fator de escala $k$. Apesar de parecer que a envoltória é fundamental para a recuperação dos símbolos transmitidos, o seu crescimento exponencial pode causar uma degradação no desempenho do algoritmo, que é tanto pior quanto maior for a a ordem da constelação QAM. Além disso, a função de erro apresenta um comportamento assimétrico nas vizinhanças das coordenadas de um símbolo, o que também pode degradar o desempenho do algoritmo.

Baseando-se no erro do MRD, se introduz agora o algoritmo SBD. Pode-se observar que o erro do MRD (curva contínua da Figura 2.8-(a)) se aproxima de uma reta em cada intervalo de $y_{\mathrm{R}}(n)$ entre duas mudanças abruptas, como no algoritmo de decisão direta 

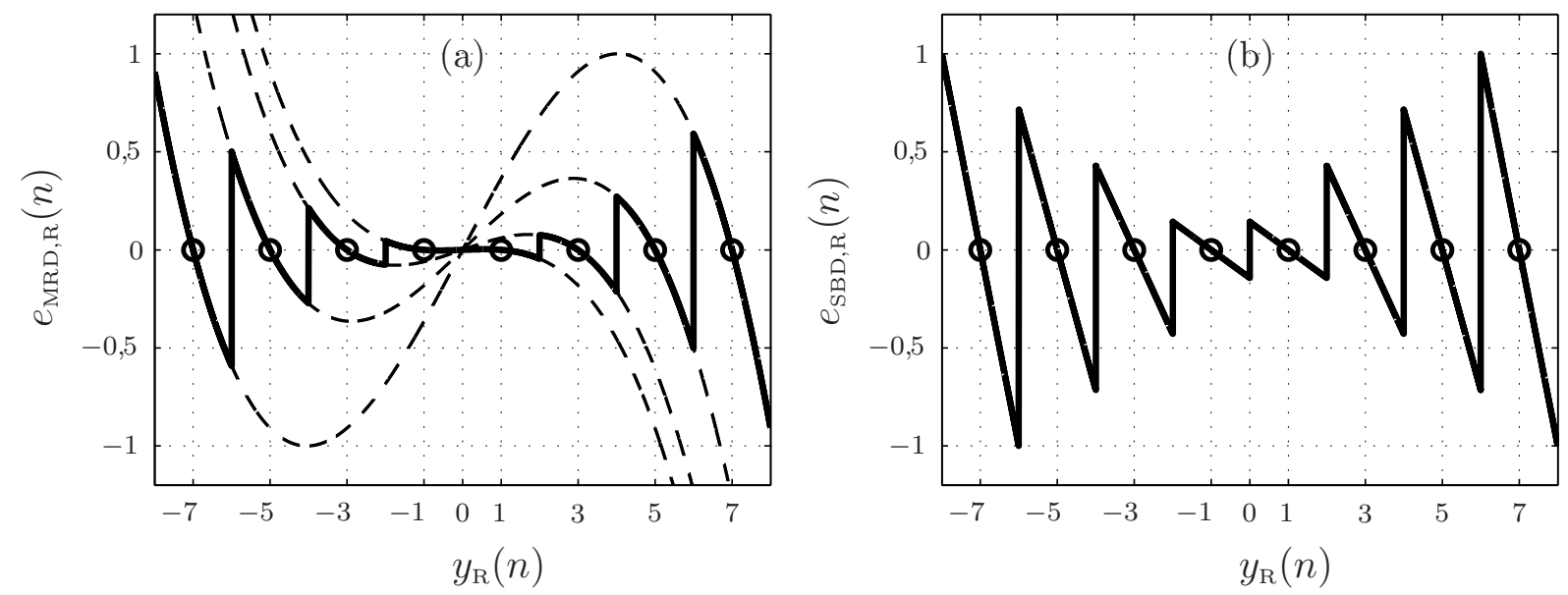

Figura 2.8: Parte real do erro para (a) MRD (64-QAM, curva contínua) e MMA (4-QAM com quatro diferentes fatores de escala, curvas tracejadas), $K=128$; (b) SBD (64-QAM), $K=7$. Os erros nas coordenadas dos símbolos da constelação são indicados por o.

[MAZO, 1980; MACCHI; EWEDA, 1984]. Esse comportamento sugere a função de erro mostrada na Figura 2.8-(b), com uma expressão geral dada por

$$
e_{\mathrm{SBD}}(n)=\left|\hat{a}_{\mathrm{R}}(n)\right|\left[\hat{a}_{\mathrm{R}}(n)-y_{\mathrm{R}}(n)\right]+j\left|\hat{a}_{\mathrm{I}}(n)\right|\left[\hat{a}_{\mathrm{I}}(n)-y_{\mathrm{I}}(n)\right]
$$

que é obtida através da minimização da seguinte função custo

$$
J_{\mathrm{SBD}}=\mathrm{E}\left\{\left|\hat{a}_{\mathrm{R}}(n)\right|\left[\hat{a}_{\mathrm{R}}(n)-y_{\mathrm{R}}(n)\right]^{2}+\left|\hat{a}_{\mathrm{I}}(n)\right|\left[\hat{a}_{\mathrm{I}}(n)-y_{\mathrm{I}}(n)\right]^{2}\right\} .
$$

As variáveis $\left|\hat{a}_{\mathrm{R}}(n)\right|$ e $\left|\hat{a}_{\mathrm{I}}(n)\right|$ criam uma envoltória no erro do SBD, que parece ser essencial para a recuperação dos símbolos transmitidos. Como a envoltória cresce linearmente e não exponencialmente como no erro do MRD, o desempenho do SBD tende a ser superior ao do MRD. Comparando a Figura 2.8-(b) com a Figura 2.7, verifica-se que há uma certa semelhança entre as funções de erro do SBD e a do DD e por isso, o algoritmo SBD pode ser interpretado como uma extensão do algoritmo DD para equalização de sinais QAM.

As operações do algoritmo SBD são mostradas na Tabela 2.2. 
Tabela 2.2: Sumário do algoritmo SBD.

Inicialize o algoritmo ajustando:

$$
\mathbf{w}(0)=\left[\begin{array}{lllllll}
0 & \cdots & 0 & 1 & 0 & \cdots & 0
\end{array}\right], \quad 0<\mu<2 / \sqrt{S} \text { e } \quad 0<\delta \ll 1
$$

Para $n=1,2,3 \ldots$, calcule:

$$
\begin{aligned}
& y(n)=\mathbf{u}^{T}(n) \mathbf{w}(n-1)=y_{\mathrm{R}}(n)+j y_{\mathrm{I}}(n) \\
& \hat{a}_{\mathrm{R}}(n)=\operatorname{dec}\left[y_{\mathrm{R}}(n)\right] ; \quad \hat{a}_{\mathrm{I}}(n)=\operatorname{dec}\left[y_{\mathrm{I}}(n)\right] \\
& e_{\mathrm{R}}(n)=\left|\hat{a}_{\mathrm{R}}(n)\right|\left[\hat{a}_{\mathrm{R}}(n)-y_{\mathrm{R}}(n)\right] ; \quad e_{\mathrm{I}}(n)=\left|\hat{a}_{\mathrm{I}}(n)\right|\left[\hat{a}_{\mathrm{I}}(n)-y_{\mathrm{I}}(n)\right] \\
& e(n)=e_{\mathrm{R}}(n)+j e_{\mathrm{I}}(n) \\
& \mathbf{w}(n)=\mathbf{w}(n-1)+\frac{\mu}{\delta+\|\mathbf{u}(n)\|^{2}} e(n) \mathbf{u}^{*}(n)
\end{aligned}
$$

Fim

\subsection{Custo computacional}

A Tabela 2.3 contém as expressões dos erros de estimação dos algoritmos aqui considerados. Como esses algoritmos atualizam o vetor de coeficientes através de (2.1), o que diferencia um algoritmo de outro é apenas o cálculo do erro. Portanto, eles apresentam um custo computacional semelhante e compatível com uma implementação prática como pode ser observado na Tabela 2.4. Nesta tabela são mostrados os números de operações reais (multiplicações reais, somas reais, divisões reais, comparações $\mathcal{C}$ e cálculos exponenciais) que cada algoritmo requer por iteração. O custo computacional do algoritmo NLMS também é mostrado para comparação. Se as amostras do vetor de entrada forem obtidas a partir de uma linha de atrasos como é o caso da equalização na taxa de símbolos, os custos computacionais dos algoritmos podem ser reduzidos através da seguinte recursão [SAYED, 2008]:

$$
\|\mathbf{u}(n)\|^{2}=\|\mathbf{u}(n-1)\|^{2}-|u(n-M)|^{2}+|u(n)|^{2},
$$

com inicialização $\|\mathbf{u}(0)\|^{2}=0$. 
Tabela 2.3: Erros de estimação dos algoritmos considerados.

\begin{tabular}{|c|c|}
\hline Algoritmos & Erros de estimação $e(n)$ \\
\hline MMA & {$\left[r_{2}-y_{\mathrm{R}}^{2}(n)\right] y_{\mathrm{R}}(n)+j\left[r_{2}-y_{\mathrm{I}}^{2}(n)\right] y_{\mathrm{I}}(n)$} \\
\hline $\mathrm{CSD}$ & $\beta\left[r_{2}-y_{\mathrm{R}}^{2}(n)\right] y_{\mathrm{R}}(n)+\varepsilon_{\ell}(n)+j\left\{\beta\left[r_{2}-y_{\mathrm{I}}^{2}(n)\right] y_{\mathrm{I}}(n)+\varepsilon_{m}(n)\right\}$ \\
\hline $\mathrm{MSD}$ & $\left|c_{\ell}\right| \varepsilon_{\ell}(n)+j\left|c_{m}\right| \varepsilon_{m}(n)$ \\
\hline $\mathrm{RMA}$ & $\alpha_{\ell}\left[1-\breve{y}_{\ell}^{2}(n)\right] \breve{y}_{\ell}(n)+j \alpha_{m}\left[1-\breve{y}_{m}^{2}(n)\right] \breve{y}_{m}(n)$ \\
\hline $\mathrm{MRD}$ & {$\left[\hat{a}_{\mathrm{R}}^{2}(n)-y_{\mathrm{R}}^{2}(n)\right] y_{\mathrm{R}}(n)+j\left[\hat{a}_{\mathrm{I}}^{2}(n)-y_{\mathrm{I}}^{2}(n)\right] y_{\mathrm{I}}(n)$} \\
\hline $\mathrm{SBD}$ & $\left|\hat{a}_{\mathrm{R}}(n)\right|\left[\hat{a}_{\mathrm{R}}(n)-y_{\mathrm{R}}(n)\right]+j\left|\hat{a}_{\mathrm{I}}(n)\right|\left[\hat{a}_{\mathrm{I}}(n)-y_{\mathrm{I}}(n)\right]$ \\
\hline
\end{tabular}

Tabela 2.4: Custo computacional em termos de operações reais por iteração - LTE.

\begin{tabular}{|c|c|c|c|c|c|c|c|}
\hline Op. & SBD & MRD & RMA & MSD & CSD & MMA & NLMS \\
\hline$\times$ & $10 M+3$ & $10 M+9$ & $10 M+13$ & $10 M+17$ & $14 M+22$ & $10 M+8$ & $10 M+2$ \\
\hline+ & $10 M$ & $10 M+1$ & $10 M+3$ & $10 M+6$ & $14 M+12$ & $10 M+1$ & $10 M$ \\
\hline$\div$ & 1 & 3 & 3 & 7 & 7 & 3 & 1 \\
\hline $\exp$ & - & - & - & 4 & 4 & - & - \\
\hline $\mathcal{C}$ & $\log _{2}(S)$ & $\log _{2}(S)+2$ & $\log _{2}(S)$ & $\log _{2}(S)-1$ & $\log _{2}(S)-1$ & 2 & - \\
\hline
\end{tabular}

\subsection{Conclusões}

Neste capítulo, foram apresentadas diferentes funções de erro de estimação que podem ser usadas na atualização do vetor de coeficientes do equalizador baseado na classe de algoritmos normalizados da Equação (2.1).

O bom comportamento do algoritmo concorrente depende da escolha adequada dos passos de adaptação, já que eles afetam a forma da função de erro. Através dos resultados de simulação de [CHEN, 2003], é possível verificar que a melhor forma dessa função é aquela que se anula nas proximidades das coordenadas dos símbolos da constelação. Além disso, verificase que o MMA tem um papel importante no algoritmo CSD, já que ele faz com que o erro fique diferente em cada região, o que possibilita a recuperação dos símbolos transmitidos. Sem o MMA, o concorrente se torna igual ao SDD, que, sem o processo de adaptação multiestágio, 
só consegue obter bons resultados em situações favoráveis para equalização, isto é, quando o MSE já é baixo.

Baseando-se nas características da função de erro do concorrente e substituindo o papel do MMA por fatores de escala, foram propostos os algoritmos RMA e SBD, cujas funções de erro são contínuas por partes e se anulam nas coordenadas dos símbolos da constelação. Com essas características, espera-se que eles sejam capazes de ter um desempenho próximo ao do algoritmo supervisionado NLMS.

Pelo fato da função de erro do MRD apresentar uma envoltória com crescimento exponencial, apenas o RMA e o SBD serão analisados nos próximos capítulos. Como será visto no Capítulo 7, esses algoritmos podem ter velocidades de convergência diferentes, o que justifica um estudo mais aprofundado do comportamento de ambos. Cabe observar que se percorreu um longo caminho até se chegar ao algoritmo SBD, que é tão simples como o algoritmo da decisão direta, porém com um erro associado a uma envoltória. No entanto, isso só foi possível graças aos resultados existentes na literatura, que possibilitaram justificar as vantagens da função de erro desse algoritmo. 


\section{Capítulo 3}

\section{O receptor de Wiener e soluções}

\section{autodidatas}

Os algoritmos de equalização supervisionada, como por exemplo, o algoritmo NLMS, convergem em média quadrática para a solução linear ótima que minimiza o erro quadrático médio, ou seja, a solução de Wiener-Hopf. Deseja-se que os algoritmos autodidatas tenham um comportamento similar ao dos algoritmos supervisionados. A capacidade que os algoritmos baseados no critério do módulo constante possuem de se aproximar da solução do Wiener já foi bem explorada na literatura. Porém, os algoritmos propostos neste trabalho são baseados em critérios diferentes do módulo constante. Por isso, é de interesse avaliar qualitativamente o quanto as soluções em regime dos algoritmos autodidatas propostos se aproximam da solução linear ótima. Neste capítulo, se estabelece uma relação teórica entre os vetores de coeficientes do RMA e do SBD com a solução de Wiener-Hopf, que por simplicidade é chamada de solução de Wiener.

\subsection{O receptor de Wiener}

A solução linear ótima decorre da minimização do erro quadrático médio (MSE - Mean Squared Error), definido como

$$
J_{\mathrm{MSE}}(\mathbf{w}, \Delta) \triangleq \mathrm{E}\left\{|\xi(n)|^{2}\right\}=\mathrm{E}\left\{\xi_{\mathrm{R}}^{2}(n)+\xi_{\mathrm{I}}^{2}(n)\right\}
$$


em que

$$
\xi(n)=\xi_{\mathrm{R}}(n)+j \xi_{\mathrm{I}}(n)=a(n-\Delta)-y(n),
$$

sendo $a(n-\Delta)$ a resposta desejada e $y(n)$ o sinal de saída do equalizador. Representando $y(n)$ em termos do vetor regressor e dos coeficientes do filtro, ou seja, $y(n)=\mathbf{u}^{T}(n) \mathbf{w}$ a equação (3.1) pode ser expressa como

$$
J_{\mathrm{MSE}}(\mathbf{w}, \Delta)=\sigma_{a}^{2}+\mathbf{w}^{H} \mathbf{R} \mathbf{w}-\mathbf{w}^{T} \mathbf{p}_{\Delta}^{*}-\mathbf{w}^{H} \mathbf{p}_{\Delta},
$$

em que $(\cdot)^{H}$ representa o complexo conjugado e transposto de um vetor ou de uma matriz, $\sigma_{a}^{2}=\mathrm{E}\left\{|a(n)|^{2}\right\}, \mathbf{R} \triangleq \mathrm{E}\left\{\mathbf{u}^{*}(n) \mathbf{u}^{T}(n)\right\}$ é a matriz de autocorrelação do sinal de entrada, e $\mathbf{p}_{\Delta} \triangleq \mathrm{E}\left\{a(n-\Delta) \mathbf{u}^{*}(n)\right\}$ é a correlação cruzada entre o vetor regressor de entrada e o sinal desejado. O ponto de mínimo da função $J_{\mathrm{MSE}}(\mathbf{w}, \Delta)$ em relação a w ocorre quando a relação $\mathbf{R} \mathbf{w}=\mathbf{p}_{\Delta}$ é satisfeita. O vetor que satisfaz essa igualdade,

$$
\mathbf{w}_{\mathrm{WIE}} \triangleq \mathbf{R}^{-1} \mathbf{p}_{\Delta}
$$

representa a solução de Wiener [HAYKIN, 2002]. Substituindo (3.4) em (3.3) resulta em

$$
J_{\min }(\Delta)=\min _{\mathbf{w}}\left\{J_{\mathrm{MSE}}(\mathbf{w}, \Delta)\right\}=\sigma_{a}^{2}-\mathbf{w}_{\mathrm{WIE}}^{T} \mathbf{p}_{\Delta}^{*}
$$

que é, portanto, o menor valor que a função $J_{\mathrm{MSE}}(\mathbf{w}, \Delta)$ pode alcançar.

É importante ressaltar que os algoritmos de equalização supervisionada convergem em média quadrática para (3.4). Essa solução minimiza um momento de segunda ordem e para um determinado atraso é única. Usualmente, a equalização autodidata considera critérios baseados em momentos de ordem superior a dois e a sua solução não é única, como é o caso do critério do módulo constante [JOHNSON R. et al., 1998]. Mesmo ciente que um algoritmo autodidata pode convergir para soluções distintas, deseja-se que estas se aproximem da solução de Wiener.

A estreita relação entre as soluções dos critérios do módulo constante e do MSE começou a ser efetivamente explorada no trabalho [LI; LIU; DING, 1996] para obter uma localização aproximada dos pontos estacionários do critério do módulo constante e o seu desempenho em termos do valor do MSE. Posteriormente, outros trabalhos surgiram usando diferentes 
abordagens para tratar a mesma questão. Em especial, os trabalhos [SUYAMA et al., 2003; SUYAMA, 2003] abordaram a relação entre as soluções dos critérios do módulo constante e do MSE de forma simples e elegante para sinais de módulo constante do tipo 2-PAM. Esses resultados foram estendidos em [BELLANGER, 2004] para o caso de sinais complexos do tipo 4-QAM. Inspirando-se nos trabalhos [SUYAMA et al., 2003; SUYAMA, 2003] e [BELLANGER, 2004] e usando inclusive as mesmas suposições e aproximações, a seguir são deduzidas as relações entre as soluções autodidatas do RMA e do SBD e a solução de Wiener.

\subsection{A solução RMA e o receptor de Wiener}

A expressão da função custo do RMA, Equação (2.19), é repetida a seguir

$$
J_{\mathrm{RMA}}=\mathrm{E}\left\{\alpha_{\ell}\left[1-\breve{y}_{\ell}^{2}(n)\right]^{2}\right\}+\mathrm{E}\left\{\alpha_{m}\left[1-\breve{y}_{m}^{2}(n)\right]^{2}\right\}
$$

Para obter uma relação entre $J_{\mathrm{RMA}}$ e $J_{\mathrm{MSE}}$, admite-se inicialmente que

A1) a razão sinal-ruído em regime é alta suficientemente para que $a_{\mathrm{R}}(n-\Delta)$ seja igual a um dos símbolos $a_{\ell, 1}$ ou $a_{\ell, 2}$ da região $A_{\ell}$ a que $y_{\mathrm{R}}(n)$ pertence. O mesmo se aplica para a parte imaginária. Em outras palavras, as regiões $A_{\ell}$ e $A_{m}$ contêm $a_{\mathrm{R}}(n-\Delta)$ e $a_{\mathrm{I}}(n-\Delta)$, respectivamente.

Com esta condição, define-se

$$
\breve{a}_{\ell}(n) \triangleq a_{\mathrm{R}}(n-\Delta)-c_{\ell}
$$

e

$$
\breve{a}_{m}(n) \triangleq a_{\mathrm{I}}(n-\Delta)-c_{m}
$$

Sob A1 e devido à translação para a origem da reta real, $\breve{a}_{\ell}(n)$ e $\breve{a}_{m}(n)$ sempre assumem um valor do conjunto $\{-1,+1\}$. Portanto,

$$
\breve{a}_{\ell}^{k}(n)=\breve{a}_{m}^{k}(n)=1, \quad \text { para } k \geq 0 \text { e par }
$$

e

$$
\mathrm{E}\left\{\breve{a}_{\ell}^{k}(n)\right\}=\mathrm{E}\left\{\breve{a}_{m}^{k}(n)\right\}=\left\{\begin{array}{ll}
1, & \text { para } k \geq 0 \text { e par } \\
0, & \text { para } k<0 \text { e ímpar }
\end{array} .\right.
$$


Para prosseguir, ainda é necessário considerar as seguintes suposições em regime:

A2) Os fatores de escala $\alpha_{\ell}$ e $\alpha_{m}$ são independentes de $\left[1-\breve{y}_{\ell}(n)\right]^{2}$ e $\left[1-\breve{y}_{m}(n)\right]^{2}$. Esta suposição exige essencialmente que as flutuações em regime dos erros quadráticos $\left[1-\breve{y}_{\ell}(n)\right]^{2}$ e $\left[1-\breve{y}_{m}(n)\right]^{2}$ sejam insensíveis a $\alpha_{\ell}$ e $\alpha_{m}$, respectivamente;

A3) A saída do equalizador adaptado com o RMA fica próxima daquela obtida com um equalizador supervisionado adaptado, por exemplo, com o algoritmo NLMS, cujos coeficientes são atualizados usando o erro (3.2). Esta suposição é razoável quando A1 for satisfeita em regime e o atraso $\Delta$ for o mesmo para ambas as estimativas dos equalizadores autodidata e supervisionado;

A4) Os termos $\left[a_{\mathrm{R}}(n-\Delta)+y_{\mathrm{R}}(n)-2 c_{\ell}\right]^{2}$ e $\left[a_{\mathrm{I}}(n-\Delta)+y_{\mathrm{I}}(n)-2 c_{m}\right]^{2}$ são independentes de $\xi_{\mathrm{R}}^{2}(n)$ e $\xi_{\mathrm{I}}^{2}(n)$, respectivamente;

A5) O centro da região $A_{\ell}$, isto é, $c_{\ell}$, é independente de $a_{\mathrm{R}}(n-\Delta)$ e $y_{\mathrm{R}}(n)$, o que implica na igualdade $\mathrm{E}\left\{c_{\ell} a_{\mathrm{R}}(n-\Delta)\right\}=\mathrm{E}\left\{c_{\ell} y_{\mathrm{R}}(n)\right\}=0$. O mesmo se aplica para $c_{m}$.

As suposições A3 e A4 são similares às feitas em [SUYAMA et al., 2003; BELLANGER, 2004].

Usando A2 e observando que $\mathrm{E}\left\{\alpha_{\ell}\right\}=\mathrm{E}\left\{\alpha_{m}\right\} \triangleq \bar{\alpha}$ para constelações QAM quadradas, a função custo (3.6) pode ser reescrita de forma aproximada em regime como

$$
J_{\mathrm{RMA}} \approx \bar{\alpha}\left[\mathrm{E}\left\{\left[1-\breve{y}_{\ell}(n)\right]^{2}\left[1+\breve{y}_{\ell}(n)\right]^{2}\right\}+\mathrm{E}\left\{\left[1-\breve{y}_{m}(n)\right]^{2}\left[1+\breve{y}_{m}(n)\right]^{2}\right\}\right] .
$$

Como $\breve{a}_{\ell}(n)= \pm 1$ e $\breve{a}_{m}(n)= \pm 1$, são obtidas as seguintes relações

$$
\left[1-\breve{y}_{\ell}(n)\right]^{2}\left[1+\breve{y}_{\ell}(n)\right]^{2}=\left[\breve{a}_{\ell}(n)-\breve{y}_{\ell}(n)\right]^{2}\left[\breve{a}_{\ell}(n)+\breve{y}_{\ell}(n)\right]^{2}
$$

e

$$
\left[1-\breve{y}_{m}(n)\right]^{2}\left[1+\breve{y}_{m}(n)\right]^{2}=\left[\breve{a}_{m}(n)-\breve{y}_{m}(n)\right]^{2}\left[\breve{a}_{m}(n)+\breve{y}_{m}(n)\right]^{2}
$$

Substituindo essas relações em (3.11), obtém-se

$$
J_{\mathrm{RMA}} \approx \bar{\alpha}\left[\mathrm{E}\left\{\left[\breve{a}_{\ell}-\breve{y}_{\ell}(n)\right]^{2}\left[\breve{a}_{\ell}+\breve{y}_{\ell}(n)\right]^{2}\right\}+\mathrm{E}\left\{\left[\breve{a}_{m}-\breve{y}_{m}(n)\right]^{2}\left[\breve{a}_{m}+\breve{y}_{m}(n)\right]^{2}\right\}\right] .
$$


Lembrando que $\xi_{\mathrm{R}}(n)=a_{\mathrm{R}}(n-\Delta)-y_{\mathrm{R}}(n)$, usando $\breve{y}_{\ell}(n)=y_{\mathrm{R}}(n)-c_{\ell}$, (3.7) e A3, obtém-se

$$
\breve{a}_{\ell}(n)-\breve{y}_{\ell}(n) \approx \xi_{\mathrm{R}}(n)
$$

e

$$
\breve{a}_{\ell}(n)+\breve{y}_{\ell}(n) \approx a_{\mathrm{R}}(n-\Delta)+y_{\mathrm{R}}(n)-2 c_{\ell} .
$$

Substituindo (3.13) e (3.14) em (3.12), usando A4 e a mesma aproximação para a parte imaginária, chega-se a

$$
\begin{aligned}
J_{\mathrm{RMA}} \approx & \bar{\alpha}\left[\mathrm{E}\left\{\xi_{\mathrm{R}}^{2}(n)\right\} \mathrm{E}\left\{\left[a_{\mathrm{R}}(n-\Delta)+y_{\mathrm{R}}(n)-2 c_{\ell}\right]^{2}\right\}\right. \\
& \left.+\mathrm{E}\left\{\xi_{\mathrm{I}}^{2}(n)\right\} \mathrm{E}\left\{\left[a_{\mathrm{I}}(n-\Delta)+y_{\mathrm{I}}(n)-2 c_{m}\right]^{2}\right\}\right] .
\end{aligned}
$$

Para constelações QAM quadradas vale

$$
\mathrm{E}\left\{c_{\ell}^{2}\right\}=\mathrm{E}\left\{c_{m}^{2}\right\} \triangleq \sigma_{c}^{2}
$$

$\mathrm{e}$

$$
\mathrm{E}\left\{\xi_{\mathrm{R}}^{2}(n)\right\}=\mathrm{E}\left\{\xi_{\mathrm{I}}^{2}(n)\right\}=0.5 J_{\mathrm{MSE}}(\mathbf{w}, \Delta)
$$

Portanto, o termo $0.5 J_{\mathrm{MSE}}(\mathbf{w}, \Delta)$ pode ser colocado em evidência em (3.15), o que leva, sob a suposição A5, à seguinte aproximação

$$
\mathrm{E}\left\{\left[a_{\mathrm{R}}(n-\Delta)+y_{\mathrm{R}}(n)-2 c_{\ell}\right]^{2}+\left[a_{\mathrm{I}}(n-\Delta)+y_{\mathrm{I}}(n)-2 c_{m}\right]^{2}\right\} \approx J_{\mathrm{MSE}}(-\mathbf{w}, \Delta)+8 \sigma_{c}^{2},
$$

Substituindo (3.16) em (3.15), chega-se a

$$
J_{\mathrm{RMA}} \approx 0.5 \bar{\alpha} J_{\mathrm{MSE}}(\mathbf{w}, \Delta)\left[J_{\mathrm{MSE}}(-\mathbf{w}, \Delta)+8 \sigma_{c}^{2}\right]
$$

Substituindo (3.3) em (3.17), derivando a expressão resultante em relação a w* $\mathbf{w}^{*}$ e igualando a derivada a zero, obtém-se finalmente

$$
\mathbf{w}_{\mathrm{RMA}} \approx \frac{\mathbf{w}_{\mathrm{RMA}}^{T} \mathbf{p}_{\Delta}^{*}+\mathbf{w}_{\mathrm{RMA}}^{H} \mathbf{p}_{\Delta}+4 \sigma_{c}^{2}}{\sigma_{a}^{2}+\mathbf{w}_{\mathrm{RMA}}^{H} \mathbf{R w}_{\mathrm{RMA}}+4 \sigma_{c}^{2}} \mathbf{w}_{\mathrm{WIE}} \cdot
$$

Observa-se a partir de (3.18) que $\mathbf{w}_{\mathrm{RMA}}$ e $\mathbf{w}_{\mathrm{WIE}}$ estão relacionados apenas por um fator de escala, em outras palavras, são colineares. Portanto, sob certas condições, a minimização da função custo (3.6) leva a uma solução colinear àquela da minimização da função custo (3.1). 
Para se certificar dessas observações, reescreve-se $(3.18)$ como $\mathbf{w}_{\mathrm{RMA}} \approx \psi \mathbf{w}_{\mathrm{WIE}}$. O escalar $\psi$ pode ser expresso em termos de $J_{\min }(\Delta)$ identificando-se (3.5) em (3.18), ou seja,

$$
\psi=\frac{2 \psi\left[\sigma_{a}^{2}-J_{\min }(\Delta)\right]+4 \sigma_{c}^{2}}{\sigma_{a}^{2}+\psi^{2}\left[\sigma_{a}^{2}-J_{\min }(\Delta)\right]+4 \sigma_{c}^{2}}
$$

Tal relação leva à seguinte equação cúbica em $\psi$

$$
\psi^{3}+\psi\left(\frac{\sigma_{a}^{2}+4 \sigma_{c}^{2}}{\sigma_{a}^{2}-J_{\min }(\Delta)}-2\right)-\frac{4 \sigma_{c}^{2}}{\sigma_{a}^{2}-J_{\min }(\Delta)}=0
$$

cujas raízes são expressões complicadas. Entretanto, considerando a seguinte aproximação

$$
\frac{\sigma_{a}^{2}}{\sigma_{a}^{2}-J_{\min }(\Delta)} \approx 1
$$

a raiz real de (3.20) se aproxima da unidade, e nesse caso, o RMA pode convergir, em média quadrática, para a a solução de Wiener. Tal fato permite que o desempenho em regime do RMA se aproxime daquele de um algoritmo supervisionado, independentemente da ordem da constelação QAM.

\subsection{A solução SBD e o receptor de Wiener}

A expressão da função custo do SBD, Equação (2.23), é repetida a seguir

$$
J_{\mathrm{SBD}}=\mathrm{E}\left\{\left|\hat{a}_{\mathrm{R}}(n)\right|\left[\hat{a}_{\mathrm{R}}(n)-y_{\mathrm{R}}(n)\right]^{2}+\left|\hat{a}_{\mathrm{I}}(n)\right|\left[\hat{a}_{\mathrm{I}}(n)-y_{\mathrm{I}}(n)\right]^{2}\right\} .
$$

Agora, para se obter uma relação entre $J_{\mathrm{SBD}}$ e $J_{\mathrm{MSE}}$, são utilizadas as seguintes suposições em regime:

A6) Não há erro nas decisões tomadas a partir da saída do equalizador, em outras palavras, $\hat{a}_{\mathrm{R}}(n)=a_{\mathrm{R}}(n-\Delta)$ e $\hat{a}_{\mathrm{I}}(n)=a_{\mathrm{I}}(n-\Delta) ;$

A7) $\left|a_{\mathrm{R}}(n-\Delta)\right|$ e $\left|a_{\mathrm{I}}(n-\Delta)\right|$ são independentes de $\xi_{\mathrm{R}}^{2}(n)$ e $\xi_{\mathrm{I}}^{2}(n)$ em regime. Essencialmente, esta suposição exige que as flutuações em regime em $\xi_{\mathrm{R}}^{2}(n)$ e $\xi_{\mathrm{I}}^{2}(n)$ sejam insensíveis a $\left|a_{\mathrm{R}}(n-\Delta)\right|$ e $\left|a_{\mathrm{I}}(n-\Delta)\right|$, respectivamente.

Usando A6 e A7, (3.22) pode ser aproximada em regime por

$$
J_{\mathrm{SBD}} \approx \mathrm{E}\left\{\left|a_{\mathrm{R}}(n)\right|\right\} \mathrm{E}\left\{\xi_{\mathrm{R}}^{2}(n)\right\}+\mathrm{E}\left\{\left|a_{\mathrm{I}}(n)\right|\right\} \mathrm{E}\left\{\xi_{\mathrm{I}}^{2}(n)\right\}
$$


Como $\mathrm{E}\left\{\left|a_{\mathrm{R}}(n)\right|\right\}=\mathrm{E}\left\{\left|a_{\mathrm{I}}(n)\right|\right\}=\sqrt{S} / 2$ para constelações $S$-QAM quadradas e usando (3.1), chega-se a

$$
J_{\mathrm{SBD}} \approx \frac{\sqrt{S}}{2} J_{\mathrm{MSE}}(\mathbf{w}, \Delta)
$$

o que leva a

$$
\mathrm{w}_{\mathrm{SBD}} \approx \mathrm{w}_{\mathrm{WIE}} \cdot
$$

Cabe observar que a aproximação (3.24) revela que $J_{\mathrm{SBD}}$ exibirá um ponto estacionário próximo da solução de Wiener. Porém esta aproximação decorre das suposições A6 e A7. Em especial, A6 é razoável somente quando a interferência intersimbólica é suficientemente baixa. Em outras palavras, o SBD deve mitigar suficientemente a interferência intersimbólica durante a fase transitória para permitir a convergência em média quadrática para solução de Wiener em regime.

\subsection{Conclusões}

Neste capítulo foram estabelecidas relações entre os algoritmos autodidatas propostos e a solução de Wiener. Verificou-se analiticamente que sob certas condições favoráveis do ponto de vista da equalização, tanto o RMA quanto o SBD apresentam soluções colineares com a solução de Wiener, independentemente da ordem da constelação QAM. Cabe notar que as relações (3.18) e (3.25) não asseguram a convergência em média quadrática das soluções RMA e SBD para a solução de Wiener, mas indicam que em condições favoráveis, a melhor solução alcançada é a do receptor de Wiener. Essa característica é particularmente importante após a convergência pois fornece informações acerca das possíveis soluções dos algoritmos autodidatas.

Em situações não favoráveis, os algoritmos propostos podem convergir para mínimos locais indesejados e apresentar uma convergência lenta. A velocidade de convergência depende da inicialização, do tipo de canal, da razão sinal-ruído, da ordem da constelação QAM, entre outros fatores. Outro problema que os algoritmos propostos podem enfrentar é a divergência. No capítulo seguinte são apresentados mecanismos para acelerar a convergência e também assegurar a estabilidade do RMA e do SBD. 


\section{Capítulo 4}

\section{Esquemas que aumentam a velocidade de convergência e evitam a}

\section{divergência}

Diversas questões devem ser levadas em conta na escolha de um algoritmo adaptativo. Em aplicações práticas de tempo-real, como a equalização, deseja-se que o algoritmo atinja o regime permanente o mais rápido possível, sempre volte a funcionar adequadamente após algum distúrbio e tenha uma boa capacidade para acompanhar variações do canal de comunicação. Essas características são conhecidas na literatura respectivamente como velocidade de convergência, robustez e capacidade de rastreio. Para um algoritmo ser robusto, não pode haver divergência, i.e., a norma do vetor de coeficientes deve permanecer sempre limitada, independentemente da precisão de sua representação numérica. Evitar a divergência de algoritmos com não-linearidades, como os de equalização autodidata, não é trivial.

Neste capítulo, são propostos esquemas para aumentar a velocidade de convergência e evitar a divergência dos algoritmos RMA e SBD. Inicialmente, mostra-se com simulações que o aumento da ordem da constelação influencia a velocidade de convergência desses algoritmos. Fato que também é observado no caso supervisionado. Por esse motivo, são apresentados esquemas que usam a informação da vizinhança do símbolo estimado para aumentar a velocidade de convergência dos algoritmos propostos. Além disso, são apresentadas condições 
para assegurar a convergência desses algoritmos.

\subsection{Simulações introdutórias}

A velocidade de convergência dos algoritmos de equalização baseados no gradiente estocástico sofre influência de vários fatores, como por exemplo, dificuldade de equalização do canal, razão sinal-ruído, inicialização, passo de adaptação, ordem da constelação, entre outros [HAYKIN, 2002; SAYED, 2008]. Esses fatores ainda podem fazer com que um dado algoritmo divirja, i.e., a norma de seu vetor de coeficientes pode tender a infinito.

A seguir, são mostrados alguns resultados de simulação para verificar a influência da ordem da constelação QAM na velocidade de convergência dos algoritmos NLMS, RMA e SBD. O algoritmo NLMS é usado aqui como referência, já que se deseja que os algoritmos propostos se comportem de maneira semelhante a ele. Em seguida, são mostrados resultados de simulação para ilustrar o problema da divergência do RMA.

\subsubsection{A velocidade de convergência e a ordem da constelação QAM}

A fim de avaliar a influência da ordem da constelação QAM na velocidade de convergência dos algoritmos de equalização, são considerados:

1. três constelações distintas: 64-QAM, 256-QAM e 1024-QAM;

2. o sistema de comunicação de tempo discreto conforme Figura 1.9 da página 18;

3. o canal de comunicação com função de transferência $H(z)=0,3+z^{-1}+0,3 z^{-2}$ e ausência de ruído;

4. um equalizador com $M=21$ coeficientes, operando na taxa de transmissão dos símbolos;

5. inicialização de todos os coeficientes com zero, exceto o central que é inicializado com "um" (center spike initialization); 
6. o erro quadrático médio em excesso (EMSE) ao longo das iterações como medida de desempenho; e

7. um filtro de média móvel com 500 coeficientes para facilitar a visualização das curvas de EMSE.

O EMSE é definido como a diferença entre o MSE do algoritmo e o valor mínimo obtido com a solução de Wiener, i.e., $J_{\min }(\Delta)$ (veja Apêndice A). Dessa forma, um algoritmo que atinge um EMSE baixo apresenta uma solução que varia pouco em torno da solução de Wiener. O EMSE foi escolhido aqui pois o MSE depende da potência do sinal transmitido e consequentemente o valor de MSE obtido com o NLMS varia conforme a constelação, o que dificulta a comparação em termos de velocidade de convergência.

O passo de adaptação do NLMS foi ajustado para que o mesmo EMSE em regime fosse atingido pelo algoritmo, independentemente da ordem da constelação QAM. Considera-se um atraso de $\Delta=11$ amostras, i.e., o sinal desejado usado no algoritmo NLMS é dado por $d(n)=a(n-\Delta)$. Na Figura 4.1, é mostrado o EMSE ao longo das iterações para as três constelações consideradas, estimado com uma média de conjunto de 100 realizações. Nos três casos o NLMS atinge um EMSE em regime em torno de -100 dB. É possível observar que a medida que a ordem da constelação aumenta, o número de iterações necessárias para que o algoritmo atinja o regime também aumenta, ou seja, menor é a sua velocidade de convergência. No caso, para 64-QAM, 256-QAM e 1024-QAM, foram necessárias $0,1 \times 10^{6}$, $0,4 \times 10^{6}$ e $2,3 \times 10^{6}$ iterações, respectivamente. Tal fato pode ser justificado da seguinte forma: mesmo com a informação exata da posição do símbolo da constelação no sinal desejado, a medida que a ordem da constelação aumenta, o algoritmo precisa de mais iterações para melhorar a qualidade de sua estimativa, já que a diversidade de símbolos do sinal transmitido é maior. Além disso, o valor do passo de adaptação associado a cada uma das constelações para atingir o mesmo patamar de EMSE também influencia o resultado. 


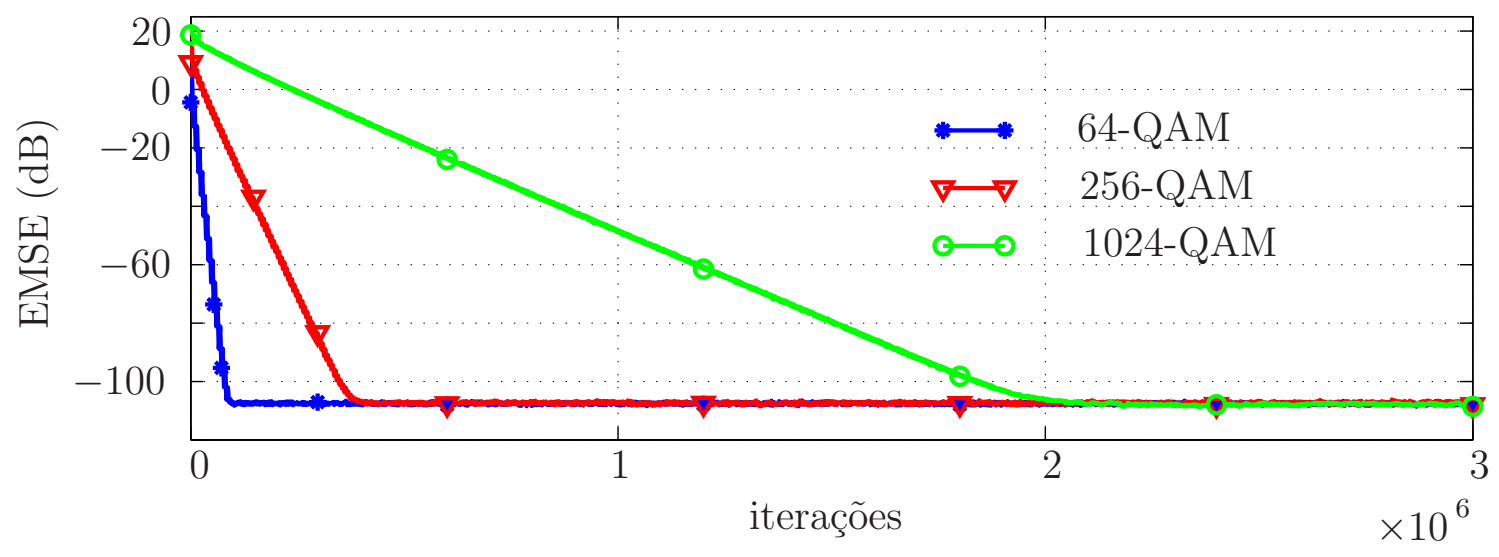

Figura 4.1: Erro quadrático médio em excesso do algoritmo NLMS, média de 100 realizações, $\mu_{64-\mathrm{QAM}}=2 \times 10^{-2}, \mu_{256-\mathrm{QAM}}=5 \times 10^{-3}$ e $\mu_{1024-\mathrm{QAM}}=1 \times 10^{-3}$.

Como no caso supervisionado, os passos de adaptação do RMA e SBD foram ajustados para cada constelação de modo a alcançar o mesmo EMSE em regime. As Figuras 4.2-(a) e 4.2-(b) mostram as curvas de EMSE do RMA e SBD respectivamente, levando-se em conta as três constelações. Para essas simulações, foi considerada apenas uma realização, já que o regime pode ser atingido depois de vários milhões de iterações, como se observa na Figura 4.2-(b) para o SBD, e em especial para 1024-QAM. Como no caso supervisionado com o NLMS, os algoritmos RMA e SBD atingem um EMSE em regime em torno de $-100 \mathrm{~dB}$, o que indica que eles convergem aproximadamente para a solução de Wiener, como observado analiticamente no Capítulo 3. Comparando com a Figura 4.1, a medida que a ordem da constelação QAM aumenta, os algoritmos autodidatas necessitam de um número de iterações muito maior para atingirem o regime. Essa convergência lenta pode ser justificada lembrando que no caso autodidata, com a ausência da resposta desejada, os algoritmos não possuem a informação exata da posição do símbolo transmitido. Assim, além de precisar de um número maior de iterações para obter uma estimativa de boa qualidade, os algoritmos autodidatas também precisam de informações adicionais para obter a posição do símbolo transmitido, principalmente nos casos em que essa estimativa está distante de $a(n-\Delta)$. Na Seção 4.2, são apresentados esquemas baseados na vizinhança do símbolo estimado para aumentar a velocidade de convergência dos algoritmos propostos. 

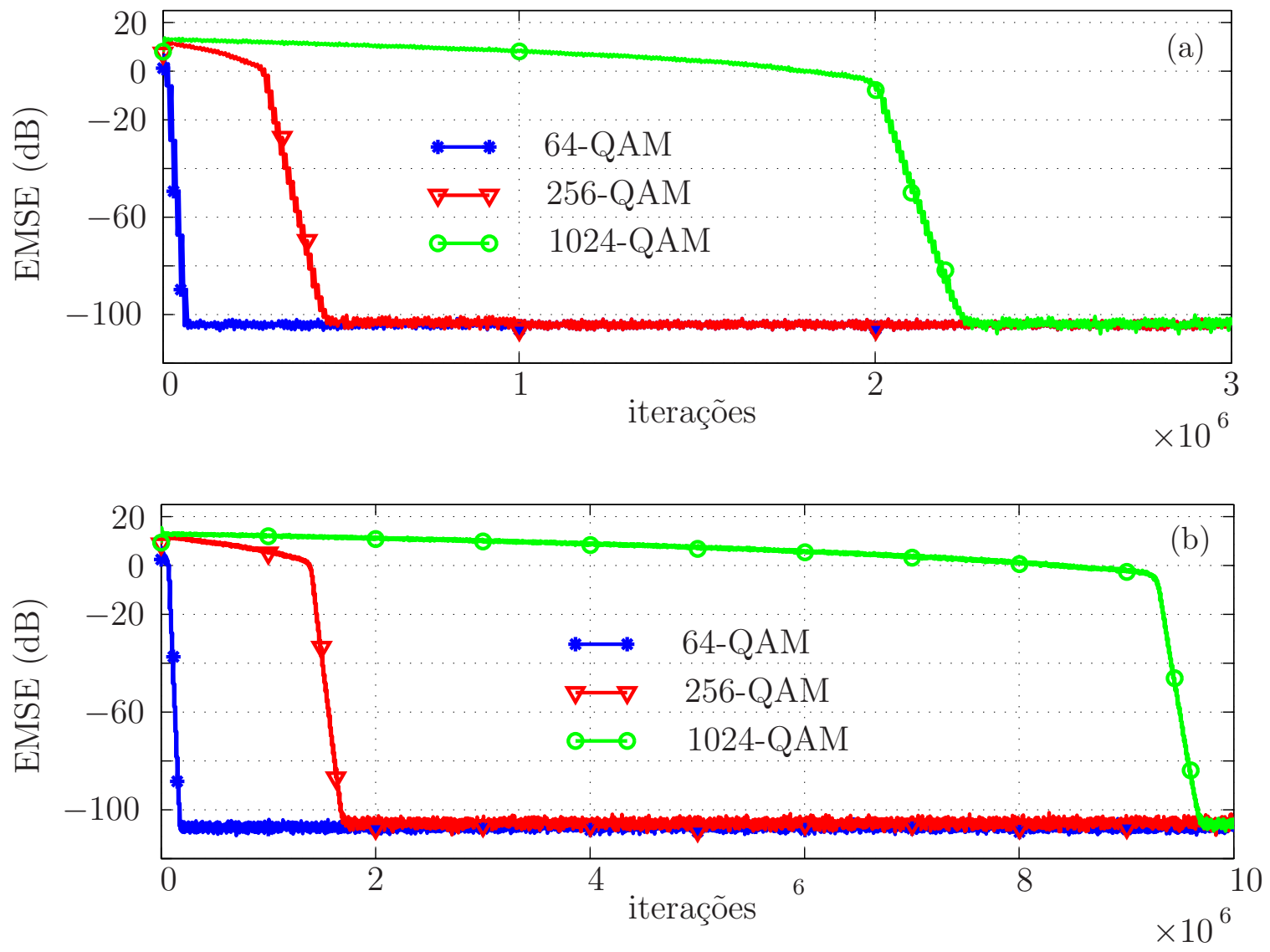

Figura 4.2: Erro quadrático em excesso, única realização; (a) algoritmo RMA, $\mu_{64-\mathrm{QAM}}=4 \times 10^{-3}, \mu_{256-\mathrm{QAM}}=6 \times 10^{-4}$ e $\mu_{1024-\mathrm{QAM}}=2 \times 10^{-4} ;$ (b) algoritmo $\mathrm{SBD}$, $\mu_{64-\mathrm{QAM}}=4 \times 10^{-3}, \mu_{256-\mathrm{QAM}}=7 \times 10^{-4}$ e $\mu_{1024-\mathrm{QAM}}=2,5 \times 10^{-4}$.

\subsubsection{A divergência do RMA}

É bem conhecido na literatura que uma escolha inadequada do passo de adaptação, uma inicialização distante da solução ótima e uma razão sinal-ruído baixa são fatores que podem levar algoritmos baseados no módulo constante como o CMA ou MMA à divergência [MIRANDA; SILVA; NASCIMENTO, 2008a, 2008b]. A maior sensibilidade desses algoritmos a esses fatores ocorre devido ao fato do erro de estimação ser uma função não-linear do sinal de saída do equalizador. Por exemplo, se em algum determinado instante de tempo o ruído for alto, o sinal de saída do equalizador pode atingir valores muito elevados. Como esse sinal aparece ao cubo no erro de estimação, a norma do vetor de coeficientes pode rapidamente ultrapassar o limite de representação numérica do sistema, levando o algoritmo à divergência. Como o 
RMA é baseado no módulo constante, ele também apresenta esse problema.

Para ilustrar essa característica, foi feita uma simulação com as condições 1 a 7 da subseção anterior, mas com passos de adaptação maiores, escolhidos de forma a induzir a divergência do RMA para as constelações 64-QAM, 256-QAM e 1024-QAM. Na Figura 4.3, são mostradas as curvas de EMSE ao longo das iterações para uma única realização. É possível observar que quanto maior a ordem da constelação, mais rápido o algoritmo diverge. Isso ocorre pois o sinal $y(n)$ aumenta com a ordem da constelação e consequentemente um distúrbio que não afetaria a equalização de um sinal 64-QAM pode afetar a de um sinal 1024-QAM.

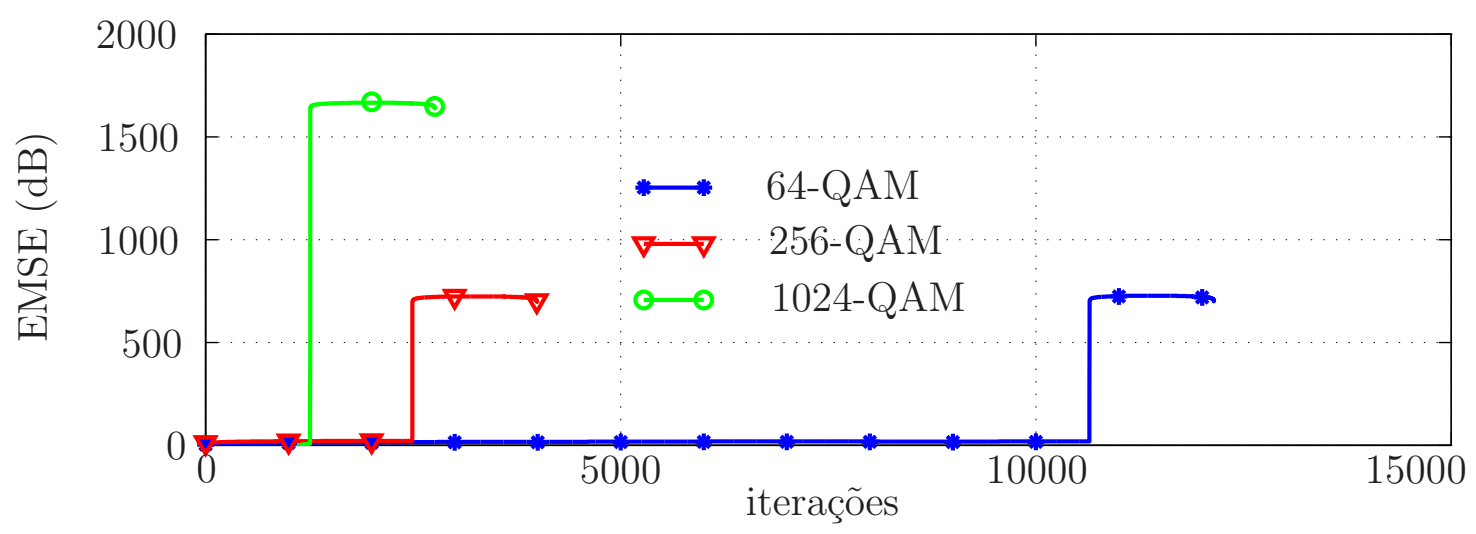

Figura 4.3: Erro quadrático em excesso do algoritmo RMA, única realização, sem mecanismo para evitar divergência, $\mu_{64-\mathrm{QAM}}=2,75 \times 10^{-2}, \mu_{256-\mathrm{QAM}}=1,5 \times 10^{-2}$ e $\mu_{1024-\mathrm{QAM}}=2,4 \times 10^{-3}$.

Não é simples encontrar uma forma de evitar a divergência de algoritmos baseados no módulo constante e que ainda assegure um bom desempenho. Uma solução que satisfaz esses dois requisitos foi encontrada em [MIRANDA; SILVA; NASCIMENTO, 2008a], em que se propôs uma versão normalizada do CMA com dois modos de operação. O algoritmo proposto em [MIRANDA; SILVA; NASCIMENTO, 2008a] descarta estimativas não-consistentes do sinal transmitido, o que faz com que ele consiga voltar a funcionar mesmo depois da existência de algum distúrbio.

Cabe observar que o erro de estimação do algoritmo SBD não usa o cubo do sinal de saída do equalizador. Além disso, o sinal de saída do decisor faz o papel do sinal desejado e o fator de escala pode ser incorporado ao passo de adaptação. Essas características sugerem 
que a forma de garantir sua convergência seja similar à do algoritmo NLMS.

Na Seção 4.3, é proposto um mecanismo para evitar a divergência do RMA, similar ao de [MIRANDA; SILVA; NASCIMENTO, 2008a]. No caso do SBD, os resultados da análise do NLMS são estendidos diretamente para obter o intervalo do passo de adaptação que garanta sua estabilidade.

\subsection{Aumentando a velocidade de convergência}

Grosso modo, pode-se dizer que a velocidade de convergência de um algoritmo está associada às informações que permitam obter uma boa estimativa do símbolo transmitido. Assim, inspirando-se em técnicas empregadas em algoritmos de classificação estatística [BISHOP, 2006], propõe-se usar os símbolos da constelação que estão próximos do símbolo estimado para ajudar o algoritmo autodidata a melhorar a qualidade da estimativa do símbolo transmitido e consequentemente a sua velocidade de convergência. Essa ideia levou a dois esquemas de baixo custo computacional, denominados de vizinhança Axial-1 e vizinhança Axial-2, que podem ser usados para aumentar a velocidade de convergência dos algoritmos propostos. A seguir, esses esquemas são apresentados no contexto do RMA e estendidos para o algoritmo SBD.

\subsubsection{A vizinhança no erro de estimação do RMA}

\section{Vizinhança Axial-1}

Na Figura 4.4, podem ser observadas quatro regiões da parte real de uma constelação 64-QAM. Se a parte real da saída do equalizador cair na região $A_{-1}$, as regiões $A_{-2}$ e $A_{1}$ são consideradas suas vizinhas e os seus símbolos podem ser usados de modo a auxiliar o RMA a aprender mais rapidamente a geometria da constelação QAM. Para isso, o erro usado na atualização do algoritmo é calculado considerando o erro devido à região principal e os erros provenientes das regiões vizinhas, multiplicados por fatores de ponderação. No cálculo do erro de uma região vizinha, tudo se passa como se a saída do equalizador pertencesse a essa região. Além disso, multiplica-se esse erro por um fator de ponderação, que é tanto 
menor quanto mais distante a região vizinha estiver da região principal. Assim, o erro da região principal sempre terá um peso maior no cálculo do erro total.

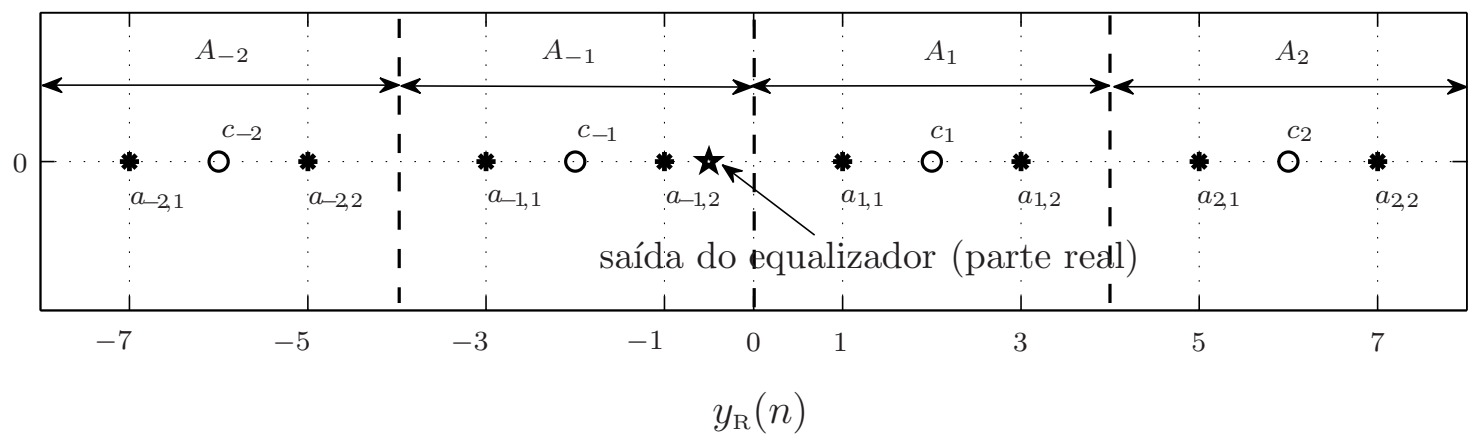

Figura 4.4: Regiões da parte real de uma constelação 64-QAM; o centro da região $A_{k}$ é representado por $c_{k}$ e $k= \pm 2, \pm 1$.

Para obter uma expressão do erro que incorpore a vizinhança, cabe lembrar que as regiões principais que contêm as partes real e imaginária da saída do equalizador são denotadas como $A_{\ell}$ e $A_{m}$, respectivamente. No caso em que são considerados apenas dois vizinhos de cada região principal, o erro do RMA é calculado levando em conta não somente as regiões principais $A_{\ell}$ e $A_{m}$, mas também as regiões $A_{\ell \pm 1}$ e $A_{m \pm 1}$ nas suas vizinhanças. Assim, a expressão do erro do RMA passa a ser dada por

$$
e_{\mathrm{RMA}}(n)=\sum_{k=\ell-1}^{\ell+1} \chi_{k} \alpha_{k}\left[1-\breve{y}_{k}^{2}(n)\right] \breve{y}_{k}(n)+j\left[\sum_{l=m-1}^{m+1} \chi_{l} \alpha_{l}\left[1-\breve{y}_{l}^{2}(n)\right] \breve{y}_{l}(n)\right],
$$

sendo $\breve{y}_{k}(n)=y_{\mathrm{R}}(n)-c_{k}$ e $\breve{y}_{l}(n)=y_{\mathrm{I}}(n)-c_{l}$ versões transladadas das partes real e imaginária da estimativa do sinal transmitido e $\chi_{k}$ e $\chi_{l}$ os fatores de ponderação, escolhidos experimentalmente como

$$
\chi_{k}=\frac{15}{16} \delta_{k \ell}+\frac{1}{16}
$$

e

$$
\chi_{l}=\frac{15}{16} \delta_{l m}+\frac{1}{16}
$$

com

$$
\delta_{k_{1} k_{2}}= \begin{cases}1, & \text { se } k_{1}=k_{2} \\ 0, & \text { caso contrário }\end{cases}
$$


o delta de Kronecker. Com essa ponderação, o erro de uma região principal $(k=\ell$ ou $l=m)$ tem peso igual a "um" no erro total e o erro de uma região vizinha ( $k=\ell \pm 1$ ou $l=m \pm 1)$ tem peso igual ao inverso do quadrado da distância entre os centros das regiões vizinha e principal.

É importante observar que se $A_{\ell}$ e $A_{m}$ forem uma das regiões de borda da constelação ( $\ell, m= \pm 2$ no caso de 64-QAM), haverá apenas vizinhos internos. Além disso, para obter um bom desempenho quando a ordem da constelação QAM é elevada, pode ser necessário incluir mais vizinhos. Neste caso, algumas regiões vizinhas podem não ser adjacentes à região principal, fazendo fronteira apenas com outra região vizinha. A partir de simulações, observou-se que dois vizinhos para a parte real e dois para a parte imaginária são suficientes para a maioria das constelações quadradas (de 64 a 1024-QAM). Porém, no caso de 4096-QAM, a velocidade de convergência só aumenta razoavelmente quando são utilizados quatro vizinhos para a parte real e quatro para a parte imaginária.

A utilização dos vizinhos no RMA faz com que sua função de erro (veja Figura 2.6 da página 43) sofra uma distorção. Para se ter uma ideia da distorção causada pela vizinhança, a parte real do erro (4.1) em função de $y_{\mathrm{R}}(n)$ é mostrada na Figura 4.5-(a) para 64-QAM e na Figura 4.5-(b) para 256-QAM. Cada curva de erro foi normalizada por um fator $K$ (indicado na legenda da figura) para que o máximo no intervalo de $y_{\mathrm{R}}(n)$ fosse sempre igual a "um". É possível observar nessas figuras que a vizinhança faz com que a função de erro do RMA deixe de apresentar zeros nas coordenadas dos símbolos da constelação. Em contrapartida, a função de erro passa a ter uma envoltória que lembra o erro de estimação do MMA, cujo gráfico para 256-QAM está mostrado na Figura 4.5-(b). Como o MMA apresenta uma velocidade de convergência que em geral é maior que a de outros algoritmos autodidatas para equalização de sinais QAM, conjectura-se que a maior velocidade do RMA com o esquema Axial-1 ocorra devido à envoltória que aparece na função de erro. Observa-se que os vizinhos fornecem de alguma forma uma estimativa do fator de dispersão $r_{2}$ do MMA, que por sua vez, contém informações estatísticas dos símbolos da constelação. Embora possa haver um aumento na velocidade de convergência com esse esquema, o desempenho do algoritmo em termos de MSE em regime é prejudicado. Essa característica sugere que os pesos dos erros 
dos vizinhos sejam alterados. A questão que surge é: "Como alterar os pesos dos erros da vizinhança para fazer com que o RMA apresente uma rápida velocidade de convergência e sua função de erro continue apresentando zeros próximos das coordenadas dos símbolos da constelação?" Uma possível resposta a essa pergunta é baseada em um outro esquema de vizinhança apresentado a seguir.
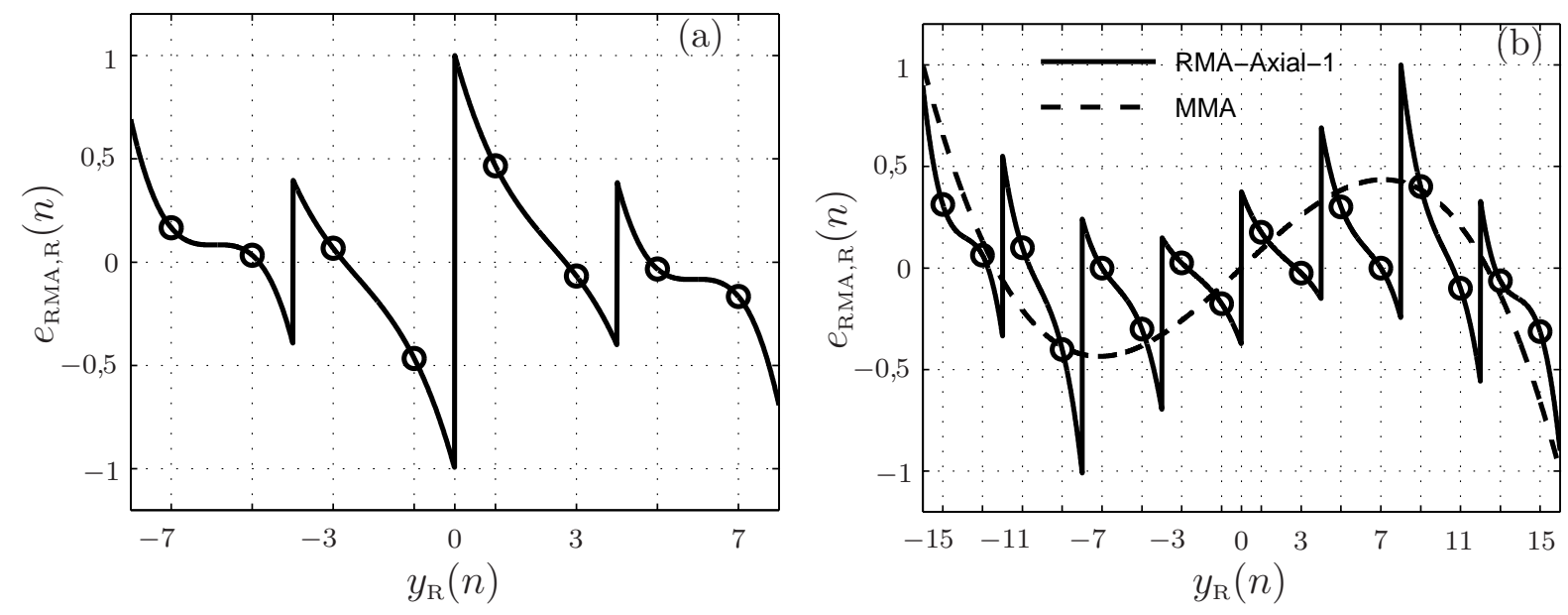

Figura 4.5: Parte real do erro do RMA em função de $y_{\mathrm{R}}(n)$ para (a) 64-QAM $(K=90)$ e (b) 256-QAM $(K=239,43)$ segundo o esquema de vizinhança Axial-1. A parte real do erro do MMA $(K=1660,80)$ para 256-QAM é mostrada apenas para referência. Os erros nas coordenadas dos símbolos da constelação são indicados por o.

\section{Vizinhança Axial-2}

O esquema de vizinhança Axial-2 é baseado na divisão do plano complexo em $S / 4$ regiões quadradas, cada uma contendo quadro símbolos da constelação, como ilustrado na Figura 4.6 para 64-QAM. Admitindo que a saída do equalizador encontra-se na região $A_{\ell, m}$, as quatro regiões $A_{\ell+1, m}, A_{\ell-1, m}, A_{\ell, m+1}$, e $A_{\ell, m-1}$ são consideradas suas vizinhas. Cabe observar que o centro de uma dada região $A_{k, l}$ é denotado como $c_{k, l}=c_{k}+j c_{l}$. Para ilustrar, supõe-se na Figura 4.6 que $\ell=m=1$. Como no caso anterior, além de calcular o erro na região principal, ele é calculado em cada uma das regiões vizinhas. Descreve-se a seguir apenas o cálculo da parte real do erro total, já que o cálculo de sua parte imaginária é similar. 


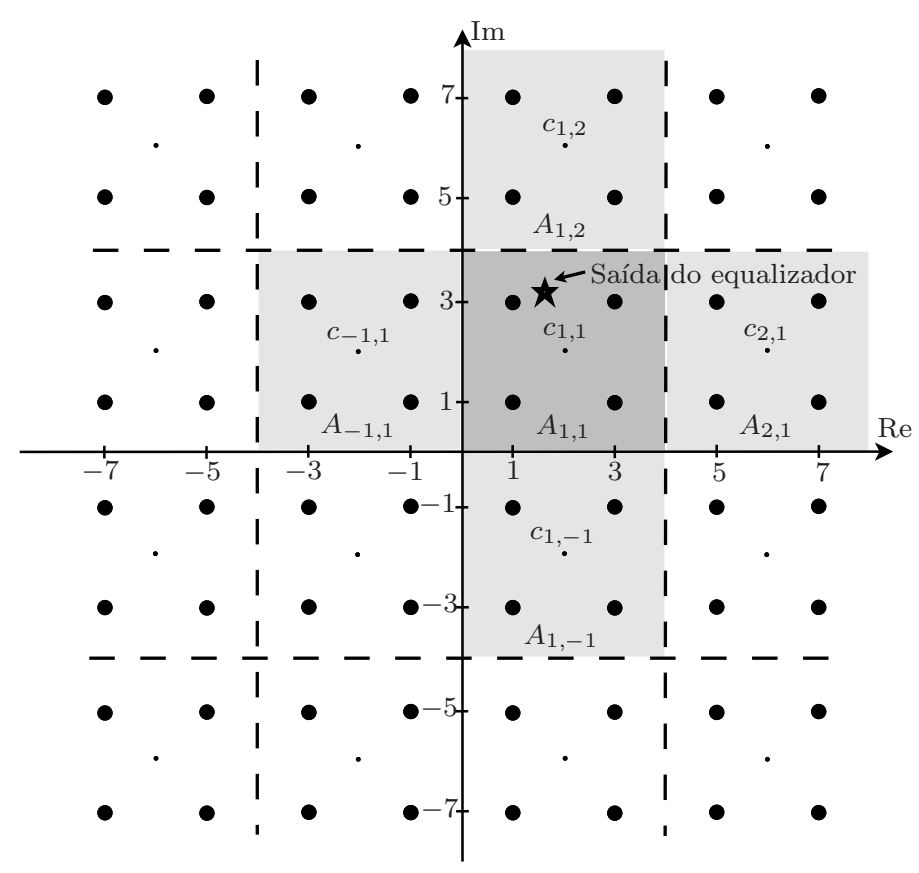

Figura 4.6: Esquema de vizinhança Axial-2 com quatro vizinhos para o RMA em uma constelação 64-QAM.

Levando em conta quatro vizinhos como na Figura 4.6, a parte real do erro total é composta de apenas três erros, ou seja,

- o erro da região principal $A_{\ell, m}$, i.e.,

$$
c_{\ell}\left[1-\breve{y}_{\ell}^{2}(n)\right] \breve{y}_{\ell}(n)
$$

em que $\breve{y}_{\ell}(n)=y_{\mathrm{R}}(n)-c_{\ell}$. Esse erro é igual à parte real do erro das regiões vizinhas $A_{\ell, m+1}$ e $A_{\ell, m-1}$, localizadas acima e abaixo da região principal, respectivamente. Embora esse erro apareça três vezes na parte real do erro total, sua ponderação é diferente, i.e., ele aparece uma vez ponderado por "um", que corresponde à ponderação do erro da região principal e duas vezes ponderado por 1/16 devido às regiões vizinhas;

- o erro da região $A_{\ell+1, m}$, à direita da principal, ou seja,

$$
c_{\ell+1}\left[1-\breve{y}_{\ell+1}^{2}(n)\right] \breve{y}_{\ell+1}(n)
$$

ponderado por $1 / 16$; e 
- o erro da região $A_{\ell-1, m}$, à esquerda da principal, ou seja,

$$
c_{\ell-1}\left[1-\breve{y}_{\ell-1}^{2}(n)\right] \breve{y}_{\ell-1}(n),
$$

que também é ponderado por 1/16.

Comparando com o esquema de vizinhança anterior, é possível observar que todos os erros calculados no esquema Axial-2 já apareciam no erro total do Axial-1, a diferença está apenas no fator de ponderação dado ao erro da região principal. Levando em conta quatro vizinhos como na Figura 4.6, a expressão do erro total segundo o esquema Axial-2 também é dada por (4.1), mas os fatores de ponderação passam a valer

$$
\chi_{k}=\frac{17}{16} \delta_{k \ell}+\frac{1}{16}
$$

$\mathrm{e}$

$$
\chi_{l}=\frac{17}{16} \delta_{l m}+\frac{1}{16}
$$

Essa pequena diferença é responsável por uma mudança na função de erro que pode possibilitar um aumento ainda maior na velocidade de convergência do RMA e um MSE em regime menor que no caso Axial-1. A parte real do erro (4.1) em função de $y_{\mathrm{R}}(n) \operatorname{com} \chi_{k}$ dado por (4.5) é mostrada na Figura 4.7-(a) para 64-QAM e na Figura 4.7-(b) para 256-QAM. Comparando com a Figura 4.5, verifica-se que no caso de 64-QAM praticamente não há diferença. Porém para 256-QAM, o esquema Axial-2 faz com que o erro nas coordenadas dos símbolos da constelação fique mais próximo de zero que no esquema Axial-1. Além disso, é possível identificar uma envoltória que lembra a função de erro do MMA.

Como no esquema Axial-1, regiões vizinhas que não fazem fronteira com a região principal também podem ser consideradas, desde que o peso dado ao erro seja inversamente proporcional ao quadrado da distância entre o centro da região vizinha e o centro da região principal. A utilização de mais regiões pode levar a uma forma ainda mais adequada da função de erro que a da Figura 4.7-(b). No entanto, nas simulações desta tese com o esquema Axial-2, serão consideradas apenas quatro regiões vizinhas, independentemente da ordem da constelação QAM. Pretende-se abordar esse assunto com mais profundidade em um trabalho futuro. A seguir os esquemas de vizinhança propostos são estendidos para o algoritmo SBD. 

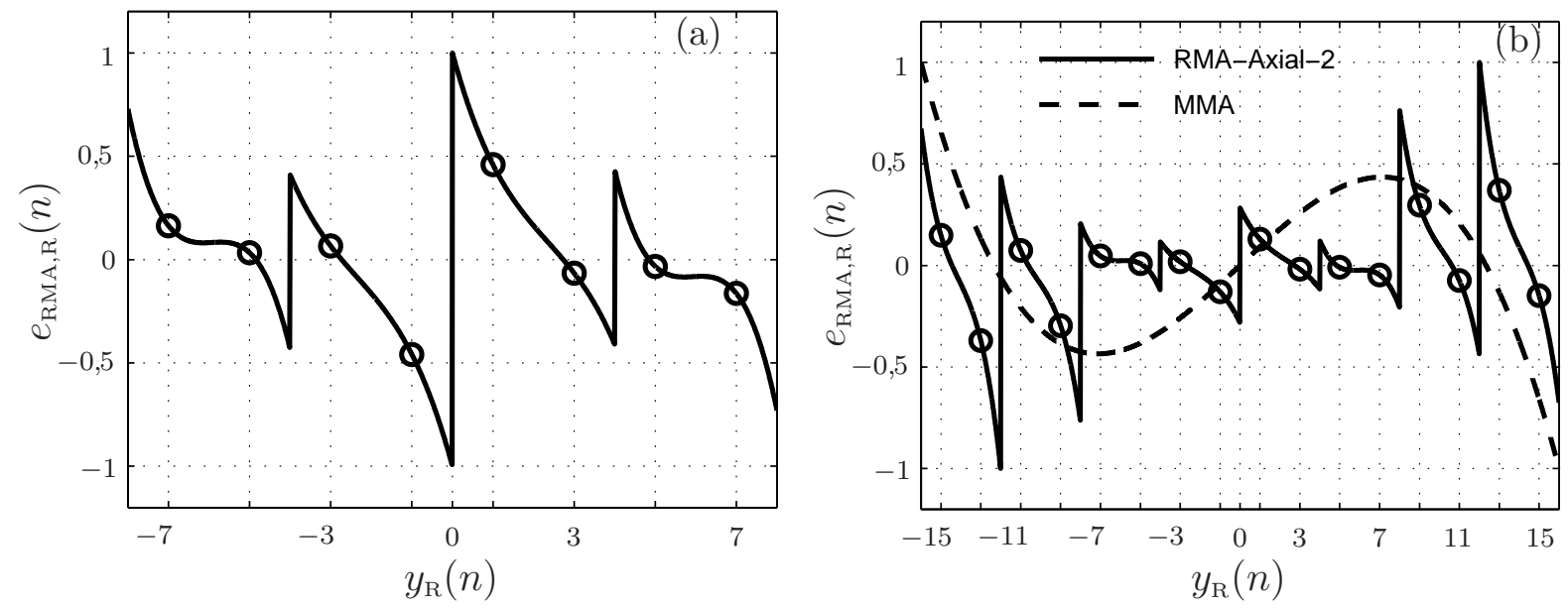

Figura 4.7: Parte real do erro do RMA em função de $y_{\mathrm{R}}(n)$ para (a) 64-QAM $(K=91,5)$ e (b) 256-QAM $(K=324,01)$ segundo o esquema de vizinhança Axial-2. A parte real do erro do MMA $(K=1660,80)$ para 256-QAM é mostrada apenas para referência. Os erros nas coordenadas dos símbolos da constelação são indicados por o.

\subsubsection{A vizinhança no erro de estimação do SBD}

Os esquemas de vizinhança propostos para o RMA podem ser estendidos para o algoritmo SBD a fim de acelerar sua convergência. A diferença é que no caso do SBD cada região é constituída somente pela coordenada de um símbolo. Na Figura 4.8, são mostradas as regiões da parte real de uma constelação 64-QAM, admitindo novamente que a saída do equalizador está em $A_{-1}$.

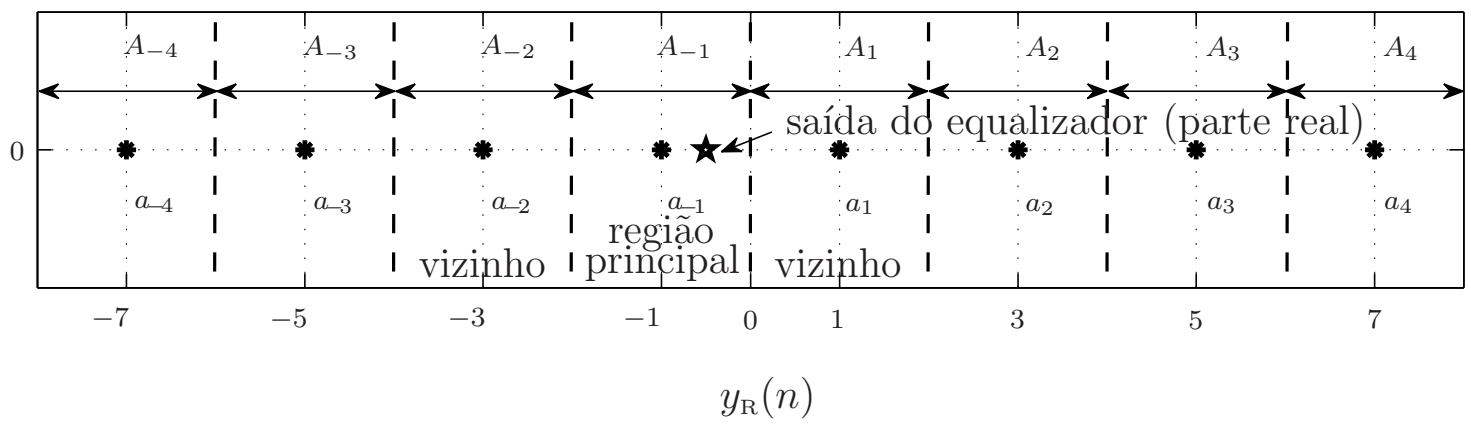

Figura 4.8: Regiões da parte real de 64-QAM para o algoritmo SBD.

Denotando a coordenada do símbolo da constelação em uma dada região $A_{k}$ por $a_{k}$ no esquema Axial-1 e em uma dada região $A_{k, l}$ por $a_{k, l}=a_{k}+j a_{l}$ no esquema Axial-2, o erro 
de estimação do SBD segundo esses esquemas de vizinhança é dado por

$$
e_{\mathrm{SBD}}(n)=\sum_{k=\ell-1}^{\ell+1} \chi_{k}\left|a_{k}\right|\left[a_{k}-y_{\mathrm{R}}(n)\right]+j\left[\sum_{l=m-1}^{m+1} \chi_{l}\left|a_{l}\right|\left[a_{l}-y_{\mathrm{I}}(n)\right]\right] .
$$

No SBD as distâncias entre os centros de duas regiões adjacentes é igual a dois. Por isso, no esquema Axial-1, os fatores de ponderação foram escolhidos como

$$
\chi_{k}=\frac{3}{4} \delta_{k \ell}+\frac{1}{4} \quad \text { e } \quad \chi_{l}=\frac{3}{4} \delta_{l m}+\frac{1}{4} .
$$

No esquema Axial-2, o plano complexo é dividido em $S$ regiões contendo um único símbolo da constelação como mostrado na Figura 4.9 para 64-QAM e os fatores de ponderação são dados por

$$
\chi_{k}=\frac{5}{4} \delta_{k \ell}+\frac{1}{4} \quad \text { e } \quad \chi_{l}=\frac{5}{4} \delta_{l m}+\frac{1}{4} .
$$

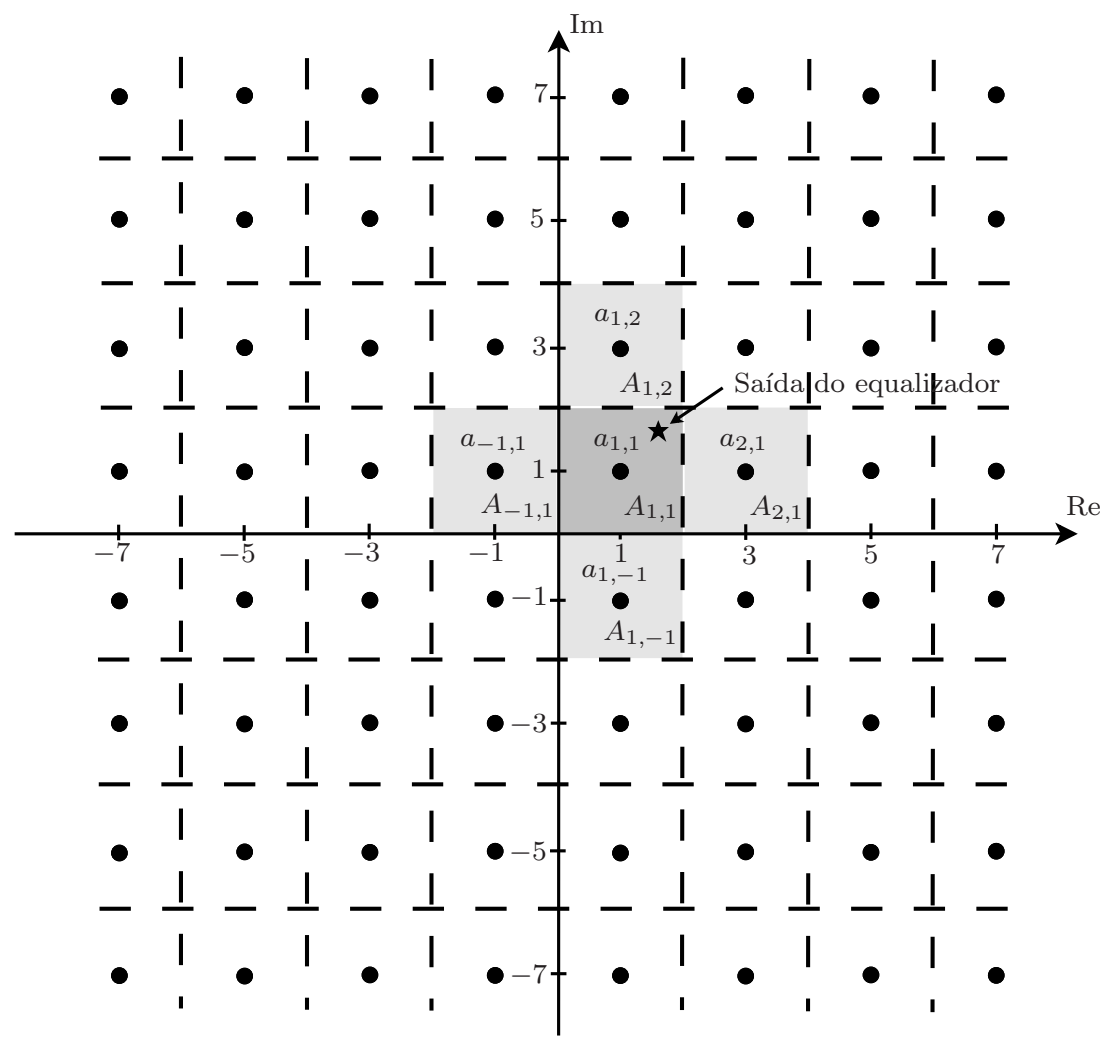

Figura 4.9: Esquema de vizinhança Axial-2 com quatro vizinhos para o SBD em uma constelação 64-QAM. 
O efeito desses esquemas na forma da função de erro do algoritmo SBD é mostrado na Figura 4.10. Novamente, os vizinhos fazem com que os zeros da função de erro deixem de coincidir com as coordenadas dos símbolos da constelação. No entanto, esse efeito é mais suave no SBD que no RMA. Como no RMA, o esquema Axial-2 não tem muito efeito para 64-QAM em relação ao Axial-1. No entanto para 256-QAM, ele faz com que a função de erro volte a se aproximar de zero nas coordenadas de todos os símbolos. Em especial, é possível observar esse efeito para os símbolos \pm 15 . Para comparação, a função de erro do MMA para 256-QAM é mostrada na figura. Nota-se novamente que há uma "envoltória" no erro do SBD com os esquemas de vizinhança que lembra a envoltória do erro do MMA.
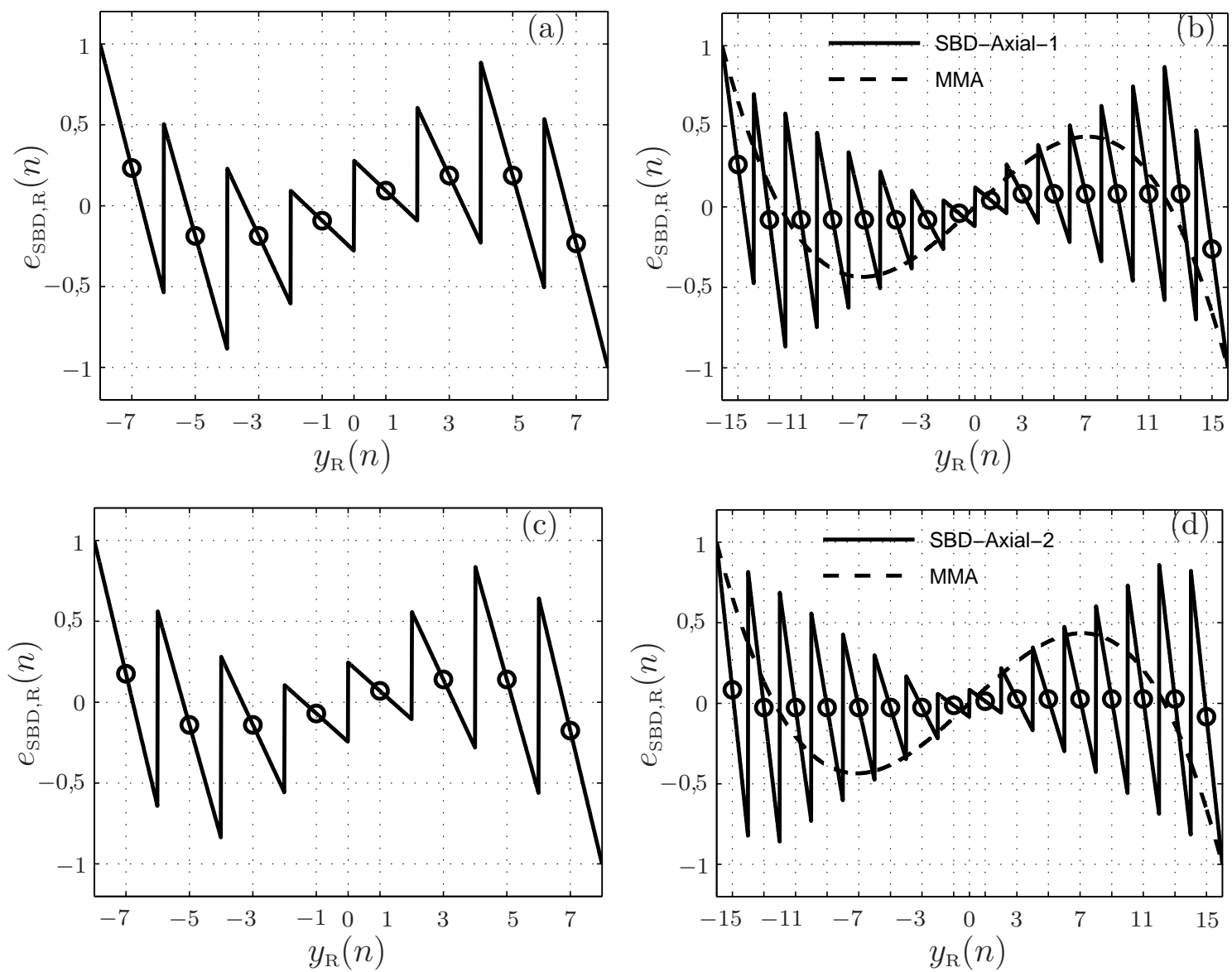

Figura 4.10: Parte real do erro do SBD em função de $y_{\mathrm{R}}(n)$ considerando o esquema Axial-1: (a) 64-QAM $(K=10,75)$ e (b) 256-QAM $(K=24,75)$; e o esquema Axial-2: (c) 64-QAM $(K=14,25)$ e $($ d) 256 -QAM $(K=19,31)$. A parte real do erro do MMA $(K=1660,80)$ para 256-QAM é mostrada apenas para referência. Os erros nas coordenadas dos símbolos da constelação são indicados por o. 


\subsubsection{Descartando a vizinhança}

A velocidade de convergência do RMA e do SBD aumenta com a ajuda dos vizinhos. Entretanto, o MSE em regime também aumenta devido aos erros dos vizinhos somados ao erro principal em cada instante de tempo. Por essa razão, é interessante desconsiderar a ajuda dos vizinhos quando os algoritmos atingem o regime. Assim, em vez de ponderar os erros dos vizinhos com um valor fixo, pode ser mais interessante ponderá-los com uma função que varie no tempo.

Considerando o esquema de vizinhança Axial-1, propõem-se

$$
\chi_{k}(n)=\left[1-b^{p(n)}\right] \delta_{k \ell}+b^{p(n)}
$$

e

$$
\chi_{l}(n)=\left[1-b^{p(n)}\right] \delta_{l m}+b^{p(n)}
$$

e para o esquema Axial-2

$$
\chi_{k}(n)=\left[1+b^{p(n)}\right] \delta_{k \ell}+b^{p(n)}
$$

e

$$
\chi_{l}(n)=\left[1+b^{p(n)}\right] \delta_{l m}+b^{p(n)}
$$

em que $b=1 / 16$ para o RMA e $b=1 / 4$ para o SBD. O expoente $p(n)$ é dado pela seguinte função não-linear

$$
p(n)=7,1467 \frac{\exp [8(\bar{\xi}(n)-0,03)]-1}{\exp [8(\bar{\xi}(n)-0,03)]+1}-9,1467,
$$

em que $\bar{\xi}(n)=\lambda \bar{\xi}(n-1)+(1-\lambda)|\hat{a}(n-\Delta)-y(n)|^{2}$ é uma estimativa do valor médio do erro de decisão ao quadrado e $0 \ll \lambda<1$ é um fator de esquecimento. Essa função força $p(n)$ a ficar no intervalo $-10 \leq p(n) \leq-2$. Assim, quanto menor o MSE, menor será o valor do expoente $p(n)$ e consequentemente menor será o peso dado aos vizinhos. Essa função foi obtida experimentalmente e é mostrada na Figura 4.11-(a). Na Figura 4.11-(b) é mostrada a "medida" da influência dos vizinhos de forma ilustrativa. Ou seja, quanto maior o valor 
de $\bar{\xi}(n)$, maior é a influência dos vizinhos e vice-versa. Quando o nível de MSE se reduz de tal forma que os vizinhos não mais contribuem para a convergência, estes podem ser descartados completamente, sendo essa possibilidade de comutação também mostrada nessa figura. É importante observar que a comutação efetuada nessa hora melhora o MSE, pois a convergência já deve ter sido atingida e a exclusão do erro dos vizinhos melhora a estimativa do erro do algoritmo. Além disso, de acordo com as simulações realizadas essa comutação não causa nenhuma degradação para a recuperação do sinal transmitido. A Figura 4.11-(c) mostra, também de forma ilustrativa, a "medida" de abertura do padrão de olho em função de $\bar{\xi}(n)$. Quando o MSE é elevado, no início da convergência, o padrão de olho encontra-se fechado. Ao término da convergência espera-se que o MSE seja mínimo e que o padrão de olho encontre-se aberto. Com os fatores de ponderação que variam no tempo, os vizinhos são dispensados quando os algoritmos atingem o regime e nesse caso, os algoritmos voltam a utilizar as funções de erro que apresentam zeros nas coordenadas dos símbolos da constelação, o que possibilita aos mesmos atingir a solução de Wiener como visto no Capítulo 3.
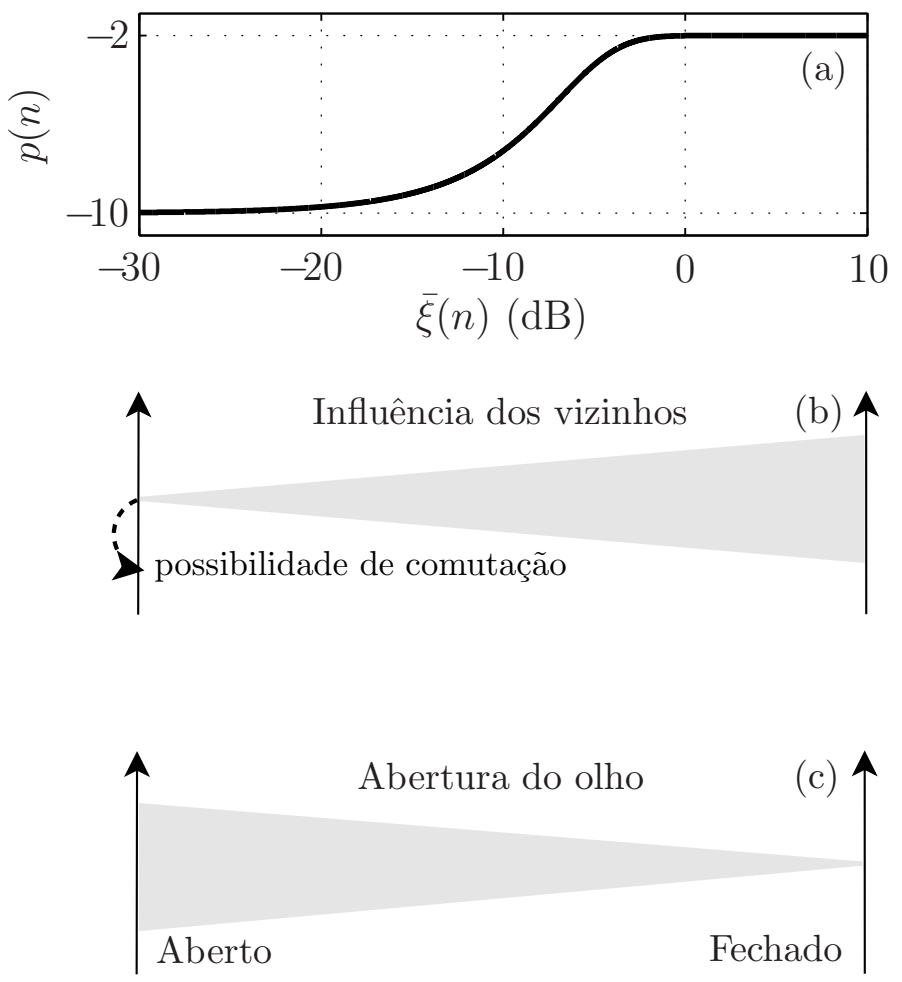

Figura 4.11: (a) o expoente $p(n)$ em função de $\bar{\xi}(n)$; (b) "medida" da influência dos vizinhos em função de $\bar{\xi}(n)$; (c) "medida" da abertura do olho em função de $\bar{\xi}(n)$. 


\subsubsection{O efeito dos esquemas Axial-1 e Axial-2 na convergência}

De forma a verificar a contribuição dos vizinhos na convergência dos algoritmos RMA e SBD, as simulações da Seção 4.1.1 foram repetidas sob as condições 1 a 7, levando em conta os dois esquemas de vizinhança e a ponderação variante no tempo da Seção 4.2.3. Os resultados das simulações são exibidos na Figura 4.12 para o RMA e na Figura 4.13 para o SBD. Dos resultados das Figuras 4.12 e 4.13 e independentemente do tipo de vizinhança utilizada, observa-se que há um aumento na velocidade de convergência com a utilização do mecanismo que considera os vizinhos em relação à convergência sem tal auxílio. Esse aumento é mais evidente à medida em que a ordem da constelação aumenta. Para constelações menores como 64-QAM o ganho não é tão expressivo quanto para 256-QAM e 1024-QAM. Nesses dois últimos casos, os números de iterações para convergência sem vizinhos e com os esquemas Axial-1 e Axial-2 são mostrados na Tabela 4.1.

Tabela 4.1: Número de iterações para convergência.

\begin{tabular}{|c|c|c|c|c|c|c|}
\hline & \multicolumn{2}{|c|}{ Sem vizinhos } & \multicolumn{2}{c|}{ Axial 1 } & \multicolumn{2}{c|}{ Axial 2} \\
\hline Constelação & RMA & SBD & RMA & SBD & RMA & SBD \\
\hline 256-QAM & $5,0 \times 10^{5}$ & $1,7 \times 10^{6}$ & $2,0 \times 10^{5}$ & $8,0 \times 10^{5}$ & $2,0 \times 10^{5}$ & $8,0 \times 10^{5}$ \\
\hline 1024-QAM & $2,3 \times 10^{6}$ & $9,0 \times 10^{6}$ & $1,6 \times 10^{6}$ & $2,1 \times 10^{6}$ & $1,0 \times 10^{6}$ & $2,0 \times 10^{6}$ \\
\hline
\end{tabular}

No caso do RMA para equalização de 1024-QAM, é possível observar na Figura 4.12 que as curvas de EMSE apresentam um decaimento significativo antes de atingir o patamar de regime. Por exemplo, o RMA sem vizinhos atinge um EMSE de $-50 \mathrm{~dB}$ próximo da iteração $2,1 \times 10^{6}$, enquanto com o esquema Axial-1, ele atinge esse mesmo valor na iteração $0,8 \times 10^{5}$ e com o esquema Axial-2 na iteração $0,65 \times 10^{5}$. Ainda dos resultados obtidos das curvas das Figuras 4.12 e 4.13, verifica-se que a utilização da vizinhança Axial-2 pode ser melhor que a utilização da vizinhança Axial-1, produzindo um ganho relativo na velocidade de convergência em algumas situações. Entretanto, essa comparação é válida para o cenário de simulação apresentado, podendo ser diferente sob outras condições. Cabe observar que a convergência ainda é lenta, entretanto, a utilização de mais vizinhos, outros esquemas 
de vizinhança e/ou demais mecanismos que acelerem a convergência podem ser usados para sinais de ordem mais elevada. Isso se justifica, já que o aumento da eficiência da comunicação decorrente da utilização de constelações de alta ordem compensa um eventual acréscimo no custo computacional.
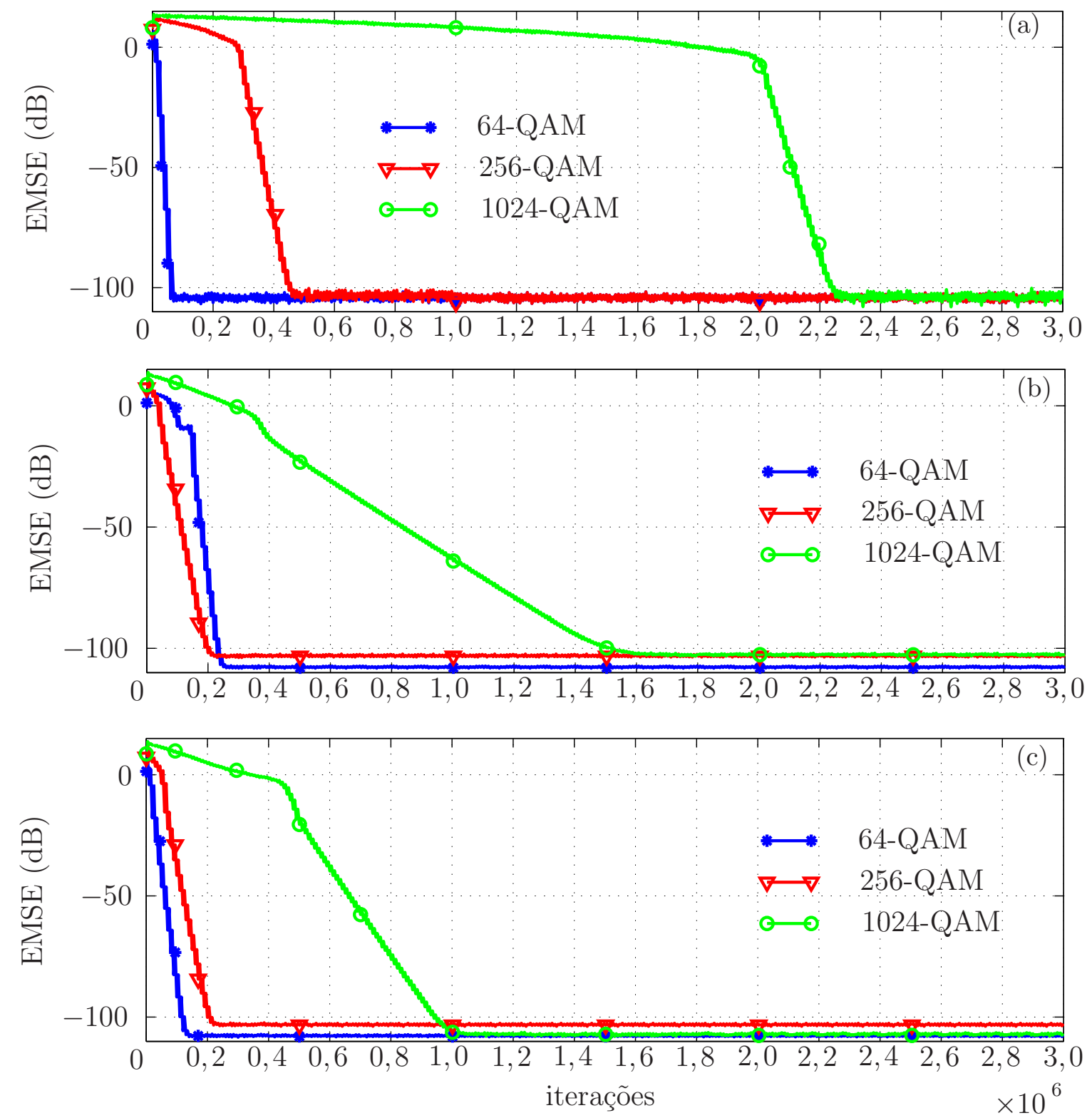

Figura 4.12: EMSE para o RMA, média de conjunto de 20 realizações. (a) Sem vizinhos (repetição da Figura (4.2)-(a)); (b) vizinhança Axial-1, (c) vizinhança Axial-2, $\mu_{64-\mathrm{QAm}}=$ $1,8 \times 10^{-3}, \mu_{256-\mathrm{QAM}}=6 \times 10^{-4}$ e $\mu_{1024-\mathrm{QAM}}=9 \times 10^{-5}$. 

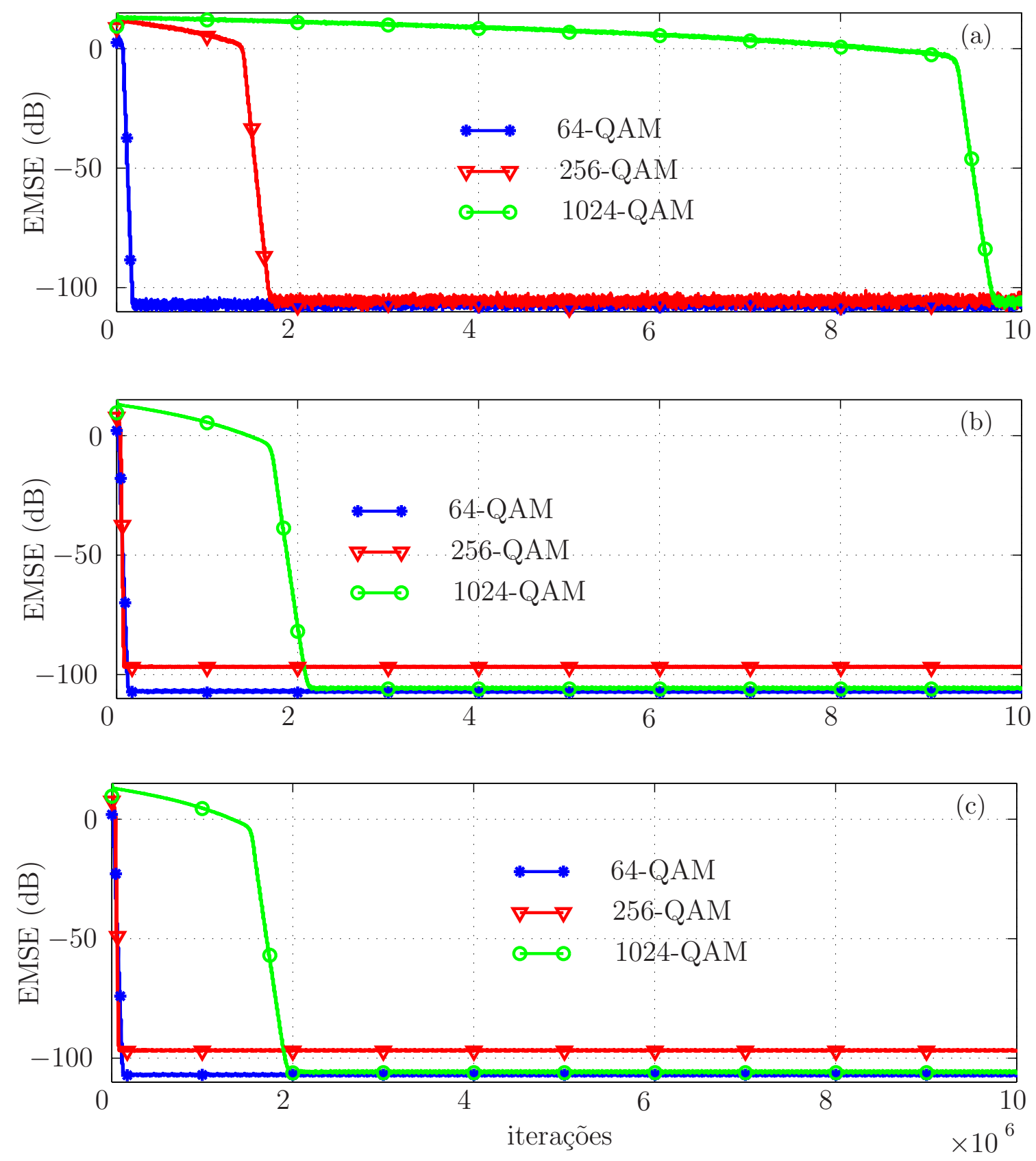

Figura 4.13: EMSE para o SBD, média de conjunto de 20 realizações. (a) sem vizinhos (repetição da Figura (4.2)-(b)); (b) vizinhança Axial-1, (c) vizinhança Axial-2; $\mu_{64-\mathrm{QAm}}=$ $4 \times 10^{-3}, \mu_{256-\mathrm{QAM}}=5 \times 10^{-3}$ e $\mu_{1024-\mathrm{QAM}}=2,5 \times 10^{-4}$. 


\subsection{Sobre a convergência do SBD e do RMA}

A questão da convergência de algoritmos adaptativos supervisionados já foi bem analisada na literatura, de onde surgiram condições para assegurar a estabilidade do LMS (veja, e.g., [GUO; LJUNG; WANG, 1997; NASCIMENTO, 1999]) e do NLMS (veja, e.g., página 80 de [MAREELS; POLDERMAN, 1996] e [RUPP, 2011]). No caso de algoritmos autodidatas, a questão é bem mais complicada visto que em geral existe uma não linearidade na definição do erro de estimação.

A convergência e a estabilidade dos algoritmos baseados no critério do módulo constante têm sido objeto de pequisa há vários anos. Como exemplo, podem-se citar os trabalhos [JOHNSON R. et al., 1998; DABEER; MASRY, 2003; NASCIMENTO; SILVA, 2008] e suas referências. Observou-se em [NASCIMENTO; SILVA, 2008] que numa faixa de passo do adaptação, o CMA pode divergir ou não numa dada realização, com uma probabilidade de divergência que depende do passo de adaptação, de quão perto o vetor de coeficientes inicial está de um mínimo da função custo e da razão sinal-ruído. Apesar desses resultados serem importantes para entender o comportamento do CMA, eles não resolvem o problema de divergência em situações práticas, já que os mínimos da função custo são desconhecidos.

A fim de evitar divergência, foi proposta em [MIRANDA; SILVA; NASCIMENTO, 2008a] uma versão modificada do CMA com dois modos distintos de operação. No primeiro modo, o algoritmo trabalha como um CMA normalizado e no segundo modo, ele rejeita estimativas inconsistentes do sinal transmitido. Apesar da falta de prova da estabilidade numérica desse algoritmo, se observou em [MIRANDA; SILVA; NASCIMENTO, 2008a], através de várias simulações, que ele nunca diverge. A mesma filosofia foi utilizada em [MIRANDA; SILVA; NASCIMENTO, 2008b] para evitar a divergência no algoritmo de Shalvi-Weinstein, mas com uma prova teórica de sua estabilidade.

A seguir, revisitam-se alguns resultados da convergência do algoritmo NLMS. Esses resultados são estendidos para o algoritmo SBD para obter o intervalo do passo de adaptação que assegura sua estabilidade. Em seguida, um mecanismo similar ao de [MIRANDA; SILVA; NASCIMENTO, 2008b] é utilizado para evitar a divergência do RMA. 


\subsubsection{Revisitando a convergência do NLMS}

A Equação de atualização (1.12), repetida aqui por conveniência,

$$
\mathbf{w}(n)=\mathbf{w}(n-1)+\frac{\mu}{\delta+\|\mathbf{u}(n)\|^{2}} e(n) \mathbf{u}^{*}(n),
$$

se reduz ao algoritmo NLMS quando $e(n)=a(n-\Delta)-\mathbf{u}^{T}(n) \mathbf{w}(n-1)$. Definindo o vetor regressor de entrada normalizado, i.e.,

$$
\tilde{\mathbf{u}}(n) \triangleq \frac{\mathbf{u}(n)}{\sqrt{\delta+\|\mathbf{u}(n)\|^{2}}}
$$

e substituindo a definição de $e(n)$ em (4.14), obtém-se

$$
\mathbf{w}(n)=\mathbf{M}(n) \mathbf{w}(n-1)+\mu a(n-\Delta) \frac{\tilde{\mathbf{u}}^{*}(n)}{\sqrt{\delta+\|\mathbf{u}(n)\|^{2}}},
$$

sendo a matriz $\mathbf{M}(n)$ dada por

$$
\mathbf{M}(n) \triangleq \mathbf{I}-\mu \tilde{\mathbf{u}}^{*}(n) \tilde{\mathbf{u}}^{T}(n)
$$

e I a matriz identidade $M \times M$.

A matriz $\mathbf{M}(n)$ possui um autovalor igual a $\lambda_{1} \triangleq 1-\mu\|\tilde{\mathbf{u}}(n)\|^{2}$ e $M-1$ autovalores iguais a "um", isto é $\lambda_{2}=\lambda_{3}=\cdots=\lambda_{M}=1$ [HORN; JOHNSON, 1985]. A convergência de (4.16) estará assegurada se $\left|\lambda_{1}\right|<1$ e se a norma do termo $\mu a(n-\Delta) \tilde{\mathbf{u}}^{*}(n) / \sqrt{\delta+\|\mathbf{u}(n)\|^{2}}$ for limitada [MAREELS; POLDERMAN, 1996; SOLO; KONG, 1995; WEISS; MITRA, 1979; SETHARES, 1992; nASCIMENTO, 1999]. Como a norma do vetor $\tilde{\mathbf{u}}(n)$ é menor ou igual a "um", já que

$$
0 \leq\|\tilde{\mathbf{u}}(n)\|^{2}=\tilde{\mathbf{u}}^{H}(n) \tilde{\mathbf{u}}(n)=\frac{\|\mathbf{u}(n)\|^{2}}{\delta+\|\mathbf{u}(n)\|^{2}}<1,
$$

para garantir $\left|\lambda_{1}\right|<1$, basta escolher o passo de adaptação no intervalo

$$
0<\mu<2
$$

Como $0<\|\tilde{\mathbf{u}}(n)\|<1$ e $\delta$ é um escalar positivo, vale a desigualdade

$$
\frac{\left\|\tilde{\mathbf{u}}^{*}(n)\right\|}{\sqrt{\delta+\|\mathbf{u}(n)\|^{2}}}<\frac{1}{\sqrt{\delta}}
$$


Lembrando que $|a(n-\Delta)|<\sqrt{S}$, é fácil mostrar que a norma do segundo termo do lado direito de (4.16) é limitada, ou seja,

$$
0 \leq \mu|a(n-\Delta)| \frac{\left\|\tilde{\mathbf{u}}^{*}(n)\right\|}{\sqrt{\delta+\|\mathbf{u}(n)\|^{2}}} \leq \mu \sqrt{\frac{S}{\delta}}<\infty .
$$

Portanto, para assegurar a convergência do NLMS, basta escolher o passo de adaptação no intervalo (4.18). Esse resultado é estendido para o algoritmo SBD na seção seguinte.

\subsubsection{Assegurando a convergência do SBD}

Para obter uma condição suficiente para assegurar a convergência do algoritmo SBD sem os vizinhos, se particulariza seu erro para uma constelação $S$-QAM quadrada, substituindo-se os fatores $\left|\hat{a}_{\mathrm{R}}(n)\right|$ e $\left|\hat{a}_{\mathrm{I}}(n)\right|$ por $(\sqrt{S}-1) \geq \max \left\{\left|\hat{a}_{\mathrm{R}}(n)\right|,\left|\hat{a}_{\mathrm{I}}(n)\right|\right\}$, o que leva a

$$
e_{\mathrm{SBD}}(n)=(\sqrt{S}-1)\left[\hat{a}(n)-\mathbf{u}^{T}(n) \mathbf{w}(n-1)\right] .
$$

Cabe observar que o erro de estimação do SBD só é igual a (4.21) se ambas as partes real e imaginária da saída do equalizador caírem em uma das regiões mais afastadas da origem da reta real. Neste caso, o fator de escala que aparece no erro é igual $(\sqrt{S}-1)$ para ambas as componentes, o que possibilita colocá-lo em evidência na expressão do erro. Como este é o caso em que o fator de escala é máximo, ele deve ser considerado na análise de convergência do SBD.

Comparando (4.21) com o erro do algoritmo NLMS, verifica-se que $\hat{a}(n)$ faz o papel do sinal desejado $a(n-\Delta)$ e a única diferença é o fator de escala $(\sqrt{S}-1)$, que, por sua vez, pode ser incorporado ao passo de adaptação $\mu$. Dessa forma, a convergência do SBD (sem vizinhos) estará assegurada se o passo de adaptação $\mu$ for escolhido no intervalo

$$
0<\mu<\frac{2}{\sqrt{S}}<\frac{2}{\sqrt{S}-1} .
$$

Supõe-se agora que $y_{\mathrm{R}}(n)$ e $y_{\mathrm{I}}(n)$ "caem" respectivamente nas regiões $A_{\ell}$ e $A_{m}$, tendo como regiões vizinhas $A_{\ell \pm 1}$ e $A_{m \pm 1}$. Utilizando as propriedades de simetria $\hat{a}_{\ell \pm 1}=\hat{a}_{\ell} \pm 2 \mathrm{e}$ $\hat{a}_{m \pm 1}=\hat{a}_{m} \pm 2$, o erro de estimação pode ser particularizado como

$$
e_{\mathrm{SBD}}(n)=3(\sqrt{S}-1) \chi_{\max }\left[\hat{a}(n)-\mathbf{u}^{T}(n) \mathbf{w}(n-1)\right]
$$


em que $\chi_{\max }$ é o peso máximo dado aos três erros calculados no esquema Axial-1 ou no esquema Axial-2. Neste caso, o erro de estimação do SBD nunca assume o valor dado por (4.23), já que o peso do erro da região principal em (4.1) é sempre maior que os pesos dados aos erros da vizinhança. No entanto, essa expressão corresponde a um pior caso que deve ser levado em conta na análise de estabilidade. Incorporando novamente o fator $3(\sqrt{S}-1) \chi_{\max }$ ao passo de adaptação e usando os resultados de convergência do NLMS, obtém-se para o caso de quatro vizinhos

$$
0<\mu<\frac{2}{3 \sqrt{S} \chi_{\max }} .
$$

No esquema Axial-1, $\chi_{\max }=1$ e no Axial-2 $\chi_{\max }=1,5$. Assim, o SBD é estável levando-se em conta quatro vizinhos, se o passo for escolhido no intervalo

$$
0<\mu<\frac{4}{9 \sqrt{S}},
$$

independentemente do esquema de vizinhança.

\subsubsection{Evitando a divergência do RMA}

Quando o erro de estimação $e(n)$ é uma função não-linear da saída do equalizador como acontece nos algoritmos baseados no módulo constante, as condições para assegurar a convergência de (4.14) não são evidentes. A forma encontrada em [MIRANDA; SILVA; NASCIMENTO, 2008a] para evitar a divergência do CMA foi reescrever o erro de estimação como no caso supervisionado, ou seja, como uma diferença entre uma estimativa do sinal desejado denotada por $d(n)$ e a saída do equalizador $y(n)$. É importante observar que diferentemente do caso supervisionado que usa uma sequência de treinamento, ou seja, em que $d(n)=a(n-\Delta)$, no caso autodidata, tanto $d(n)$ como $y(n)$ são estimativas do sinal transmitido. Escrevendo o erro de estimação dessa forma, toda a não linearidade fica incluída na estimativa $d(n)$. Em [MIRANDA; SILVA; NASCIMENTO, 2008a], conjecturou-se que quando os sinais dessas duas estimativas são diferentes, a estimativa $d(n)$ deixa de ser consistente e o melhor a ser feito neste caso é descartar essa estimativa, ou seja, fazê-la igual a zero. Em outras palavras, o sinal de $d(n)$ diferente do de $y(n)$ é usado como um "aviso" de que algo está errado e que o algoritmo pode estar no caminho da divergência. Assim, é melhor usar o erro de estimação igual a 
$-y(n)$ nas iterações em que a estimativa $d(n)$ é considerada inconsistente. Nesse modo de operação, o algoritmo deixa de trabalhar na chamada região de interesse (ROI - region of interest), já que ele não consegue recuperar a sequência transmitida sem a informação das estatísticas de ordem superior que estão incluídas em $d(n)$. No entanto, é possível mostrar por simulações que ele retorna para a ROI depois de um número finito de iterações, voltando a funcionar como esperado.

Para escrever o erro de estimação do MMA e do RMA como a diferença entre duas estimativas, define-se o escalar

$$
\bar{\gamma} \triangleq 1.5 \sigma_{a}^{2}-r_{2}
$$

em que $\sigma_{a}^{2}=\mathrm{E}\left\{|a(n)|^{2}\right\}$ é a variância do sinal transmitido. Assim, reescrevem-se os passos de adaptação e os erros desses algoritmos como

$$
\mu=\frac{\tilde{\mu}}{\bar{\gamma}}
$$

e

$$
e(n)=\bar{\gamma} \tilde{e}(n),
$$

em que

$$
\tilde{e}(n)=\frac{e(n)}{\bar{\gamma}}=d(n)-y(n)
$$

Como em [MIRANDA; SILVA; NASCIMENTO, 2008a], conjectura-se que o algoritmo estará na ROI se houver consistência entre as estimativas $d(n)=\tilde{e}(n)+y(n)$ e $y(n)$, ou seja, se suas componentes reais tiverem o mesmo sinal (igualmente para as componentes imaginárias). Se as componentes reais ou imaginárias dessas estimativas não possuírem o mesmo sinal, a estimativa $d(n)$ deve ser simplesmente rejeitada, o que resulta $\tilde{e}(n)=-y(n)$ e $e(n)=-\bar{\gamma} y(n)$. Neste caso, o algoritmo deixa a ROI e entra no segundo modo de operação. Em [MIRANDA; SILVA; NASCIMENTO, 2008a] foi mostrado, para filtros CMA escalares, que $e(n)=-\bar{\gamma} y(n)$ faz o algoritmo retornar à ROI. No caso vetorial, o bom desempenho do algoritmo foi confirmado através de simulações numéricas. É importante salientar que esse mecanismo pode ser usado juntamente com os esquemas de vizinhança da Seção 4.2.1, já que a única diferença está no cálculo do erro e(n) considerado em (4.27). 
A constante $\bar{\gamma}$ tem um papel importante aqui já que está relacionada com a definição da ROI. Por exemplo, usando (4.27) no MMA, $d_{\mathrm{R}}(n)$ e $y_{\mathrm{R}}(n)$ terão o mesmo sinal para $0 \leq\left|y_{\mathrm{R}}(n)\right| \leq \sqrt{1.5} \sigma_{a}$. Neste caso, sempre se tem $\max \left\{\left|a_{\mathrm{R}}(n)\right|\right\} \leq \sqrt{1.5} \sigma_{a}=\sqrt{3 \mathrm{E}\left\{a_{\mathrm{R}}^{2}(n)\right\}}$ (analogamente para a componente imaginária). Portanto, o limite $\sqrt{1.5} \sigma_{a}$ permite incluir todas as coordenadas dos símbolos no conjunto de valores que $y_{\mathrm{R}}(n)$ e $y_{\mathrm{I}}(n)$ podem atingir quando o algoritmo opera dentro da ROI, independentemente da ordem da constelação QAM.

Fora da ROI, (4.14) se reduz a

$$
\mathbf{w}(n)=\left[\mathbf{I}-\mu \bar{\gamma} \tilde{\mathbf{u}}^{*}(n) \tilde{\mathbf{u}}^{T}(n)\right] \mathbf{w}(n-1)
$$

Portanto, usando os resultados da análise do algoritmo NLMS, a convergência tanto do MMA quanto do RMA fora da ROI estará assegurada se

$$
0<\mu<\frac{2}{\bar{\gamma}}
$$

Esse resultado não depende do esquema de vizinhança, já que os vizinhos afetam somente a definição de $d(n)$, que é descartada fora da ROI. Dentro da ROI, a análise de estabilidade do MMA e do RMA não é simples e será tratada em outro trabalho.

\section{Voltando às simulações da Seção 4.1.2}

Para ilustrar o comportamento do RMA com os dois modos de operação, retomam-se as simulações da Seção 4.1.2 sob as mesmas condições 1 a 7 da Seção 4.1.1. Na Figura 4.3, repetida na Figura 4.14-(a) por conveniência, observa-se que o RMA sem o esquema de vizinhança diverge para as três constelações avaliadas. Esse comportamento se repete quando o esquema de vizinhança Axial-1 com a ponderação variante no tempo da Seção 4.2 .3 é utilizado, como pode ser observado na Figura 4.14-(b). Nessa simulação, utilizaram-se passos de adaptação menores para que fosse possível observar a divergência para os três sinais de teste. Caso os passos do cenário da Figura 4.14-(a) fossem mantidos, o algoritmo divergiria nas primeiras iterações, não sendo possível observar quaisquer diferenças entre os EMSEs dos sinais 64-QAM, 256-QAM e 1024-QAM. Tal comportamento é explicado pelo fato do erro total no esquema de vizinhança ser maior em módulo que no caso sem vizinhos, o que 
faz com que a divergência seja observada mesmo para passos de adaptação menores, que não causariam divergência quando os vizinhos não são utilizados.
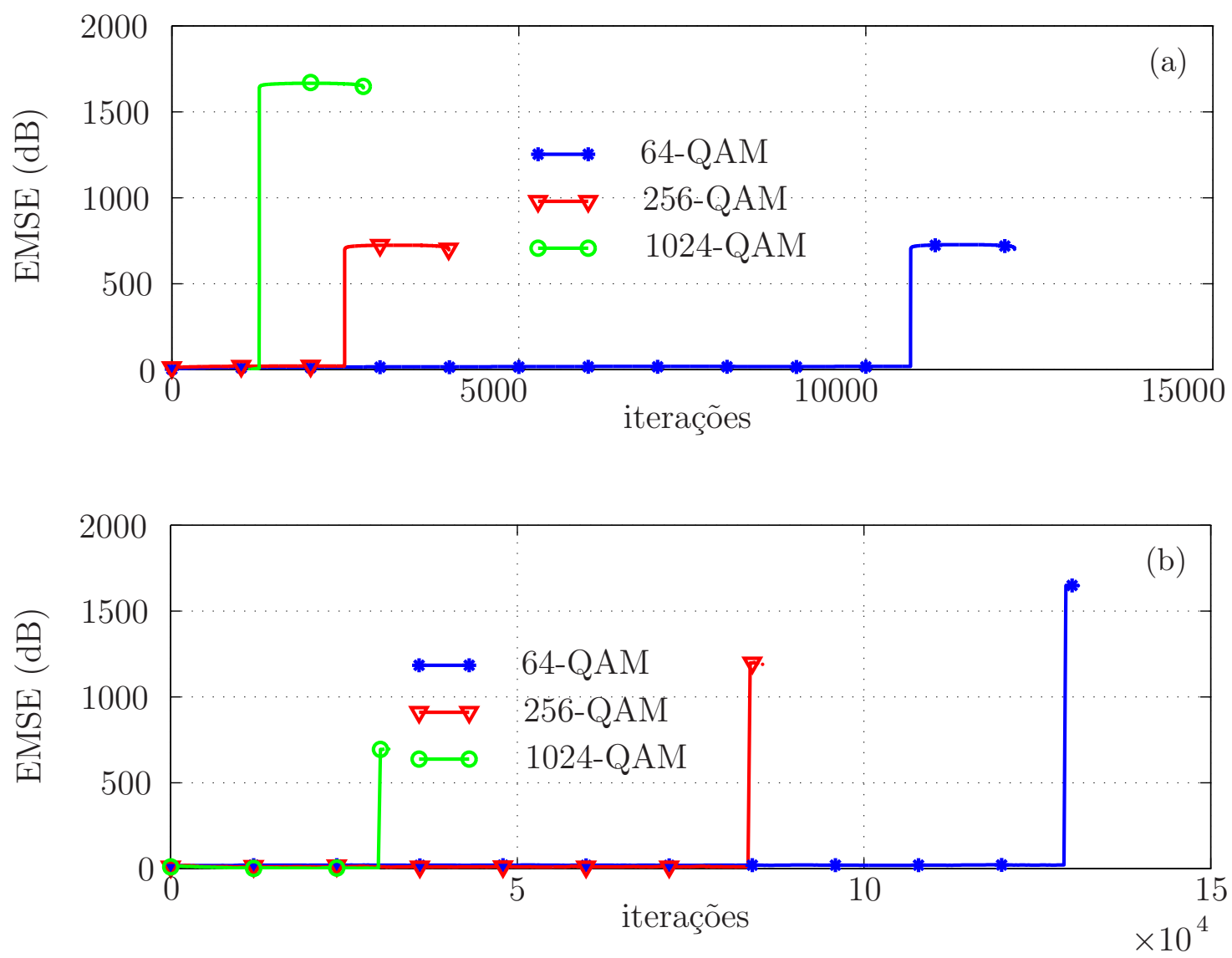

Figura 4.14: Erro quadrático em excesso do algoritmo RMA, única realização, sem mecanismo para evitar divergência (a) sem vizinhos, $\mu_{64-\mathrm{QAM}}=2,75 \times 10^{-2}, \mu_{256-\mathrm{QAM}}=1,5 \times 10^{-2}$ e $\mu_{1024-\mathrm{QAM}}=2,4 \times 10^{-3}$; (b) com vizinhos, $\mu_{64-\mathrm{QAM}}=9 \times 10^{-3}, \mu_{256-\mathrm{QAM}}=5 \times 10^{-3}$ e $\mu_{1024-\mathrm{QAM}}=1,5 \times 10^{-3}$.

Nas Figuras 4.15-(a), 4.15-(b) e 4.15-(c), são mostradas curvas de EMSE, obtidas com uma média de conjunto de 100 realizações, levando em conta o mecanismo que evita a divergência e os mesmos passos de adaptação das simulações anteriores. As curvas exibem um formato do tipo "dente de serra" devido aos valores dos passos de adaptação, escolhidos de forma a forçar uma eventual divergência. Entretanto, esse formato de EMSE não ocorre quando os passos de adaptação são menores. As Figuras 4.15-(a) e 4.15-(c) correspondem aos casos das Figuras 4.14-(a) e 4.14-(b), respectivamente. A divergência foi evitada em ambos os casos e o esquema Axial-1 fez com que o RMA atingisse o regime mais rapidamente que 
no caso sem vizinhos. No caso da Figura 4.15-(b), consideraram-se os passos de adaptação do caso sem vizinhos, o que fez com que o RMA exibisse uma velocidade de convergência ainda maior sem ocorrência de divergência.
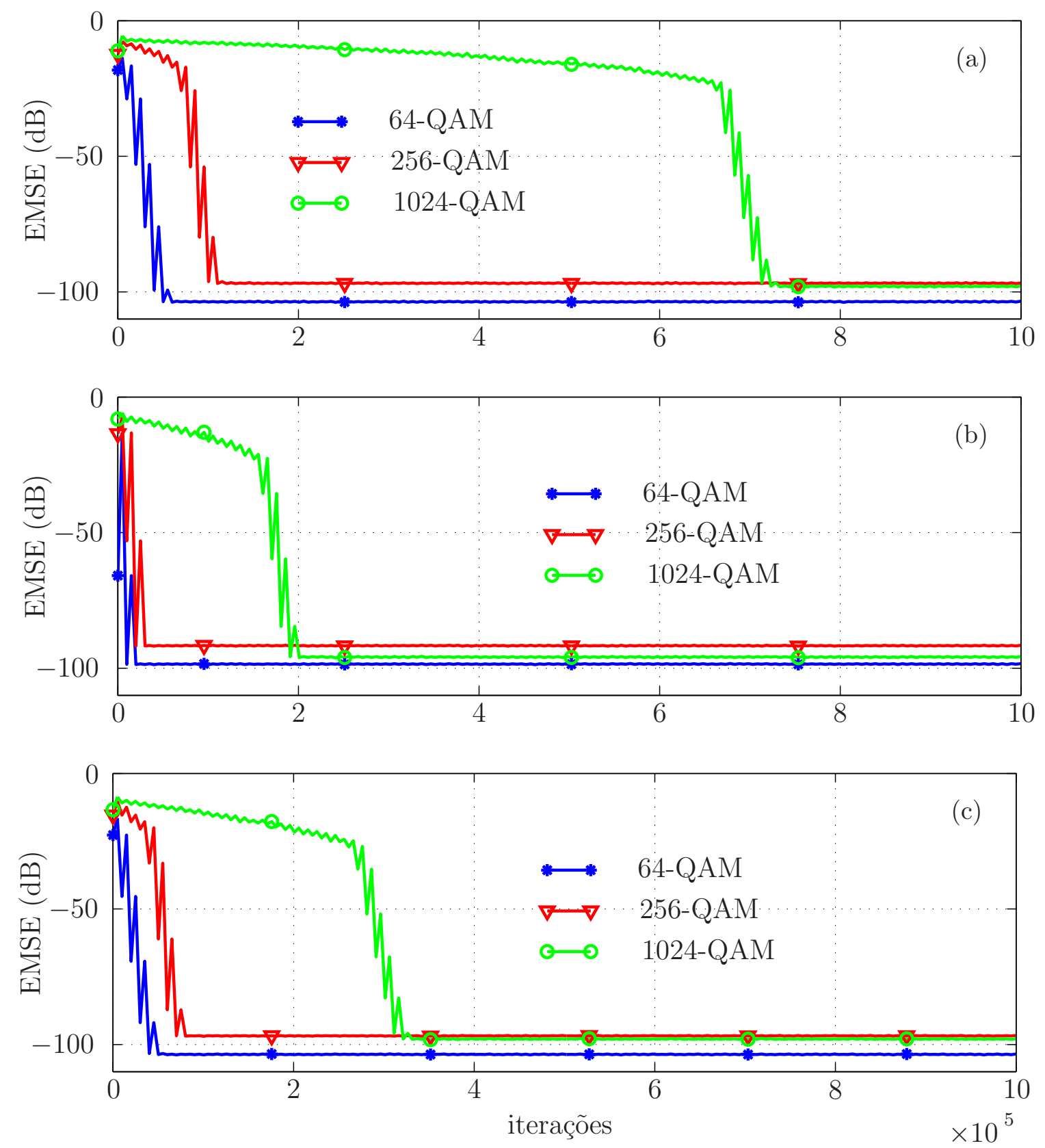

Figura 4.15: EMSE para o algoritmo RMA, com mecanismo para evitar divergência, média de 100 realizações: (a) sem vizinhos, (b) com vizinhos, $\mu_{64-\mathrm{QAM}}=2,75 \times 10^{-2}$, $\mu_{256-\mathrm{QAM}}=1,5 \times 10^{-2}$ e $\mu_{1024-\mathrm{QAM}}=2,4 \times 10^{-3} ; \quad$ (c) com vizinhos, $\mu_{64-\mathrm{QAM}}=9 \times 10^{-3}$, $\mu_{256-\mathrm{QAM}}=5 \times 10^{-3}$ e $\mu_{1024-\mathrm{QAM}}=1,5 \times 10^{-3}$. 


\subsection{Conclusões}

Neste capítulo foram sugeridos um mecanismo para melhorar a velocidade de convergência do RMA e do SBD e outro para evitar a divergência do RMA. Adicionalmente, foram obtidos intervalos do passo de adaptação que asseguram a convergência do algoritmo SBD com e sem vizinhos.

Quanto à melhoria da velocidade de convergência, foram propostos mecanismos para os quais o erro de estimação dos algoritmos autodidatas propostos considera não só a região principal na qual se encontra a saída do equalizador, mas também suas regiões vizinhas. Através de simulações numéricas, foram comparados dois esquemas de vizinhança. Como essas simulações foram realizadas na ausência de ruído e em apenas um canal não se pode dizer muito acerca da comparação entre os esquemas propostos. Entretanto, de uma forma geral, ambos os algoritmos com tais esquemas se mostram vantajosos, especialmente para constelações QAM de ordem elevada, quando comparados aos seus pares desprovidos de tal mecanismo. Como essa técnica envolve somente o cálculo de escalares, o custo computacional do RMA e do SBD sofre apenas um pequeno incremento. Em implementações práticas, os valores de $b^{p(n)}$ podem ser lidos de forma simples a partir de uma tabela. Além disso, a utilização dos vizinhos apenas no transitório assegura praticamente o mesmo desajuste em regime dos algoritmos propostos, já que $b^{p(n)}$ tende a valores relativamente pequenos em regime.

A partir dos resultados da convergência do algoritmo NLMS, obtiveram-se os intervalos do passo de adaptação que assegura a convergência do SBD. No caso do RMA, o mecanismo proposto em [MIRANDA; SILVA; NASCIMENTO, 2008b] foi utilizado para evitar sua divergência. Especificamente em relação ao RMA, foram realizadas simulações, que atestam o bom funcionamento desse mecanismo ainda que o passo de adaptação seja aumentado. 


\section{Capítulo 5}

\section{Análise de rastreio}

Uma das propriedades importantes de um algoritmo adaptativo é a sua capacidade de rastreio (tracking), ou seja, sua capacidade de acompanhar variações nas estatísticas do ambiente. Essa propriedade é essencial no caso da equalização, já que os equalizadores adaptativos precisam acompanhar as possíveis variações do canal de comunicação. Por essa razão, os algoritmos de equalização adaptativa devem apresentar uma boa capacidade de rastreio.

A análise de rastreio de algoritmos adaptativos consiste em obter expressões analíticas para o erro quadrático médio em excesso (EMSE) em regime quando a solução ótima $\mathbf{w}_{\mathrm{o}}$ varia com o tempo. Esse tipo de análise estatística não é simples, já que filtros adaptativos são sistemas variantes no tempo, estocásticos e não-lineares [SAYED, 2008]. Diante disso, é comum introduzir algumas hipóteses simplificadoras que, na maior parte dos casos, consistem em aproximar o valor esperado do produto de duas ou mais variáveis como o produto de seus valores esperados, ou seja, $\mathrm{E}\{x y\} \approx \mathrm{E}\{x\} \mathrm{E}\{y\}$. Embora muitas dessas aproximações não sejam realistas na maior parte dos casos, elas são essenciais para facilitar a análise.

Neste capítulo, são obtidas expressões analíticas para o EMSE do MMA, RMA e do algoritmo SBD, admitindo um ambiente não-estacionário. A análise é baseada no método da realimentação, também conhecido como método de conservação de energia, aplicado ao algoritmo NLMS [SAYED, 2008] em conjunto com resultados da análise de rastreio do CMA [MAI; SAYED, 2000; YOUSEF; SAYED, 1999; SILVA; MIRANDA, 2004; SILVA; NASCIMENTO, 2008a, 2008b]. Diferentemente da análise apresentada no Capítulo 3, supõe-se aqui que 
a solução ótima varia com o tempo. Para facilitar a análise, os esquemas de vizinhança apresentados no Capítulo 4 não são considerados. Como esses esquemas são usados apenas no transitório para melhorar a velocidade de convergência dos algoritmos propostos, eles não afetam o resultado em regime.

\subsection{Preliminares da análise}

Nesta seção, são apresentados os modelos e as definições utilizados nas análises deste capítulo. Além disso, utiliza-se o método da realimentação para obter uma expressão que depende da média do erro de estimação ao quadrado e da média do produto do erro de estimação com o erro a priori. Essa expressão é valida para a classe de algoritmos normalizados (1.12) (página 20) considerada nesta tese. Nas seções seguintes, essa expressão é particularizada para os algoritmos MMA normalizado, RMA e SBD a fim de obter uma expressão analítica para o EMSE em regime em um ambiente não-estacionário.

\subsubsection{Modelo para variação da solução ótima}

Supõe-se que a solução ótima $\mathbf{w}_{\mathrm{o}}$ varia segundo o random-walk model, ver por exemplo [SAYED, 2008, Sec. 20.2], ou seja,

$$
\mathbf{w}_{\mathrm{o}}(n)=\mathbf{w}_{\mathrm{o}}(n-1)+\mathbf{q}(n)
$$

sendo $\mathbf{q}(n)$ uma perturbação aleatória independente das condições iniciais $\left\{\mathbf{w}_{\mathrm{o}}(-1), \mathbf{w}(-1)\right\}$ e do vetor de entrada $\{\mathbf{u}(l)\}$ para todo $l<n$. Na equalização, $\mathbf{q}(n)$ modela a variação do canal e é considerado independente e identicamente distribuído (i.i.d.), com média nula e matriz de covariância positiva-definida dada por

$$
\mathbf{Q}=\mathrm{E}\left\{\mathbf{q}^{*}(n) \mathbf{q}^{T}(n)\right\}
$$

A solução ótima $\mathbf{w}_{\mathrm{o}}$ representa um dos mínimos globais de uma função custo. Quando os algoritmos são implementados na taxa de símbolos, $\mathbf{w}_{\mathrm{o}}$ pode estar próximo da solução de Wiener [ZENG; TONG; JOHNSON, 1998; SUYAMA et al., 2003] ou pode coincidir com ela como 
ocorre para o RMA e o SBD sob certas condições, como foi visto no Capítulo 3. Neste caso, $\mathbf{w}_{\text {o }}$ não leva à equalização perfeita, mas pode alcançar um MSE relativamente baixo. Em contrapartida, quando os algoritmos são implementados com sobreamostragem na ausência de ruído e sob certas condições bem conhecidas na literatura, $\mathbf{w}_{\mathrm{o}}$ representa a solução ótima de forçamento a zero, que leva à equalização perfeita [TREICHLER; FIJALKOW; JR., 1996].

O modelo (5.1) é muito utilizado na análise de algoritmos adaptativos no contexto de identificação de sistemas [SAYED, 2008]. No entanto, sua aplicação em equalização autodidata não é direta, principalmente quando não se conhece a solução ótima. No Apêndice A de [CANDIDO, 2009], foi mostrado que subtrair $\mathbf{q}(n)$ na adaptação do vetor de coeficientes do algoritmo em cada instante de tempo é equivalente a utilizar o random-walk model. Dessa forma, não é necessário se conhecer a priori a solução ótima para utilizar esse modelo no contexto de equalização autodidata.

\subsubsection{Medida de desempenho}

Uma medida do desempenho de algoritmos adaptativos é dada pelo EMSE em regime, definido como

$$
\zeta \triangleq \lim _{n \rightarrow \infty} \mathrm{E}\left\{\left|e_{a}(n)\right|^{2}\right\}=\lim _{n \rightarrow \infty} \mathrm{E}\left\{e_{a, \mathrm{R}}^{2}(n)+e_{a, \mathrm{I}}^{2}(n)\right\}
$$

em que

$$
e_{a}(n)=e_{a, \mathrm{R}}(n)+j e_{a, \mathrm{I}}(n)=\mathbf{u}^{T}(n) \widetilde{\mathbf{w}}(n-1)
$$

é o erro a priori e

$$
\widetilde{\mathbf{w}}(n-1)=\mathbf{w}_{\mathrm{o}}(n-1)-\mathbf{w}(n-1)
$$

é o vetor de erro dos coeficientes. No Apêndice A, é mostrada a relação entre o EMSE e outras medidas de desempenho como o MSE e o desajuste.

\subsubsection{Modelo para a saída do equalizador}

Nas análises em regime de algoritmos de equalização autodidata como as de [FIJALKOW; MANLOVE; JOHNSON, 1998; MAI; SAYED, 2000; SILVA; MIRANDA, 2004; SILVA; NASCIMENTO, 2008a, 2008b], considera-se que $a(n-\Delta) \approx \mathbf{u}^{T}(n) \mathbf{w}_{\mathrm{o}}(n-1)$. Em outras palavras, admite-se 
que o filtro ótimo leva à equalização perfeita, condição que pode ser alcançada utilizando-se sobreamostragem num ambiente livre de ruído [TREICHLER; FIJALKOW; JR., 1996]. Em [MAI; SAYED, 2000], foi mostrado que quando o sinal transmitido em um ambiente estacionário e livre de ruído é de módulo constante, o EMSE do CMA é zero se for utilizada a sobreamostragem. No entanto, a literatura não contém resultados de análise de algoritmos autodidatas implementados na taxa de símbolos.

Os algoritmos RMA e SBD podem convergir em média quadrática para a solução de Wiener quando utilizados para adaptar um equalizador na taxa de símbolos, como mostrado no Capítulo 3. Além disso, como esses algoritmos tratam uma constelação QAM de módulo não-constante como se tivesse módulo constante, é de se esperar que em um ambiente estacionário e livre de ruído eles também apresentem um EMSE em regime nulo. Por esses motivos, na análise apresentada neste capítulo, também é levado em conta o caso em que o equalizador é implementado na taxa de símbolos. Além das análises do RMA e SBD, apresenta-se uma análise de rastreio também para o MMA normalizado.

Dessa forma, admite-se que

$$
a(n-\Delta)=\mathbf{u}^{T}(n) \mathbf{w}_{\mathrm{o}}(n-1)+v(n),
$$

em que $v(n)=v_{\mathrm{R}}(n)+j v_{\mathrm{I}}(n)$ representa o papel de uma perturbação que é considerada i.i.d., de média nula, independente de $\mathbf{u}(n), a(n-\Delta)$ e $e_{a}(n)$ em regime. Com a inclusão de $v(n)$ em (5.6), o caso da equalização na taxa de símbolos é coberto já que $v(n) \neq 0$ significa que o filtro ótimo não alcança a equalização perfeita. Este modelo é mais comumente usado no contexto de identificação de sistemas sendo referido como modelo de regressão linear [SAYED, 2008], mas também pode ser usado na análise de algoritmos de equalização adaptativa como mostrado em [RUPP, 2011].

Usando (5.6), a saída do equalizador pode ser escrita como

$$
\begin{aligned}
y(n) & =\mathbf{u}^{T}(n) \mathbf{w}(n-1)=\mathbf{u}^{T}(n)\left[\mathbf{w}_{\mathrm{o}}(n-1)-\widetilde{\mathbf{w}}(n-1)\right] \\
& =a(n-\Delta)-e_{a}(n)-v(n),
\end{aligned}
$$

cujas partes real e imaginária são dadas respectivamente por

$$
y_{\mathrm{R}}(n)=a_{\mathrm{R}}(n-\Delta)-e_{a, \mathrm{R}}(n)-v_{\mathrm{R}}(n)
$$


$\mathrm{e}$

$$
y_{\mathrm{I}}(n)=a_{\mathrm{I}}(n-\Delta)-e_{a, \mathrm{I}}(n)-v_{\mathrm{I}}(n) .
$$

Esse modelo é usado nas análises em regime deste capítulo.

\subsubsection{Método da realimentação}

O método da realimentação, também conhecido como método de conservação de energia, foi proposto em [RUPP; SAYED, 1996] e tem sido usado na análise de uma vasta classe de algoritmos adaptativos, como mostrado em [SAYED, 2008]. Embora ele possa ser usado na análise do transitório de filtros adaptativos, uma de suas maiores vantagens está na análise em regime, já que ele possibilita obter expressões analíticas para o EMSE em regime, sem ter que calculá-las como limites de expressões obtidas na análise do transitório. Por isso, esse método foi escolhido para análise dos algoritmos propostos.

A equação de atualização dos coeficientes da classe de algoritmos normalizados considerada nesta tese é dada pela Equação (1.12), repetida aqui por conveniência,

$$
\mathbf{w}(n)=\mathbf{w}(n-1)+\frac{\mu}{\delta+\|\mathbf{u}(n)\|^{2}} e(n) \mathbf{u}^{*}(n) .
$$

Subtraindo ambos os lados de (5.10) de $\mathbf{w}_{\mathrm{o}}(n)$ e usando o modelo (5.1), obtém-se uma equação recorrente para o vetor de erro dos coeficientes, ou seja,

$$
\mathbf{w}_{\mathrm{o}}(n)-\mathbf{w}(n)=\mathbf{w}_{\mathrm{o}}(n-1)+\mathbf{q}(n)-\mathbf{w}(n-1)-\frac{\mu}{\delta+\|\mathbf{u}(n)\|^{2}} e(n) \mathbf{u}^{*}(n),
$$

o que leva a

$$
\widetilde{\mathbf{w}}(n)=\widetilde{\mathbf{w}}(n-1)-\frac{\mu}{\delta+\|\mathbf{u}(n)\|^{2}} e(n) \mathbf{u}^{*}(n)+\mathbf{q}(n) .
$$

Para facilitar, supõe-se que o fator de regularização é suficientemente pequeno $(\delta \approx 0)$, de modo a não levá-lo em conta na análise daqui por diante.

Calculando a norma euclidiana ao quadrado de ambos os lados de (5.12) e tomando a esperança, obtém-se

$$
\begin{aligned}
\mathrm{E}\left\{\|\widetilde{\mathbf{w}}(n)\|^{2}\right\}= & \mathrm{E}\left\{\|\widetilde{\mathbf{w}}(n-1)\|^{2}\right\}+\mu^{2} \mathrm{E}\left\{\frac{|e(n)|^{2}}{\|\mathbf{u}(n)\|^{2}}\right\}+\mathrm{E}\left\{\|\mathbf{q}(n)\|^{2}\right\} \\
& -\mu \mathrm{E}\left\{\frac{e(n) \widetilde{\mathbf{w}}^{H}(n-1) \mathbf{u}^{*}(n)}{\|\mathbf{u}(n)\|^{2}}\right\}-\mu \mathrm{E}\left\{\frac{e^{*}(n) \mathbf{u}^{T}(n) \widetilde{\mathbf{w}}(n-1)}{\|\mathbf{u}(n)\|^{2}}\right\} .
\end{aligned}
$$


Cabe notar que segundo o modelo (5.1), q(n) tem média nula e é independente de $\widetilde{\mathbf{w}}(n-1)$, $e(n)$ e $\mathbf{u}(n)$, o que justifica a ausência de termos cruzados contendo $\mathbf{q}(n)$ no lado direito de (5.13).

No caso em que o algoritmo opera em condições estáveis,

$$
\mathrm{E}\left\{\|\widetilde{\mathbf{w}}(n)\|^{2}\right\} \approx \mathrm{E}\left\{\|\widetilde{\mathbf{w}}(n-1)\|^{2}\right\}
$$

em regime $(n \rightarrow \infty)$. Lembrando que $e_{a}(n)=\mathbf{u}^{T}(n) \widetilde{\mathbf{w}}(n-1),(5.13)$ pode ser reescrita em regime como

$$
\mu \mathrm{E}\left\{\frac{|e(n)|^{2}}{\|\mathbf{u}(n)\|^{2}}\right\}+\frac{\mathrm{E}\left\{\|\mathbf{q}(n)\|^{2}\right\}}{\mu}=\mathrm{E}\left\{\frac{e(n) e_{a}^{*}(n)}{\|\mathbf{u}(n)\|^{2}}\right\}+\mathrm{E}\left\{\frac{e^{*}(n) e_{a}(n)}{\|\mathbf{u}(n)\|^{2}}\right\} .
$$

Notando que $\mathrm{E}\left\{\|\mathbf{q}(n)\|^{2}\right\}$ é igual ao traço da matriz $\mathbf{Q}$ e que os dois termos a direita de (5.15) são complexos conjugados, chega-se a

$$
\mu \mathrm{E}\left\{\frac{|e(n)|^{2}}{\|\mathbf{u}(n)\|^{2}}\right\}+\frac{\operatorname{Tr}(\mathbf{Q})}{\mu}=2 \operatorname{Re}\left[\mathrm{E}\left\{\frac{e_{a}^{*}(n) e(n)}{\|\mathbf{u}(n)\|^{2}}\right\}\right],
$$

em que $\operatorname{Tr}(\cdot)$ denota o traço de uma matriz. Como (5.10) possui a mesma estrutura do algoritmo NLMS, se obtém a mesma relação de variância de [SAYED, 2008, Eq.(21.17)].

Para simplificar (5.16), admite-se que ${ }^{1}$

A8) $\|\mathbf{u}(n)\|^{2}$ é independente de $|e(n)|^{2}$ e de $e_{a}^{*}(n) e(n)$ em regime. Essa suposição é conhecida na literatura como princípio da separação [SAYED, 2008, Ch. 17].

Utilizando A8, (5.16) pode ser simplificada para

$$
\mu \eta_{u} \mathrm{E}\left\{|e(n)|^{2}\right\}+\mu^{-1} \operatorname{Tr}(\mathbf{Q}) \approx 2 \eta_{u} \operatorname{Re}\left[\mathrm{E}\left\{e_{a}^{*}(n) e(n)\right\}\right]
$$

em que $\eta_{u} \triangleq \mathrm{E}\left\{1 /\|\mathbf{u}(n)\|^{2}\right\}$. Para entradas gaussianas e número elevado de coeficientes, $\eta_{u}$ pode ser aproximado por $1 /\left[\sigma_{u}^{2}(M-2)\right] \operatorname{com} \sigma_{u}^{2}=\mathrm{E}\left\{|u(n)|^{2}\right\}$ [COSTA; BERMUDEZ, 2002]. A aproximação (5.17) ainda precisa de estimativas teóricas para $\mathrm{E}\left\{|e(n)|^{2}\right\}$ e $\mathrm{E}\left\{e_{a}^{*}(n) e(n)\right\}$ em regime. Tais estimativas dependem de cada algoritmo e são obtidas nas próximas seções para o MMA, RMA, e SBD.

\footnotetext{
${ }^{1}$ Adotou-se uma numeração sequencial para todas as suposições desta tese. As suposições A1-A7 apareceram anteriormente nas análises do Capítulo 3.
} 


\subsection{Análise do algoritmo multimódulo}

A fim de analisar o MMA normalizado implementado na taxa de símbolos, estende-se inicialmente o modelo do erro de estimação em regime de algoritmos baseados no módulo constante proposto em [SILVA; NASCIMENTO, 2008a]. Para esse propósito, supõe-se que

A9) Em regime, os termos dependentes de $e_{a, \mathrm{R}}^{k}(n), e_{a, \mathrm{I}}^{k}(n), v_{\mathrm{R}}^{k}(n)$, e $v_{\mathrm{I}}^{k}(n), k \geq 2$ podem ser desconsiderados já que eles são suficientemente pequenos quando comparados aos termos dependentes de $e_{a, \mathrm{R}}(n), e_{a, \mathrm{I}}(n), v_{\mathrm{R}}(n)$, e $v_{\mathrm{I}}(n)$, respectivamente. Em outras palavras, o equalizador pode não alcançar a equalização perfeita, mas pode mitigar suficientemente a interferência intersimbólica introduzida pelo canal. Uma suposição similar foi usada na análise do CMA [MAI; SAYED, 2000; SILVA; NASCIMENTO, 2008a; NASCIMENTO; SILVA, 2008].

A10) Em regime, a parte real do erro a priori é independente de sua parte imaginária.

O erro de estimação do MMA é definido na Equação (2.4), repetida aqui por conveniência,

$$
e(n)=\left[r_{2}-y_{\mathrm{R}}^{2}(n)\right] y_{\mathrm{R}}(n)+j\left[r_{2}-y_{\mathrm{I}}^{2}(n)\right] y_{\mathrm{I}}(n)
$$

Assim, substituindo (5.8) na parte real de (5.18) e usando A9, obtém-se

$$
e_{\mathrm{R}}(n) \approx \gamma_{\mathrm{R}}(n) e_{a, \mathrm{R}}(n)+\beta_{\mathrm{R}}(n)
$$

em que

$$
\gamma_{\mathrm{R}}(n) \triangleq 3 a_{\mathrm{R}}^{2}(n-\Delta)-r_{2}-6 v_{\mathrm{R}}(n) a_{\mathrm{R}}(n-\Delta)
$$

e

$$
\beta_{\mathrm{R}}(n) \triangleq r_{2} a_{\mathrm{R}}(n-\Delta)-a_{\mathrm{R}}^{3}(n-\Delta)+v_{\mathrm{R}}(n)\left[3 a_{\mathrm{R}}^{2}(n-\Delta)-r_{2}\right]
$$

O modelo para $e_{\mathrm{I}}(n)$ pode ser obtido substituindo o subscrito R pelo subscrito I nas equações (5.19) à (5.21).

Para calcular o primeiro e o segundo momentos das variáveis aleatórias $\gamma_{\mathrm{R}}(n), \gamma_{\mathrm{I}}(n)$, $\beta_{\mathrm{R}}(n)$, e $\beta_{\mathrm{I}}(n)$, salienta-se que 
R1) Constelações QAM quadradas possuem simetria circular, ou seja,

$$
\mathrm{E}\left\{a_{\mathrm{R}}^{k}(n)\right\}=\mathrm{E}\left\{a_{\mathrm{I}}^{k}(n)\right\}=0
$$

para todo $k$ inteiro, ímpar e positivo $(k>0)$.

Usando R1, obtêm-se $\mathrm{E}\left\{\beta_{\mathrm{R}}(n)\right\}=\mathrm{E}\left\{\beta_{\mathrm{I}}(n)\right\}=0$,

$$
\begin{aligned}
& \sigma_{\beta}^{2} \triangleq \mathrm{E}\left\{\beta_{\mathrm{R}}^{2}(n)\right\}=\mathrm{E}\left\{\beta_{\mathrm{I}}^{2}(n)\right\}=\mathrm{E}\left\{a_{\mathrm{R}}^{6}(n)-r_{2}^{2} a_{\mathrm{R}}^{2}(n)\right\}+0.5 \sigma_{v}^{2} \mathrm{E}\left\{3 a_{\mathrm{R}}^{4}(n)+r_{2}^{2}\right\} \\
& \bar{\gamma} \triangleq \mathrm{E}\left\{\gamma_{\mathrm{R}}(n)\right\}=\mathrm{E}\left\{\gamma_{\mathrm{I}}(n)\right\}=1.5 \sigma_{a}^{2}-r_{2}
\end{aligned}
$$

e

$$
\overline{\bar{\gamma}} \triangleq \mathrm{E}\left\{\gamma_{\mathrm{R}}^{2}(n)\right\}=\mathrm{E}\left\{\gamma_{\mathrm{I}}^{2}(n)\right\}=1.5\left(r_{2}+6 \sigma_{v}^{2}\right) \sigma_{a}^{2}+r_{2}^{2}
$$

em que $\sigma_{v}^{2} / 2=\mathrm{E}\left\{v_{\mathrm{R}}^{2}(n)\right\}=\mathrm{E}\left\{v_{\mathrm{I}}^{2}(n)\right\}$ e $\sigma_{a}^{2} / 2=\mathrm{E}\left\{a_{\mathrm{R}}^{2}(n)\right\}$. Cabe notar que a variável $\bar{\gamma}$ já havia sido definida na página 80, já que ela tem um papel importante no mecanismo que evita divergência de algoritmos baseados no módulo constante.

É importante observar que usando (5.6), a variância de $v(n)$ pode ser estimada teoricamente, utilizando a seguinte expressão

$$
\sigma_{v}^{2} \approx \sigma_{a}^{2}-\overline{\mathbf{w}}_{\mathrm{o}}^{H} \mathbf{R} \overline{\mathbf{w}}_{\mathrm{O}}
$$

em que $\overline{\mathbf{w}}_{\mathrm{o}} \triangleq \mathrm{E}\left\{\mathbf{w}_{\mathrm{o}}(n)\right\}=\mathbf{w}_{\mathrm{o}}(-1)$. Quando o filtro ótimo alcança a equalização perfeita $\overline{\mathbf{w}}_{\mathrm{o}}^{H} \mathbf{R} \overline{\mathbf{w}}_{\mathrm{o}}=\sigma_{a}^{2}$ e $\sigma_{v}^{2}=0$. Além disso, percebendo que $\mathbf{w}_{\mathrm{WIE}}^{T} \mathbf{p}_{\Delta}^{*}=\mathbf{w}_{\mathrm{WIE}}^{H} \mathbf{p}_{\Delta}$, quando $\overline{\mathbf{w}}_{\mathrm{o}}=\mathbf{w}_{\mathrm{WIE}}$, $\sigma_{v}^{2}=J_{\min }(\Delta)$ definido em (3.5) (página 51).

Usando (5.19), o modelo equivalente para a parte imaginária do erro, (5.22)-(5.24) e A9, obtém-se

$$
\mathrm{E}\left\{|e(n)|^{2}\right\} \approx \overline{\bar{\gamma}} \mathrm{E}\left\{\left|e_{a}(n)\right|^{2}\right\}+2 \sigma_{\beta}^{2}
$$

$\mathrm{e}$

$$
\mathrm{E}\left\{e_{a}^{*}(n) e(n)\right\} \approx \bar{\gamma} \mathrm{E}\left\{\left|e_{a}(n)\right|^{2}\right\}
$$

Lembrando que $\zeta \triangleq \lim _{n \rightarrow \infty} \mathrm{E}\left\{\left|e_{a}(n)\right|^{2}\right\}$ e substituindo (5.26) e (5.27) em (5.17), chega-se a

$$
\zeta_{\mathrm{MMA}} \approx \frac{1}{2 \bar{\gamma}-\mu \overline{\bar{\gamma}}}\left[2 \mu \sigma_{\beta}^{2}+\frac{\operatorname{Tr}(\mathbf{Q})}{\mu \eta_{u}}\right] .
$$


De (5.28), pode-se observar que $\zeta_{\mathrm{MMA}}$ é zero, somente num ambiente estacionário $(\mathbf{Q}=\mathbf{0})$, admitindo equalização com sobreamostragem na ausência de ruído $(v(n)=0)$ e para sinais de módulo constante $\left(\sigma_{\beta}^{2}=0\right)$. Para sinais de módulo não-constante, mesmo quando a solução de forçamento a zero é alcançada, o algoritmo exibe um EMSE não-nulo inerente aos algoritmos baseados no módulo constante [MAI; SAYED, 2000; SILVA; MIRANDA, 2004; SILVA; NASCIMENTO, 2008a, 2008b].

\subsection{Análise do RMA}

O erro de estimação do RMA definido na Equação (2.16), repetida aqui por conveniência, depende das partes real e imaginária da saída do equalizador, transladadas para a origem da reta real, ou seja,

$$
e(n)=\alpha_{\ell}\left[1-\breve{y}_{\ell}^{2}(n)\right] \breve{y}_{\ell}(n)+j \alpha_{m}\left[1-\breve{y}_{m}^{2}(n)\right] \breve{y}_{m}(n)
$$

Admitindo que $y_{\mathrm{R}}(n)$ e $y_{\mathrm{I}}(n)$ estão nas regiões $A_{\ell}$ e $A_{m}$ e subtraindo os centros $c_{\ell}$ e $c_{m}$ de ambos os lados de (5.8) e (5.9), respectivamente, obtêm-se

$$
\breve{y}_{\ell}(n)=y_{\mathrm{R}}(n)-c_{\ell}=a_{\mathrm{R}}(n-\Delta)-c_{\ell}-e_{a, \mathrm{R}}(n)-v_{\mathrm{R}}(n)
$$

e

$$
\breve{y}_{m}(n)=y_{\mathrm{I}}(n)-c_{m}=a_{\mathrm{I}}(n-\Delta)-c_{m}-e_{a, \mathrm{I}}(n)-v_{\mathrm{I}}(n) .
$$

Usando as definições (3.7) e (3.8) da página 52, as versões transladadas das partes real e imaginária da saída do equalizador podem ser escritas como

$$
\breve{y}_{\ell}(n)=\breve{a}_{\ell}(n)-e_{a, \mathrm{R}}(n)-v_{\mathrm{R}}(n)
$$

e

$$
\breve{y}_{m}(n)=\breve{a}_{m}(n)-e_{a, \mathrm{I}}(n)-v_{\mathrm{I}}(n)
$$

Substituindo (5.32) e (5.33) em (5.29), lembrando que (ver página 52)

$$
\breve{a}_{\ell}^{k}(n)=\breve{a}_{m}^{k}(n)=1, \text { para } k \geq 0 \text { e par }
$$


e usando A9, chega-se a

$$
\begin{aligned}
e(n) \approx & \alpha_{\ell}\left[2 v_{\mathrm{R}}-6 \breve{a}_{\ell}(n) e_{a, \mathrm{R}}(n) v_{\mathrm{R}}(n)+2 e_{a, \mathrm{R}}(n)\right] \\
& +j \alpha_{m}\left[2 v_{\mathrm{I}}-6 \breve{a}_{m}(n) e_{a, \mathrm{I}}(n) v_{\mathrm{I}}(n)+2 e_{a, \mathrm{I}}(n)\right]
\end{aligned}
$$

Definindo $\overline{\bar{\alpha}} \triangleq \mathrm{E}\left\{\alpha_{\ell}^{2}\right\}=\mathrm{E}\left\{\alpha_{m}^{2}\right\}$ e usando (5.35) e (5.34), obtêm-se

$$
\mathrm{E}\left\{|e(n)|^{2}\right\} \approx \bar{\alpha}\left[2 \vartheta \mathrm{E}\left\{\left|e_{a}(n)\right|^{2}\right\}+4 r_{\alpha} \sigma_{v}^{2}\right]
$$

$\mathrm{e}$

$$
\mathrm{E}\left\{e_{a}^{*}(n) e(n)\right\} \approx 2 \bar{\alpha} \mathrm{E}\left\{\left|e_{a}(n)\right|^{2}\right\}
$$

em que $r_{\alpha} \triangleq \mathrm{E}\left\{\alpha_{\ell}^{2}\right\} / \mathrm{E}\left\{\alpha_{\ell}\right\}=\overline{\bar{\alpha}} / \bar{\alpha}$ e $\vartheta \triangleq r_{\alpha}\left(9 \sigma_{v}^{2}+2\right)$.

Substituindo (5.36) e (5.37) em (5.17), chega-se a

$$
\zeta_{\mathrm{RMA}} \approx \frac{1}{2-\mu \vartheta}\left[2 \mu r_{\alpha} \sigma_{v}^{2}+\frac{\operatorname{Tr}(\mathbf{Q})}{2 \mu \bar{\alpha} \eta_{u}}\right] .
$$

Diferentemente do MMA, num ambiente estacionário $(\mathbf{Q}=\mathbf{0})$ e admitindo equalização com sobreamostragem na ausência de ruído $(v(n)=0)$, o RMA alcança um EMSE nulo, independentemente da ordem da constelação QAM.

Para encerrar esta seção, obtém-se uma expressão para o EMSE em regime dos algoritmos MMA e RMA que evitam a divergência (ver Seção 4.3.3, página 80). Fora da região de interesse (ROI), a estimativa da resposta desejada é descartada e a equação de atualização de ambos os algoritmos se reduz à Equação (4.28), repetida aqui por conveniência,

$$
\mathbf{w}(n)=\left[\mathbf{I}-\mu \bar{\gamma} \tilde{\mathbf{u}}^{*}(n) \tilde{\mathbf{u}}^{T}(n)\right] \mathbf{w}(n-1) .
$$

Como a atualização (5.39) faz com que os algoritmos retornem para a ROI, o MMA e o RMA operam nesse modo somente por um intervalo de tempo finito. Portanto, a expressão analítica obtida aqui é o resultado de uma análise de pior caso. Usando o método da realimentação, a relação de variância em regime fora da ROI pode ser obtida substituindo-se $e(n)$ e $\mu$ em (5.17) por $-y(n)$ e $\mu \bar{\gamma}$, respectivamente, o que resulta em

$$
\mu \bar{\gamma} \eta_{u} \mathrm{E}\left\{|y(n)|^{2}\right\}+\frac{\operatorname{Tr}(\mathbf{Q})}{\mu \bar{\gamma}} \approx-2 \eta_{u} \operatorname{Re}\left[\mathrm{E}\left\{e_{a}^{*}(n) y(n)\right\}\right] .
$$


Usando (5.7), chega-se a

$$
\zeta_{\text {outROI }} \approx \frac{1}{2-\mu \bar{\gamma}}\left[\mu \bar{\gamma}\left(\sigma_{a}^{2}+\sigma_{v}^{2}\right)+\frac{\operatorname{Tr}(\mathbf{Q})}{\mu \bar{\gamma} \eta_{u}}\right] .
$$

Uma expressão similar foi obtida em [CANDIDO et al., 2010] para o CMA normalizado com dois modos de operação, admitindo sobreamostragem e ausência de ruído.

Como o MMA e o RMA que evitam divergência ficam chaveando entre dois modos de operação (dentro e fora da ROI), o EMSE em regime desses algoritmos deve ficar entre o valor predito pela expressão (5.41) (fora da ROI) e os valores preditos pelas expressões (5.38) e (5.28) para o RMA e MMA dentro da ROI, respectivamente.

\subsection{Análise do algoritmo SBD}

O erro de estimação do algoritmo SBD é definido na Equação (2.22), repetida aqui por conveniência,

$$
e(n)=\left|\hat{a}_{\mathrm{R}}(n)\right|\left[\hat{a}_{\mathrm{R}}(n)-y_{\mathrm{R}}(n)\right]+j\left|\hat{a}_{\mathrm{I}}(n)\right|\left[\hat{a}_{\mathrm{I}}(n)-y_{\mathrm{I}}(n)\right] .
$$

Substituindo (5.8) e (5.9) em (5.42) e admitindo que $\hat{a}(n)=a(n-\Delta)$, se obtém

$$
e(n) \approx\left|a_{\mathrm{R}}(n-\Delta)\right|\left[e_{a, \mathrm{R}}(n)+v_{\mathrm{R}}(n)\right]+j\left|a_{\mathrm{I}}(n-\Delta)\right|\left[e_{a, \mathrm{I}}(n)+v_{\mathrm{I}}(n)\right] .
$$

Admitindo que

A11) $a(n-\Delta)$ é independente do erro a priori e de $v(n)$ em regime,

chega-se a

$$
\mathrm{E}\left\{|e(n)|^{2}\right\} \approx \mathrm{E}\left\{\left|a_{\mathrm{R}}(n)\right|^{2}\right\}\left[\mathrm{E}\left\{\left|e_{a}(n)\right|^{2}\right\}+\sigma_{v}^{2}\right]
$$

e

$$
\mathrm{E}\left\{e_{a}^{*}(n) e(n)\right\} \approx \mathrm{E}\left\{\left|a_{\mathrm{R}}(n)\right|\right\} \mathrm{E}\left\{\left|e_{a}(n)\right|^{2}\right\}
$$

Substituindo (5.44) e (5.45) em (5.17), definindo $r_{1} \triangleq \mathrm{E}\left\{a_{\mathrm{R}}^{2}(n)\right\} / \mathrm{E}\left\{\left|a_{\mathrm{R}}(n)\right|\right\}$ e observando que $\mathrm{E}\left\{\left|a_{\mathrm{R}}(n)\right|\right\}=\mathrm{E}\left\{\left|a_{\mathrm{I}}(n)\right|\right\}=\sqrt{S} / 2$ para constelações $S$-QAM quadradas, chega-se a

$$
\zeta_{\mathrm{SBD}} \approx \frac{1}{2-\mu r_{1}}\left[\mu r_{1} \sigma_{v}^{2}+\frac{\operatorname{Tr}(\mathbf{Q})}{\mu \eta_{u} \sqrt{S} / 2}\right] .
$$


Similarmente ao RMA, o EMSE do SBD é zero num ambiente estacionário $(\mathbf{Q}=\mathbf{0})$ e admitindo equalização com sobreamostragem na ausência de ruído $(v(n)=0)$, independentemente da ordem da constelação QAM.

\subsection{Conclusões}

Neste capítulo, foram obtidas expressões analíticas para o EMSE em regime do MMA normalizado, RMA e algoritmo SBD, todos implementados na taxa de símbolos e considerando um ambiente não-estacionário. A análise do MMA nessas condições é também uma contribuição desta tese, já que os resultados contidos na literatura foram obtidos a partir da suposição de que a solução ótima leva à equalização perfeita, condição que só pode ser atingida com sobreamostragem.

A partir da expressão do EMSE em regime do MMA, verifica-se que seu erro em excesso é nulo somente quando se usa sobreamostragem em um ambiente estacionário e sem ruído e quando os sinais transmitidos são de módulo constante. Isso justifica o fato do MMA apresentar um desempenho insatisfatório na equalização de sinais QAM de ordem elevada. Em contrapartida, os algoritmos RMA e SBD tratam constelações QAM de módulo nãoconstante como se tivessem módulo constante. Assim, independentemente da ordem do sinal QAM, esses algoritmos podem atingir um EMSE em regime igual a zero em um ambiente estacionário e sem ruído.

Cabe observar que a partir das expressões obtidas neste capítulo, podem ser derivadas expressões analíticas para os valores dos passos de adaptação que minimizam o EMSE em regime. Além disso, os resultados em um ambiente estacionário podem ser obtidos diretamente das expressões de EMSE, fazendo $\operatorname{Tr}(\mathbf{Q})=0$. Nota-se que o caso de sobreamostragem também é contemplado pelas expressões, sendo que para isso, basta considerar $v(n)=0$. 


\section{Capítulo 6}

\section{O equalizador de decisão realimentada}

Diferentemente dos equalizadores lineares transversais (LTEs), os equalizadores de decisão realimentada (DFE - decision feedback equalizer) podem apresentar um bom desempenho em ambientes difíceis de equalizar como canais com respostas impulsivas longas e esparsas, de fase não-mínima, com nulos espectrais pronunciados e/ou que exibam não-linearidades. Como acontece com o LTE, a adaptação autodidata do DFE é mais eficiente em termos de largura de banda que a adaptação supervisionada. Porém, quando o algoritmo de equalização autodidata é baseado na função custo do módulo constante, ele pode convergir para soluções degeneradas. Além disso, ocorrem os inconvenientes comuns ao LTE, como ambiguidade de fase e desajuste relativamente elevado ao recuperar sinais de módulo não-constante.

Neste capítulo, são propostos algoritmos eficientes para a adaptação autodidata do DFE, levando-se em conta a classe de algoritmos normalizados da Equação (1.12) e os erros de estimação do SBD e RMA. Esses erros permitem obter um DFE autodidata que pode alcançar um EMSE próximo ao do DFE supervisionado, independentemente da ordem da constelação QAM. Para evitar soluções degeneradas, o mecanismo proposto em [SZCZECINSKI; GEI, 2002] é incluído na adaptação. Além disso, para aumentar a velocidade de convergência e evitar divergência, são considerados os esquemas de vizinhança axial e o mecanismo para evitar divergência do RMA, propostos no Capítulo 4. Dessa forma, os algoritmos propostos neste capítulo podem ser interpretados como extensões do RMA e do algoritmo SBD para a adaptação autodidata conjunta dos filtros direto e de realimentação do DFE. 


\subsection{O modelo do DFE}

O modelo simplificado de um sistema de comunicação, mostrado na Figura 6.1, considera um DFE com sobreamostragem por um fator dois $(T / 2)$. A sobreamostragem é considerada

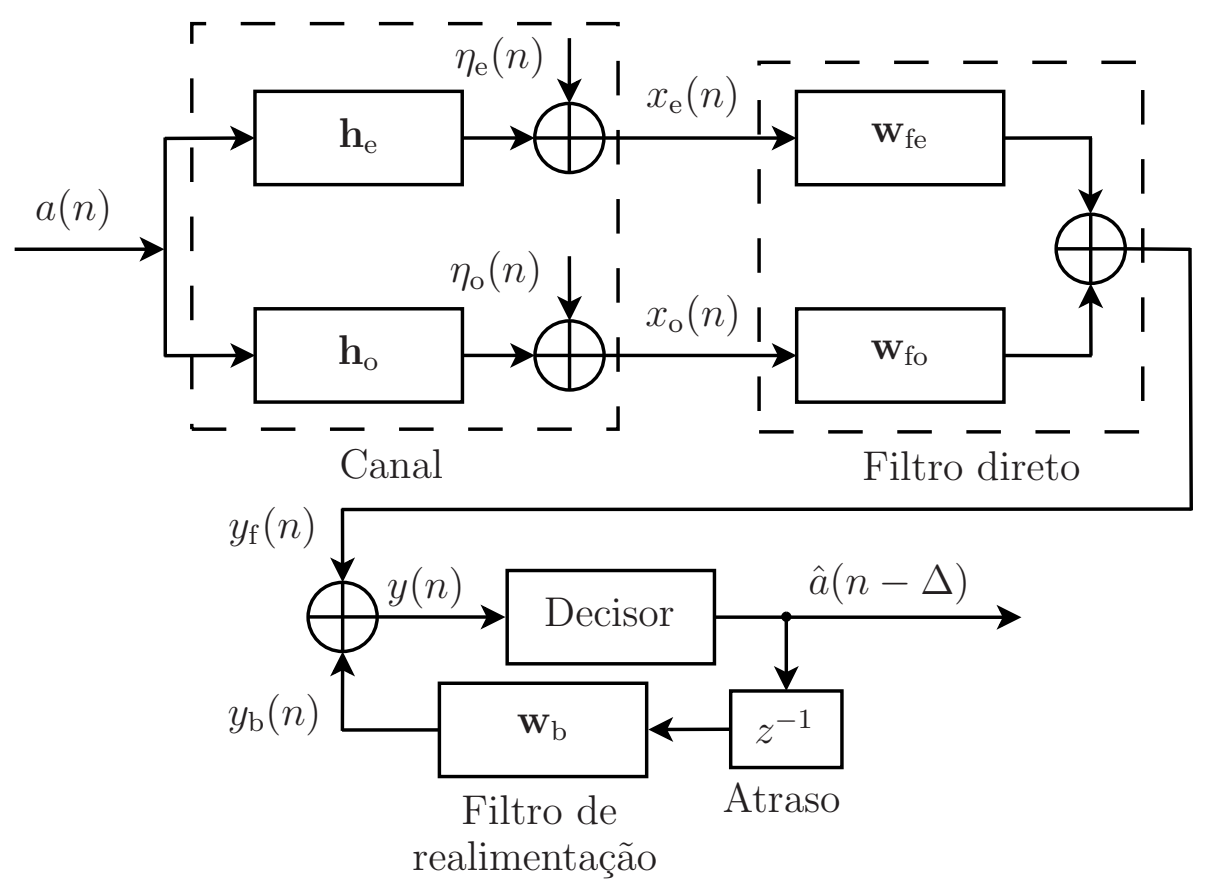

Figura 6.1: Sistema de comunicação simplificado com DFE e sobreamostragem $(T / 2)$.

devido às suas vantagens inerentes, que são bem conhecidas e justificadas, por exemplo, em [TREICHLER; FIJALKOW; JR., 1996; QIN et al., 2004; SZCZECINSKI; GEI, 2002; SILVA, 2005] e suas referências. Um sinal i.i.d. e não-gaussiano $a(n)$ é transmitido através de um canal de comunicação desconhecido e modelado pelos vetores de sua resposta impulsiva

$$
\mathbf{h}_{\mathrm{e}}=\left[\begin{array}{llll}
h_{0} & h_{2} & \cdots & h_{2 N-2}
\end{array}\right]^{T}
$$

e

$$
\mathbf{h}_{\mathrm{o}}=\left[h_{1} h_{3} \cdots h_{2 N-1}\right]^{T} \text {, }
$$

e por um ruído aditivo branco gaussiano (AWGN), cujas amostras são denotadas por $\eta_{\mathrm{e}}(n)$ e $\eta_{\mathrm{o}}(n)$. Cabe observar que $h_{0}, h_{1}, \cdots, h_{2 N-1}$ são amostras de um modelo de canal em tempo contínuo, amostrado com o dobro da frequência nominal de símbolos. Os sinais $x_{\mathrm{e}}(n)$ 
e $x_{\mathrm{o}}(n)$ são versões distorcidas do sinal de transmissão, devido aos efeitos da interferência intersimbólica e do ruído. Estes sinais são filtrados por filtros FIR ( $\left.\mathbf{w}_{\mathrm{fe}} \mathrm{e} \mathbf{w}_{\mathrm{fo}}\right)$, cada um com $M_{\mathrm{f}} / 2$ coeficientes, formando o filtro direto sobreamostrado, cuja saída é denotada por

$$
y_{\mathrm{f}}(n)=\mathbf{x}^{T}(n) \mathbf{w}_{\mathrm{f}}(n-1)
$$

sendo $\mathbf{w}_{\mathrm{f}}(n-1)$ o vetor de coeficientes do filtro direto, formado pela concatenação dos vetores de coeficientes $\mathbf{w}_{\mathrm{fe}}(n-1)$ e $\mathbf{w}_{\mathrm{fo}}(n-1)$, i.e.,

$$
\mathbf{w}_{\mathrm{f}}(n-1)=\left[\mathbf{w}_{\mathrm{fe}}^{T}(n-1) \mathbf{w}_{\mathrm{fo}}^{T}(n-1)\right]^{T}
$$

e

$$
\mathbf{x}(n)=\left[\begin{array}{ll}
\mathbf{x}_{\mathrm{e}}^{T}(n) & \mathbf{x}_{\mathrm{o}}^{T}(n)
\end{array}\right]^{T}
$$

o vetor regressor de entrada, em que

$$
\mathbf{x}_{\mathrm{e}}(n)=\left[x_{\mathrm{e}}(n) x_{\mathrm{e}}(n-1) \cdots x_{\mathrm{e}}\left(n-M_{\mathrm{f}} / 2+1\right)\right]^{T}
$$

$\mathrm{e}$

$$
\mathbf{x}_{\mathrm{o}}(n)=\left[x_{\mathrm{o}}(n) x_{\mathrm{o}}(n-1) \cdots x_{\mathrm{o}}\left(n-M_{\mathrm{f}} / 2+1\right)\right]^{T} .
$$

As decisões passadas são realimentadas e filtradas por um filtro de realimentação FIR com $M_{\mathrm{b}}$ coeficientes, denotado por $\mathbf{w}_{\mathrm{b}}$, resultando no sinal de saída

$$
y_{\mathrm{b}}(n)=\hat{\mathbf{a}}_{\Delta}^{T}(n) \mathbf{w}_{\mathrm{b}}(n-1),
$$

sendo

$$
\hat{\mathbf{a}}_{\Delta}(n)=\left[\hat{a}(n-\Delta-1) \cdots \hat{a}\left(n-\Delta-M_{b}\right)\right]^{T} .
$$

Por conveniência, os vetores regressores de entrada são concatenados em um único vetor coluna, aqui denotado como

$$
\mathbf{u}(n)=\left[\begin{array}{ll}
\mathbf{x}^{T}(n) & \hat{\mathbf{a}}_{\Delta}^{T}(n)
\end{array}\right]^{T}
$$


As saídas dos filtros direto e de realimentação são somadas para gerar a saída do DFE, ou seja, $y(n)=y_{\mathrm{f}}(n)+y_{\mathrm{b}}(n)$, que é encaminhada ao decisor. Definindo o vetor de coeficientes w como a concatenação dos vetores dos filtros direto e de realimentação, ou seja,

$$
\mathbf{w}(n-1)=\left[\mathbf{w}_{\mathrm{f}}^{T}(n-1) \mathbf{w}_{\mathrm{b}}^{T}(n-1)\right]^{T},
$$

e usando o vetor (6.7), a saída do DFE pode ser calculada como o produto interno

$$
y(n)=\mathbf{u}^{T}(n) \mathbf{w}(n-1) .
$$

Deseja-se que o DFE mitigue de forma eficiente os efeitos do canal de modo a recuperar $a(n)$ a partir de $y(n)$ para algum atraso $\Delta$. Como no caso do LTE, a adaptação do DFE pode ser feita de forma supervisionada ou autodidata, sendo a adaptação autodidata mais eficiente em termos de largura de banda. As condições suficientes para sua equalização perfeita podem ser encontradas, por exemplo, em [PAPADIAS; PAULRAJ, 1995; SILVA, 2005] e suas referências. Essas condições relacionam as ordens dos filtros direto e de realimentação com a ordem do canal e foram obtidas considerando ausência de ruído e realimentação de decisões corretas. Embora elas sejam restritas do ponto de vista prático, são interessantes porque mostram que o DFE pode apresentar um bom desempenho na equalização de canais com resposta ao pulso unitário finita, mesmo quando implementado na taxa de símbolos. Esses resultados motivam a busca de algoritmos eficientes para o DFE.

\subsection{O DFE autodidata: problemas e soluções}

Uma solução simples e intuitiva para recuperar $a(n)$ na saída do DFE sem uma sequência de treinamento é usar o CMA, que busca alcançar os pontos estacionários da função custo do módulo constante [GODARD, 1980]. Neste caso, o vetor w definido em (6.8) é adaptado através da equação

$$
\mathbf{w}(n)=\mathbf{w}(n-1)+\mu e(n) \mathbf{u}^{*}(n)
$$

em que $e(n)=\left(r-|y(n)|^{2}\right) y(n)$ é o erro de estimação do módulo constante e $\mathbf{u}(n)$ o vetor de entrada, definido em (6.7) . Supondo que o sinal transmitido é do tipo 4-QAM em que 
$r=2$, os coeficientes dos filtros direto e de realimentação podem assumir a forma

$$
\mathbf{w}_{\mathrm{f}}(n)=\mathbf{0}, \quad \text { e } \quad \mathbf{w}_{\mathrm{b}}(n)=\sqrt{r / 2}\left[\begin{array}{lllllll}
0 & \cdots & 0 & 1 & 0 & \cdots & 0
\end{array}\right]^{T} .
$$

Nesta situação, $e(n)=0$, o sinal de saída se torna independente do sinal de entrada e a atualização dos coeficientes com o CMA deixa de ocorrer. Esse tipo de solução indesejada é conhecida na literatura como solução degenerada e uma vez que ela ocorra, mesmo que as condições do sinal de entrada mudem, a saída do filtro não volta a fornecer resultados relacionados com o sinal transmitido.

Para evitar essas soluções, surgiram diferentes propostas como as dos trabalhos [CASAS et al., 1995, 1999; TONG; LIU, 1997; LABAT; MACCHI; LAOT, 1998; SZCZECINSKI; GEI, 2002]. Dentre essas soluções, destaca-se a proposta em [SZCZECINSKI; GEI, 2002] que considera o critério do módulo constante com uma restrição que depende da variável

$$
C(n)=\left\|\mathbf{w}_{\mathrm{b}}(n-1)\right\|^{2}-E_{y_{\mathrm{f}}}(n),
$$

em que $E_{y_{\mathrm{f}}}(n)$ representa uma estimativa da potência do sinal de saída do filtro direto. Esse critério é minimizado com um algoritmo do gradiente estocástico denotado por DFE-CMA-FB, que atualiza os coeficientes do filtro direto e de realimentação respectivamente por

$$
\mathbf{w}_{\mathrm{f}}(n)=\mathbf{w}_{\mathbf{f}}(n-1)+\mu\left[\lambda_{\mathrm{L}}(n) \mathbf{g}(n)-e(n) \mathbf{x}^{*}(n)\right]
$$

$\mathrm{e}$

$$
\mathbf{w}_{\mathrm{b}}(n)=\left[1-\mu \lambda_{\mathrm{L}}(n)\right] \mathbf{w}_{\mathrm{b}}(n-1)-\mu e(n) \hat{\mathbf{a}}_{\Delta}^{*}(n),
$$

em que $\mathbf{g}(n)$ representa uma estimativa da correlação cruzada entre o vetor $\mathbf{x}(n)$ e a saída do filtro direto $y_{\mathrm{f}}(n)$ e a variável $\lambda_{\mathrm{L}}(n)$ representa o multiplicador de Lagrange que é associado à função custo do módulo constante para contornar o efeito das soluções degeneradas e sua atuação no algoritmo depende do valor de $C(n)$. Conforme demonstrado por contradição em [SZCZECINSKI; GEI, 2002], quando $C(n)$ é menor ou igual a zero as soluções degeneradas não ocorrem. Assim, se $C(n) \leq 0$, faz-se $\lambda_{\mathrm{L}}(n)=0$ e o DFE-CMA-FB funciona como o CMA convencional. Em contrapartida, se $C(n)>0$, a atualização dos coeficientes $\mathbf{w}_{\mathrm{f}}$ e $\mathbf{w}_{\mathrm{b}}$ é feita supondo $\lambda_{\mathrm{L}}(n)$ igual a uma constante positiva $\lambda_{0}$, cujo valo usual é $\lambda_{\mathrm{L}}(n)=\lambda_{0}=2$. 
Apesar do DFE-CMA-FB evitar soluções degeneradas, dois outros inconvenientes intrínsecos aos algoritmos baseados na função custo do módulo constante são encontrados:

- a impossibilidade de resolver a ambiguidade de fase introduzida pelo canal e

- um desajuste relativamente elevado ao recuperar sinais de módulo não-constante, como no caso de sinais QAM de ordem alta.

A rotação de fase aleatória é um problema comum da equalização autodidata baseada no critério do módulo constante. Várias propostas podem ser encontradas na literatura para contornar esse problema, como por exemplo, as dos trabalhos [HEIDARI; NASIRI-KENARI, 2000; SZCZECINSKI; GEI, 2002; OH; CHIN, 1995; YANG; WERNER; DUMONT, 2002]. Dentre essas soluções, destaca-se a que deu origem ao MMA, que minimiza separadamente a dispersão das componentes real e imaginária da saída do equalizador. A questão da rotação de fase do MMA é abordada em detalhes na demonstração encontrada em [GARTH; YANG; WERNER, 2001]).

Visando uma redução do desajuste obtido com o algoritmo DFE-CMA-FB na equalização de sinais QAM e inspirando-se nos resultados de [DE CASTRO; DE CASTRO; ARANTES, 2001; CHEN, 2003], em [SILVA; MIRANDA; SOARES, 2004, 2005; SILVA, 2005; SOARES, 2004], foi proposta a operação concorrente do DFE-CMA-FB com o algoritmo de decisão direta suave (SDD) para adaptação conjunta dos filtros direto e de realimentação do DFE. O algoritmo resultante, denotado por NDEG-SDD-CMA, apresenta um desempenho melhor na equalização de sinais QAM em relação ao DFE-CMA-FB ao custo de um acréscimo moderado na complexidade computacional. No entanto, como no caso dos algoritmos concorrentes para o LTE, o NDEG-SDD-CMA não apresenta resultados satisfatórios para a equalização autodidata de sinais QAM, o que justifica a busca de algoritmos mais eficientes para a adaptação autodidata do DFE.

Dessa forma, os erros de estimação abordados no Capítulo 2 podem ser usados para adaptação do DFE na equalização de sinais QAM, desde que se tome o devido cuidado para evitar soluções degeneradas. Dentre as diferentes possibilidades, destacam-se os algoritmo RMA e SBD modificados segundo o mecanismo que evita soluções degeneradas, proposto 
em [SZCZECINSKI; GEI, 2002]. Um sumário das relações entre os algoritmos é mostrado na Figura 6.2, na qual as linhas tracejadas indicam que um algoritmo foi usado como uma fonte de inspiração. Na próxima seção, a extensão do RMA e SBD para o DFE é abordada com detalhes.

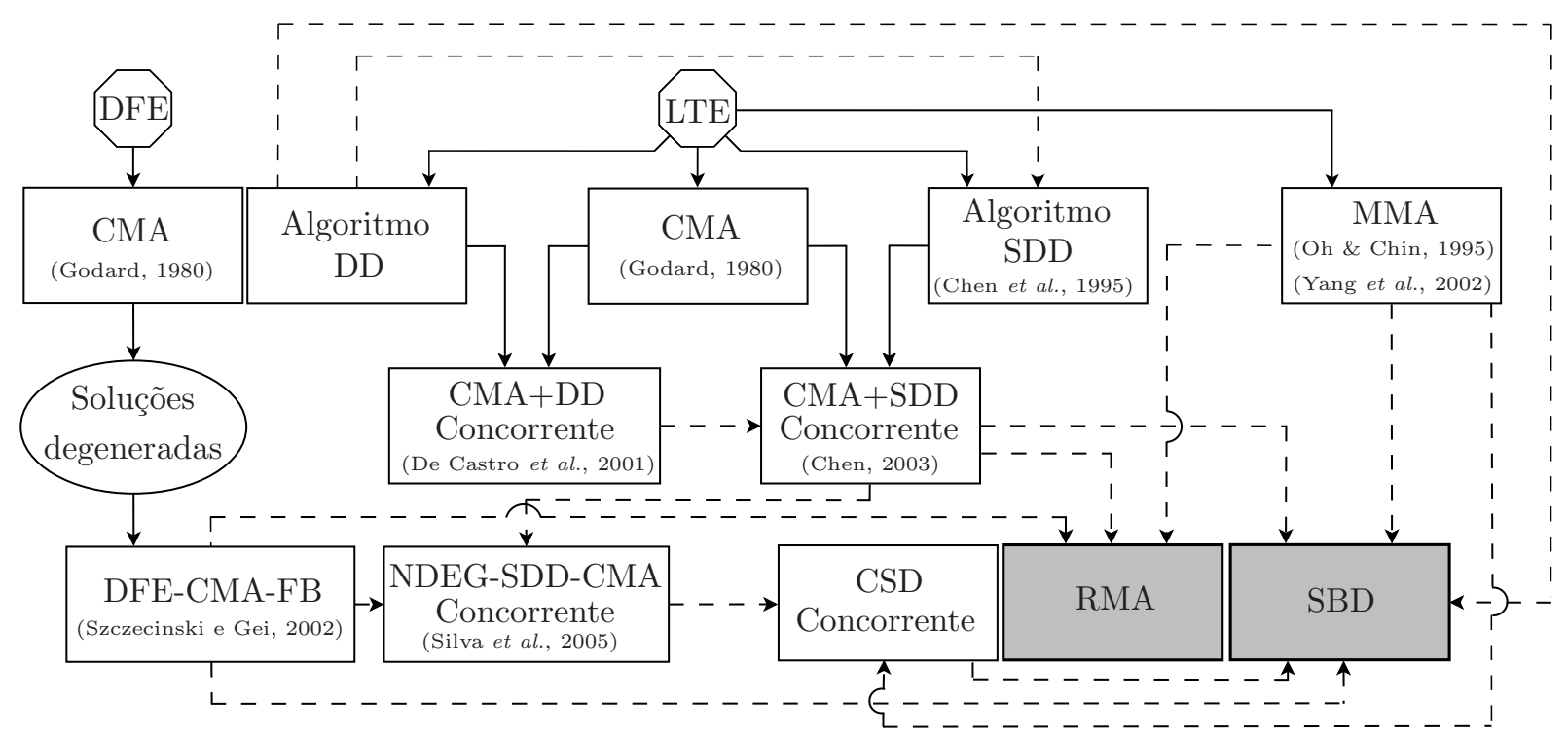

Figura 6.2: Relações entre algoritmos autodidatas para a equalização de sinais QAM com o DFE.

\subsection{Algoritmos eficientes para o DFE autodidata}

Ao incluir o mecanismo para evitar soluções degeneradas de [SZCZECINSKI; GEI, 2002] na classe de algoritmos normalizados (1.12), resulta a seguinte equação

$$
\left[\begin{array}{c}
\mathbf{w}_{\mathrm{f}}(n) \\
\mathbf{w}_{\mathrm{b}}(n)
\end{array}\right]=\left[\begin{array}{r}
\mathbf{w}_{\mathrm{f}}(n-1) \\
{\left[1-\tilde{\mu}(n) \lambda_{\mathrm{L}}(n)\right] \mathbf{w}_{\mathrm{b}}(n-1)}
\end{array}\right]+\tilde{\mu}(n) e(n) \mathbf{u}^{*}(n)+\tilde{\mu}(n) \lambda_{\mathrm{L}}(n)\left[\begin{array}{c}
\mathbf{g}(n) \\
\mathbf{0}_{M_{\mathrm{b}}}
\end{array}\right],
$$

sendo $e(n)$ o erro de estimação, $\mathbf{u}(n)$ definido em (6.7), $\mathbf{0}_{M_{\mathrm{b}}}$ um vetor nulo com $M_{\mathrm{b}}$ elementos,

$$
\tilde{\mu}(n)=\frac{\mu}{\delta+\|\mathbf{u}(n)\|^{2}},
$$

o passo de adaptação e $\delta$ o fator de regularização (constante positiva pequena). O vetor $\mathbf{g}(n)$ e o multiplicador de Lagrange $\lambda_{\mathrm{L}}(n)$ aparecem em (6.12) para evitar soluções degeneradas. 
Quando $\lambda_{\mathrm{L}}(n)=0$, (6.12) se reduz a um algoritmo autodidata normalizado com possível convergência para soluções degeneradas.

Quando as componentes de $e(n)=e_{\mathrm{R}}(n)+j e_{\mathrm{I}}(n)$ são calculadas separadamente como no MMA, (6.12) se reduz à versão normalizada do MMA que evita soluções degeneradas. As equações deste algoritmo, aqui denotado como DFE-MMA-FB, são apresentadas na Tabela 6.1. Como no caso da equalização com um filtro linear transversal, esse algoritmo pode contornar o problema da rotação da fase mas seu desajuste ainda é insatisfatório para equalizar sinais QAM de alta ordem. Diferentes erros de estimação com componentes real e imaginária calculadas separadamente podem ser considerados. Os candidatos naturais são os erros apresentados no Capítulo 2. Propõe-se usar os erros do RMA e do SBD (eqs. (2.16) e (2.22), respectivamente) diretamente em (6.12) devido às suas características convenientes. Os algoritmos que resultam do uso desses erros de estimação estão apresentados nas Tabelas 6.2 e 6.3, respectivamente.

Na Tabela 6.4, são mostrados os custos computacionais dos algoritmos DFE-MMA-FB, RMA e SBD para adaptação do DFE. Além disso, considera-se para efeito de comparação o custo computacional do algoritmo CSD, que é a versão do MMA do NDEG-SDD-CMA. Na tabela são mostrados os números de multiplicações reais $(\times)$, somas reais $(+)$, divisões reais $(\div)$, comparações $\mathcal{C}$ e cálculos de exponencial (exp). Os custos computacionais do RMA e SBD são similares aos do DFE-MMA-FB. O algoritmo CSD, por sua vez, apresenta um custo computacional superior, mas que ainda cresce linearmente com o número de coeficientes dos filtros direto e de realimentação.

Para encerrar esta seção, cabe observar que os esquemas de vizinhança propostos no Capítulo 4 para acelerar a convergência dos algoritmos propostos podem ser estendidos diretamente para os algoritmos SBD e RMA, considerando a adaptação do DFE. Como esses esquemas são baseados em cálculos de erros em regiões vizinhas da saída do equalizador, o custo computational adicional é relativamente baixo, já que esses cálculos não dependem do número de coeficientes dos filtros direto e de realimentação. Além disso, o mecanismo que evita divergência do RMA da Seção 4.3.3 também deve ser levado em conta aqui, já que esse algoritmo pode divergir quando usado para adaptar o DFE como acontece com o MMA. No 
caso do algoritmo SBD, sua convergência é assegurada, escolhendo-se os passos de adaptação nos intervalos obtidos na Seção 4.3.2.

Tabela 6.1: Sumário do DFE-MMA-FB.

Inicialização do algoritmo:

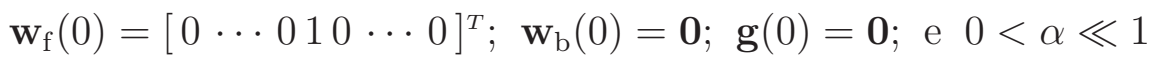

$$
\begin{aligned}
& E_{y_{\mathrm{f}}}(0)=0 ; \quad \lambda_{0}=2 ; \quad v(x)=\{1, \text { se } x \geq 0 \quad \text { e } \quad 0, \text { caso contrário }\}
\end{aligned}
$$

Para cada instante de tempo, $n=1,2, \cdots$, calcule:

$$
\begin{aligned}
& \mathbf{u}(n)=\left[\begin{array}{ll}
\mathbf{x}^{T}(n) & \hat{\mathbf{a}}_{\Delta}^{T}(n)
\end{array}\right]^{T} \\
& y_{\mathrm{f}}(n)=\mathbf{x}^{T}(n) \mathbf{w}_{\mathrm{f}}(n-1) \\
& y_{\mathrm{b}}(n)=\hat{\mathbf{a}}_{\Delta}^{T}(n) \mathbf{w}_{\mathrm{b}}(n-1) \\
& y(n)=y_{\mathrm{f}}(n)+y_{\mathrm{b}}(n)=y_{\mathrm{R}}(n)+j y_{\mathrm{I}}(n) \\
& \tilde{\mu}(n)=\frac{\mu}{\delta+\|\mathbf{u}(n)\|^{2}} \\
& e_{\mathrm{R}}(n)=\left(\left|y_{\mathrm{R}}(n)\right|^{2}-r_{2}\right) y_{\mathrm{R}}(n) \\
& e_{\mathrm{I}}(n)=\left(\left|y_{\mathrm{I}}(n)\right|^{2}-r_{2}\right) y_{\mathrm{I}}(n) \\
& e(n)=e_{\mathrm{R}}(n)+j e_{\mathrm{I}}(n) \\
& E_{y_{\mathrm{f}}}(n)=\alpha E_{y_{\mathrm{f}}}(n-1)+(1-\alpha)\left|y_{\mathrm{f}}(n)\right|^{2} \\
& \mathbf{g}(n)=\alpha \mathbf{g}(n-1)+(1-\alpha) y_{f}(n) \mathbf{x}^{*}(n) \\
& C(n)=\left\|\mathbf{w}_{b}(n-1)\right\|^{2}-E_{y_{f}}(n) \\
& \lambda_{\mathrm{L}}(n)=\lambda_{o} v(C(n)) \\
& \mathbf{w}_{\mathrm{f}}(n)=\mathbf{w}_{\mathrm{f}}(n-1)+\tilde{\mu}(n)\left[\lambda_{\mathrm{L}}(n) \mathbf{g}(n)-e(n) \mathbf{x}^{*}(n)\right] \\
& \mathbf{w}_{\mathrm{b}}(n)=\left[1-\tilde{\mu}(n) \lambda_{\mathrm{L}}(n)\right] \mathbf{w}_{\mathrm{b}}(n-1)-\tilde{\mu}(n) e(n) \hat{\mathbf{a}}_{\Delta}^{*}(n)
\end{aligned}
$$

Fim 
Tabela 6.2: Sumário do RMA que evita soluções degeneradas.

Inicialização do algoritmo:

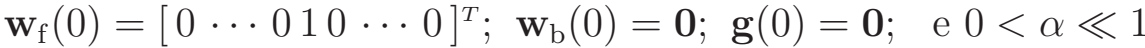

$E_{y_{\mathrm{f}}}(0)=0 ; \quad \lambda_{0}=2 ; \quad v(x)=\{1$, se $x \geq 0 \quad$ e 0, caso contrário $\}$

Para cada instante de tempo, $n=1,2, \cdots$, calcule:

$$
\begin{aligned}
& \mathbf{u}(n)=\left[\begin{array}{ll}
\mathbf{x}^{T}(n) & \hat{\mathbf{a}}_{\Delta}^{T}(n)
\end{array}\right]^{T} \\
& y_{\mathrm{f}}(n)=\mathbf{x}^{T}(n) \mathbf{w}_{\mathrm{f}}(n-1) \\
& y_{\mathrm{b}}(n)=\hat{\mathbf{a}}_{\Delta}^{T}(n) \mathbf{w}_{\mathrm{b}}(n-1) \\
& y(n)=y_{\mathrm{f}}(n)+y_{\mathrm{b}}(n)=y_{\mathrm{R}}(n)+j y_{\mathrm{I}}(n) \\
& \tilde{\mu}(n)=\frac{\mu}{\delta+\|\mathbf{u}(n)\|^{2}}
\end{aligned}
$$

A partir de $y_{\mathrm{R}}(n)$ e $y_{\mathrm{I}}(n)$, obtêm-se $c_{\ell}$ e $c_{m}$, respectivamente

$$
\begin{aligned}
& \breve{y}_{\ell}(n)=y_{\mathrm{R}}(n)-c_{\ell} ; \quad \breve{y}_{m}(n)=y_{\mathrm{I}}(n)-c_{m} \\
& e_{\mathrm{R}}(n)=\left|c_{\ell}\right|\left[1-\breve{y}_{\ell}^{2}(n)\right] \breve{y}_{\ell}(n) ; \quad e_{\mathrm{I}}(n)=\left|c_{m}\right|\left[1-\breve{y}_{m}^{2}(n)\right] \breve{y}_{m}(n) \\
& e(n)=e_{\mathrm{R}}(n)+j e_{\mathrm{I}}(n) \\
& E_{y_{\mathrm{f}}}(n)=\alpha E_{y_{\mathrm{f}}}(n-1)+(1-\alpha)\left|y_{\mathrm{f}}(n)\right|^{2} \\
& \mathbf{g}(n)=\alpha \mathbf{g}(n-1)+(1-\alpha) y_{f}(n) \mathbf{x}^{*}(n) \\
& C(n)=\left\|\mathbf{w}_{b}(n-1)\right\|^{2}-E_{y_{f}}(n) \\
& \lambda_{\mathrm{L}}(n)=\lambda_{o} v(C(n)) \\
& \mathbf{w}_{\mathrm{f}}(n)=\mathbf{w}_{\mathrm{f}}(n-1)+\tilde{\mu}(n)\left[\lambda_{\mathrm{L}}(n) \mathbf{g}(n)-e(n) \mathbf{x}^{*}(n)\right] \\
& \mathbf{w}_{\mathrm{b}}(n)=\left[1-\tilde{\mu}(n) \lambda_{\mathrm{L}}(n)\right] \mathbf{w}_{\mathrm{b}}(n-1)-\tilde{\mu}(n) e(n) \hat{\mathbf{a}}_{\Delta}^{*}(n)
\end{aligned}
$$

Fim 
Tabela 6.3: Sumário do SBD que evita soluções degeneradas.

Inicialização do algoritmo:

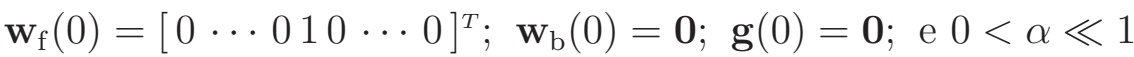

$E_{y_{\mathrm{f}}}(0)=0 ; \quad \lambda_{0}=2 ; \quad v(x)=\{1$, se $x \geq 0 \quad$ e $\quad 0$, caso contrário $\}$

Para cada instante de tempo, $n=1,2, \cdots$, calcule:

$$
\begin{aligned}
& \mathbf{u}(n)=\left[\begin{array}{ll}
\mathbf{x}^{T}(n) \hat{\mathbf{a}}_{\Delta}^{T}(n)
\end{array}\right]^{T} \\
& y_{\mathrm{f}}(n)=\mathbf{x}^{T}(n) \mathbf{w}_{\mathrm{f}}(n-1) \\
& y_{\mathrm{b}}(n)=\hat{\mathbf{a}}_{\Delta}^{T}(n) \mathbf{w}_{\mathrm{b}}(n-1) \\
& y(n)=y_{\mathrm{f}}(n)+y_{\mathrm{b}}(n)=y_{\mathrm{R}}(n)+j y_{\mathrm{I}}(n) \\
& \tilde{\mu}(n)=\frac{\mu}{\delta+\|\mathbf{u}(n)\|^{2}} \\
& \hat{a}_{\mathrm{R}}(n)=\operatorname{dec}\left[y_{\mathrm{R}}(n)\right] ; \quad \hat{a}_{\mathrm{I}}(n)=\operatorname{dec}\left[y_{\mathrm{I}}(n)\right] \\
& e_{\mathrm{R}}(n)=\left|\hat{a}_{\mathrm{R}}(n)\right|\left[\hat{a}_{\mathrm{R}}(n)-y_{\mathrm{R}}(n)\right] ; \quad e_{\mathrm{I}}(n)=\left|\hat{a}_{\mathrm{I}}(n)\right|\left[\hat{a}_{\mathrm{I}}(n)-y_{\mathrm{I}}(n)\right] \\
& e(n)=e_{\mathrm{R}}(n)+j e_{\mathrm{I}}(n) \\
& E_{y_{\mathrm{f}}}(n)=\alpha E_{y_{\mathrm{f}}}(n-1)+(1-\alpha)\left|y_{\mathrm{f}}(n)\right|^{2} \\
& \mathbf{g}(n)=\alpha \mathbf{g}(n-1)+(1-\alpha) y_{f}(n) \mathbf{x}^{*}(n) \\
& C(n)=\left\|\mathbf{w}_{b}(n-1)\right\|^{2}-E_{y_{f}}(n) \\
& \lambda_{\mathrm{L}}(n)=\lambda_{o} v(C(n)) \\
& \mathbf{w}_{\mathrm{f}}(n)=\mathbf{w}_{\mathrm{f}}(n-1)+\tilde{\mu}(n)\left[\lambda_{\mathrm{L}}(n) \mathbf{g}(n)-e(n) \mathbf{x}^{*}(n)\right] \\
& \mathbf{w}_{\mathrm{b}}(n)=\left[1-\tilde{\mu}(n) \lambda_{\mathrm{L}}(n)\right] \mathbf{w}_{\mathrm{b}}(n-1)-\tilde{\mu}(n) e(n) \hat{\mathbf{a}}_{\Delta}^{*}(n)
\end{aligned}
$$

Fim 
Tabela 6.4: Custo computacional em termos de operações reais por iteração - DFE.

\begin{tabular}{|c|c|c|c|c|}
\hline Op. & DFE-MMA-FB & CSD & RMA & SBD \\
\hline$\times$ & $18 M_{\mathrm{f}}+14 M_{\mathrm{b}}+15$ & $22 M_{\mathrm{f}}+18 M_{\mathrm{b}}+33$ & $18 M_{\mathrm{f}}+14 M_{\mathrm{b}}+17$ & $18 M_{\mathrm{f}}+14 M_{\mathrm{b}}+13$ \\
\hline+ & $13 M_{\mathrm{f}}+12 M_{\mathrm{b}}+5$ & $19 M_{\mathrm{f}}+18 M_{\mathrm{b}}+11$ & $13 M_{\mathrm{f}}+12 M_{\mathrm{b}}+7$ & $13 M_{\mathrm{f}}+12 M_{\mathrm{b}}+5$ \\
\hline$\div$ & 2 & 5 & 2 & 2 \\
\hline $\exp$ & - & 4 & - & - \\
\hline $\mathcal{C}$ & 1 & $\log _{2}(S)$ & $\log _{2}(S)-1$ & $\log _{2}(S)+1$ \\
\hline
\end{tabular}

\subsection{Conclusões}

Os esquemas apresentados neste capítulo sugerem que é possível obter um DFE autodidata com comportamento similar ao do DFE supervisionado. Entre outras características, os algoritmos aqui propostos apresentam:

1. um erro de estimação nulo quando a saída do equalizador coincide com o sinal transmitido;

2. uma recuperação simultânea do módulo e da fase do sinal,

3. um EMSE próximo daquele obtido no caso supervisionado com o NLMS,

4. ausência de soluções degeneradas,

5. estabilidade assegurada quando os passos de adaptação estão em um intervalo determinado e

6. velocidade de convergência aumentada, levando-se em conta a informação dos símbolos vizinhos ao símbolo estimado.

As boas propriedades sugerem que os algoritmos RMA e SBD para a adaptação do DFE podem apresentar um desempenho comparável ao do NLMS sendo, portanto, bons candidatos para serem usados na prática. No próximo capítulo esses algoritmos são avaliados em situações práticas distintas e comparados com o NLMS. 


\section{Capítulo 7}

\section{Resultados de simulação}

Neste capítulo, são mostrados resultados de simulação que ilustram o bom comportamento dos algoritmos RMA e SBD em diferentes cenários. Para efeito de comparação, são considerados a solução de Wiener, o algoritmo NLMS e o MMA. Em algumas simulações, também consideram-se os algoritmos CSD, MSD e MRD, descritos no Capítulo 2, e o algoritmo SMMA, proposto em [ABRAR; AMIN; SIDDIQ, 2005]. Inicialmente, são apresentados resultados com o equalizador linear transversal (LTE) e em seguida com o equalizador de decisão realimentada (DFE). No caso o DFE, o mecanismo para evitar soluções degeneradas é incorporado aos algoritmos, como descrito no Capítulo 6. Além disso, os mecanismos apresentados no Capítulo 4 para aumentar a velocidade de convergência e evitar divergência (nos casos do MMA e RMA) são sempre considerados, salvo explicitado o contrário. Cabe observar que nos trabalhos listados na Seção 1.8 (página 24) são apresentados outros resultados de simulação que corroboram os aqui alcançados.

\subsection{Canais de comunicação}

As respostas impulsivas dos canais de comunicação usados nas simulações são mostradas na Tabela 7.1. O canal $\mathbf{h}_{1}$ foi obtido com uma sobreamostragem por um fator dois e considerado nas simulações de [CHEN, 2003; CHEN; COOK; ANDERSON, 2004]. O canal $\mathbf{h}_{2}$ modela um canal telefônico na faixa de voz e foi utilizado nas simulações de [PICCHI; PRATI, 1987]. O canal 
$\mathbf{h}_{4}$ modela um canal de TV a cabo com 128 coeficientes complexos, foi obtido com uma sobreamostragem por um fator dois e utilizado nas simulações de [DE CASTRO; DE CASTRO; ARANTES, 2001]. Por fim, os canais $\mathbf{h}_{3}, \mathbf{h}_{5}$ e $\mathbf{h}_{6}$ são canais de fase não mínima e norma unitária.

Tabela 7.1: Coeficientes dos canais considerados nas simulações.

\begin{tabular}{|c|}
\hline Coeficientes dos canais \\
\hline 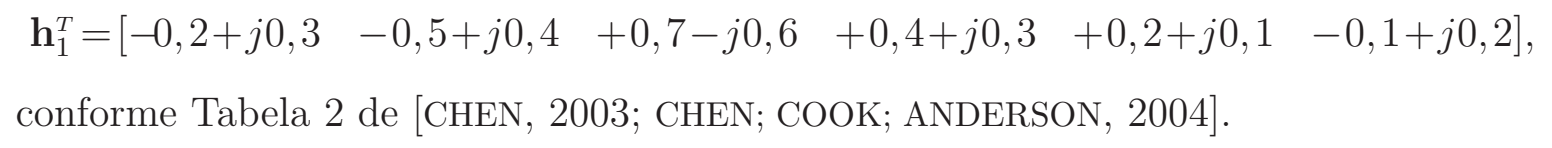 \\
\hline $\begin{array}{l}\mathbf{h}_{2}^{T}=[-0,005-j 0,004+0,009+j 0,030-0,024-j 0,104+0.854+j 0,520 \\
-0,218+j 0,273+0,049-j 0,074-0,016+j 0,020] \\
\text { conforme Figura } 2 \text { de [PICCHI; PRATI, 1987]. }\end{array}$ \\
\hline $\mathbf{h}_{3}^{T}=\left[\begin{array}{lll}0,36 & 0,86 & 0,36\end{array}\right]$ \\
\hline $\mathbf{h}_{4}$ : "data2.mat", base de dados disponível em http://spib.rice.edu/spib/cable.html. \\
\hline $\mathbf{h}_{5}^{T}=\left[\begin{array}{lll}0,1925 & 0,9623 & 0,1925\end{array}\right]$ \\
\hline $\mathbf{h}_{6}^{T}=\left[\begin{array}{lll}0,2762 & 0,9206 & 0,2762\end{array}\right]$ \\
\hline
\end{tabular}

\subsection{Simulações com o equalizador linear transversal}

Nesta seção, considera-se o modelo do sistema comunicação de tempo discreto da Figura 1.9, mostrado novamente na Figura 7.1 por conveniência. Nesse sistema, supõe-se que o canal de comunicação é modelado por uma das funções de transferência da Tabela 7.1 e ruído aditivo do tipo AWGN. O equalizador é constituído por um filtro linear transversal com $M$ coeficientes.

Os resultados de simulação dessa seção são divididos em cinco subseções. Em cada uma delas, são apresentados resultados que salientam características importantes dos algoritmos propostos. Nas simulações, todos os algoritmos (incluindo o NLMS) foram inicializados com o vetor do tipo "pino" (center spike initialization), em que apenas o coeficiente central é igual a "um" e os demais são iguais a zero. Além disso, o fator de regularização de todos os algoritmos é feito igual $\delta=10^{-8}$ (veja Equação (1.12), página 20). Em vez de usar os fatores 


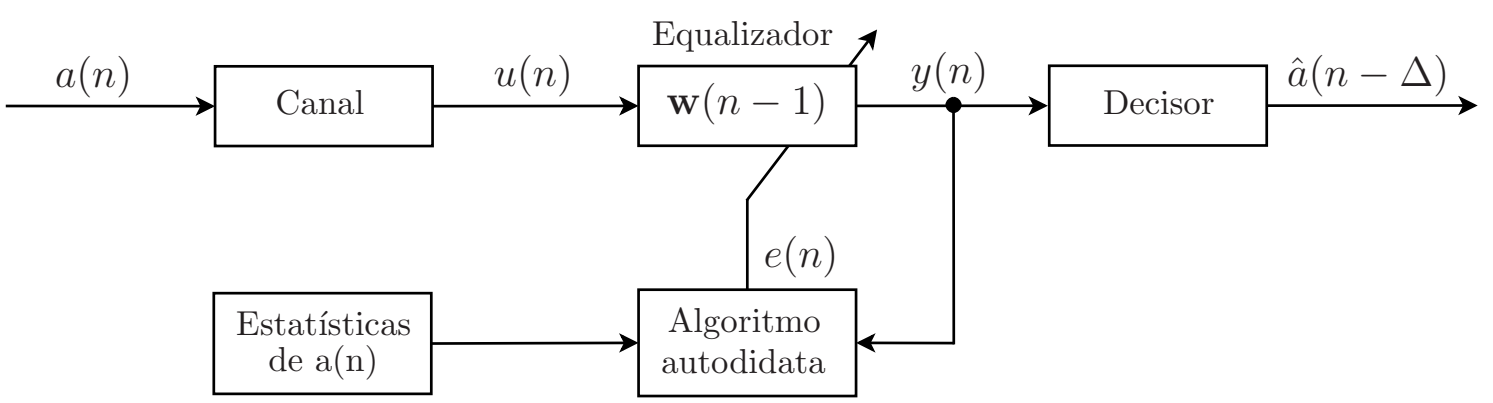

Figura 7.1: Sistema de comunicação simplificado com um equalizador autodidata.

de escala ótimos $\alpha_{\ell, \mathrm{o}}$ e $\alpha_{m, \mathrm{o}}$ no RMA (Equações (2.20) e (2.21), página 42), foram utilizados os valores absolutos dos centros das regiões, ou seja, $\alpha_{\ell}=\left|c_{\ell}\right|$ e $\alpha_{m}=\left|c_{m}\right|$. Isso facilita sua implementação já que a distância entre os centros das regiões adjacentes é sempre igual a quatro. Além disso, as curvas de MSE foram filtradas por um filtro de média móvel com 500 coeficientes para facilitar a visualização.

\subsubsection{Equalização perfeita}

Na Figura 7.2, são mostradas curvas da média de conjunto do erro de decisão ao quadrado (MSE de decisão), estimadas a partir de uma média de 50 realizações. Admite-se um equalizador sobreamostrado com $T / 2$, com $M=20$ coeficientes e a transmissão do sinal 1024-QAM através do canal $\mathbf{h}_{1}$ na ausência de ruído. Usando (5.28) com $\sigma_{v}^{2}=\operatorname{Tr}(\mathbf{Q})=0, \mu=2 \times 10^{-6}$ e as estatísticas de 1024-QAM, se obtém $\zeta_{\mathrm{MMA}} \approx-9.27 \mathrm{~dB}$, que está de acordo com os resultados experimentais, já que se pode observar na Figura 7.2-(a) que o MMA alcança um MSE em regime ligeiramente superior a $-10 \mathrm{~dB}$ (é importante salientar que como $\sigma_{v}^{2}=0$, os valores do EMSE e do MSE são iguais). Esse comportamento é esperado para sinais de módulo não-constante como no caso de 1024-QAM. O algoritmo CSD apresenta um desempenho superior ao do MMA, mas inferior ao do MSD. Apesar do sinal transmitido poder ser recuperado pelo MSD neste caso, a equalização perfeita não é alcançada, já que o MSE em regime é aproximadamente $-30 \mathrm{~dB}$. Isso ocorre devido ao fato de seu erro de estimação não ser igual a zero quando a saída do equalizador coincide com uma das coordenadas dos símbolos da constelação. Em contrapartida, pode-se observar na Figura 7.2-(b) que o SBD, o RMA e o MRD e o NLMS convergem para a solução de Wiener (denotada por "WIE" 
na figura), que exibe equalização perfeita neste caso (-300 dB na precisão do Matlab). Os resultados experimentais do RMA e do SBD estão de acordo com os resultados analíticos, já que o MSE previsto por (5.38) (página 95) e por (5.46) (página 96) é nulo para o equalizador sobreamostrado com $T / 2$ num ambiente estacionário $\left(\sigma_{v}^{2}=\operatorname{Tr}(\mathbf{Q})=0\right)$. A principal limitação para a utilização desses algoritmos em situações práticas é a convergência lenta dos mesmos. Observa-se que o SBD, o RMA e o MRD levam respectivamente $1,5 \times 10^{6}$, $2,5 \times 10^{6}$ e $5 \times 10^{6}$ iterações para alcançar a equalização perfeita. Essa desvantagem pode ser superada utilizando-se a técnica da Seção 4.2 (página 63) como mostrado a seguir. Como o algoritmo MRD apresenta a convergência mais lenta, que se torna pior com o aumento da ordem do sinal QAM, ele foi desconsiderado nas simulações seguintes.
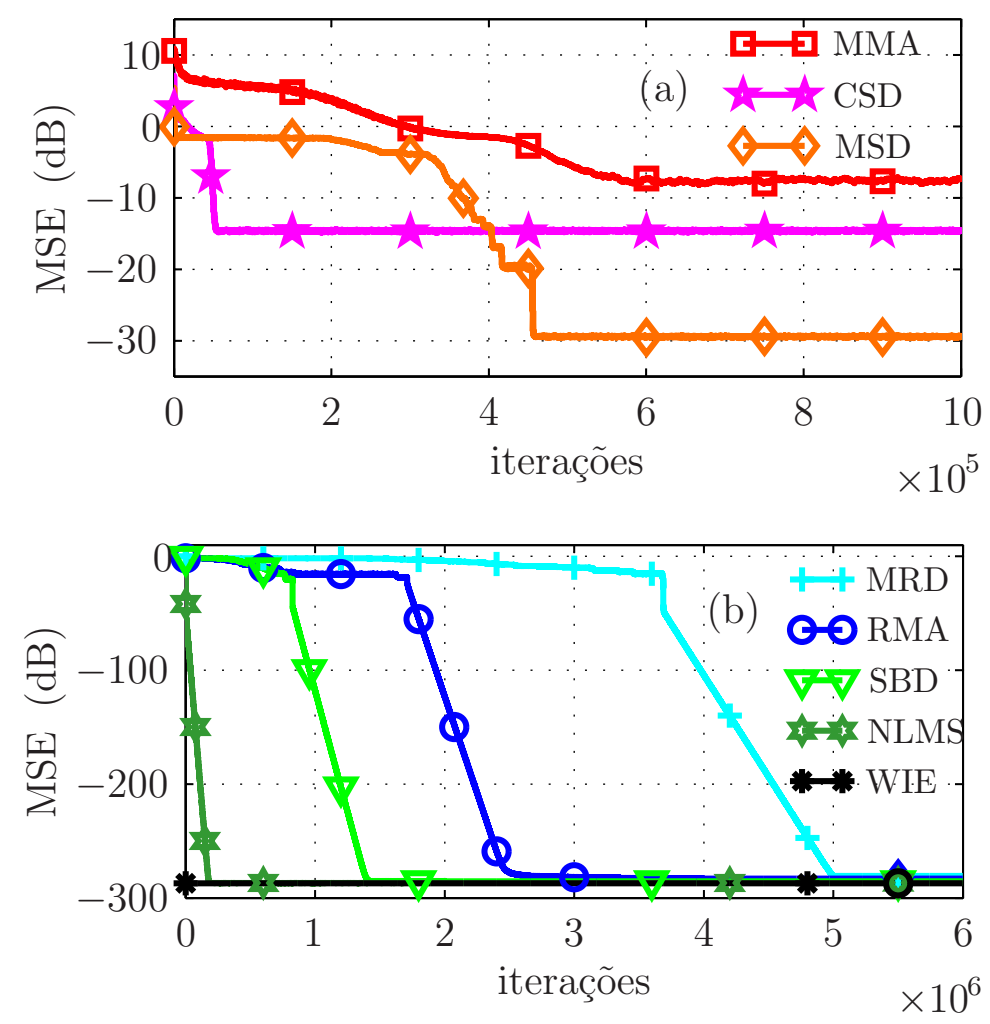

Figura 7.2: MSE para (a) MMA $\left(\mu=2 \times 10^{-6}\right)$, CSD $\left(\mu=10^{-1}, \beta=10^{-4}, \rho=0,6\right)$, MSD $\left(\mu=8 \times 10^{-3}, \rho=0,6\right)$; (b) $\operatorname{MRD}\left(\mu=10^{-4}\right), \operatorname{RMA}\left(\mu=4 \times 10^{-3}\right), \operatorname{SBD}\left(\mu=10^{-2}\right)$, NLMS $\left(\mu=5 \times 10^{-1}, \Delta_{1}=2\right)$, WIE $\left(\Delta_{1}=2\right)$; canal $\mathbf{h}_{1}, M=20$, 1024-QAM, equalizador sobreamostrado com $T / 2$, ausência de ruído, sem vizinhos, média de conjunto de 50 simulações independentes. 


\subsubsection{Solução de Wiener e vizinhança}

Para ilustrar a vantagem da técnica proposta na Seção 4.2 (página 63), são mostradas na Figura 7.3-(a) curvas de MSE para o RMA e para o SBD com o esquema de vizinhança Axial-1 (curvas contínuas) e sem vizinhos (curvas tracejadas), considerando a transmissão do sinal 256-QAM através de dois canais diferentes. Da iteração 0 até a iteração $10^{6}-1$, considera-se o canal telefônico $\mathbf{h}_{2}$. Na iteração $10^{6}$, é introduzida uma mudança abrupta para o canal $\mathbf{h}_{3}$. Em ambos os casos, admitem-se ausência de ruído e um equalizador implementado na taxa de símbolos com $M=21$ coeficientes. Pode-se observar na Figura 7.3-(a) que o SBD e o RMA se comportam como o NLMS em regime, convergindo para a solução de Wiener, como previsto no Capítulo 3. Além disso, observa-se que os vizinhos aumentam consideravelmente as taxas de convergência dos algoritmos, sendo essenciais em ambientes não-estacionários. Por exemplo, depois da mudança abrupta no canal e considerando a ajuda dos vizinhos, o RMA leva aproximadamente menos do que 0,5 × $10^{6}$ iterações para convergir para a solução de Wiener. Como referência, também são mostradas as curvas de MSE obtidas com os algoritmos NLMS e MMA. Na Figura 7.3-(b), é apresentada a média de conjunto do expoente $p(n)$. Quando $p(n) \approx-10$, a ajuda dos vizinhos pode ser descartada sem degradação do desempenho. Foram considerados apenas dois vizinhos para a parte real e dois para parte imaginária. Além disso, os vizinhos fazem ambos os algoritmos convergirem aproximadamente com a mesma taxa. É importante notar que em algumas vezes, os algoritmos propostos não convergem para a melhor solução de Wiener. Isso ocorre, nessa simulação, no caso do canal $\mathbf{h}_{2}$. Neste caso, os algoritmos autodidatas recuperam o sinal transmitido com um atraso de $\Delta_{2}=11$ amostras, enquanto a melhor solução de Wiener ocorre para um atraso de 13 amostras. Entretanto, essa questão pode ser resolvida com um ajuste na inicialização dos algoritmos.

Considerando novamente o canal telefônico $\mathbf{h}_{2}$, mas admitindo a transmissão de um sinal 4096-QAM, se obtêm as curvas de MSE da Figura 7.4-(a). Neste caso, foram usados quatro vizinhos para a parte real e quatro vizinhos para a parte imaginária, já que menos vizinhos não são suficientes para acelerar a convergência do SBD e do RMA. Pode-se observar que os vizinhos propiciam uma considerável redução no tempo de convergência 

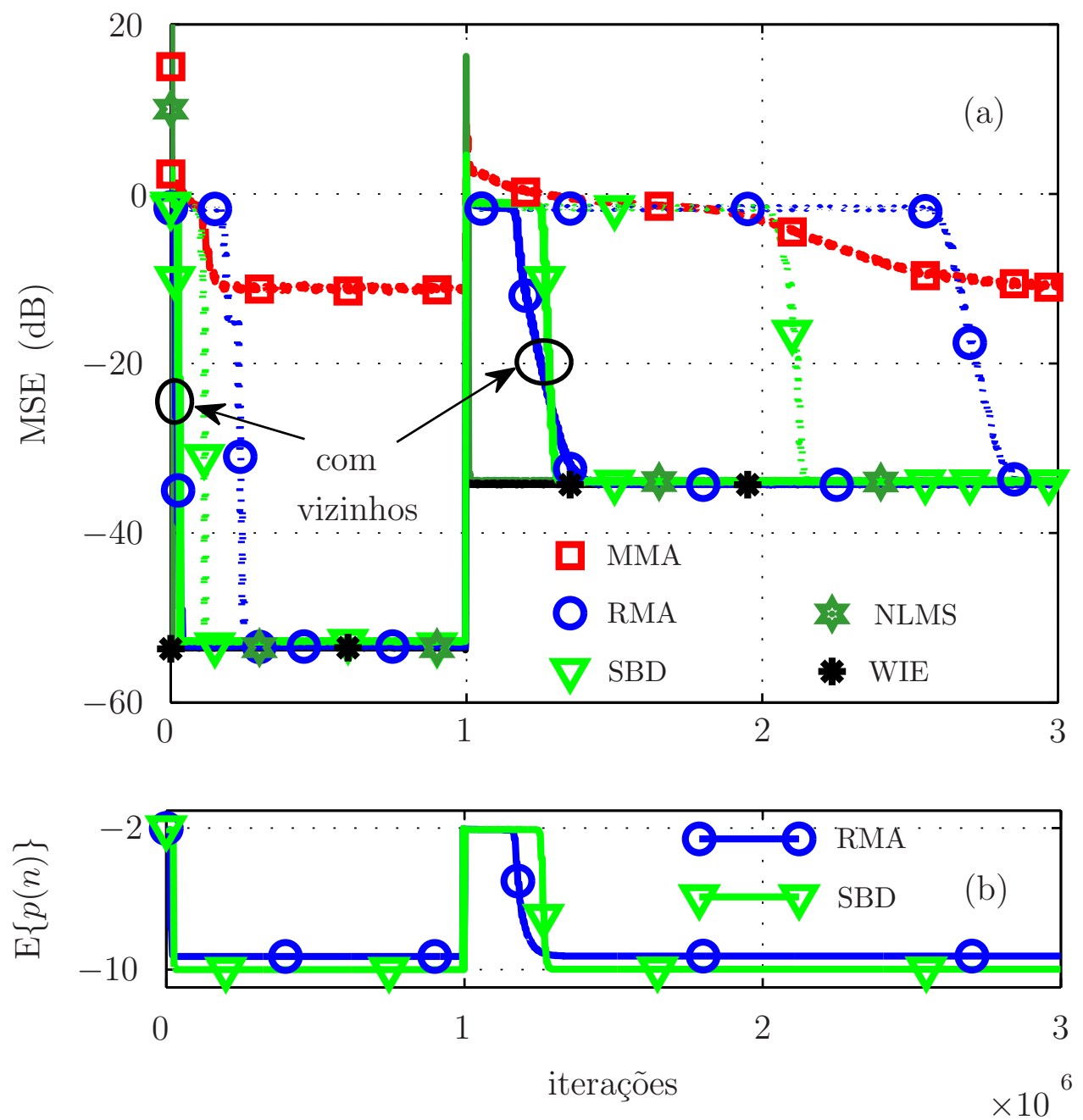

Figura 7.3: (a) MSE para MMA $\left(\mu=2 \times 10^{-5}\right)$, RMA $\left(\mu=10^{-3}\right)$, SBD $\left(\mu=10^{-2}\right)$, NLMS $\left(\mu=5 \times 10^{-1}, \Delta_{2}=\Delta_{3}=11\right)$, WIE $\left(\Delta_{2}=\Delta_{3}=11\right)$; (b) média de $p(n)$; vizinhança Axial-1 (2 vizinhos), canais $\mathbf{h}_{2}$ e $\mathbf{h}_{3}, M=21,256$-QAM; sem ruído, 50 realizações.

dos algoritmos propostos. Mais uma vez, eles atingem aproximadamente a solução de Wiener em regime, que, neste caso, apresenta um MSE de $J_{\min }(13)=\sigma_{v}^{2}=-41.37 \mathrm{~dB}$. Em contrapartida, o MMA apresenta um MSE ligeiramente superior a $-10 \mathrm{~dB}$. Os resultados experimentais podem ser previstos pela análise realizada, já que o EMSE previsto por (5.28), (5.38) e (5.46) são respectivamente $\zeta_{\mathrm{MMA}} \approx-10.20 \mathrm{~dB}, \zeta_{\mathrm{RMA}} \approx-57.99 \mathrm{~dB}$ e $\zeta_{\mathrm{SBD}} \approx-56.18 \mathrm{~dB}$. Lembrando que $\mathrm{MSE}=\zeta+\sigma_{v}^{2}$, se obtém $\mathrm{MSE}_{\mathrm{MMA}} \approx-10.19 \mathrm{~dB}$, $\mathrm{MSE}_{\mathrm{RMA}} \approx-41.28 \mathrm{~dB}$ e $\mathrm{MSE}_{\mathrm{SBD}} \approx-41.23 \mathrm{~dB}$, que estão de acordo com os resultados experimentais. A Figura 7.4-(b) mostra a média de conjunto do expoente $p(n)$. A ajuda dos 
vizinhos pode ser desconsiderada para $p(n) \approx-10$, o que reduz ligeiramente o custo computacional dos algoritmos propostos em regime. Nessa simulação, também se pode observar que o RMA com ou sem vizinho converge mais rapidamente que o SBD. Entretanto, esse comportamento depende do cenário considerado para a simulação, já que o SBD apresenta uma convergência mais rápida que o RMA em algumas outras situações.

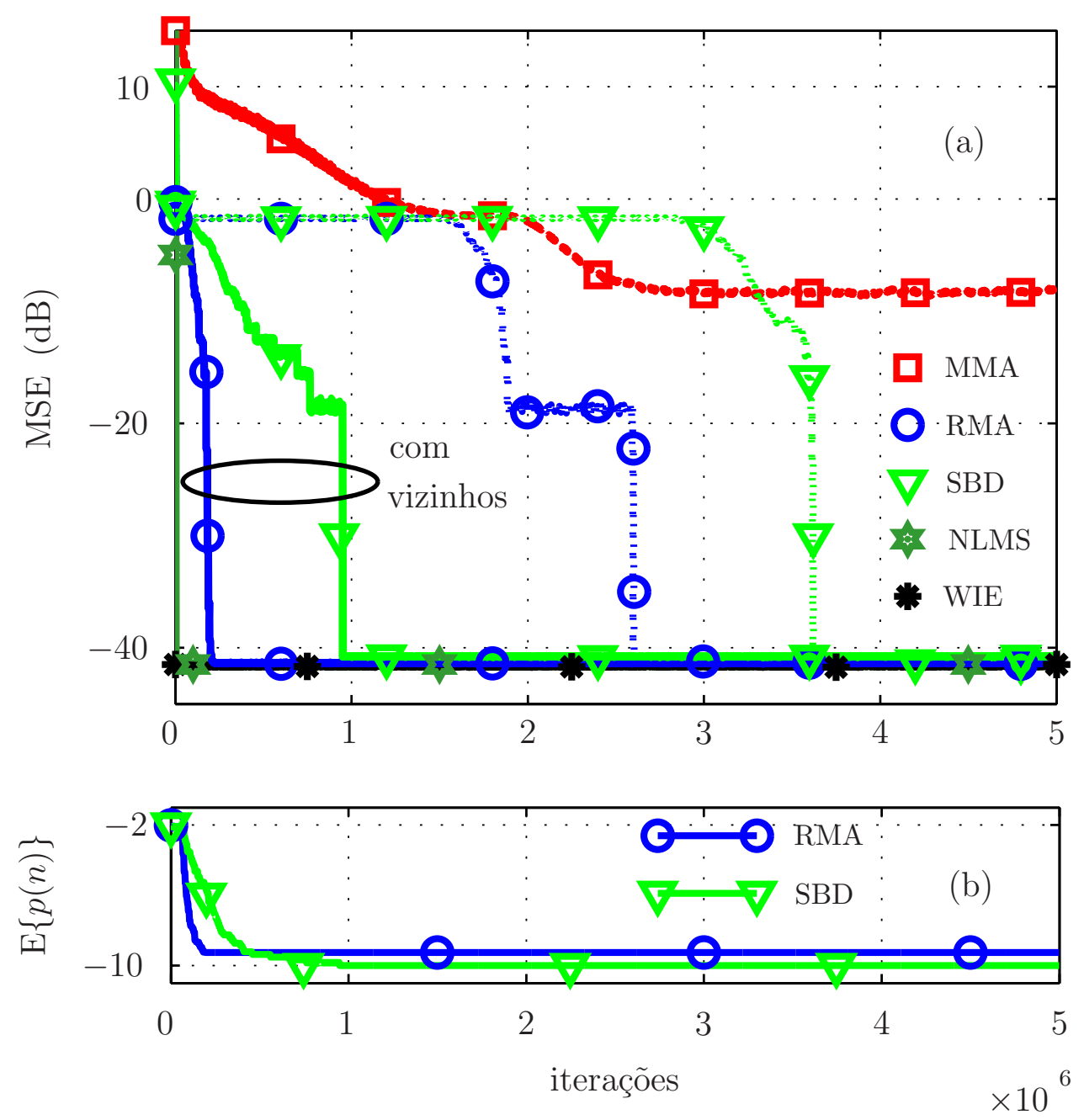

Figura 7.4: (a) MSE para MMA $\left(\mu=10^{-7}\right)$, RMA $\left(\mu=5 \times 10^{-4}\right)$, SBD $\left(\mu=1.5 \times 10^{-3}\right)$, RMA com vizinhos $\left(\mu=10^{-4}\right)$, SBD com vizinhos $\left(\mu=5 \times 10^{-3}\right)$, NLMS $\left(\mu=5 \times 10^{-1}\right)$; (b) média de $p(n) ; \Delta_{2}=13$; vizinhança Axial-1 (4 vizinhos); canal $\mathbf{h}_{2} ; M=21 ; 4096$-QAM; sem ruído; 50 realizações. 


\subsubsection{Desempenho com ruído}

Na Figura 7.5, são mostradas curvas de SER em função da SNR, admitindo o canal $\mathbf{h}_{4}$ e um equalizador sobreamostrado com $T / 2$ e $M=52$.
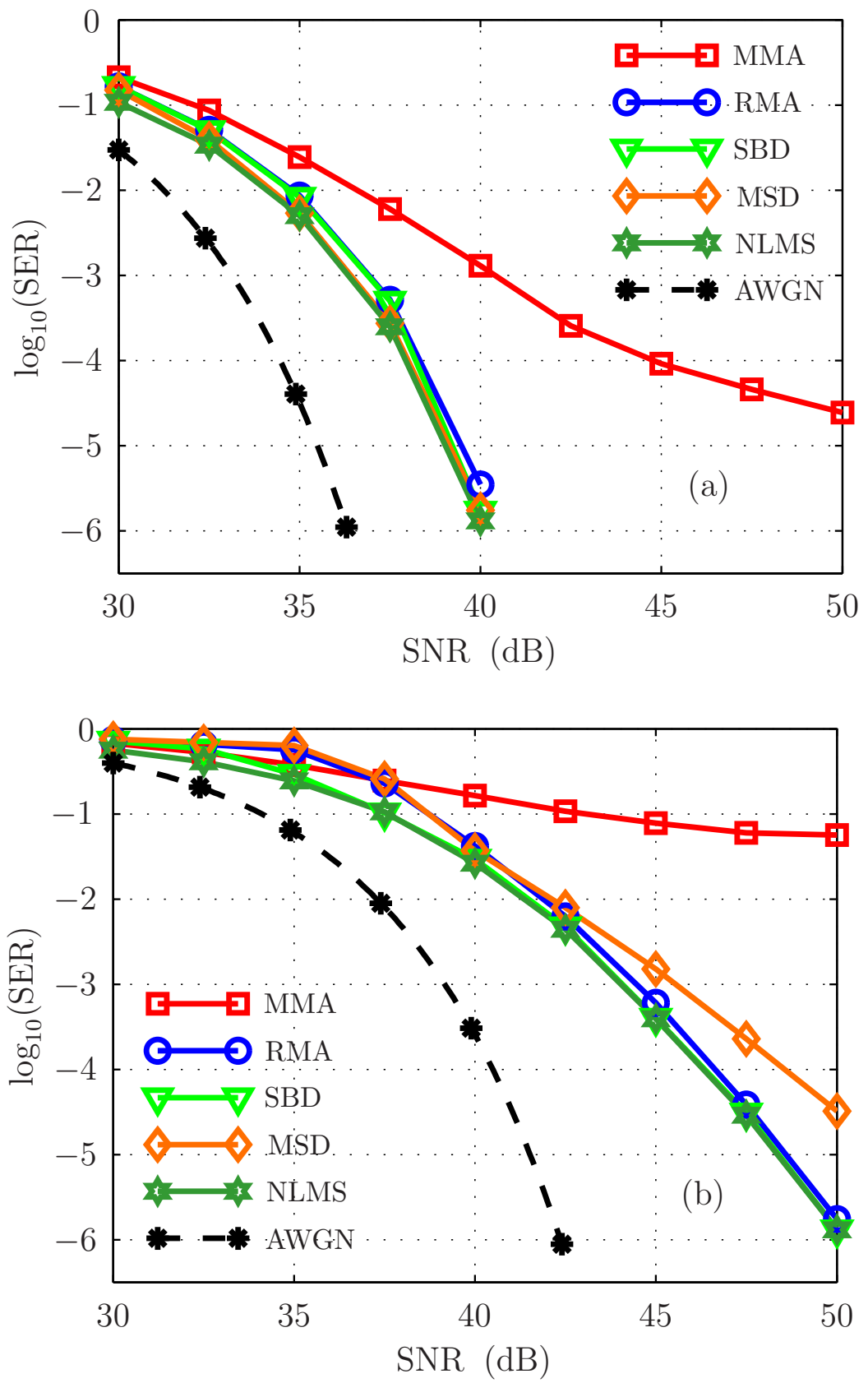

Figura 7.5: Log da SER em função da SNR: (a) 1024-QAM, MMA $\left(\mu=2 \times 10^{-6}\right)$, MSD $\left(\mu=5 \times 10^{-3}\right)$, RMA $\left(\mu=4 \times 10^{-3}\right)$, SBD $\left(\mu=5 \times 10^{-3}\right)$; (b) 4096-QAM, MMA $\left(\mu=10^{-7}\right)$, $\operatorname{MSD}\left(\mu=2 \times 10^{-3}\right)$, RMA e SBB $\left(\mu=3 \times 10^{-3}\right) ; \operatorname{NLMS}\left(\mu=0,5, \Delta_{4}=44\right) ; \rho=0,6$; vizinhança Axial-1 (quatro vizinhos); canal $\mathbf{h}_{4} ; M=52$. 
Em situações práticas, sinais 1024-QAM e 4096-QAM não-codificados necessitam altas SNRs (superiores a $40 \mathrm{~dB}$ ) para que possam exibir baixas taxas de erro de símbolos (veja Figura 1.6 da página 8). A curva para o canal AWGN é considerada como referência. Os algoritmos MSD, RMA e SBD foram implementados com o esquema de vizinhança Axial-1 para acelerar suas respectivas taxas de convergência. Para 1024-QAM (Figura 7.5-(a)), o RMA, SBD, e MSD se aproximam do NLMS e todos apresentam desempenho superior ao do MMA. Para 4096-QAM (Figura 7.5-(b)), observa-se que o SBD se aproxima do NLMS para toda a faixa de valores de SNR. O MMA apresenta o pior desempenho, já que no melhor caso exibe uma SER de aproximadamente $10^{-1}$. O MSD apresenta um desempenho intermediário, sendo melhor que o MMA, mas pior do que o NLMS. Finalmente, o RMA apresenta um desempenho próximo ao do MSD para SNR $<40$ dB e próximo ao NLMS para SNR > $40 \mathrm{~dB}$. Possivelmente, para que a estimativa do vetor de coeficientes do RMA fique mais próxima da solução de Wiener, o número de vizinhos deveria ser aumentado para baixas SNRs. A partir dessas simulações, observa-se que o RMA e o SBD podem se aproximar do desempenho de um algoritmo supervisionado, mesmo na presença de ruído e independentemente da ordem da constelação QAM.

\subsubsection{Precisão da análise em regime}

Para verificar a precisão da análise em regime do Capítulo 5, admitem-se a transmissão do sinal 256-QAM através do canal $\mathbf{h}_{5}$ na ausência de ruído e um equalizador na taxa de símbolos com $M=21$ coeficientes. Na Figura 7.6, são mostradas as curvas teóricas de EMSE obtidas a partir das equações (5.28), (5.38), (5.41) e (5.46). Também são mostrados os valores experimentais estimados através de uma média de conjunto de 50 realizações. Devese notar que o esquema de vizinhança Axial-1 é usado durante o transitório para acelerar a convergência e descartado em regime. Com esse esquema, o RMA e o SBD podem alcançar rapidamente o regime e os vizinhos não interferem nos resultados experimentais obtidos.

Na Figura 7.6-(a), são mostradas as curvas de EMSE, admitindo um ambiente estacionário $(\operatorname{Tr}(\mathbf{Q})=0)$. Observa-se que os resultados experimentais estão de acordo com as análises obtidas para uma ampla faixa de passos de adaptação. É importante salien- 
tar que as linhas verticais representam um limite de estabilidade para cada algoritmo. O MMA com dois modos de operação opera dentro da ROI para pequenos passos de adaptação $\left(10^{-5} \leq \mu \leq 10^{-3}\right)$ e neste caso, seu comportamento é previsto por (5.28). No intervalo de $\mu$ em que a probabilidade de divergência é maior, o MMA opera fora da ROI durante um grande número de iterações. Neste caso, o EMSE experimental é limitado pela curva teórica prevista por (5.41), admitindo a operação fora da ROI, como se pode notar para $3 \times 10^{-3} \leq \mu \leq 2 \times 10^{-2}$. O EMSE em regime para o RMA é previsto razoavelmente bem por (5.38) para $10^{-5} \leq \mu \leq 10^{-2}$. Para $\mu$ em torno de $10^{-2}$ seu comportamento também é limitado por (5.41) devido ao mecanismo usado para evitar divergência. Finalmente, o EMSE experimental para o SBD também é previsto razoavelmente bem pela Equação (5.46) para uma ampla faixa de $\mu$. Entretanto, o máximo valor de $\mu$ que assegura estabilidade é menor do que o previsto por (5.46). Neste caso, pode-se observar que o RMA e o SBD apresentam um desempenho similar, que é melhor do que o do MMA.

Na Figura 7.6-(b), são mostradas curvas de EMSE, admitindo um ambiente não-estacionário $\left(\mathbf{Q}=10^{-7} \mathbf{I}\right)$. Como no caso estacionário, o EMSE experimental do MMA concorda com (5.28) para $10^{-5} \leq \mu \leq 3 \times 10^{-3}$ e está limitado por (5.41) para $\mu>3 \times 10^{-3}$. Adicionalmente, pode-se identificar intervalos de $\mu$ para os quais o EMSE em regime do RMA e do SBD pode ser bem previsto pela análise. Para passos de adaptação maiores, o comportamento se assemelha ao do caso estacionário, ou seja, o EMSE do RMA é limitado por (5.41) e o desempenho do SBD se torna pior um pouco antes do previsto por (5.46). Para passos de adaptação menores, o RMA e o SBD exibem soluções piores do que as previstas. Conjecturase que isso ocorra devido à presença de mínimos locais, no entanto, se faz necessário um estudo mais aprofundado nesse sentido. Observa-se ainda que o SBD é ligeiramente melhor do que o RMA, já que pode alcançar um EMSE em regime menor para $10^{-2} \leq \mu \leq 3 \times 10^{-2}$. Esse comportamento foi observado em outros cenários de simulação.

Alterando o sinal para 64-QAM, obtêm-se os resultados mostrados na Figura 7.7. Novamente, a análise concorda com a simulação para o MMA. No entanto, os intervalos dos passos de adaptação para os quais os resultados analíticos e experimentais concordam nos casos dos algoritmos RMA e SBD são menores. Em especial, no ambiente não-estacionário 
considerado, a análise só conseguiu prever o comportamento do RMA razoavelmente bem no intervalo $4 \times 10^{-4}<\mu<10^{-3}$.
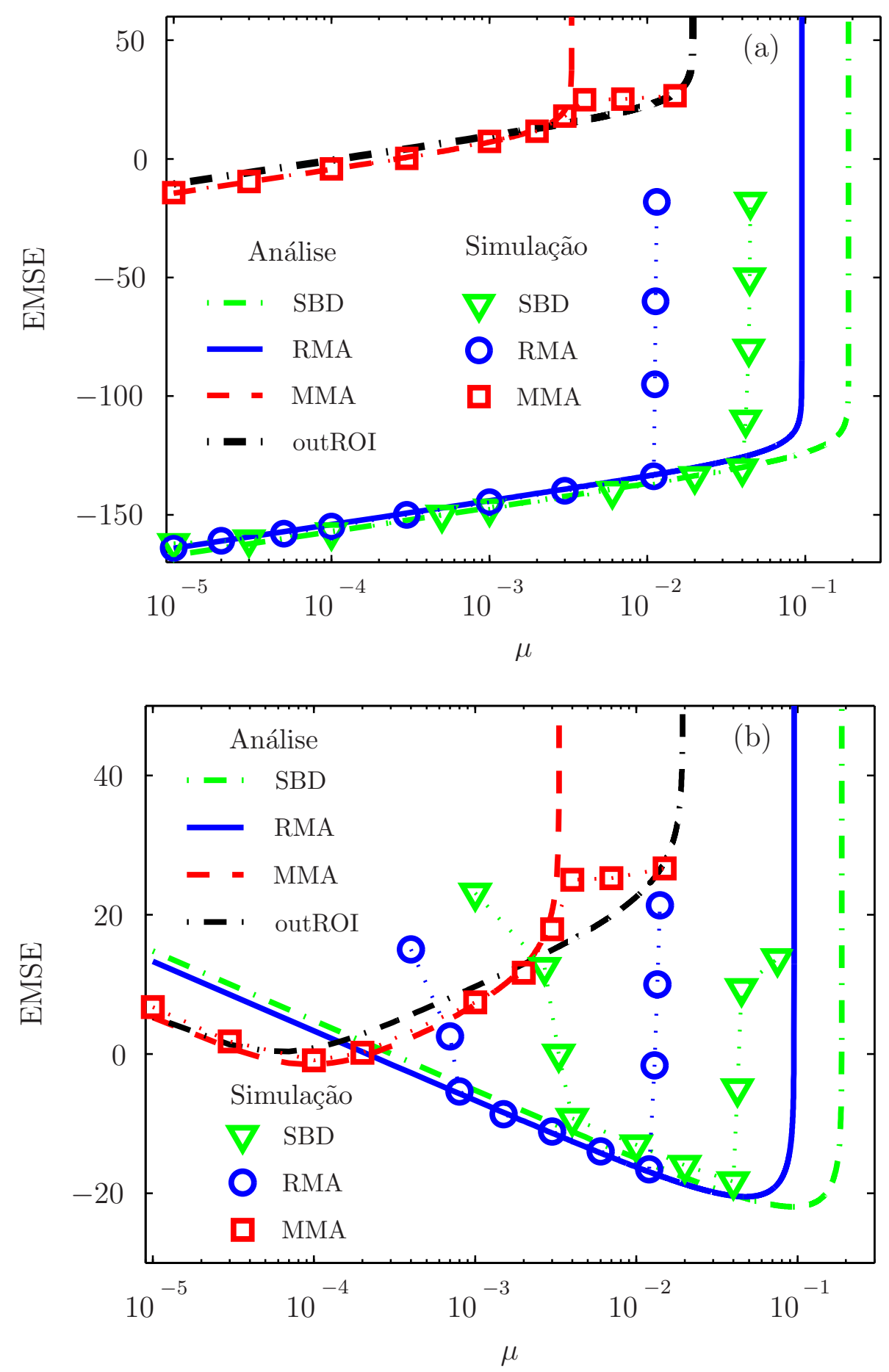

Figura 7.6: EMSE em função do passo de adaptação $\mu$ (a) ambiente estacionário (b) ambiente não-estacionário $\mathbf{Q}=10^{-7} \mathbf{I} ; 256$-QAM, canal $\mathbf{h}_{5}$, ausência de ruído, equalizador à taxa de símbolos, sem vizinhos, $M=21$, média de conjunto de 50 realizações independentes. 

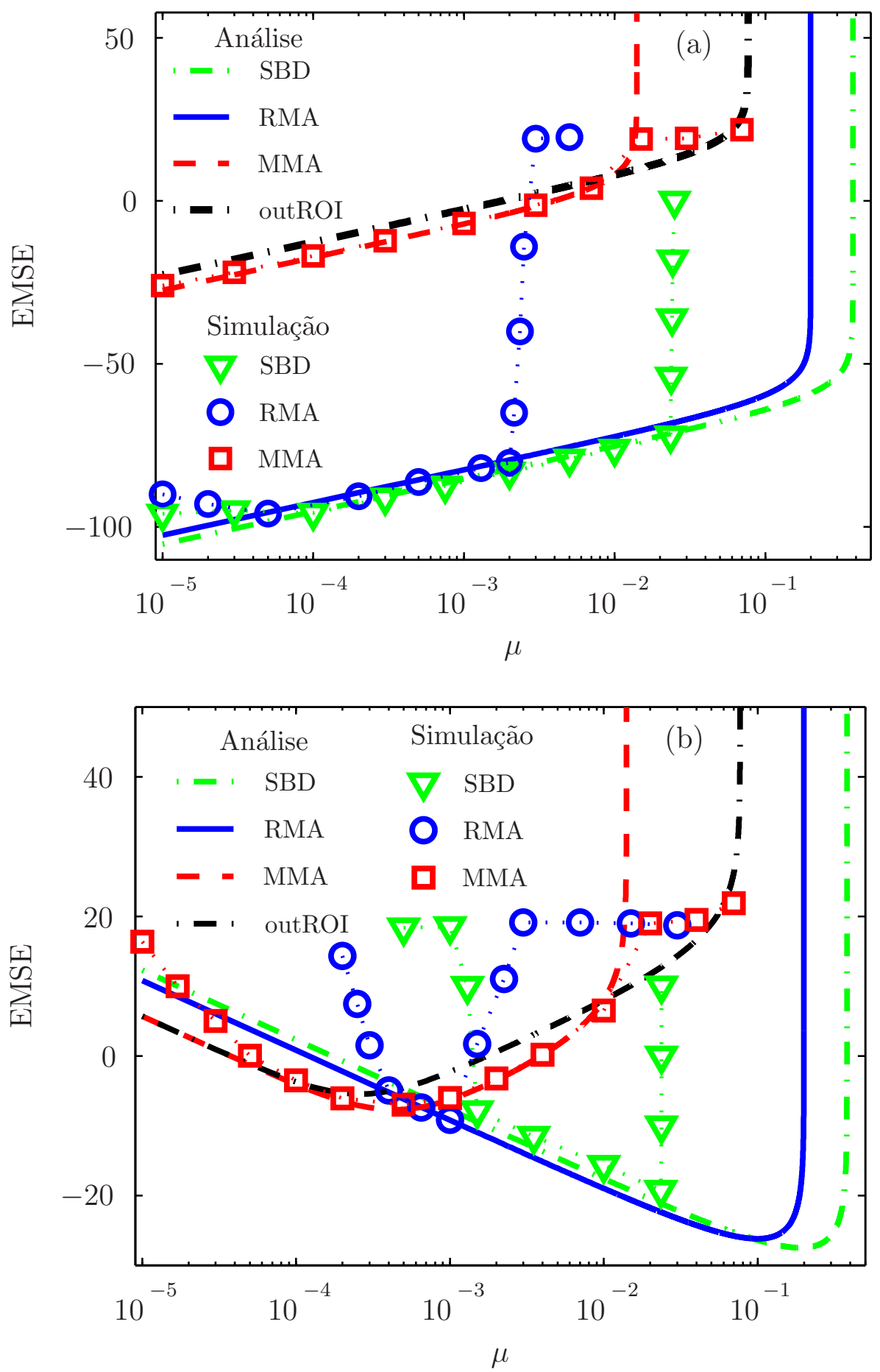

Figura 7.7: EMSE em função do passo de adaptação $\mu$ (a) ambiente estacionário (b) ambiente não-estacionário $\mathbf{Q}=10^{-7} \mathbf{I} ; 64$-QAM, canal $\mathbf{h}_{5}$, ausência de ruído, equalizador à taxa de símbolos, sem vizinhos, $M=21$, média de conjunto de 50 realizações independentes. 


\subsection{Evitando a divergência do MMA e RMA}

Com o objetivo de mostrar a influência do mecanismo que evita a divergência do MMA e do RMA da Seção 4.3 .3 (página 80), é feita uma simulação em que o sinal 256-QAM é transmitido através do canal $\mathbf{h}_{6}$ sem ruído e considerando um equalizador com $M=21$ coeficientes. Na Figura 7.8-(a), são mostradas as curvas do erro de decisão ao quadrado para o MMA e RMA, considerando uma única realização em que o sinal de entrada sofre um distúrbio do tipo spike com amplitude $10^{10}$. No caso do MMA, esse distúrbio ocorre nas iterações $3,125 \times 10^{5}$ e 4,375 × $10^{5}$, enquanto para o RMA, eles ocorrem nas iterações $2,500 \times 10^{5}$ e $3,750 \times 10^{5}$. É possível observar na figura que o MMA e o RMA não divergem e voltam à região de interesse depois de algumas iterações. Esse comportamento também pode ser confirmado através do expoente $p(n)$ usado no esquema de vizinhança Axial-1 do RMA, que está mostrado na Figura 7.8-(b). Como nos casos anteriores, o MMA converge para um nível de erro de decisão em regime elevado, quando comparado ao do RMA.

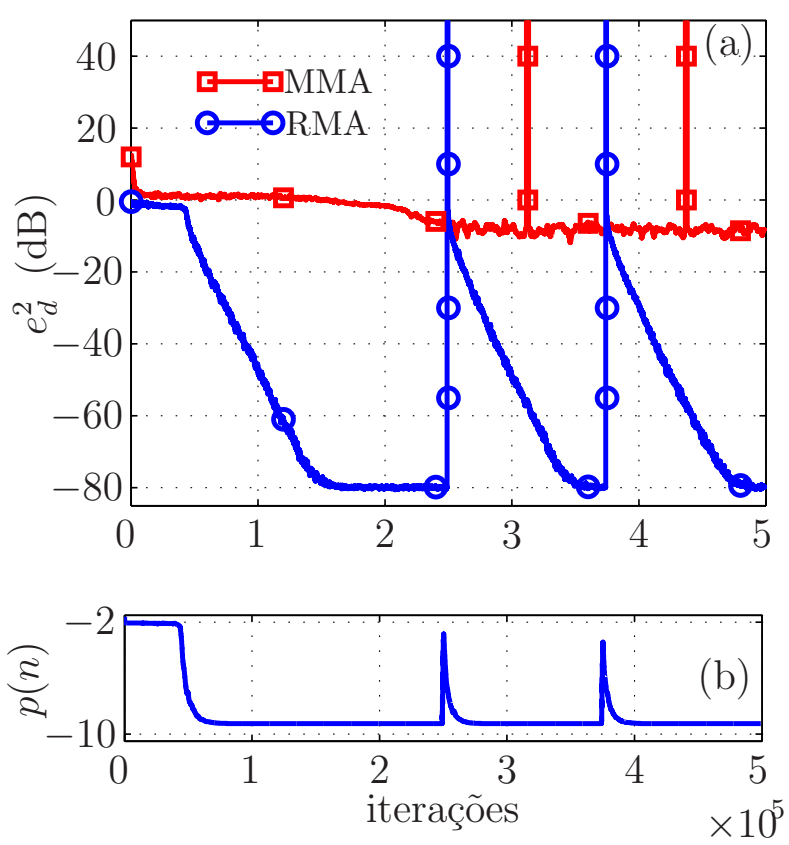

Figura 7.8: (a) Erro de decisão ao quadrado ao longo das iterações; (b) Expoente $p(n)$ ao longo das iterações; 256-QAM, canal $\mathbf{h}_{6}$, única realização, MMA $\left(\mu=4 \times 10^{-5}\right)$, RMA $\left(\mu=7 \times 10^{-4}\right)$ com vizinhos, ausência de ruído, equalizador à taxa de símbolos. 


\subsection{Simulações com realimentação de decisões}

Nesta seção, considera-se o modelo do sistema comunicação de tempo discreto da Figura 6.1, mostrado novamente na Figura 7.9 por conveniência. Nesse sistema, supõe-se que o canal de comunicação é modelado pela função de transferência de um canal de TV a cabo (canal $\mathbf{h}_{4}$ da Tabela 7.1) e ruído aditivo do tipo AWGN. O equalizador é constituído por um filtro direto com $M_{\mathrm{f}}=118$ coeficientes e por um filtro de realimentação com $M_{\mathrm{b}}=20$ coeficientes, sendo o filtro direto sobreamostrado com $T / 2$. Como no caso do LTE, o vetor de coeficientes do filtro direto de todos os algoritmos (incluindo o NLMS) foi inicializado com um vetor do tipo "pino" (center spike initialization). Em contrapartida, o vetor do filtro de realimentação foi inicializado com zero. Além disso, o fator de regularização de todos os algoritmos é feito igual $\delta=10^{-8}$. Novamente, as curvas de MSE foram filtradas por um filtro de média móvel com 500 coeficientes para facilitar a visualização. Para efeito de comparação, também se considera uma versão normalizada do algoritmo Sliced-MMA (SMMA) proposto em [ABRAR; AMIN; SIDDIQ, 2005] e que evita soluções degeneradas devido à utilização do mecanismo de [SZCZECINSKI; GEI, 2002]. No caso dos algoritmos RMA e SBD, considerou-se o esquema de vizinhança Axial-1 em todas as simulações.

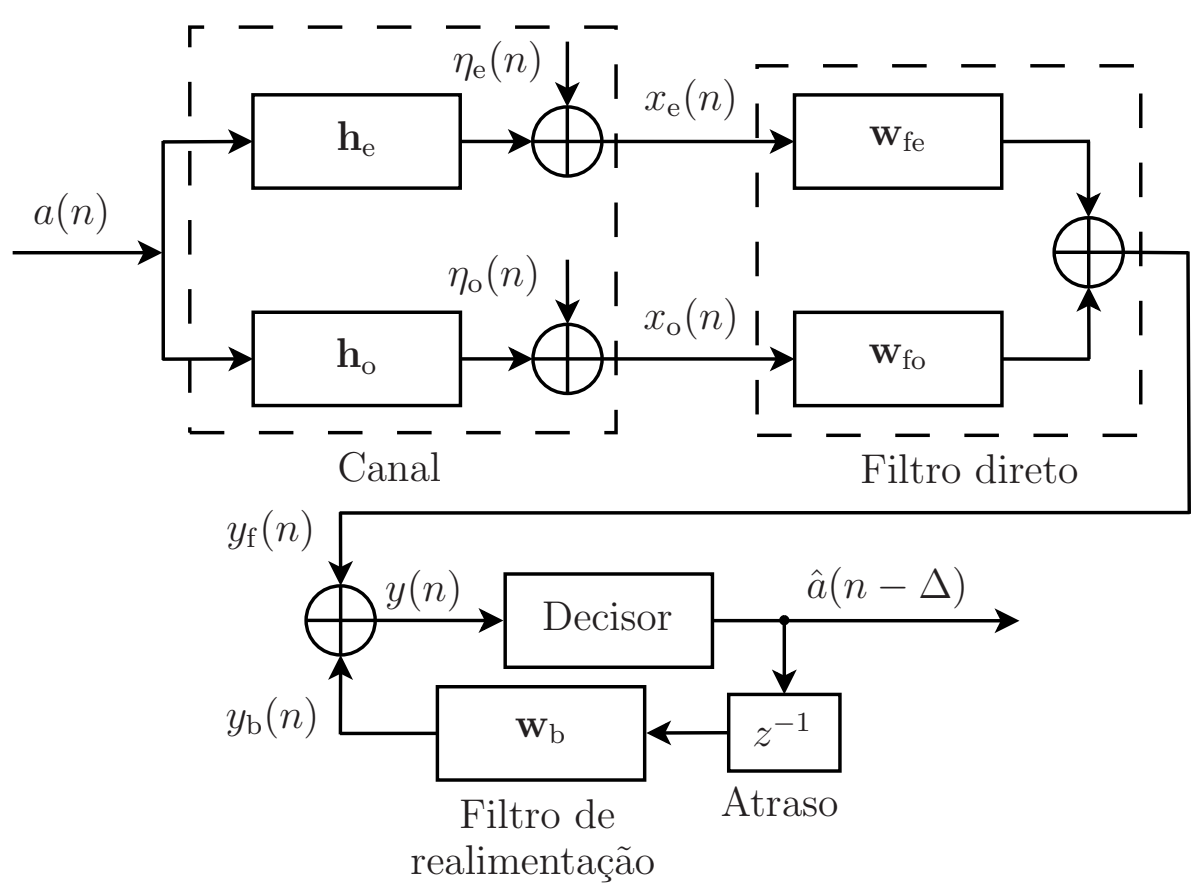

Figura 7.9: Sistema de comunicação simplificado com DFE e sobreamostragem $(T / 2)$. 
Nas Figuras 7.10, 7.11 e 7.12, são mostradas curvas de MSE e os valores médios dos expoentes $p(n)$ (do esquema de vizinhança Axial-1 do RMA e do SBD), considerando os sinais 64-QAM, 1024-QAM e 4096-QAM e razões sinal-ruído iguais a 35 dB, 40 dB e 50 dB, respectivamente. Todas as curvas são estimadas a partir de uma média de conjunto de 50 realizações. Para a ordem crescente das constelações, pode-se dizer que o MMA apresentou o pior desempenho com valores de MSE da ordem de $-15 \mathrm{~dB},-8 \mathrm{~dB}$ e $-5 \mathrm{~dB}$, respectivamente. Os resultados do SMMA seguem a mesma sequência com MSE da ordem de -17 dB, $-10 \mathrm{~dB}$ e $-8 \mathrm{~dB}$ e apresentando maiores velocidades de convergência que o MMA. O algoritmo CSD apresentou melhor desempenho que o MMA e o SMMA tanto para 64-QAM como para 1024-QAM, aproximando-se de valores de MSE iguais a -11,1 dB e -18,6 dB, respectivamente. Entretanto para 4096-QAM, o MSE ficou em -12,3 dB, mais distante do MSE do NLMS do que nas duas outras constelações. O RMA e o SBD são os que apresentam o melhor comportamento em regime, aparecendo praticamente de forma coincidente com o NLMS, com valores de MSE iguais a $-18,5 \mathrm{~dB},-11,2 \mathrm{~dB}$ e $-14,3 \mathrm{~dB}$ na ordem crescente das constelações avaliadas. Além disso, eles apresentaram as maiores velocidades de convergência, exceção feita à constelação de 4096-QAM. Para essa constelação o SDB e o RMA apresentaram um ligeiro decaimento na velocidade de convergência, o que talvez indique a necessidade de inclusão de mais vizinhos. É importante ressaltar que para a inicialização do tipo center spike initialization, os algoritmos propostos e o NLMS convergem para um MSE em regime que não coincide com o da solução de Wiener, devido à realimentação de decisões presente no DFE. Por fim, cabe destacar que a partir da média de conjunto do expoente $p(n)$, é possível observar o ponto em que o RMA e o SBD atingem o regime. Nas iterações iniciais, $\mathrm{E}\{p(n)\}$ está em torno de -2 e após a convergência, encontra-se em torno de -10 . Esse comportamento é similar para as três constelações avaliadas. 

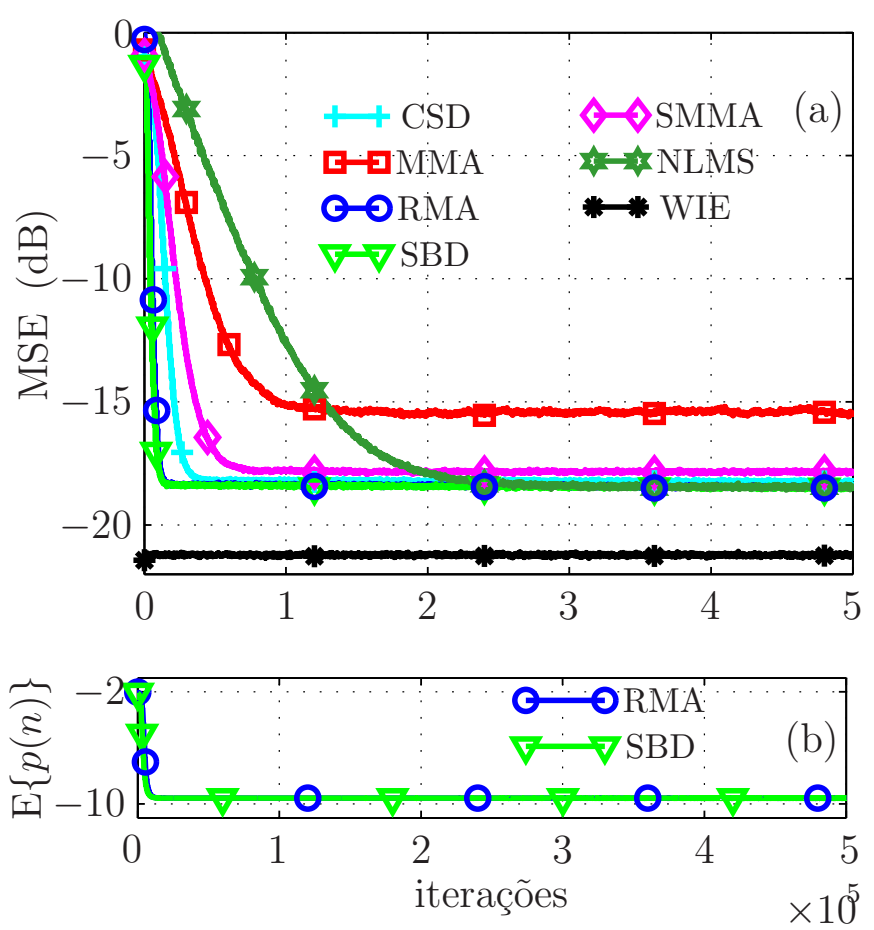

Figura 7.10: (a) MSE; (b) média de $p(n)$; 64-QAM; SNR $=35 \mathrm{~dB} ; \Delta=61$; CSD ( $\mu_{\mathrm{MMA}}=$ $\left.10^{-5} ; \mu_{\mathrm{SDD}}=10^{-2} ; \rho=0,6\right) ; \mu_{\mathrm{MMA}}=2 \times 10^{-3} ; \mu_{\mathrm{SMMA}}=10^{-4} ; \mu_{\mathrm{NLMS}}=\mu_{\mathrm{RMA}}=\mu_{\mathrm{SBD}}=5 \times 10^{-3}$.
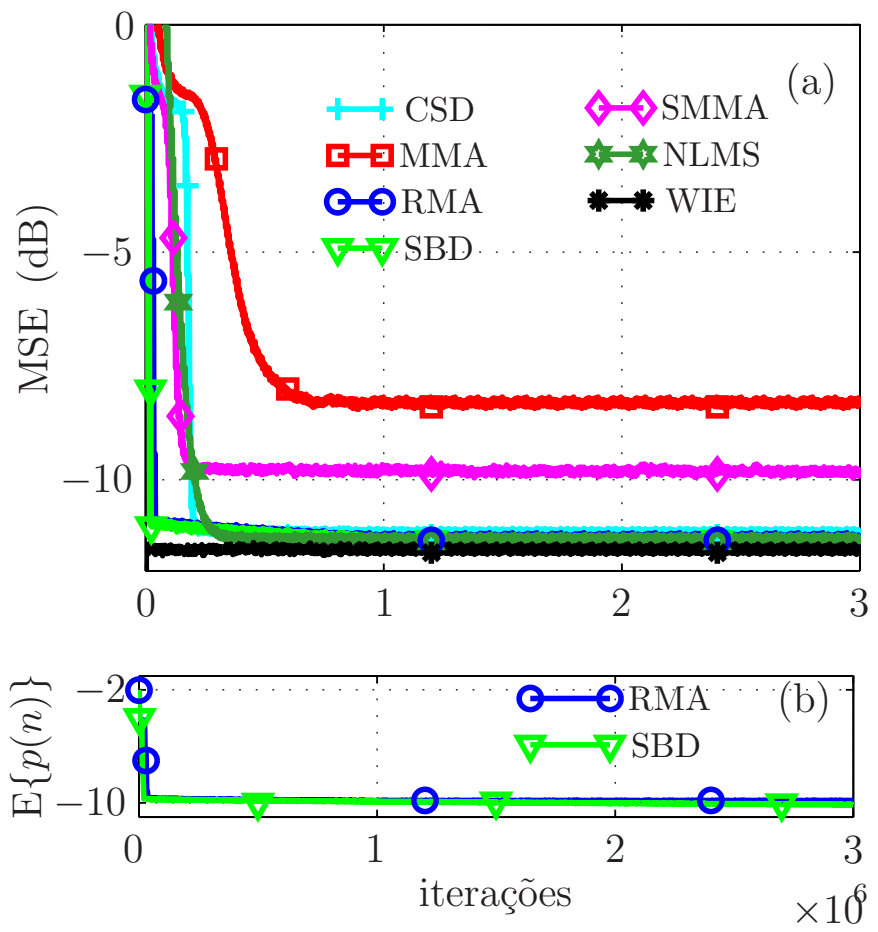

Figura 7.11: (a) MSE; (b) $\mathrm{E}\{p(n)\} ; 1024-\mathrm{QAM} ; \mathrm{SNR}=40 \mathrm{~dB} ; \Delta=61$; CSD $\left(\mu_{\mathrm{MMA}}=5 \times 10^{-7}\right.$; $\left.\mu_{\mathrm{SDD}}=10^{-2} ; \rho=0,6\right) ; \mu_{\mathrm{NLMS}}=10^{-3} ; \mu_{\mathrm{MMA}}=5 \times 10^{-4} ; \mu_{\mathrm{SMMA}}=4 \times 10^{-6} ; \mu_{\mathrm{RMA}}=\mu_{\mathrm{SBD}}=5 \times 10^{-3}$. 

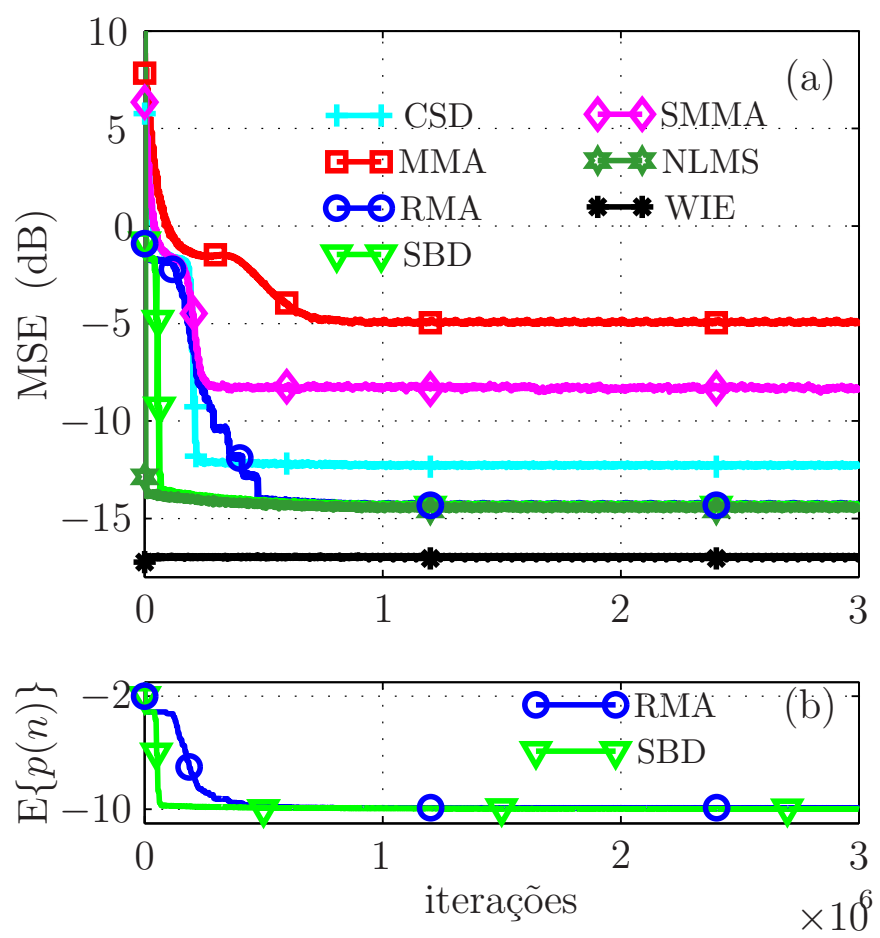

Figura 7.12: (a) MSE; (b) $\mathrm{E}\{p(n)\}$; 4096-QAM; SNR $=50 \mathrm{~dB} ; \Delta=61$; $\mathrm{CSD}\left(\mu_{\mathrm{MMA}}=3 \times 10^{-7}\right.$; $\left.\mu_{\mathrm{SDD}}=10^{-2} ; \rho=0,6\right) ; \mu_{\mathrm{NLMS}}=5 \times 10^{-2} ; \mu_{\mathrm{MMA}}=5 \times 10^{-4} ; \mu_{\mathrm{SMMA}}=9 \times 10^{-7} ; \mu_{\mathrm{RMA}}=\mu_{\mathrm{SBD}}=2 \times 10^{-3}$.

As Figuras 7.13, 7.14 e 7.15 exibem as curvas de SER em função da SNR. A curva para o canal AWGN é considerada como referência. Para 64-QAM (Figura 7.13), o SBD apresenta o melhor desempenho, muito próximo ao do NLMS, seguido pelo RMA, que por sua vez é seguido pelo CSD e, posteriormente, pelo SMMA. O MMA apresentou o pior desempenho entre os algoritmos avaliados.Para 1024-QAM (Figura 7.14), se observa que o SBD apresenta o melhor desempenho, praticamente igual ao do NLMS, principalmente para razões sinalruído superiores a $30 \mathrm{~dB}$. O CSD e o RMA apresentam desempenhos similares, com pequena vantagem para esse último. Já o SMMA apresenta um desempenho intermediário entre o do CSD e o do MMA, que apresenta o pior desempenho. Finalmente, para 4096-QAM, o SBD e o NLMS apresentam desempenhos similares praticamente em toda a faixa de valores de SNR. Acima de $40 \mathrm{~dB}$, esse comportamento também é compartilhado pelo RMA. Do MMA, passando pelo SMMA e chegando ao CSD se percebe um aumento no desempenho, entretanto, mesmo para o melhor desses três algoritmos, e se considerando a $\mathrm{SNR}=50 \mathrm{~dB}$, se chega a uma taxa de erro de símbolo de apenas $3 \times 10^{-5}$. 


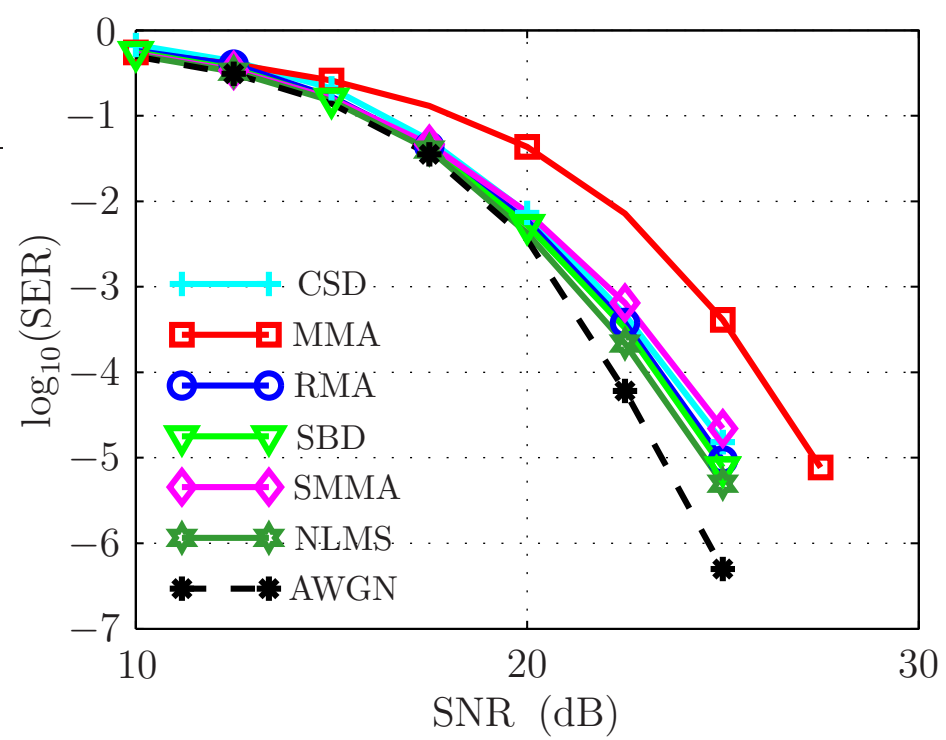

Figura 7.13: Log da SER em função da SNR para 64-QAM, SER para CSD $\left(\mu_{\mathrm{CMA}}=1 \times 10^{-5}\right.$; $\left.\mu_{\mathrm{SDD}}=1 \times 10^{-2} ; \rho=0,6\right), \operatorname{MMA}\left(\mu=2 \times 10^{-3}\right), \operatorname{RMA}\left(\mu=5 \times 10^{-3}\right), \operatorname{SBD}\left(\mu=5 \times 10^{-3}\right)$, SMMA $\left(\mu=1 \times 10^{-4}\right)$, NLMS $\left(\mu=5 \times 10^{-3}\right)$, WIE (Atraso $\left.\Delta=61\right)$; vizinhança Axial 1 (2 vizinhos), canal $\mathbf{h}_{4} ; M_{\mathrm{f}}=118, M_{\mathrm{b}}=20$.

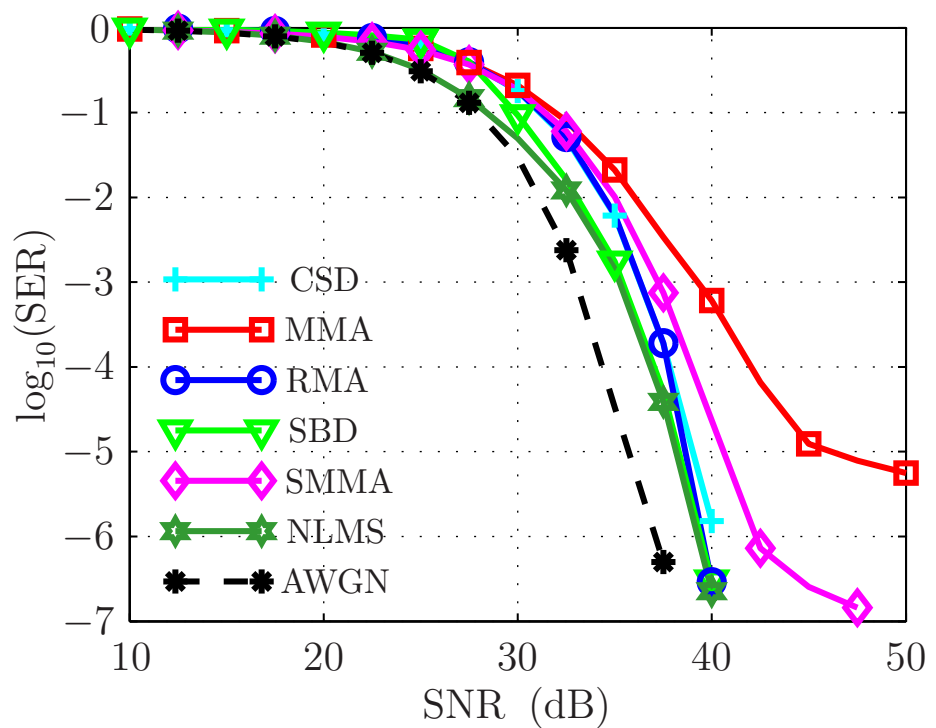

Figura 7.14: Log da SER em função da SNR para 1024-QAM, SER para CSD ( $\mu_{\mathrm{CMA}}=$ $\left.5 \times 10^{-7} ; \mu_{\mathrm{SDD}}=1 \times 10^{-2} ; \rho=0,6\right), \operatorname{MMA}\left(\mu=5 \times 10^{-4}\right), \mathrm{RMA}\left(\mu=5 \times 10^{-3}\right), \mathrm{SBD}$ $\left(\mu=5 \times 10^{-3}\right)$, SMMA $\left(\mu=4 \times 10^{-6}\right)$, NLMS $\left(\mu=1 \times 10^{-3}\right)$, WIE (Atraso $\left.\Delta=61\right)$; vizinhança Axial 1 (2 vizinhos), canal $\mathbf{h}_{4} ; M_{\mathrm{f}}=118, M_{\mathrm{b}}=20$. 


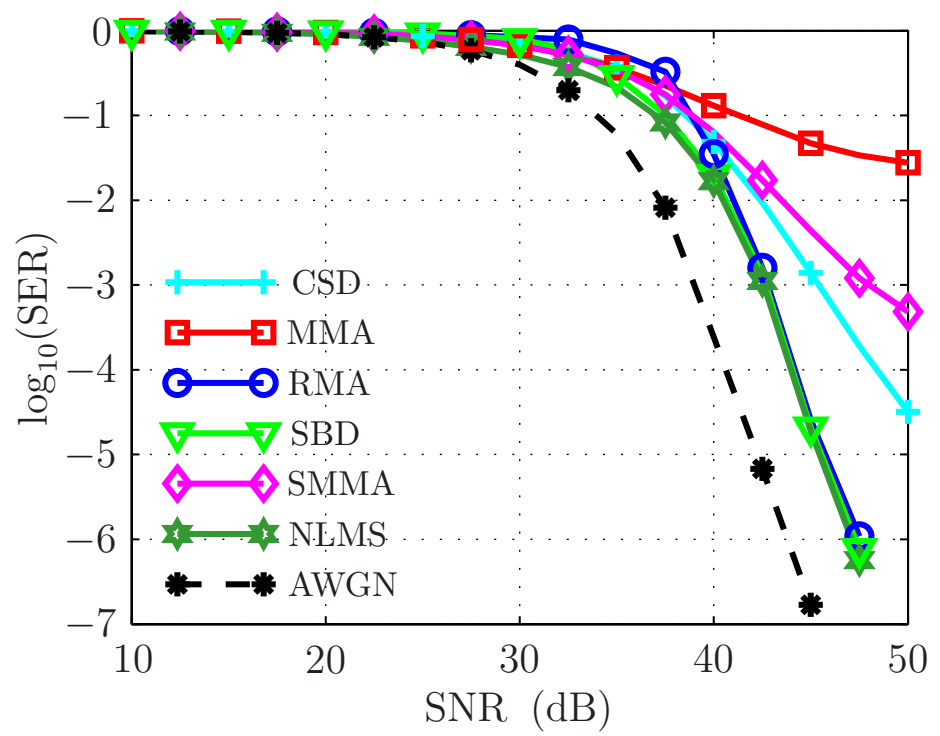

Figura 7.15: Log da SER em função da SNR para 4096-QAM, SER para CSD $\left(\mu_{\mathrm{CMA}}=\right.$ $\left.3 \times 10^{-7} ; \mu_{\mathrm{SDD}}=1 \times 10^{-2} ; \rho=0,6\right)$, MMA $\left(\mu=5 \times 10^{-4}\right)$, RMA $\left(\mu=2 \times 10^{-3}\right)$, SBD $\left(\mu=2 \times 10^{-3}\right)$, SMMA $\left(\mu=9 \times 10^{-7}\right)$, NLMS $\left(\mu=5 \times 10^{-2}\right)$, WIE (Atraso $\left.\Delta=61\right)$; vizinhança Axial 1 (4 vizinhos), canal $\mathbf{h}_{4} ; M_{\mathrm{f}}=118, M_{\mathrm{b}}=20$.

\subsection{Conclusões}

Neste capítulo, foram mostrados resultados de simulação, realizadas em diversos cenários e que justificam as afirmações e análises desenvolvidas nos Capítulos 2 ao 6. Inicialmente, verificou-se que os algoritmos RMA e SBD, assim como o algoritmo supervisionado NLMS, quando utilizados num ambiente sem ruído e com sobreamostragem convergem para a solução de Wiener, exibindo equalização perfeita. O mesmo não ocorre com outros algoritmos utilizados como comparação a exemplo do CSD, MSD e MMA sem o esquema de chaveamento, em função desses últimos algoritmos não apresentarem as funções de erro com nulos nas coordenadas dos símbolos da constelação.

Foram também mostrados resultados de simulação que ilustram o aumento de desempenho do RMA e do SBD quando esses algoritmos incorporam o mecanismo para acelerar a convergência. Observa-se que os vizinhos aumentam consideravelmente as taxas de convergência dos algoritmos, para diferentes constelações QAM e cenários de simulação. Além 
disso, o mecanismo ainda permite que o RMA e o SBD se comportem como o NLMS em regime, convergindo para a solução de Wiener, uma vez que os vizinhos podem ser descartados. Quanto ao ruído, a partir da avaliação da SER, foi possível observar nas simulações realizadas que os algoritmos propostos podem se aproximar do desempenho de um algoritmo supervisionado, na presença de ruído e independentemente da ordem da constelação QAM. O mesmo não se pode dizer dos algoritmos utilizados na comparação como o MMA, que apresentou o pior desempenho.

Resultados de simulação também foram mostrados para se avaliar a precisão da análise de rastreio. Neste caso, foram realizadas simulações com constelações 256-QAM e 64-QAM. Para ambas as constelações, o MMA apresentou resultados que estão de acordo com as análises desenvolvidas. Já para os algoritmos RMA e SBD, os resultados das simulações estão de acordo com as análises apenas em intervalos de passos de adaptação que são menores no caso de 64-QAM do que de 256-QAM. Uma melhor aproximação poderá ser realizada num trabalho futuro.

Outro ponto salientado pelas simulações foi a utilização do mecanismo que evita divergência tanto pelo MMA como pelo RMA. Apesar desse último algoritmo apresentar um patamar de MSE melhor quando comparado ao primeiro, ambos os algoritmos conseguiram suportar as pertubações de amplitude elevada sem divergirem e retornando aos seus patamares de MSE anteriores.

Adicionalmente, simulações com equalizadores do tipo DFE também foram realizadas. Neste caso, os algoritmos RMA e SBD adotaram o mecanismo para se evitar soluções degeneradas e também se aproximaram do comportamento do algoritmo NLMS. Em alguns cenários de simulação, essa convergência não coincidiu com a solução de Wiener de melhor atraso em função da inicialização utilizada no vetor direto de coeficientes. 


\section{Capítulo 8}

\section{Conclusões e trabalhos futuros}

Há praticamente três décadas, a equalização autodidata de canais de comunicação vem sendo intensamente abordada na literatura. Foram propostos inúmeros esquemas e algoritmos adaptativos sempre com particularidades destacadas. Muitos desses algoritmos foram analisados de diferentes formas em condições não muito realistas do ponto de vista prático. No entanto, essas análises foram importantes pois possibilitaram prever o comportamento de alguns algoritmos em muitas situações.

O algoritmo do módulo constante (CMA) ganhou destaque em muitas aplicações práticas, como acontece com o algoritmo LMS, devido ao seu baixo custo computacional. Quando usado para recuperar sinais de módulo constante e sob algumas condições bem conhecidas na literatura, o CMA possibilita obter um EMSE nulo em regime. Porém, para aumentar a eficiência em termos de taxa de transmissão, os sistemas de comunicação usam sinais de módulo não-constante, como os sinais com modulação do tipo QAM, e nessa situação o EMSE do CMA não é nulo e aumenta conforme o aumento da ordem da constelação. Para contornar o problema na prática, o CMA é empregado para abrir o olho em sistemas de transmissão com portadora única e chaveado para o algoritmo de decisão direta a fim de continuar a equalização. A passagem da equalização com o CMA para a equalização com o DD também já foi bem explorada na literatura. Interessantes propostas surgiram, porém muito ainda pode ser feito para melhorar o desempenho em situações práticas.

Embora nem sempre colocado de modo explícito, deseja-se obter um algoritmo auto- 
didata que se comporte como um algoritmo supervisionado em termos de velocidade de convergência, robustez, capacidade de rastreio e EMSE em regime. Esse objetivo, conforme observado na literatura, ainda não tinha sido alcançado antes deste trabalho. As principais conclusões desta tese são comentadas a seguir.

\subsection{Conclusões}

A família de algoritmos autodidatas aqui abordada é do tipo gradiente estocástico com normalização e com erros de estimação que consideram as partes real e imaginária calculadas separadamente. No Capítulo 2, foram propostas duas funções de erro de estimação contínuas por partes e que se anulam quando o símbolo estimado coincide com um símbolo da constelação. Além disso, a essas funções estão associadas envoltórias, que permitem aos algoritmos obterem informações das posições dos símbolos estimados na constelação. Envoltória semelhante aparece no algoritmo CMA mas não permite que o algoritmo apresente erro nulo quando o símbolo estimado coincide com os símbolos da constelação. Porém, ela não está presente no algoritmo de decisão direta, embora ele apresente erro nulo quando o símbolo estimado coincide com o símbolo da constelação. Conjectura-se que a informação fornecida pela envoltória, embora inicialmente ainda forneça uma estimativa pobre, permite ao longo das iterações melhorar a qualidade da estimativa e consequentemente ajuda o algoritmo a encontrar um menor EMSE em regime. Ambas as funções de erro apresentadas no Capítulo 2 são contínuas por partes, apresentam características distintas e originaram os algoritmos denotados como RMA e SBD.

No Capítulo 3, verificou-se analiticamente que sob certas condições favoráveis do ponto de vista da equalização, tanto o RMA quanto o SBD apresentam soluções colineares com a solução de Wiener, independentemente da ordem da constelação QAM. Mesmo que essas relações não assegurem a convergência na média do RMA e do SBD para a solução de Wiener, essa propriedade é particularmente importante para a situação após a convergência pois fornece informações acerca das soluções dos algoritmos autodidatas. Cabe observar que essa relação de colinearidade também foi observada para a solução do CMA e de Wiener em 
[SUYAMA et al., 2003].

Em situações não favoráveis, tanto o RMA com o SBD podem convergir para mínimos locais indesejados, apresentar uma convergência lenta e sofrer divergência. No Capítulo 4, foram sugeridos um mecanismo para melhorar a velocidade de convergência desses algoritmos e outro para evitar a divergência do RMA. Adicionalmente, foram obtidos intervalos do passo de adaptação que asseguram a convergência do algoritmo SBD com e sem vizinhos. Quanto à melhoria da velocidade de convergência, foram propostos dois esquemas de baixo custo computacional para os quais o erro de estimação desses algoritmos considera não só a região principal na qual se encontra a saída do equalizador, mas também suas regiões vizinhas. De uma forma geral, ambos os algoritmos com tais esquemas se mostram vantajosos, especialmente para constelações QAM de ordem elevada, quando comparados aos seus pares desprovidos de tal mecanismo. A partir dos resultados da convergência do algoritmo NLMS, obtiveram-se os intervalos do passo de adaptação que asseguram a convergência do SBD. No caso do RMA, o mecanismo proposto em [MIRANDA; SILVA; NASCIMENTO, 2008a] foi utilizado para evitar sua divergência.

No Capítulo 5, foram obtidas expressões analíticas para o EMSE em regime do MMA normalizado, RMA e algoritmo SBD, todos implementados na taxa de símbolos e considerando um ambiente não-estacionário. A análise do MMA nessas condições é também uma contribuição desta tese, já que os resultados contidos na literatura foram obtidos a partir da suposição de que a solução ótima leva à equalização perfeita, condição que só pode ser atingida com sobreamostragem. A partir da expressão do EMSE em regime do MMA, verifica-se que seu erro em excesso é nulo somente quando se usa sobreamostragem em um ambiente estacionário e sem ruído e quando os sinais transmitidos são de módulo constante. Isso justifica o fato do MMA apresentar um desempenho insatisfatório na equalização de sinais QAM de ordem elevada. Em contrapartida, os algoritmos RMA e SBD tratam constelações QAM de módulo não-constante como se tivessem módulo constante. Assim, independentemente da ordem do QAM, esses algoritmos podem atingir um EMSE em regime igual a zero em um ambiente estacionário e sem ruído. Cabe observar que a partir das expressões obtidas neste capítulo, podem ser derivadas expressões analíticas para os valores dos passos de adaptação 
que minimizam o EMSE em regime.

Devido às características atrativas que um DFE pode apresentar, os algoritmos RMA e SBD foram estendidos para a sua adaptação no Capítulo 6. Além dos erros que caracterizam os comportamentos do RMA e do SBD que foram incluídos na equação de adaptação do DFE (6.12) (página 104), considerou-se o conhecido esquema para evitar as soluções degeneradas de [SZCZECINSKI; GEI, 2002], os passos de adaptação que asseguram a convergência e os esquemas de vizinhança para permitir aumentar a velocidade de convergência. As boas propriedades confirmadas nas simulações mostram que os algoritmos RMA e SBD para a adaptação do DFE podem apresentar um desempenho comparável ao do NLMS sendo, portanto, bons candidatos para serem usados na prática.

No Capítulo 7, foram mostrados resultados de simulação que ilustram o bom comportamento dos algoritmos RMA e SBD em diferentes cenários, corroborando com as análises teóricas e conjecturas preliminares. Como mencionado no 1, neste trabalho não se considerou o tempo para sincronização da sequência pseudo-aleatória emitida pelo transmissor quando algoritmos supervisionados como o NLMS são usados. Tal fato corrobora os resultados de simulação obtidos para os algoritmos autodidatas RMA e SBD, já que se esse tempo fosse levado em conta, o NLMS demoraria mais para alcançar o regime.

\subsection{Trabalhos futuros}

Diante das contribuições e conclusões expostas, existem algumas possibilidades de trabalhos futuros, sugeridas a seguir:

- Sem um esquema para aumentar a velocidade de convergência dos algoritmos RMA e SBD, suas aplicações práticas são inviáveis. O esquema de vizinhança proposto, apesar de apresentar bons resultados, exige um estudo mais aprofundado. Neste contexto, o número de vizinhos que deve ser considerado e o fator de ponderação atribuído ao erro de cada vizinho merecem uma análise;

- Apesar dos resultados de simulação mostrarem um comportamento robusto dos algoritmos implementados, é necessário ainda verificar se eles possuem a propriedade 
da estabilidade assintótica. Verificar se um algoritmo autodidata satisfaz essa propriedade não é trivial, mas é necessária para dar confiabilidade aos algoritmos em aplicações práticas;

- Simulações com constelações QAM não-quadradas podem ser interessantes para se evitar rotação de fase, como mostra o trabalho de [YUAN; CHANG, 2007]. Testes e análises com constelações desse tipo podem ser realizados;

- Interessantes resultados da aplicação do RMA para restauração autodidata de imagens foram obtidos em [ABREU; SILVA, 2011; ABREU, 2011] e merecem ser analisados com mais profundidade;

- Um outro problema a ser investigado diz respeito à utilização dos algoritmos propostos neste trabalho quando da separação de fontes em sistemas com múltiplos usuários;

- Uma análise do transitório dos algoritmos RMA e SBD é importante para complementar os resultados do Capítulo 5. 


\section{Referências Bibliográficas}

ABRAR, S. Square-contour stop-and-go algorithm for blind channel equalization in QAM data communication systems. Proceedings of Student Conference on Engineering, Sciences and Technology, 2004. p. 73-76.

ABRAR, S.; AMIN, A.; SIDDIQ, F. Stop-and-go square-contour blind equalization algorithms: design and implementation. Proceedings of IEEE Symposium on Emerging Technologies, 2005. p. 157-162.

ABRAR, S.; AXFORD JR., R. A. Sliced multi-modulus blind equalization algorithm. ETRI Journal, v. 27, p. 257-266, Jun. 2005.

ABRAR, S.; NANDI, A. Blind equalization of square-QAM signals: a multimodulus approach.IEEE Transactions on Communications, v. 58, n. 6, p. 1674 -1685, Jun. 2010.

ABREU, R.; SILVA, M. T. M. A multimodulus algorithm for blind image deconvolution. Proceedings of International Workshop on Telecommunications (IWT), Rio de Janeiro, Brazil, 2011. p. 35-41.

ABREU, R. A. Técnicas de equalização de canais de comunicação aplicadas a imagens. Dissertação de Mestrado em Engenharia Elétrica - Escola Politécnica da Universidade de São Paulo, São Paulo, 2011.

ACÁCIO, L. C. L. Equalização pré-FFT de sistemas baseados em orthogonal frequencydivision multiplexing. Dissertação de Mestrado em Engenharia Elétrica — Escola Politécnica da Universidade de São Paulo, 2004. 
BELLANGER, M. A simple comparison of constant modulus and Wiener criteria for equalization with complex signals. Digital Signal Processing, v. 14, n. 5, p. 429-437, 2004.

BENVENISTE, A.; GOURSAT, M.; RUGET, G. Analysis of stochastic approximation schemes with discontinuous and dependent forcing terms with applications to data communication algorithms. IEEE Transactions on Automatic Control, v. 25, n. 6, p. $1042-$ 1058, Dec. 1980.

BISHOP, C. M. Pattern recognition and machine learning. Springer, Cambridge, 2006.

CANDIDO, R. Combinação afim de algoritmos adaptativos. Dissertação de Mestrado em Engenharia Elétrica — Escola Politécnica da Universidade de São Paulo, São Paulo, 2009. CANDIDO, R. et al. A statistical analysis of the dual-mode CMA. Proceedings of IEEE International Symposium on Circuits and Systems, Paris, France, 2010. p. 2510-2513.

CASAS, R. et al. Blind adaptation of decision feedback equalizers based on the constant modulus algorithm. Signals, Systems and Computers, 1995. Asilomar Conference on Record of the Twenty-Ninth, 1995. v. 1, p. $698-702$ vol.1.

CASAS, R. et al. On initialization strategies for blind adaptive DFEs. Wireless Communications and Networking Conference, 1999, IEEE. p. 792 -796 vol.2.

CHEN, S. Low complexity concurrent constant modulus algorithm and soft decision-directed scheme for blind equalization. IEE Proceedings on Vision, Image, and Signal Processing, v. 150 , p. $312-320$, Oct. 2003.

CHEN, S.; COOK, T. B.; ANDERSON, L. C. A comparative study of two blind FIR equalizers. Digital Signal Processing, v. 14, p. 18-36, Jan. 2004.

CHEN, S. et al. Multi-stage clustering equaliser. IEEE Transactions on Communications, v. 43, p. 701-705, Feb./Mar./Abr. 1995.

COSTA, M. C.; BERMUDEZ, J. C. M. An improved model for the normalized LMS algorithm with Gaussian inputs and large number of coefficients. Proceedings of IEEE 
International Conference on Acoustics, Speech, and Signal Processing, Orlando, FL., 2002. II, p. $1385-1388$.

DABEER, O.; MASRY, E. Convergence analysis of the Constant Modulus Algorithm. IEEE Transactions on Information Theory, v. 49, p. 1447-1464, Jun. 2003.

DE CASTRO, F. C. C. Desconvolução autodidata concorrente para equalização de canais de comunicação. Tese de Doutorado em Engenharia Elétrica — Faculdade de Engenharia Elétrica e Computação da Unicamp, Campinas, 2001.

DE CAStro, F. C. C.; DE CASTro, M. C. F.; ARAnTeS, D. S. Concurrent blind deconvolution for channel equalization. Proceedings of ICC'2001., 2001. v. 2, p. 366-371.

DE PAULA, A. S. Um estudo comparativo entre os sistemas OFDM e SCCP. Dissertação de Mestrado em Engenharia Elétrica - Escola Politécnica da Universidade de São Paulo, 2010.

DONOHO, D. On minimum entropy deconvolution. FINDLEY, F. D. Applied Time Series Analysis II, New York: Academic, 1981.

DVB GUIDELINES. Implementation guidelines for a second generation digital cable transmission system (DVB-C2). DVB Blue Book, DVB Document A147, p. 1-162, Mar. 2010.

ERDOGMUS, D.; PRINCIPE, J. C.; HILD, K. E. Beyond second-order statistics for learning: A pairwise interaction model for entropy estimation. Natural computing, Springer, v. 1, n. 1, p. 85-108, 2002.

FERNANDES, C. A. R.; FAVIER, G.; MOTA, J. C. M. Decision-directed adaptive blind equalization based on the constant modulus algorithm. Signal, Image and Video Processing, Springer London, v. 1, p. 333-346, 2007.

FIJALKOW, I.; MANLOVE, C. E.; JOHNSON, C. R. Adaptive fractionally spaced blind CMA equalization: Excess MSE. IEEE Transactions on Signal Processing, v. 46, p. 227-231, Jan. 1998. 
GARTH, L.; YANG, J.; WERNER, J.-J. Blind equalization algorithms for dual-mode CAP-QAM reception. IEEE Transactions on Communications, v. 49, n. 3, p. $455-466$, Mar. 2001.

GODARD, D. N. Self-recovering equalization and carrier tracking in two dimensional data communication system. IEEE Transactions on Communications, v. 28, p. 1867-1875, Nov. 1980.

GOMES, G. G. R. Modulação multiportadora codificada por bloco para radioenlaces digitais em microondas com linha de visada. Tese de Doutorado em Engenharia Elétrica Universidade Estadual de Campinas, Dez. 2002.

GOUPIL, A.; PALICOT, J. New algorithms for blind equalization: The constant norm algorithm family. IEEE Transactions on Signal Processing, IEEE, v. 55, n. 4, p. 1436-1444, 2007.

GUO, L.; LJUNG, L.; WANG, G.-J. Necessary and sufficient conditions for stability of LMS. IEEE Transactions on Automatic Control, v. 42, n. 6, p. 761 -770, Jun. 1997.

HAYKIN, S. Communication systems. 4ª edição, New York, Wiley, 2000.

HAYKIN, S. Adaptive Filter Theory. 4ª edição, Prentice Hall, Upper Saddle River, 2002.

HE, L. et al. A hybrid adaptive blind equalization algorithm for QAM signals in wireless communications. IEEE Transactions on Signal Processing, v. 52, n. 7, p. 2058-2069, Jul. 2004.

HEIDARI, A.; NASIRI-KENARI, M. A family of simple blind phase recorevy algorithms. Proceedings of ISPACS'2000, 2000. v. 1, p. 24-28.

HORN, R. A.; JOHnSON, C. R. Matrix Analysis. Cambridge University Press, 1985.

HOWALD, R. L. QAM bulks up once again: Modulation to the power of ten. Proceedings of SCTE Cable-tec EXPO, 2002. 
JOHNSON R., J. et al. Blind equalization using the constant modulus criterion: a review. Proceedings of the IEEE, v. 86, n. 10, p. 1927 -1950, Oct. 1998.

KARAOGUZ, J.; ADARLAN, S. H. A soft decision-direct blind equalization algorithm applied to equalization of mobile communication channels. Proceedings of ICC'92., 1992. v. 3, p. 343.4.1-343.4.5.

KURAKAKE, T. High-density modulation technology for digital cable TV transmission. Broadcast Technology, n. 19, p. 20, 2004.

LABAT, J.; MACCHI, O.; LAOT, C. Adaptive decision feedback equalization: can you skip the training period? IEEE Transactions on Communications, v. 46, n. 7, p. 921 -930, Jul. 1998.

LABED, A. et al. New hybrid adaptive blind equalization algorithms for QAM signals. Proceedings of IEEE International Conference on Acoustics, Speech, and Signal Processing, Taipei, Taiwan, 2009. p. 2865-2868.

LATHI, B. P. Modern digital and analog communication systems. $3^{a}$. edição, Oxford University Press, 1998. 781 p.

LI, Y.; LIU, K. J. R.; DING, Z. Length- and cost-dependent local minima of unconstrained blind channel equalizers. IEEE Transactions on Signal Processing, v. 44, n. 11, p. 2726-2735, 1996.

MACCHI, O.; EWEDA, E. Convergence analysis of self-adaptive equalizers. IEEE Transactions on Information Theory, v. 30, n. 2, p. 161-176, 1984.

MAI, J.; SAYED, A. H. A feedback approach to the steady-state performance of fractionally spaced blind adaptive equalizers. IEEE Transactions on Signal Processing, v. 48, p. 80-91, Jan. 2000.

MAREELS, I.; POLDERMAN, J. W. Adaptive systems: an introduction. Boston: Birkhäuser, 1996. 
MAZO, J. E. Analysis of decision-directed equalizer convergence. Bell Syst. Tech. Journal, v. 59, n. 10, p. $1857-1877,1980$.

MENDES FILHO, J. Sobre equalizadores autodidatas de decisão realimentada aplicados a sistemas multiusuário. Dissertação de Mestrado em Engenharia Elétrica - Universidade Presbiteriana Mackenzie, São Paulo, 2007.

MIRANDA, M. D.; SILVA, M. T. M.; NASCIMENTO, V. H. Avoiding divergence in the Constant Modulus Algorithm. Proceedings of IEEE International Conference on Acoustics, Speech, and Signal Processing, Las Vegas, 2008. p. 3565-3568.

MIRANDA, M. D.; SILVA, M. T. M.; NASCIMENTO, V. H. Avoiding divergence in the Shalvi Weinstein Algorithm. IEEE Transactions on Signal Processing, v. 56, p. 5403-5413, Nov. 2008.

NASCIMENTO, V. H. Stability and performance of adaptive filters without slow adaptation approximations. Tese de Doutorado - University of California, Los Angeles, 1999.

NASCIMENTO, V. H.; SILVA, M. T. M. Stochastic stability for the Constant Modulus Algorithm. IEEE Transactions on Signal Processing, v. 56, p. 4984-4989, Oct. 2008.

OH, K. N.; CHIN, Y. O. Modified constant modulus algorithm: Blind equalization and carrier phase recovery algorithm. Proceedings of IEEE International Conference on Communication, 1995. v. 1, p. 498-502.

OH, K. N.; PARK, J. H. Property restoral approach to blind equalization of digital transmission channels. IEEE Transactions on Consumer Electronics, v. 43, n. 3, p. 544 -549 , Aug. 1997.

PAPADIAS, C. B.; PAULRAJ, A. Decision-feedback equalization and identification of linear channels using blind algorithms of the bussgang type. Proceedings of 29th Asilomar Conference on Signals, Systems and Computers, 1995. v. 1, p. 335-340. 
PAPADIAS, C. B.; SLOCK, D. T. M. On the decision-directed equalization of constant modulus signals. The 28th Asilomar Conference on Signals, Systems, and Computers, 1994. v. 2, p. $1423-1427$.

PICCHI, G.; PRATI, G. Blind equalization and carrier recovery using a "stop-and-go" decision-directed algorithm. IEEE Transactions on Communications, COM-35, p. 877-887, Sept. 1987.

PRANDOnI, P.; VETTERLI, M. Signal Processing for Communications. $1^{\mathrm{a}}$ edição, EPFL Press, 2008. $371 \mathrm{p}$

PROAKIS, J. Digital Communications. 4ª . edição, McGraw-Hill, NY, 2001.

QIN, L. et al. Fractionally spaced adaptive decision feedback equalizers with applications to ATSC DTV receivers. IEEE Transactions on Consumer Electronics, v. 50, n. 4, p. $999-$ 1003, Nov. 2004

QURESHI, S. H. Adaptive equalization. Proceedings of the IEEE, v. 73, p. 1349-1387, Sept. 1985.

READY, M. J.; GOOCH, R. P. Blind equalization based on radius directed adaptation. Proceedings of IEEE International Conference on Acoustics, Speech, and Signal Processing, 1990. v. 3, p. 1699-1702.

REGALIA, P. A. On the equivalence between the Godard and Shalvi-Weinstein schemes of blind equalization. Signal Processing, v. 73, p. 185-190, 1999.

RUPP, M. Convergence properties of adaptive equalizer algorithms. IEEE Transactions on Signal Processing, v. 59, n. 6, p. 2562 -2574, Jun. 2011.

RUPP, M.; SAYED, A. H. Robustness of Gauss-Newton recursive methods: A deterministic feedback analysis. Signal Processing, v. 50, n. 3, p. 165 - 187, 1996.

SATO, Y. A method of self-recovering equalization for multilevel amplitude-modulation systems. IEEE Transactions on Communications, v. 23, n. 6, p. 679 - 682, Jun. 1975. 
SAYED, A. H. Adaptive Filters. John Wiley \& Sons, NJ, 2008.

SETHARES, W. A. Adaptive algorithms with nonlinear data and error functions. IEEE Transactions on Signal Processing, v. 40, n. 9, p. 2199-2206, Sep. 1992.

SHALVI, O.; WEINSTEIN, E. New criteria for blind deconvolution of nonminimum phase systems (channels). IEEE Transactions on Information Theory, v. 36, n. 2, p. 312-321, 1990.

SHALVI, O.; WEINSTEIN, E. Super-exponential methods for blind deconvolution. IEEE Transactions on Information Theory, v. 39, p. 504-519, Mar. 1993.

SHEIKH, S. A.; FAN, P. Improved square contour algorithm for blind equalization of QAM signals. Proceedings of IEEE Multitopic Conference, 2006. p. 116-119.

SHEIKH, S. A.; FAN, P. A new multimodulus blind equalizer for dense QAM constellations. Proceedings of IET International Wireless, Mobile and Multimedia Networks Conference, 2006. p. 1-4.

SILVA, M. T. M. Um estudo sobre técnicas de equalização autodidata. Tese de Doutorado em Engenharia Elétrica - Escola Politécnica da Universidade de São Paulo, São Paulo, 2005.

SILVA, M. T. M.; MIRANDA, M.; SOARES, R. Concurrent blind decision feedback equalizer. Proceedings of International Workshop on Telecommunications (IWT). Santa Rita do Sapucaí, MG, 2004. p. 107-112.

SILVA, M. T. M.; MIRANDA, M. D. Tracking issues of some blind equalization algorithms. IEEE Signal Processing Letters, v. 11, p. 760-763, Sep. 2004.

SILVA, M. T. M.; MIRANDA, M. D.; SOARES, R. Concurrent algorithm for blind adaptation of DFE. Electronics Letters, v. 41, p. 928-930, Aug. 2005.

SILVA, M. T. M.; NASCIMENTO, V. H. Improving the tracking capability of adaptive filters via convex combination. IEEE Transactions on Signal Processing, v. 56, p. 3137-3149, Jul. 2008 . 
SILVA, M. T. M.; NASCIMENTO, V. H. Tracking analysis of the Constant Modulus Algorithmn. Proceedings of IEEE International Conference on Acoustics, Speech, and Signal Processing, Las Vegas, 2008. p. 3561-3564.

SOARES, R. Um algoritmo autodidata concorrente para adaptação do DFE. Dissertação de Mestrado em Engenharia Elétrica - Universidade Presbiteriana Mackenzie, São Paulo, 2004.

SOLO, V.; KONG, X. Adaptive signal processing algorithms: stability and performance. Englewood Cliffs: Prentice Hall, Inc., 1995.

SUYAMA, R. Sobre o critério do Módulo Constante para equalização não-supervisionada e suas relações com a teoria de Wiener. Dissertação de Mestrado em Engenharia Elétrica Universidade Estadual de Campinas - Faculdade de Engenharia Elétrica e de Computação - Departamento de Comunicações, agosto 2003.

SUYAMA, R. et al. On the relationship between least squares and constant modulus criteria for adaptive filtering. The 37th Asilomar Conference on Signals, Systems and Computers, 2003. v. 2, p. 1293-1297.

SZCZECINSKI, L. L.; GEI, A. Blind decision feedback equalisers, how to avoid degenerated solutions. Signal Processing, v. 82, p. 1675-1693, Nov. 2002.

TAN, L. et al. A 70-mb/s variable-rate 1024-QAM cable receiver IC with integrated 10-b ADC and FEC decoder. IEEE Journal of Solid-State Circuits, v. 33, p. 2205-2218, 1998.

THAIUPATHUMP, T.; KASSAM, S. A. Square contour algorithm: a new algorithm for blind equalization and carrier phase recovery. Proceedings of the Conference on Signals, Systems and Computers Record of the Thirty-Seventh Asilomar Conference 2003. v. 1, p. $647-651$.

TONG, L.; LIU, D. Blind predictive decision-feedback equalization via the constant modulus algorithm. IEEE International Conference on Acoustics, Speech, and Signal Processing, v. 5, p. $3901-3904,1997$. 
TREICHLER, J. R.; AGEE, B. A new approach to multipath correction of constant modulus signals. IEEE Transactions on Acoustics, Speech, Signal Processing, ASSP-28, p. 334-358, Apr. 1983.

TREICHLER, J. R.; FIJALKOW, I.; JR., C. R. J. Fractionally spaced equalizers. IEEE Signal Processing Magazine, v. 13, p. 65-81, May. 1996.

WEISS, A.; MITRA, D. Digital adaptive filters: conditions for convergence, rates of convergence, effects of noise and errors arising from the implementation. IEEE Transactions on Information Theory, v. 25, p. 637-652, Nov. 1979.

YANG, J.; WERNER, J.-J.; DUMONT, G. A. The multimodulus blind equalization and its generalized algorithms. IEEE Journal on Selected Areas in Communications, v. 20, p. 997-1015, Jun. 2002.

YOUSEF, N. R.; SAYED, A. H. A feedback analysis of the tracking performance of blind adaptive equalization algorithms. Proceedings of IEEE Conference on Decision and Control, 1999. v. 1, p. $174-179$.

YUAN, J.-T.; CHANG, L.-W. Carrier phase tracking of multimodulus blind equalization algorithm using QAM oblong constellations. IEEE International Conference on Communications, 200\%. ICC '0\%., p. $2991-2998$.

YUAN, J.-T.; TSAI, K.-D. Analysis of the multimodulus blind equalization algorithm in QAM communication systems. IEEE Transactions on Communications, v. 53, p. 1427 1431, Sep. 2005.

ZAOUCHE, A.; DAYOUB, I.; ROUVAEN, J. . High fractionally spaced constant modulus blind equalization for high order-QAM signalling. IEEE/SP 13th Workshop on Statistical Signal Processing, 2005, p. 197-202.

ZENG, H. H.; TONG, L.; JOHNSON, C. R. Relationships between the Constant Modulus and Wiener receivers. IEEE Transactions on Information Theory, v. 44, p. 1523-1538, Jul. 1998. 
W. Zhou e L. Zou. Adaptive QAM transmission scheme to improve performance on an AWGN channel. U.S. Patent 2011/0090948A1, Apr. 21, 2011. US 2011/0090948A1. Disponível em: <http://www.freepatentsonline.com/20110090948.pdf>. 


\section{Apêndice A}

\section{Medidas de desempenho}

Uma comparação objetiva entre algoritmos adaptativos envolve várias simulações, sendo utilizados como principais medidas de desempenho: o erro quadrático médio (MSE - mean square error), o erro quadrático médio em excesso (EMSE -excess mean square error), o desajuste (misadjustment) e a taxa de erro de símbolos (SER - symbol error rate).

O erro quadrático médio é comumente utilizado como medida de desempenho na comparação entre equalizadores adaptativos, mesmo quando os algoritmos são baseados em diferentes funções custo. O MSE é definido como [SAYED, 2008]

$$
\operatorname{MSE}(n) \triangleq \mathrm{E}\left\{|e(n)|^{2}\right\}
$$

sendo $e(n)$ o erro de estimação ou erro de decisão. Em algoritmos de equalização supervisionada, utiliza-se o erro de estimação definido como

$$
e(n)=a(n-\Delta)-y(n)=a(n-\Delta)-\mathbf{u}^{T}(n) \mathbf{w}(n-1),
$$

sendo $a(n-\Delta)$ a amostra da sequência de treinamento no instante $n$. No caso de algoritmos autodidatas, em vez de utilizar o erro de estimação, calcula-se o MSE a partir do erro de decisão dado por

$$
e(n)=\hat{a}(n-\Delta)-y(n)
$$

em que $\hat{a}(n-\Delta)$ é a estimativa de $a(n-\Delta)$, obtida na saída do decisor, isto é, $\hat{a}(n-\Delta)=$ $\operatorname{dec}[y(n)]$. Em geral, considera-se o erro de decisão já que o erro de estimação de um algoritmo 
autodidata nem sempre é igual a zero quando a saída do equalizador coincide com o símbolo transmitido. Por exemplo, o uso do erro de estimação do MMA no cálculo do MSE tornaria a comparação com o caso supervisionado difícil, principalmente no caso de sinais de módulo não-constante. Cabe observar que o MSE depende do tempo, já que $\mathrm{E}\{\cdot\}$ representa uma média de conjunto. Em regime $(n \rightarrow \infty)$ e admitindo um ambiente estacionário, o MSE é um escalar dado por

$$
\operatorname{MSE}(\infty) \triangleq \lim _{n \rightarrow \infty} \mathrm{E}\left\{|e(n)|^{2}\right\} .
$$

Muitas vezes, quando se fala que um algoritmo apresenta um MSE menor que outro, se refere ao seu valor em regime.

Uma outra medida de desempenho é o erro quadrático médio em excesso, definido como

$$
\operatorname{EMSE}(n) \triangleq \mathrm{E}\left\{\left|e_{a}(n)\right|^{2}\right\}
$$

sendo

$$
e_{a}(n)=\mathbf{u}^{T}(n)\left[\mathbf{w}_{\mathrm{o}}(n-1)-\mathbf{w}(n-1)\right]
$$

o erro a priori. No caso supervisionado, o sinal desejado segue o modelo de regressão linear [SAYED, 2008; HAYKIN, 2002], ou seja,

$$
a(n-\Delta)=\mathbf{u}^{T} \mathbf{w}_{\mathrm{o}}(n-1)+v(n),
$$

em que $v(n)$ é o erro de estimação ótimo, de média nula e variância $\sigma_{v}^{2}(n)$, que é nãocorrelacionado com $\mathbf{u}(n)$ devido ao princípio da ortogonalidade [HAYKIN, 2002]. Assim, o valor mínimo da função custo do erro quadrático médio é dado neste caso por $\operatorname{MSE}_{\min }(n)=$ $J_{\min }(n)=\mathrm{E}\left\{|v(n)|^{2}\right\}=\sigma_{v}^{2}(n)$. Cabe notar que a menos que se considere sobreamostragem, ausência de ruído e outras condições bem conhecidas na literatura (veja, e.g., [SILVA, 2005]), $\mathbf{w}_{\text {o }}$ não leva à equalização perfeita, o que justifica a utilização do modelo (A.5) em um problema de equalização [RUPP, 2011]. Usando (A.5), o erro a priori está relacionado com o erro de estimação através da equação

$$
e(n)=e_{a}(n)+v(n) .
$$

Multiplicando (A.6) por seu complexo conjugado e tomando a esperança, obtém-se

$$
\mathrm{E}\left\{|e(n)|^{2}\right\}=\mathrm{E}\left\{\left|e_{a}(n)\right|^{2}\right\}+\sigma_{v}^{2}(n)+\mathrm{E}\left\{e_{a}(n) v^{*}(n)\right\}+\mathrm{E}\left\{e_{a}^{*}(n) v(n)\right\}
$$


Para $\mathbf{u}(n)$ e $v(n)$ independentes, (A.9) se reduz a

$$
\operatorname{EMSE}(n)=\operatorname{MSE}(n)-J_{\min }(n)
$$

Assim, o EMSE mede a distância entre o MSE e seu valor mínimo, correspondente à solução ótima. Em regime e admitindo um ambiente estacionário,

$$
\operatorname{EMSE}(\infty)=\lim _{n \rightarrow \infty} \mathrm{E}\left\{\left|e_{a}(n)\right|^{2}\right\}=\operatorname{MSE}(\infty)-J_{\min }
$$

Nas condições que possibilitam a equalização perfeita, $v(n)=0$ e consequentemente o MSE coincide com o EMSE.

No caso de equalização autodidata, não se conhece a solução ótima $\mathbf{w}_{\mathrm{o}}$ e uma relação entre o erro a priori e o erro de estimação não é tão simples como (A.6), como pode ser observado, por exemplo, na Seção 5.2 para o MMA. Por essa razão, o EMSE é uma medida de desempenho pouco utilizada na prática, sendo importante principalmente para um estudo teórico do desempenho dos algoritmos autodidatas. Porém, como demonstrado no Capítulo 3, os algoritmos RMA e SBD podem atingir a solução de Wiener e por isso, o EMSE pode ser calculado em um ambiente estacionário, desde que se conheça o atraso $\Delta$.

Uma outra medida relativa de desempenho é o desajuste, definido como a razão entre o EMSE e $J_{\min }$, i.e.,

$$
\mathcal{M}(n) \triangleq \frac{\operatorname{EMSE}(n)}{J_{\min }(n)}
$$

O desajuste de um algoritmo adaptativo deve ser o menor possível. Idealmente, o MSE deve tender à $J_{\min }$ e o EMSE e o desajuste devem tender à zero. Em contrapartida, se o MSE é muito maior que $J_{\min }$, o EMSE e o desajuste também serão elevados. Por isso, muitas vezes essas três medidas de desempenho são usadas como sinônimos quando se refere a um algoritmo. Cabe observar ainda que não tem sentido falar em desajuste quando $\mathbf{w}_{\mathrm{o}}$ leva à equalização perfeita, pois neste caso, $J_{\min }$ é aproximadamente zero e o desajuste pode ser muito elevado numa situação em que o EMSE e o MSE coincidem e podem ser relativamente pequenos.

Por fim, uma medida de desempenho muito utilizada em sistemas de comunicação é a taxa de erro de símbolos. Essa medida é definida como a razão entre o número de símbolos 
recuperados com erro e o número total de símbolos transmitidos, para uma determinada razão sinal-ruído (SNR) e considerando o algoritmo adaptativo em regime, ou seja,

$$
\mathrm{SER}(\mathrm{SNR})=\frac{\text { Número de símbolos recuperados com erro }}{\text { Número total de símbolos transmitidos }} .
$$

Na prática, a avaliação da SER é realizada para diferentes valores de SNR em um ambiente estacionário, i.e., com canal de comunicação fixo. Por ser uma quantidade relativamente pequena $\left(<10^{-1}\right)$, geralmente considera-se $\log _{10}\{\mathrm{SER}\}$ na comparação entre algoritmos. Além disso, quanto maior a quantidade de erros, maior será a precisão dessa medida. Por isso, costuma-se considerar a transmissão de uma quantidade de símbolos suficiente para que sejam detectados pelos menos 30 erros, independentemente da razão sinal-ruído. 